\title{
What are the Implications for Public Policy in New Zealand regarding Biochar as a Climate Change Mitigation Tool?
}

Dorothee Quade

Thesis

Environmental Studies 593

A 90 point thesis submitted to Victoria University of Wellington, as partial fulfilment for the degree of Master of Environmental Studies

School of Geography, Environment and Earth Sciences,

Victoria University of Wellington

June 2010 



\section{Abstract}

The past years have seen biochar appearing on the political radar as a potential greenhouse gas (GHG) mitigation tool. Biochar is a charcoal-like substance that is produced from smouldering biomass in oxygen-starved conditions in a kiln. The resulting light and highly porous material can be applied to soil where it has been suggested that it sequesters carbon and increases soil fertility.

This research surveys the current scientific understanding of biochar and the institutional framework pertinent to climate change mitigation and potential future biochar deployment in NZ. This is complemented by empirical data, gathered via semi-structured interviews and online surveys. The stakeholder groups determined for the purpose of this study are agriculture (with an emphasis on organic agriculture), forestry and wood processing, bioenergy/biochar businesses, research institutions and government agencies.

There is no recognition of biochar in international compliance carbon markets at present and the debate about biochar's future inclusion is ongoing. Biochar performance in soils is highly variable depending on feedstock, manufacturing conditions, soil type and climate to name a few. Scientific uncertainties are related to the permanence of carbon storage in biochar, its agronomic benefits when applied to soil and its life cycle performance in terms of greenhouse gases and energy. While research into a more detailed understanding of biochar is underway, there is still a lack of large-scale and longterm field trials both internationally and domestically.

In this context, public policy is faced with decision-making under conditions of risk and uncertainty. Theory suggests some guidance in the form of environmental policy principles such as the sustainability and Precautionary Principles. General policy criteria, including effectiveness, efficiency, equity, compliance with international obligations and political and social acceptability, as well as innovation theory are also proposed as a theoretical framework against which to assess the viability of biochar in a NZ setting.

Results suggest that biochar deployment in NZ may be a boutique solution for niche applications rather than a large-scale commercial opportunity. Biochar research in NZ is nascent, yet future policy decision-making depends on its outcomes to assess the merits of 
biochar for NZ. If biochar technology is to be diffused in NZ, policy will need to carefully craft legislation and incentive structures so as to ensure a sustainable pathway.

Various stakeholder groups need to be consulted throughout the decision-making process. Transparency is key to building trust and understanding about the potentials and pitfalls of biochar deployment in NZ. A public debate and continuous dialogue between the research, policy, practitioners and other communities is required to achieve a mutually satisfactory outcome.

Keywords: biochar, greenhouse gas mitigation, diffusion of innovations, stakeholder perceptions, public policy. 


\section{Acknowledgements}

I would like to express my gratitude to my supervisor, Cath Wallace, who tirelessly and patiently provided guidance and encouragement. My thanks goes to all forestry, wood processing and organic agriculture organisations who kindly provided their support by forwarding the survey request to their members. I am indebted to my research participants who took the time for surveys and interviews and showed keen interest in the various facets of the research topic.

I am grateful to my parents whose emotional and financial support enabled me to study on the other end of the world; to friends in Germany, Australia and New Zealand for inspiration, laughter, innumerable numbers of coffees, and for simply being there and listening. In particular, I would like to thank Eunica for being the most wonderful friend and flatmate one can wish for, and Shabana for her friendship and support throughout my studies in NZ. 


\section{Abbreviations \& Acronyms}

$\mathrm{BC}$

black carbon

CBA cost benefit analysis

CCS carbon capture and storage

$\mathrm{CH}_{4} \quad$ methane

CHP combined heat and power (refers to electricity generation)

$\mathrm{CO}_{2} \quad$ carbon dioxide

$\mathrm{CO}_{2}$-e carbon dioxide equivalent

DoC Department of Conservation

DM dry matter (when comparing different types of biomass)

EECA Energy Efficiency and Conservation Authority

ENGO environmental non-governmental organisation

EPA Environmental Protection Authority (in New Zealand)

EROEI energy return on energy invested

ETS emissions trading scheme

EU European Union

FRST Foundation for Research, Science and Technology

GHG greenhouse gas

GJ gigajoule

GtC gigatonne of carbon

HSNO Hazardous Substances and New Organisms Act

HTT highest treatment temperature

IPCC Intergovernmental Panel on Climate Change

kWh kilowatt hour

LA Local Authorities

LCA life cycle assessment

LULUCF land use, land-use change and forestry

MAF Ministry of Agriculture and Forestry

MED Ministry of Economic Development

MFAT Ministry of Foreign Affairs and Trade

MfE Ministry for the Environment

MoRST Ministry of Research, Science and Technology

MoT Ministry of Transport

NIWA National Institute of Water and Atmospheric Research 
$\mathrm{N}_{2} \mathrm{O} \quad$ nitrous oxide

NZ New Zealand

PCE Parliamentary Commissioner for the Environment

POP persistent organic pollutants

RE renewable energy

REDD reduced emissions from deforestation and forest degradation

RMA Resource Management Act

SEM scanning electron microscope

UK United Kingdom of Great Britain and Northern Ireland

UN United Nations

UNFCCC United Nations Framework Convention on Climate Change

USA United States of America

US EPA United States Environmental Protection Agency

WFPS water-filled pore space (in soil)

wt\% percent by weight (measures the weight of a substance as a percentage of the weight of the entire mixture) 


\section{Content}
Abstract

Acknowledgements .iii

Abbreviations \& Acronyms................................................................................................iv

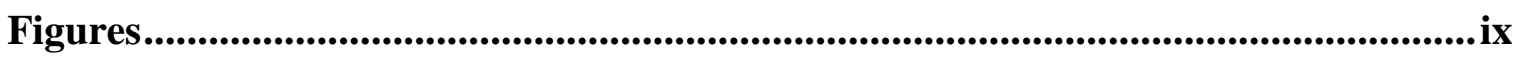

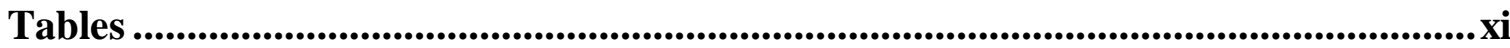

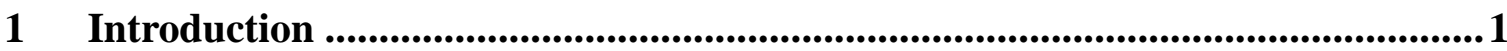

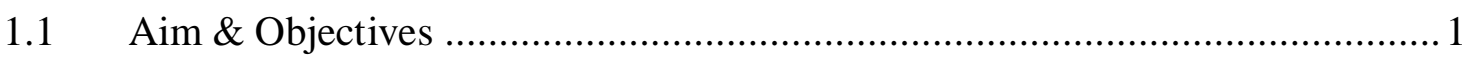

$1.2 \quad$ Research Scope

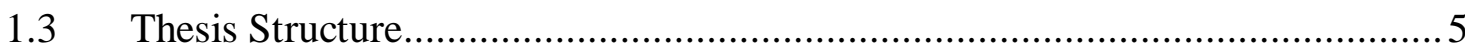

1.4 The Background Problem: Climate Change ……….......................................

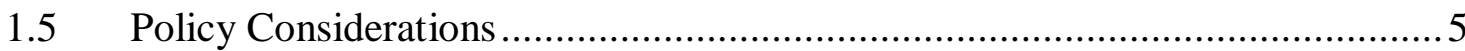

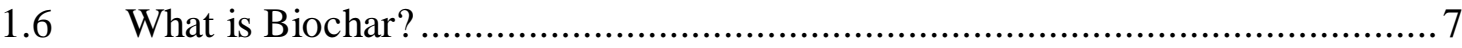

2 Methodology ........................................................................................................... 16

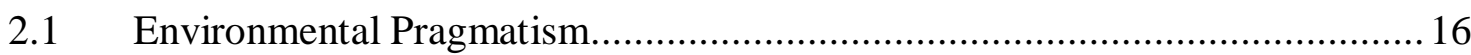

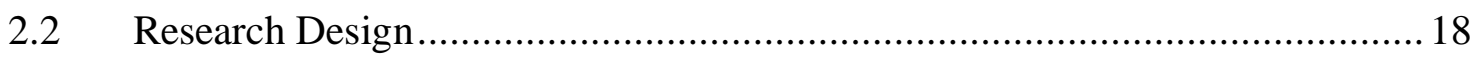

2.2.1 Literature Reviews..................................................................... 22

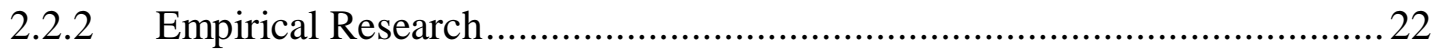

2.3 Methods: Empirical Data Collection, Recording and Analysis .........................25

2.3.1 Methods for Surveys...................................................................... 26

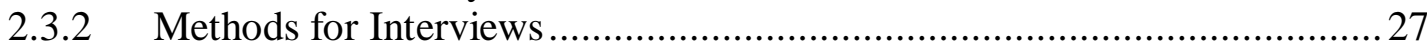

$3 \quad$ Biochar Science and Technology .................................................................31

3.1 Biochar Impacts on Soil biophysical and biochemical Properties .....................32

3.1.1 Impacts on Nutrient Retention and Nutrient Cycling in Soils ..................... 37

3.1.2 Impacts on Soil Greenhouse Gas Emissions .............................................40

3.1.3 Adsorption and Desorption Characteristics ………………………..............4

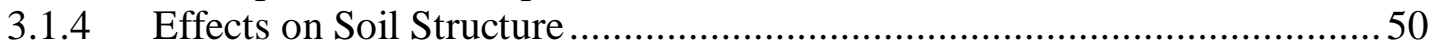

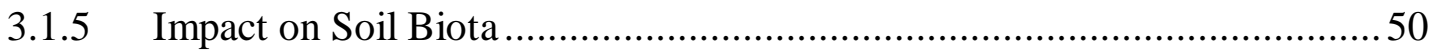

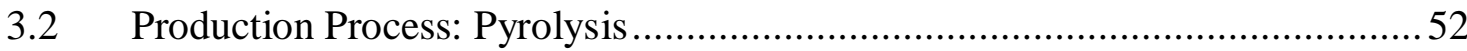

$4 \quad$ Institutional Framework...........................................................................................59 
4.1 International Agreements pertinent to Climate Change Policy ......................60 60

4.1.1 United Nations Framework Convention on Climate Change 1992 .............60

4.1.2 Kyoto Protocol 1997 ..............................................................................61 61

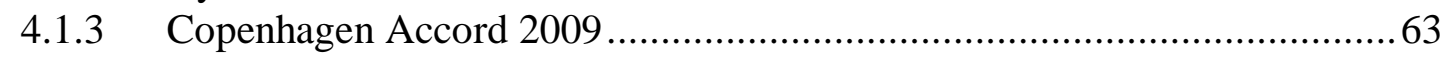

4.2 Domestic Climate Change Policy and Institutions ......................................67

4.2.1 New Zealand's Kyoto Challenge............................................................67

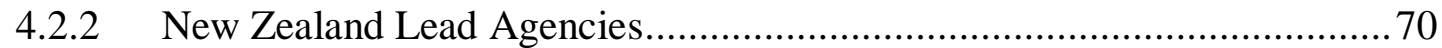

4.2.3 Legislative Framework pertinent to Biochar Deployment.........................73

4.3 New Zealand's Biochar 'Landscape' ..................................................... 93

5 Theoretical Framework .................................................................................95

5.1 Policy Design Considerations for Pollution Control ....................................96

5.1.1 A Taxonomy of Uses and Benefits of Resources: Rivalness and Excludability ......................................................................................96

5.1.2 The Greenhouse Gas and other Externalities in the Context of Biochar .....98

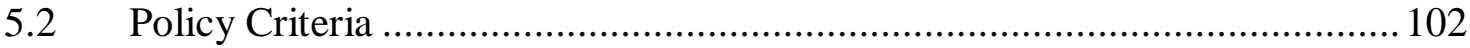

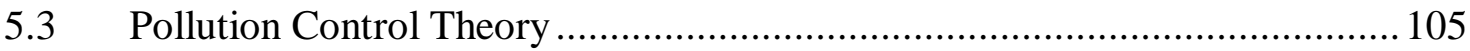

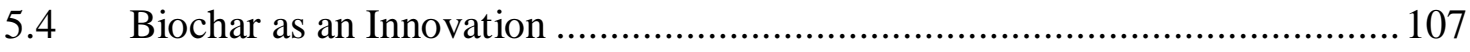

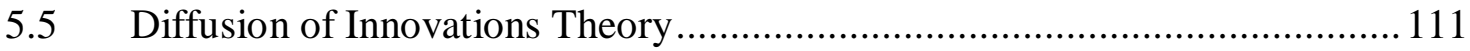

5.6 Decision-making under Conditions of Risk and Uncertainty ........................ 117

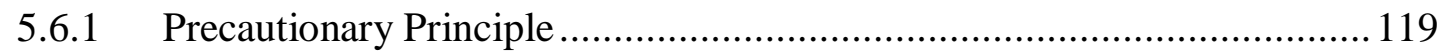

5.6.2 Sustainability Principle ............................................................... 120

5.7 Institutions and Public Participation............................................................... 122

6 Stakeholder Perspectives on Biochar: Analysis and Discussion of Empirical Material .............................................................................................................................124

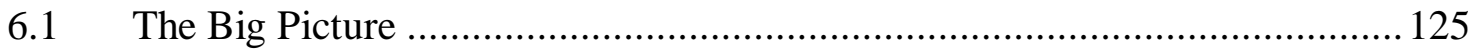

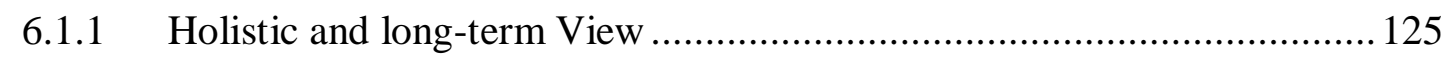

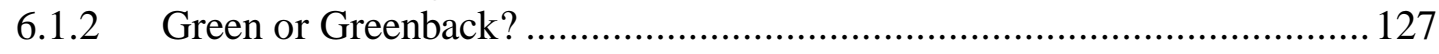

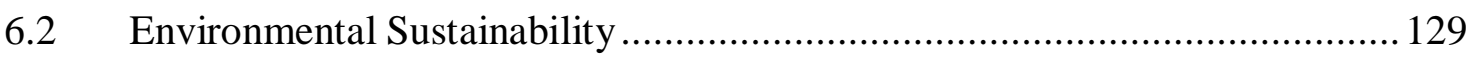

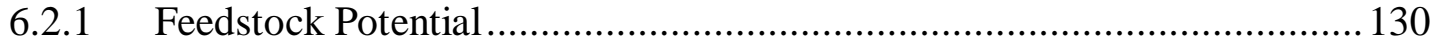

6.2.2 Greenhouse Gas and Energy Life Cycle Assessment ............................. 137

6.2.3 Recognition of Biochar as a Carbon Offset?......................................... 142

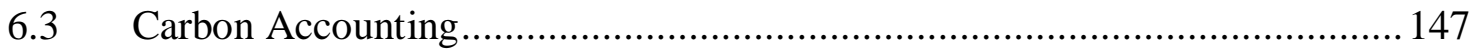

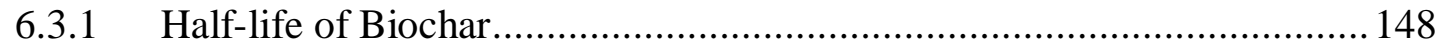

6.3.2 Stabilisation Mechanisms of Biochar-Carbon in Soil ............................ 150

6.4 Economic Considerations on Feedstocks .................................................. 153

6.4.1 Forestry and Wood Processing Residues .............................................. 153

6.4.2 Waste Streams with Tipping Fee ..................................................... 154 
6.4.3 Transport and Handling Costs, Plant Size and Type ............................. 155

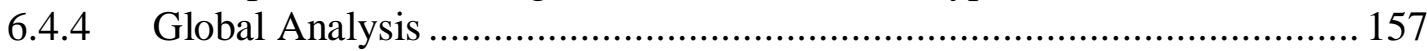

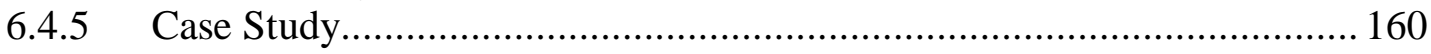

6.5 Potential Applications of Biochar in the NZ Context ................................. 163

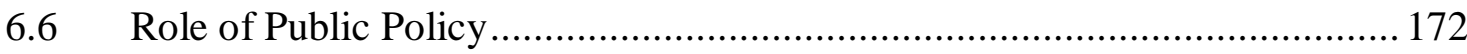

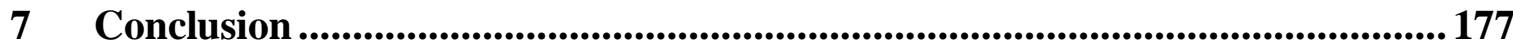

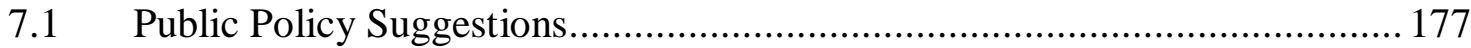

7.2 Suggestions for Further Research .......................................................... 181

7.3 Closing the Loop in Seven Steps: Revisiting Aim and Objectives ................. 183

7.3.1 Objective One, Chapter One .......................................................... 183

7.3.2 Objective Two, Chapter Two .............................................................. 184

7.3.3 Objective Three, Chapter Three .......................................................... 185

7.3.4 Objective Four, Chapter Four ……...................................................... 186

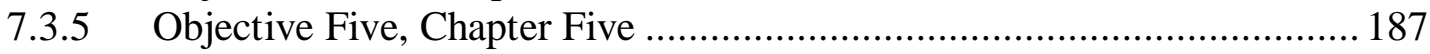

7.3.6 Objectives Six and Seven, Chapter Six ............................................. 189

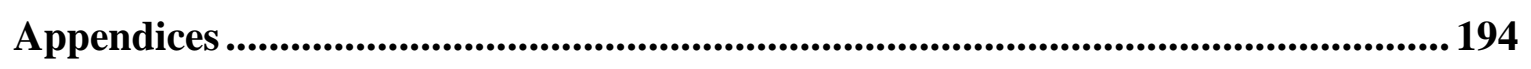

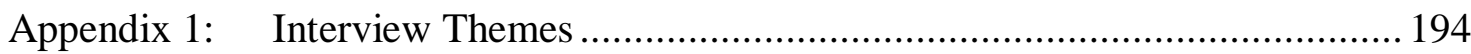

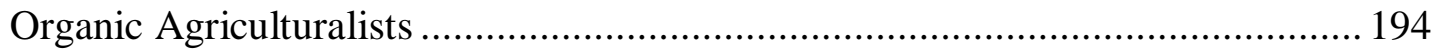

Forest Growers and Wood Processors ............................................................... 195

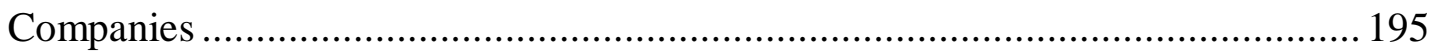

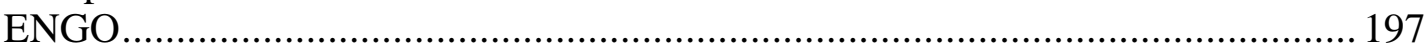

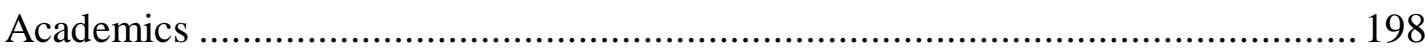

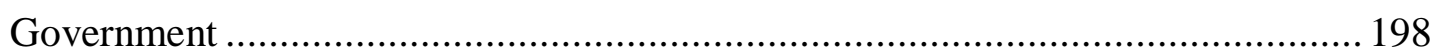

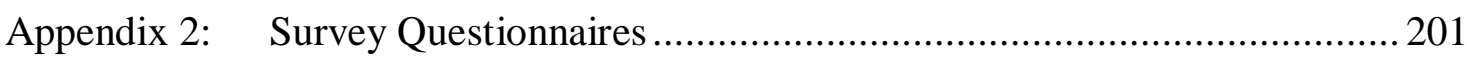

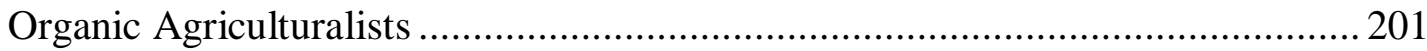

Forest Growers and Wood Processors ......................................................... 208

Appendix 3: $\quad$ VUW Human Ethics Committee Approval ................................. 212

Appendix 4: International Agreements pertinent to Climate Change ...................2 213

United Nations Framework Convention on Climate Change 1992 ........................ 213

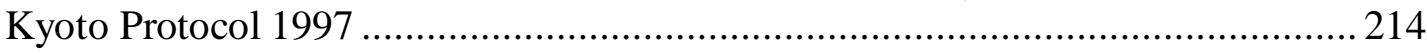

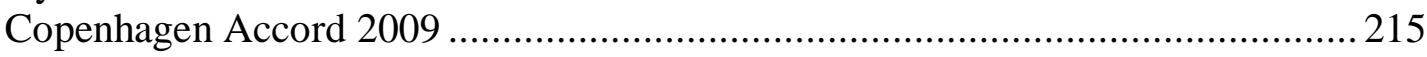

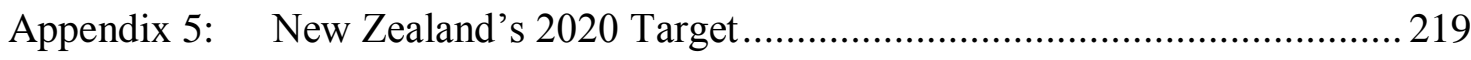

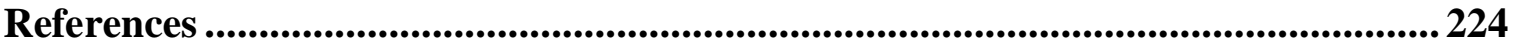




\section{Figures}

Figure 1: Overview of key questions for Chapter One to Six ................................... 4

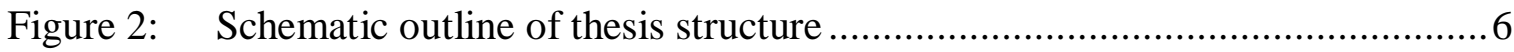

Figure 3: The probability of exceeding $2^{\circ} \mathrm{C}$ global mean equilibrium warming for different $\mathrm{CO}_{2}$-e stabilisation levels ......................................................

Figure 4: Annual global anthropogenic GHG emissions ...................................... 1

Figure 5: Projected changes in $\mathrm{CO}_{2}$ concentrations relative to pre-industrial levels with corresponding surface warming and ocean expansion 3

Figure 6: $\quad$ Agrichar $^{\mathrm{TM}}$ produced from BEST Energies demonstration facility ................ 8

Figure 7: Biochar produced by BEST Energies Australia, Pty Ltd..............................9

Figure 8: $\quad$ Structure of graphite as proven for the first time by Bernal in 1924 .............11

Figure 9: Ideal carbon ring structure development .............................................. 11

Figure 10: $\quad$ BC formation as a combustion continuum................................................ 12

Figure 11: Process of biomass charring and associated changes in biomolecular

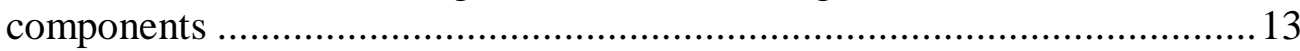

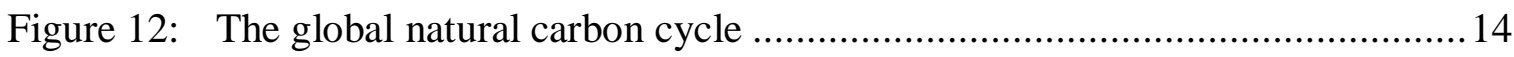

Figure 13: Matrix for mixed methods research design ............................................. 19

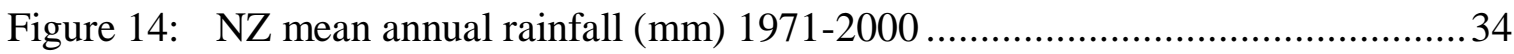

Figure 15: NZ mean annual sunshine hours 1971-2000 ...........................................35

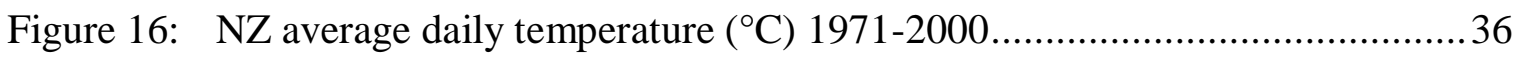

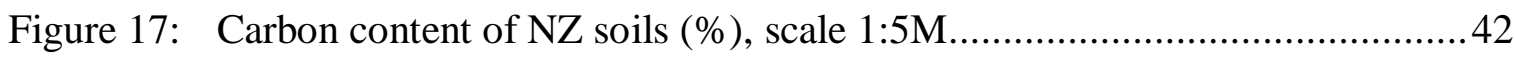

Figure 18: Scanning electron microscope (SEM) image of biochar ............................45

Figure 19: SEM image showing macroporosity of biochar produced by slow pyrolysis

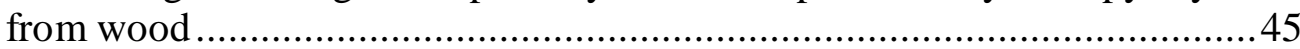

Figure 20: SEM image showing macroporosity of biochar produced by slow pyrolysis

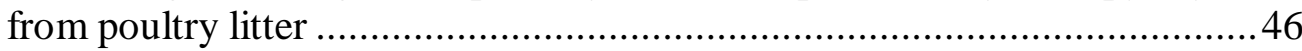

Figure 21: Soil moisture deficit on 01/02/2010 compared to historical average ............46

Figure 22: Projected annual mean precipitation change between 1980-1999 and 2030-

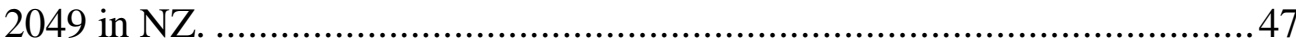

Figure 23: General concept of pyrolysis with biochar soil addition ............................53

Figure 24: Schematic diagram of fast pyrolysis processing .....................................53

Figure 25: Proportions of liquid, solid and gaseous products (on a dry wood basis) obtained from different kinds of pyrolysis of wood ....................................54

Figure 26: Schematic simplified slow pyrolysis process...........................................55

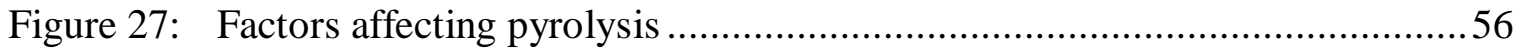

Figure 28: Effect of pyrolysis temperature on carbon recovery, cation exchange capacity (measured at $\mathrm{pH}$ 7), $\mathrm{pH}$ and surface area ..............................................57

Figure 29: NZ per-capita emissions in international comparison ...............................67 


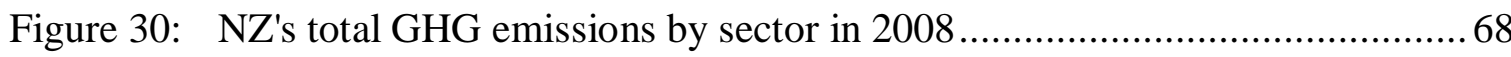

Figure 31: Change in NZ's emissions by sector from 1990 to 2008 .............................68

Figure 32: Change in NZ's emissions and removals from the LULUCF sector from 1990 to 2008

Figure 33: Percentage of electricity generation from renewable sources in NZ, 1974 2008

Figure 34: Annual electricity generation by fuel type 1974-2008 ….......................... 83

Figure 35: Feed-in tariff as a subsidy on production of renewable generation .............. 89

Figure 36: Global marginal abatement cost curve of different abatement measures. .....91

Figure 37: Marginal abatement and marginal damage costs and the efficient level of pollution under certainty about MAC and MDC 106

Figure 38: Stages in the innovation-decision process ................................................ 113

Figure 39: Bass model for forecasting adoption rates .......................................... 115

Figure 40: Schematic representation of the concept of strong sustainability 121

Figure 41: Contribution analysis of net energy and net GHG impact per tonne of feedstock dry matter (DM) for slow pyrolysis optimised for biochar production with use of co-products for bioenergy

Figure 42: Energy flows (MJ per tonne of dry feedstock) of a pyrolysis system for late stover

Figure 43: Stability of different biochars as affected by type of feedstock and pyrolysis conditions

Figure 44: Marginal abatement cost curve of biochar projects in developed and developing regions for 2030

Figure 45: Marginal abatement cost curve of various abatement technologies and strategies for the world by 2030 .

Figure 46: Contribution analysis for cost per tonne of dry feedstock 162 


\section{Tables}

Table 1: Characteristics of the six most significant GHG .......................................2

Table 2: $\quad$ Post-TAR stabilisation scenarios............................................................ 4

Table 3: $\quad$ Overview of mixed methods deployed in this study ................................21

Table 4: $\quad$ Overview of number of participants in each stakeholder group ..................29

Table 5: Quantified economy-wide emissions targets for 2020 ..............................64

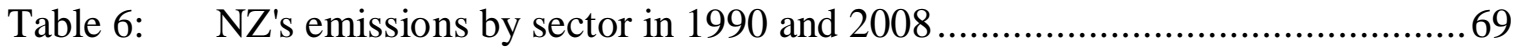

Table 7: Timetable of sector entry dates into the NZ ETS ..................................... 75

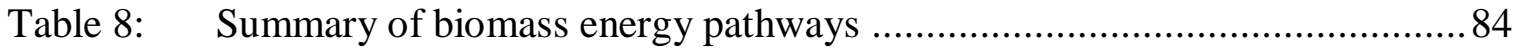

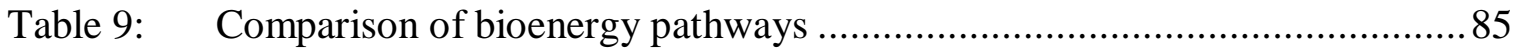

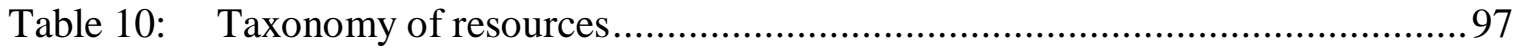

Table 11: Potential externalities associated with biochar..........................................99

Table 12: Delivered costs of forest residues to a user........................................... 156

Table 13: Net cost of biochar production under various scenarios ............................ 161

Table 14: Quantified economy-wide emissions targets for 2020 ............................221

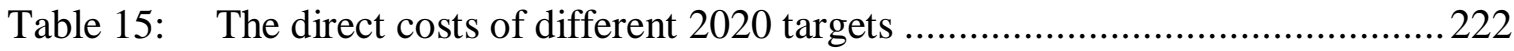



Introd | Method | Biochar | Institutions | Theory | Analys \& Disc | Concl

\section{Introduction}

\subsection{Aim \& Objectives}

The aim of this study is to develop a picture of the current debate about biochar and to explore the implications for NZ public policy.

The objectives of the research are to:

1. Briefly present the physical science base of climate change as a backdrop against which the concept of biochar as a mitigation tool is introduced (Chapter One),

2. Establish the methodological framework for this study and present the specific methods employed in primary and secondary data collection and analysis (Chapter Two),

3. Evaluate the evidence base for biochar in general and for NZ in particular (Chapter Three),

4. Outline the institutional framework regarding (i) climate change policy and law (domestic and international as applicable) and (ii) the 'biochar policy and research landscape' in NZ (domestic policy and public research institutions) (Chapter Four),

5. Establish a theoretical framework based on theories as they apply to decisionmaking under risk and uncertainty, public policy, economics and innovations to frame the problem of biochar deployment in NZ (Chapter Five)

6. Establish a picture of stakeholder perceptions of biochar deployment in NZ (Chapter Six) and

7. Discuss the issues identified by stakeholders in light of the theoretical framework established in (5.), and to flesh out implications of findings for NZ public policy as it concerns biochar deployment (Chapter Seven). 
Introd | Method | Biochar | Institutions | Theory | Analys \& Disc | Concl

\subsection{Research Scope}

This study seeks to elicit stakeholder views on biochar deployment in NZ, using a mixed methods approach that combines qualitative interviews with a supplementary quantitative survey instrument. This study does not give a quantitative account of stakeholder views in the sense of being statistically representative. No attempt is made to calculate percentages of stakeholders endorsing a particular perspective or statistical correlations between stakeholder group and preference for a specific policy approach. What this study hopes to identify are trends in thinking, underlying rationales and preferences for management concerning the issues identified. The research asks "What are their views and why?" rather than "How many people think that X, Y or Z is a problem or an advantage?"

This study is to give an account of the range of views on biochar as hold by the six stakeholder groups identified for the purpose of this study: organic agriculture, forestry/wood processing, bioenergy/biochar businesses, environmental non-government organisations (ENGO), academia and the public sector. This research does not claim to be exhaustive in the sense of covering all possible views held by NZ stakeholders, but it hopes to shed light on the main issues about which people are concerned or excited.

A theoretical background in policy, social science and Ecological Economics was chosen because individual decisions are influenced by the social context, including the institutional framework. Due to this social 'embeddedness' many assumptions of neoclassical economic theory must fail, especially in regard to environmental issues (Granovetter, 1985; Kahneman, 2003; Simon, 1956). The social context shapes people's preferences and behaviours which as a result may not be the independently formed, selfmaximising 'rational' preferences in a strictly neoclassical economic sense. In fact, 'irrationality' perceived by neoclassical economics may reflect a wider set of considerations and influences than that theory acknowledges.

Previous studies have investigated the feasibility of biochar in NZ in terms of feedstock availability, biomass processing technologies and economics (de Vos, Fortuin, Heubeck, \& Hall, 2009; Hall \& Gifford, 2007; Hall \& Jack, 2008; Jack \& Hall, 2009; Shrubsole, 2009). Biochar research on several aspects, mainly agronomic performance and production processes, is being pursued at various universities, research and commercial 
Introd | Method | Biochar | Institutions | Theory | Analys \& Disc | Concl institutions throughout NZ, including Scion (Wang, 2010), Landcare (Srinivasan, et al., 2010), Plant and Food Research (Simpson, Vogeler, \& Deurer, 2010; Sivakumaran, et al., 2010), and universities - Massey (Camps-Arbestain, et al., 2010; Jones, 2010), Lincoln (Anderson \& Condron, 2010), Waikato (Bourke, Manley-Harris, \& Antal, 2010), Canterbury (Pang, Li, \& Shaw, 2010) and collaborative work from Otago and Victoria (Dickinson, Kim, Hayman, \& Dickinson, 2010).

Biochar deployment ultimately occurs in a social and institutional setting. No investigation has so far been conducted on stakeholder views on biochar in NZ. It is hoped that this research will help to fill this gap. Figure 1 provides an overview of the key questions that Chapters One to Six aim to answer from a NZ perspective. It is acknowledged that in some aspects this study may suggest further questions rather than being able to provide answers. 


\section{Chapter 1: Introduction}

- What are the wider environmental issues based on which biochar is introduced?

- What is biochar as a material?

\section{Chapter 2: Methodology}

-What are the underlying paradigmatic assumptions of this study?

- Which specific methods are employed for primary and secondary data collection and analysis?

\section{Chapter 3: Biochar Science and Technology}

- What are the positives, negatives and unknowns about biochar in general and in the specific NZ context?

- Which potentially adverse side-effects may be anticipated?

\section{Chapter 4: Institutional Framework}

- What is the existing framework in terms of legislation, policies and agencies into which biochar would need to be integrated?

- What repercussions and effects on climate change as well as other policy areas would a decision in favour of biochar entail?

\section{Chapter 5: Theoretical Framework}

- What considerations for GHG policy design are suggested by theory and which policy criteria and principles should be applied when decisions have to be made in the face of risk and uncertainty?

- Which theoretical perspectives offer useful insights when biochar is framed as a new climate change mitigation tool?

\section{Chapter 6: Stakeholder Perspectives on Biochar: Analysis \& Discussion}

- What do stakeholders identify as positives, negatives and unknowns about biochar?

- What does the literature suggest in regard to the issues identified by stakeholders?

-What public policy approaches can be suggested based on stakeholder concerns and the literature review? Should biochar deployment in NZ be encouraged or discouraged, and under what conditions?

Figure 1: Overview of key questions for Chapter One to Six

The contribution of this research is to elicit stakeholder views on biochar deployment in $\mathrm{NZ}$, which has not been done previously. While published literature is concerned with 
Introd | Method | Biochar | Institutions | Theory | Analys \& Disc | Concl

economic, natural science and engineering aspects, an inquiry into the issues identified by those ultimately involved in the implementation of biochar systems is still lacking.

For stakeholders to make an informed decision, biochar life cycle assessments (LCA) need to be conducted on a case-by-case basis. Such evaluations should establish the net energy, greenhouse gas (GHG) and agronomic benefits or otherwise of biochar deployment. This study is not concerned with LCA but highlights the need for further research on this matter in section 7.2.

The challenge is that the topic of this thesis is highly contemporary. Biochar's properties and its overall environmental effects are subject to ongoing research. Currently proposed biophysical and biochemical mechanisms may be clarified, corrected or challenged as research efforts continue.

International climate negotiations are underway to hammer out a comprehensive and long-term agreement on global climate policy. The publication of this thesis falls in between two major international meetings on this issue - the United Nations Climate Conference in Copenhagen, Denmark, in December 2009 and its successor in Cancún, Mexico, in December 2010.

Based on climate policy directions indicated in meetings prior to Cancún as well as by domestic legislation in other countries and the final outcome of Cancún, the NZ Government may choose to alter its course in climate and related policy areas.

\subsection{Thesis Structure}

A visual account of the structure of this thesis along with a location of the objectives is given in Figure 2 below.

The following section of this chapter will briefly summarise the argument for mitigative policy action on climate change. Given that the relevant scholarly literature often presents 
Introd | Method | Biochar | Institutions | Theory | Analys \& Disc | Concl

biochar as a climate change mitigation tool, an introductory definition of biochar will be provided in section 1.6 of this chapter as a basis for discussion in the following chapters.

After presenting the methodology in Chapter Two, biochar production and deployment issues are taken up again and more closely examined in Chapter Three. Positives, negatives, unknowns and NZ-specific considerations about biochar are highlighted. This is followed in Chapter Four by an outline of the institutional framework as it potentially relates to domestic biochar deployment. Chapter Five establishes the theoretical lenses adopted for this study. Drawing on the basis established in Chapters Three to Five, an analysis and discussion of the empirical material collected for this research is presented in Chapter Six. The study closes with conclusions and suggestions for further research in Chapter Seven.

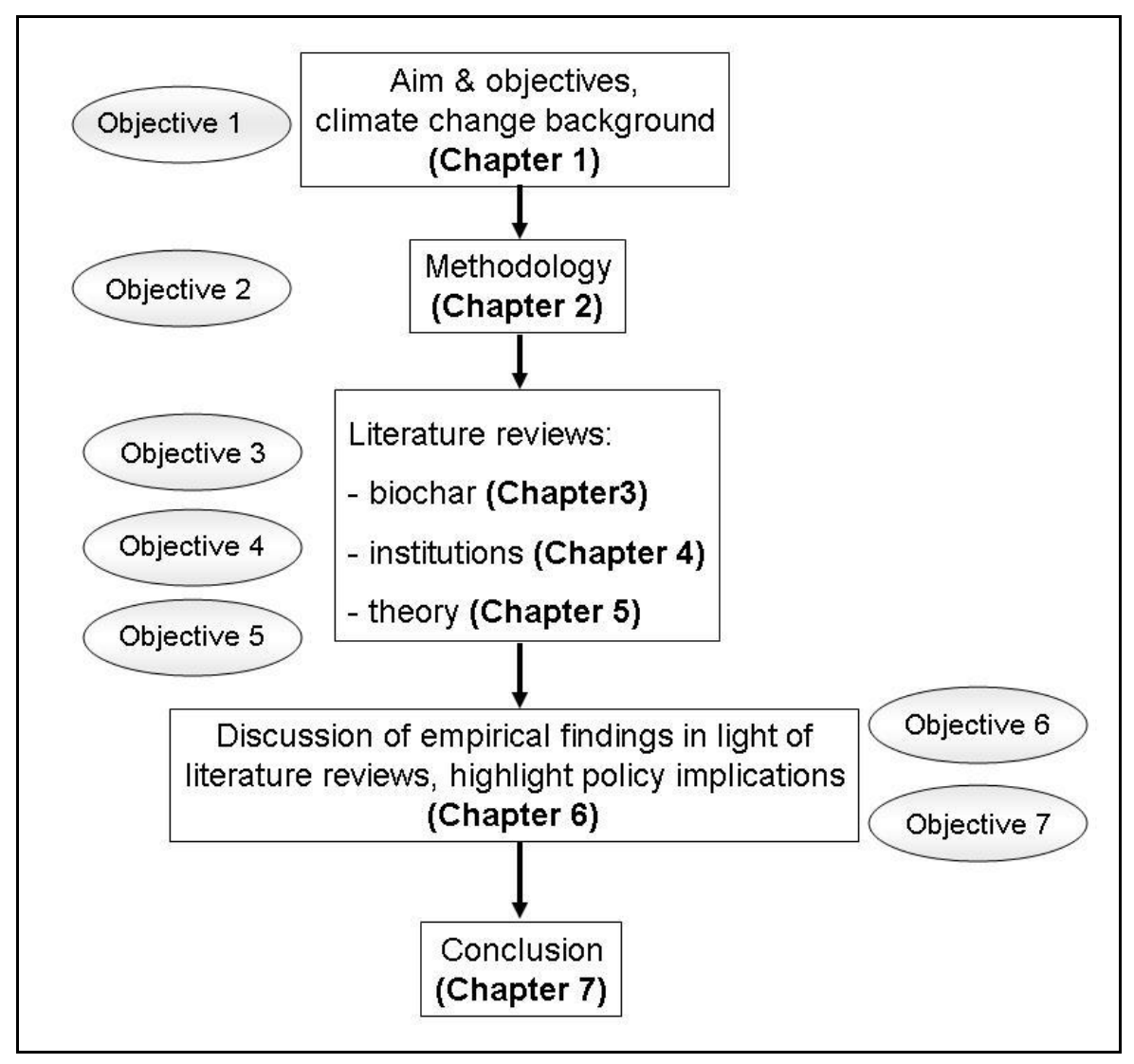

Figure 2: Schematic outline of thesis structure 
Introd | Method | Biochar | Institutions | Theory | Analys \& Disc | Concl

\subsection{The Background Problem: Climate Change}

Climate change represents an unprecedented challenge for humankind (Intergovernmental Panel on Climate Change (IPCC), 2007b; Stern, 2007). The subject has increasingly permeated the public debate over the past decades and is a challenge on multiple fronts, affecting environmental, social and economic policy portfolios.

Levels of atmospheric $\mathrm{CO}_{2}$ concentrations reached 391.06ppm measured in March 2010 at Mauna Loa (Tans, 2010b) and averaged 389.36ppm globally (Tans, 2010a). This is $111 \mathrm{ppm}$ (more than a third) above pre-industrial levels of $277 \mathrm{ppm}$ at $1700 \mathrm{AD}$ (Sigenthaler, et al., 2005). Scientific evidence suggests that only at or below $400 \mathrm{ppm}$ $\mathrm{CO}_{2}-\mathrm{e}^{1}$ can we limit global mean temperature increase to $2^{\circ} \mathrm{C}$ (see Figure 3) (Ackerman, Stanton, Hope, \& Alberth, 2009; Hansen, et al., 2008; IPCC, 2007a; Meinshausen, 2006).

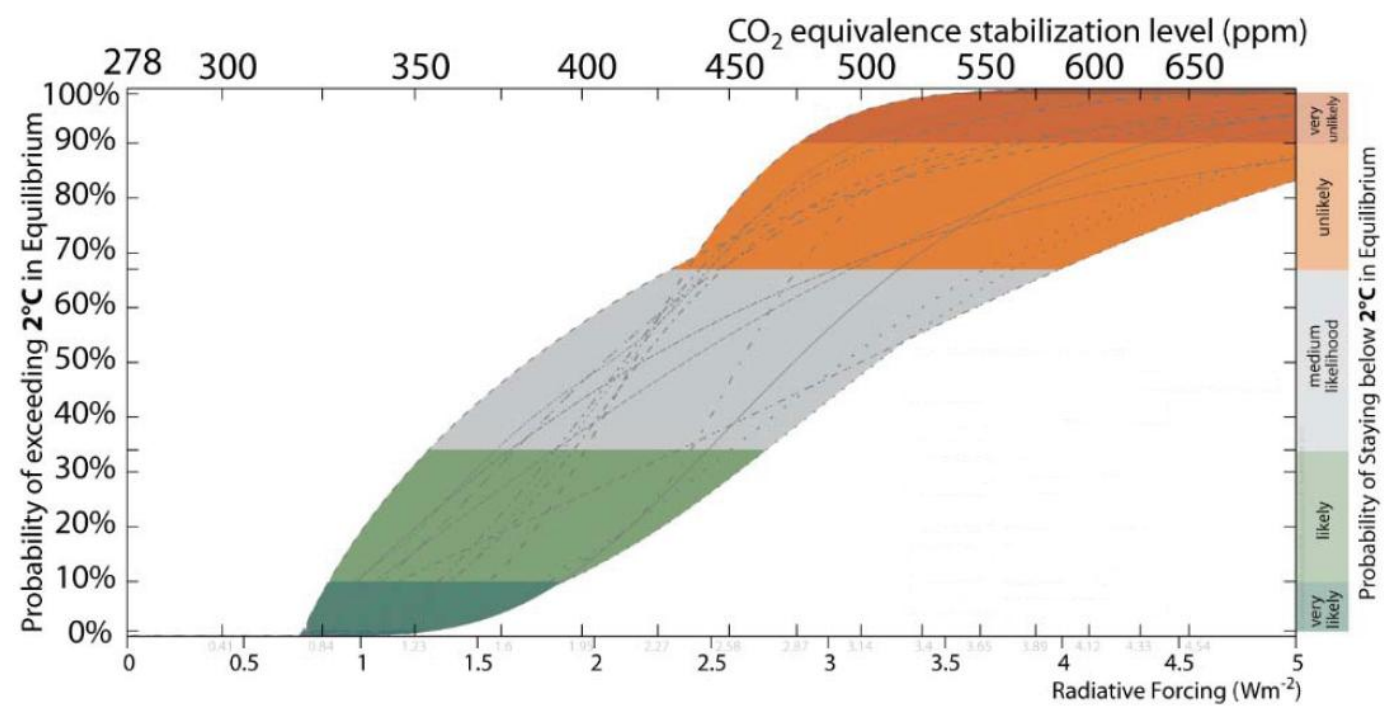

Figure 3: The probability of exceeding $2^{\circ} \mathrm{C}$ global mean equilibrium warming for different $\mathrm{CO}_{2}$-e stabilisation levels (Meinshausen, 2008, p. 13)

Present atmospheric $\mathrm{CO}_{2}$ concentration is the highest in the past 420,000 years (Petit, et al., 1999) and probably over the past 22 million years (Pearson \& Palmer, 2000). The growth rate of global

\footnotetext{
${ }^{1}$ Carbon dioxide equivalent denotes the $\mathrm{CO}_{2}$ concentration that would cause the same amount of radiative forcing as a given mixture of $\mathrm{CO}_{2}$ and other greenhouse gases. It can be seen as a conversion of the radiative forcing of non- $\mathrm{CO}_{2}$ greenhouse gases into $\mathrm{CO}_{2}$-units. $\mathrm{CO}_{2}$ has a radiative forcing of 1 (see also Table 1 below) (IPCC, 2007c).
} 

Introd | Method | Biochar | Institutions | Theory | Analys \& Disc | Concl

atmospheric $\mathrm{CO}_{2}$ over the period 2000-2006 was the highest since the beginning of measurements and averaged 1.93ppm per year with corresponding annual emissions of 4.1 gigatonnes of carbon (GtC) (Canadell, et al., 2007). Global emissions in 2004 reached 49Gt $\mathrm{CO}_{2}$-e accruing from the six major greenhouse gases $(\mathrm{GHG})$ carbon dioxide $\left(\mathrm{CO}_{2}\right)$, methane $\left(\mathrm{CH}_{4}\right)$, nitrous oxide $\left(\mathrm{N}_{2} \mathrm{O}\right)$, hydrofluorocarbons (HFCs), perfluorocarbons (PFCs) and sulphur hexafluoride (SF 6$)$ (see Figure 4)(IPCC, 2007a, 2007b).

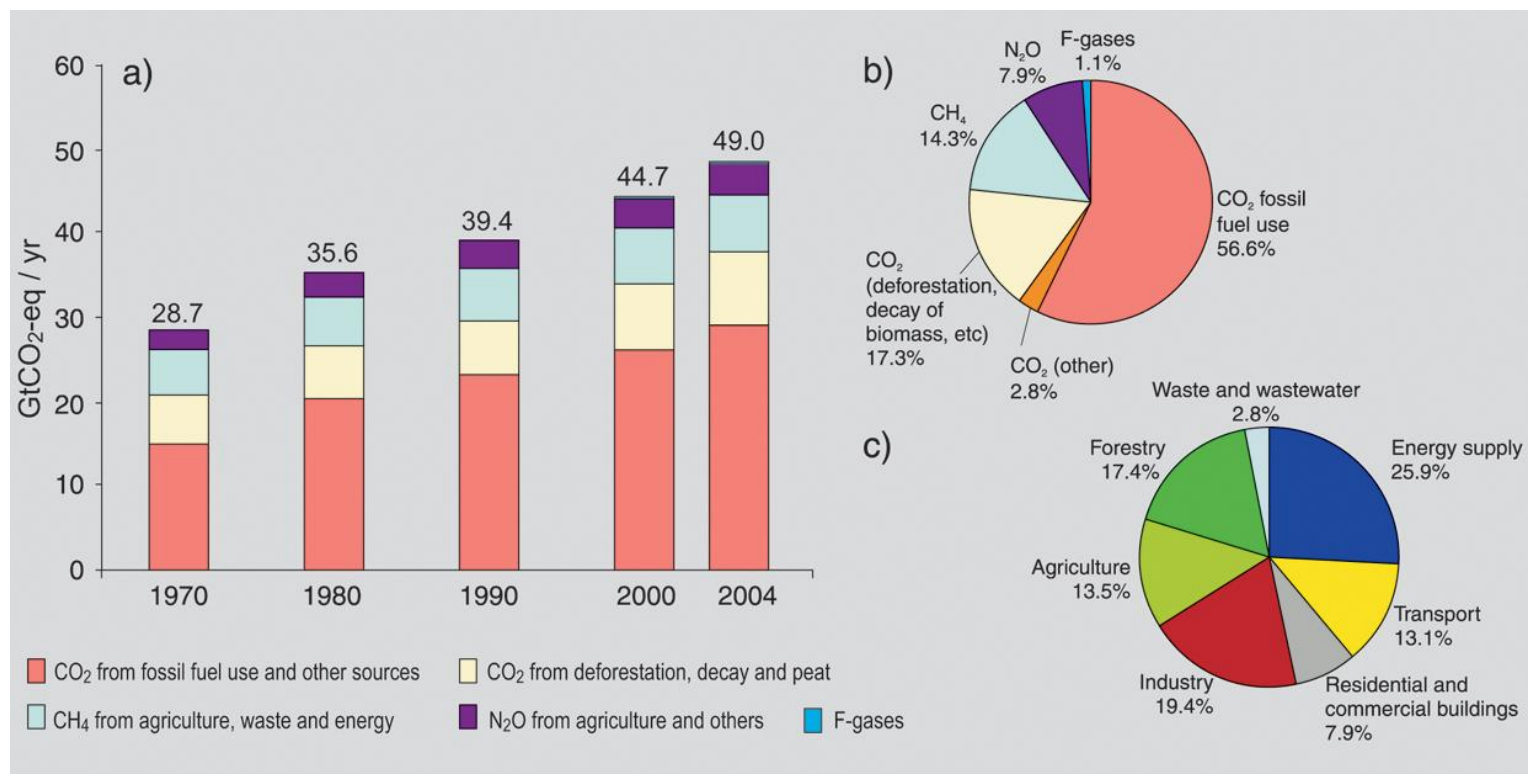

Figure 4: Annual global anthropogenic GHG emissions (IPCC, 2007b, p. 36): a) Global annual emissions of anthropogenic GHG from 1970 to 2004. b) Share of different anthropogenic GHG in total emissions in 2004 in terms of $\mathrm{CO}_{2}$-e. c) Share of different sectors in total anthropogenic GHG emissions in 2004 in terms of $\mathrm{CO}_{2}$-e whereby forestry includes deforestation.

While $\mathrm{CO}_{2}$ is not the most potent GHG, it is the most abundant GHG (IPCC, 2007c), making up more than three quarters of the GHG in the atmosphere (see Table 1) (Stern, 2007). A compounding problem is the longevity of $\mathrm{CO}_{2}$ in the atmosphere with $88 \%$ of the gas still present 200 years after its emission (IPCC, 2007b). 
Introd | Method | Biochar | Institutions | Theory | Analys \& Disc | Concl

Table 1: Characteristics of the six most significant GHG (Stern, 2007, p. 198)

\begin{tabular}{|c|c|c|c|}
\hline & $\begin{array}{c}\text { Lifetime in the } \\
\text { atmosphere } \\
\text { (years) }\end{array}$ & $\begin{array}{c}100 \text {-year Global } \\
\text { Warming } \\
\text { Potential (GWP) }\end{array}$ & $\begin{array}{c}\text { Percentage of } \\
2000 \text { emissions } \\
\text { in } \mathrm{CO}_{2} \mathrm{e}\end{array}$ \\
\hline Carbon dioxide & $5-200$ & 1 & $77 \%$ \\
\hline Methane & 10 & 23 & $14 \%$ \\
\hline Nitrous Oxide & 115 & 296 & $8 \%$ \\
\hline Hydrofluorocarbons (HFCs) & $1-250$ & $10-12,000$ & $0.5 \%$ \\
\hline Perfluorocarbons (PFCs) & $>2500$ & $>5,500$ & $0.2 \%$ \\
\hline Sulphur Hexafluoride $\left(\mathrm{SF}_{6}\right)$ & 3,200 & 22,200 & $1 \%$ \\
\hline
\end{tabular}

Changes in the global climate system are more pronounced than earlier scientific

evidence suggested and occur sooner than previously thought (Canadell, et al., 2007;

Shakhova, et al., 2010). There is a significant risk that these are irreversible (Matthews \& Caldeira, 2008; Solomon, Plattner, Knutti, \& Friedlingstein, 2009). A doubling of the preindustrial $\mathrm{CO}_{2}$ level is likely to be reached within the $21^{\text {st }}$ century, potentially even within the first half, with a best estimate of $3^{\circ} \mathrm{C}$ global average surface temperature increase (IPCC, 2007b). In fact, scientists are by now discussing adaptation to a temperature increase of $4^{\circ} \mathrm{C}$ (Alcamo, 2009; Malhi, 2009; Schellnhuber, 2009; Thornton, 2009; Vellinga, 2009).

Even if emissions had been held constant at 2000 levels, global mean surface temperature would still increase by $0.1^{\circ} \mathrm{C}$ per decade, and by $2080-2099$ would be $0.56^{\circ} \mathrm{C}$ above that of the 1980-1999 base period (IPCC, 2007c). This temperature rise entails rising sea levels and potentially irreversible marine and terrestrial ecosystems changes (Jones, Lowe, Liddicoat, \& Betts, 2009; Plattner, 2009; Rohling, et al., 2009; Solomon, Plattner, Knutti, \& Friedlingstein, 2009). Figure 5 shows the lingering effect of $\mathrm{CO}_{2}$ even if emissions fall to zero after the peaks. Due to the longevity of $\mathrm{CO}_{2}$, its atmospheric concentrations will be stable for the following millennium (Solomon, et al., 2009), which highlights the need for immediate and strong action. 
Introd | Method | Biochar | Institutions | Theory | Analys \& Disc | Concl

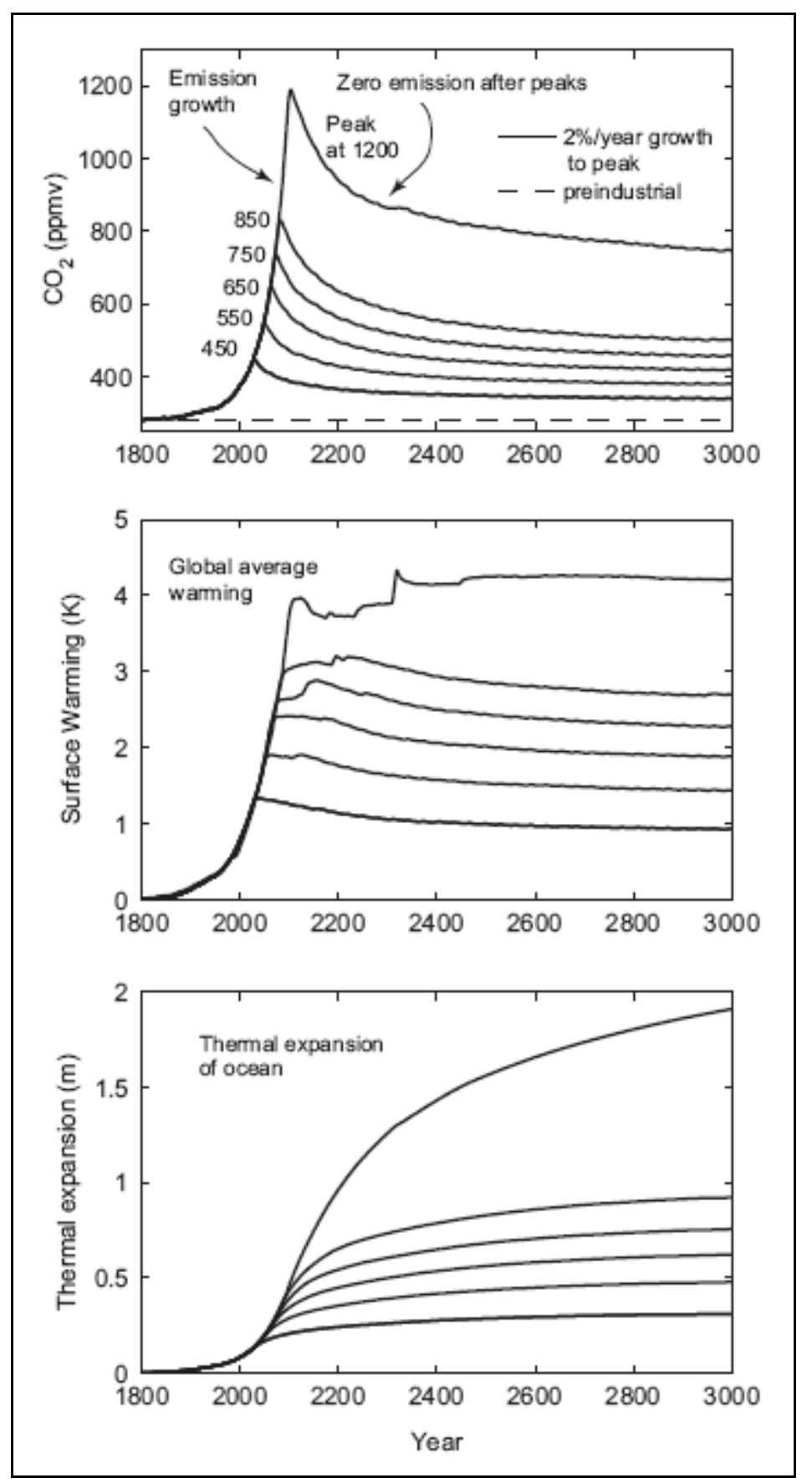

Figure 5: Projected changes in $\mathrm{CO}_{2}$ concentrations relative to pre-industrial levels with corresponding surface warming and ocean expansion (Solomon, et al., 2009, p. 1705)

Ethical and political obligations exist to stabilise "greenhouse gas concentrations in the atmosphere at a level that would prevent dangerous anthropogenic interference with the climate system" (United Nations (UN), 1992, p. 4), as stated in Article 2 of the United Nations Framework Convention on Climate Change (UNFCCC). Any definition of 'dangerous' in this context reflects individual valuation and judgment rather than a scientifically established threshold value (Meinshausen, 2006). Scientists and more than 
Introd | Method | Biochar | Institutions | Theory | Analys \& Disc | Concl

100 nations have embraced a $2^{\circ} \mathrm{C}$ target as the maximum allowable warming that is consistent with the provisions under Article 2 of the UNFCCC (Boston, 2007;

Meinshausen, et al., 2009).

Limiting warming to $2^{\circ} \mathrm{C}$ and a corresponding level of $450 \mathrm{ppm} \mathrm{CO}_{2}$-e requires emissions to fall to almost zero by 2100 (van der Linden \& Mitchell, 2009).

As shown in Table 2, if we are to stay at or below $2^{\circ} \mathrm{C}$ warming, atmospheric $\mathrm{CO}_{2}$ levels must not exceed a stabilisation level of 350-400ppm. Given current $\mathrm{CO}_{2}$ concentrations hovering around 390ppm (Tans, 2010a, 2010b), strong and urgent action is required as the time window for limiting temperature increase to $2^{\circ} \mathrm{C}$ closes rapidly (Reisinger, 2009). Information collated in the IPCC'S Fourth Assessment report may suggest that such limitation is no longer achievable.

Table 2: Post-TAR (Third Assessment Report) stabilisation scenarios and resulting long-term equilibrium global average temperature and the sea level rise component from thermal expansion only (IPCC, 2007b, p. 67). Note: The emissions reductions needed to achieve a certain $\mathrm{CO}_{2}$ stabilisation level do not include carbon cycle feedbacks.

\begin{tabular}{|c|c|c|c|c|c|c|c|}
\hline Category & $\begin{array}{l}\mathrm{CO}_{2} \\
\text { concentration } \\
\text { at stabilisation } \\
(2005=379 \\
\text { ppm })^{\mathrm{b}}\end{array}$ & $\begin{array}{l}\mathrm{CO}_{2} \text {-equivalent } \\
\text { concentration at } \\
\text { stabilisation } \\
\text { including GHGs } \\
\text { and aerosols } \\
(2005=375 \text { ppm })^{b}\end{array}$ & $\begin{array}{l}\text { Peaking year } \\
\text { for } \mathrm{CO}_{2} \\
\text { emissions }\end{array}$ & $\begin{array}{l}\text { Change in global } \\
\mathrm{CO}_{2} \text { emissions } \\
\text { in } 2050 \\
\text { (percent of } 2000 \\
\text { emissions) }\end{array}$ & $\begin{array}{l}\text { Global average } \\
\text { temperature increase } \\
\text { above pre-industrial at } \\
\text { equilibrium, using } \\
\text { 'best estimate' climate } \\
\text { sensitivity }{ }^{d, e}\end{array}$ & $\begin{array}{l}\text { Global average sea } \\
\text { level rise above } \\
\text { pre-industrial at } \\
\text { equilibrium from } \\
\text { thermal expansion } \\
\text { only }^{f}\end{array}$ & $\begin{array}{l}\text { Number of } \\
\text { assessed } \\
\text { scenarios }\end{array}$ \\
\hline & ppm & ppm & year & percent & ${ }^{\circ} \mathrm{C}$ & metres & \\
\hline
\end{tabular}

While climatic changes already occur, these will become more pronounced in the future.

Hence, ethical considerations of intertemporal equity provide an imperative for undelayed action (Brown Weiss, 1989) to not only reduce future emissions but to also to decrease the legacy load, i.e. the stock of GHG resulting from past emissions (Ackerman, et al., 2009; Hansen, et al., 2008).

There are compelling (though still disputed) grounds for strong policy commitment to climate change mitigation. They are based on biophysical and ethical considerations but 
Introd | Method | Biochar | Institutions | Theory | Analys \& Disc | Concl

also on purely economic reasoning. The costs of action far outweigh the costs of damage (Australian Government, 2008; Stern, 2007).

Limiting warming to $2-3^{\circ} \mathrm{C}$ would reduce global GDP by $0.1-3 \%$ in 2100 (exclusive of the potential for abrupt climate change) (Stern, 2007). The costs of stabilisation at 500550ppm $\mathrm{CO}_{2}$-e (or 450ppm $\mathrm{CO}_{2}$ ) have been estimated to be in the range of $-2 \%$ to $+5 \%$ of global GDP by 2050 with an average of $1 \%\left(\right.$ Stern, 2007) ${ }^{2}$. For a target of $450 \mathrm{ppm} \mathrm{CO}_{2}$-e, costs are projected to be $0.6-1.4 \%$ of global GDP in 2030 (Enkvist, Nauclér, \& Rosander, 2007).

This compares favourably with damage costs in the absence of mitigation. Under business-as-usual, global GDP would be diminished by $10.8 \%$ by 2100 (Ackerman, Stanton, Hope, \& Alberth, 2008) and by $5-20 \%$ by 2200 ; depending on a narrow or broad definition of damage (Stern, 2007). Mitigation may also be considered an insurance against dire consequences of unmitigated climate change. For comparison, the global insurance industry's turnover (excluding life insurance) in 2005 was $3.3 \%$ of global GDP (Enkvist, et al., 2007).

\subsection{Policy Considerations}

As it is becoming increasingly important to account for carbon in various forms, decisionmakers need high-quality advice on where action is best targeted.

Climate change poses the challenge to develop coherent policies across the great range of issues that it touches. A broad mitigation portfolio may include low-carbon technologies, careful land use planning, forestry and agricultural practices (Pacala \& Socolow, 2004).

\footnotetext{
${ }^{2}$ While contested, Stern's conclusions are similar to those of the Garnaut Review (Garnaut, 2008) and a report by the Australian Treasury (Australian Government, 2008) that show not only compatibility of economic development and climate change mitigation policies but also that the benefits of action outweigh their costs. Modelling of GHG policy impacts on the NZ economy as well as forestry in particular was performed by the NZ Institute of Economic Research (New Zealand Institute of Economic Research (NZIER), 2001a, 2001b; Stroombergen, Schilling, \& Ballingall, 2009) and has been criticised by Bertram (2000, 2001; Bertram, et al., 2009).
} 
More recent developments of geoengineering ${ }^{3}$ proposals are not without contest based on ethical and environmental objections (Govindasamy, Caldeira, \& Duffy, 2003; Lovelock, 2008). Long-term consequences, unintended adverse side-effects, instant or delayed, may be of significant magnitude and may even outweigh the climate benefits achieved by geoengineering schemes (Boyd, 2008; The Royal Society, 2009). Even if some future climate changes could be prevented, most geoengineering schemes cannot reverse all impacts already observed in global ecosystems such as loss of sea ice (Govindasamy, et al., 2003). Some measures may permanently sink and store carbon if the reservoir to which the carbon is added is permanently isolated from the atmosphere (Lenton \& Vaughan, 2009). Biochar has been proposed to provide such a pathway if it is incorporated into soil or otherwise stored underground (Lehmann, 2007b, Joseph, et al., 2009).

Biochar is sometimes referred to as 'soft' geoengineering because its interference with natural systems is considered less drastic than ocean fertilisation or sunshades in space (Lenton \& Vaughan, 2009; Verheijen, Jeffery, Bastos, Velde, \& Diafas, 2009). Biochar has been proposed as a lower-risk strategy compared to other carbon sequestration options. Forest fires, reversion from no-till to conventional tillage or leakage from geological carbon storage may pose challenges to those strategies (Lehmann, 2007c). Additionally, biochar has been touted with the ability to reverse elevated atmospheric $\mathrm{CO}_{2}$ levels due to a potentially carbon-negative life cycle (Lehmann, 2007a).

Biochar soil application has been proposed as a means to store carbon over geological time spans, effectively providing a carbon sink (Lehmann, 2007b; Lehmann, Gaunt, \& Rondon, 2006). While biochar's half-life is still subject to further research (Cheng, Lehmann, Thies, \& Burton, 2008), common estimates assume more than 1000 years (Laird, 2008). Amazon soils feature carbon aged several thousand years and studies of deep sea sediments indicate an age of even more than 10,000 years (Lehmann, et al., 2006; Masiello \& Druffel, 1998). On the other hand, it has also been suggested that the addition of fire-derived charcoal to soil may accelerate decomposition of native organic

\footnotetext{
${ }^{3}$ Geoengineering deliberately intervenes in the Earth's climate system by modifying the planetary energy balance to combat or counteract the effects of atmospheric changes from elevated GHG levels and associated global temperature increase (Lenton \& Vaughan, 2009; The Royal Society, 2009).
} 
Introd | Method | Biochar | Institutions | Theory | Analys \& Disc | Concl

matter and lead to a net increase in carbon released from soil (Wardle, Nilsson, \& Zackrisson, 2008a, 2008b).

Hence, biochar has its negatives and unknowns (Verheijen, et al., 2009). Policymakers must strive to foresee conflicting issues and adverse impacts by drawing on a balanced information base. Anticipating and mitigating potential repercussions will be a challenge to the research as well as policy community. Biochar deployment demands careful crafting of policy instruments in the areas of biodiversity, energy, economics and research to name a few. This study cannot be exhaustive in the sense of providing all technical details about biochar production and utilisation. Rather, it aims to offer a discriminating analysis of the potential public policy implications of biochar deployment in the specific New Zealand (NZ) context.

To provide a basis for further deliberations in subsequent chapters, the following section will introduce the subject or - rather literally - substance of discussion.

\subsection{What is Biochar?}

One of the major questions about biochar concerns the basics. The answer to what biochar actually is, based on a clear unambiguous scientific characterisation, has yet to be developed (Lehmann \& Joseph, 2009). Its definition as finely grained charcoal obtained by pyrolysis (Read, 2009) was subject to criticism because of its wordplay-like and sparsely scientific character not justifying the introduction of a new term (Monbiot, 2009). According to the International Biochar Initiative for a charcoal-like substance to be classified as biochar, it must be applied to soil in order to sequester carbon and to increase soil fertility (International Biochar Initiative (IBI), 2009b; Peacocke \& Joseph, 2009). Technically speaking, this means that charcoal burned for energy purposes is not to be termed biochar. A definition that puts emphasis on the utilisation purpose is endorsed by Lehmann and Joseph (2009) who also extend the definition to the purpose to filtration of percolating soil water (Lehmann \& Joseph, 2009). 
Introd | Method | Biochar | Institutions | Theory | Analys \& Disc | Concl

Further criteria encompass the physical and biochemical stability of the biochar product, the feedstocks used and the process conditions for biochar production: "[B]iochar is defined as the stable carbon-rich product that results from heating biomass materials (such as municipal green waste, poultry litter, forestry and agricultural residues) in limited oxygen" (IBI, 2009a).

Similarly, Lehmann and Joseph (2009) state that comparatively low temperatures $\left(<700^{\circ} \mathrm{C}\right)$ for the thermal decomposition of the biomass are used. The production process along with intended use determines the classification and convention on the denotation of the term biochar (Lehmann \& Joseph, 2009).

Figure 6 and Figure 7 below provide a visual impression of biochar.

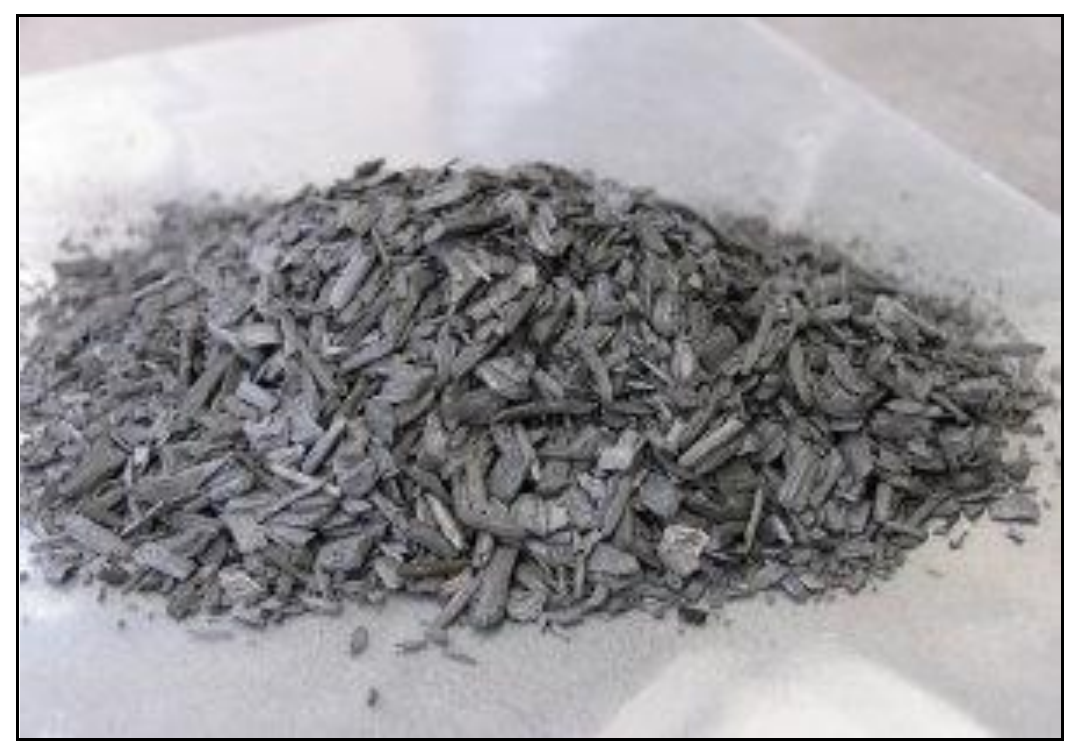

Figure 6: Agrichar $^{\mathrm{TM}}$ produced from BEST Energies demonstration facility (not true to scale) (Australia and New Zealand Biochar Researchers Network (ANZBRN), 2008: http://www.anzbiochar.org/projects.html\#five) 


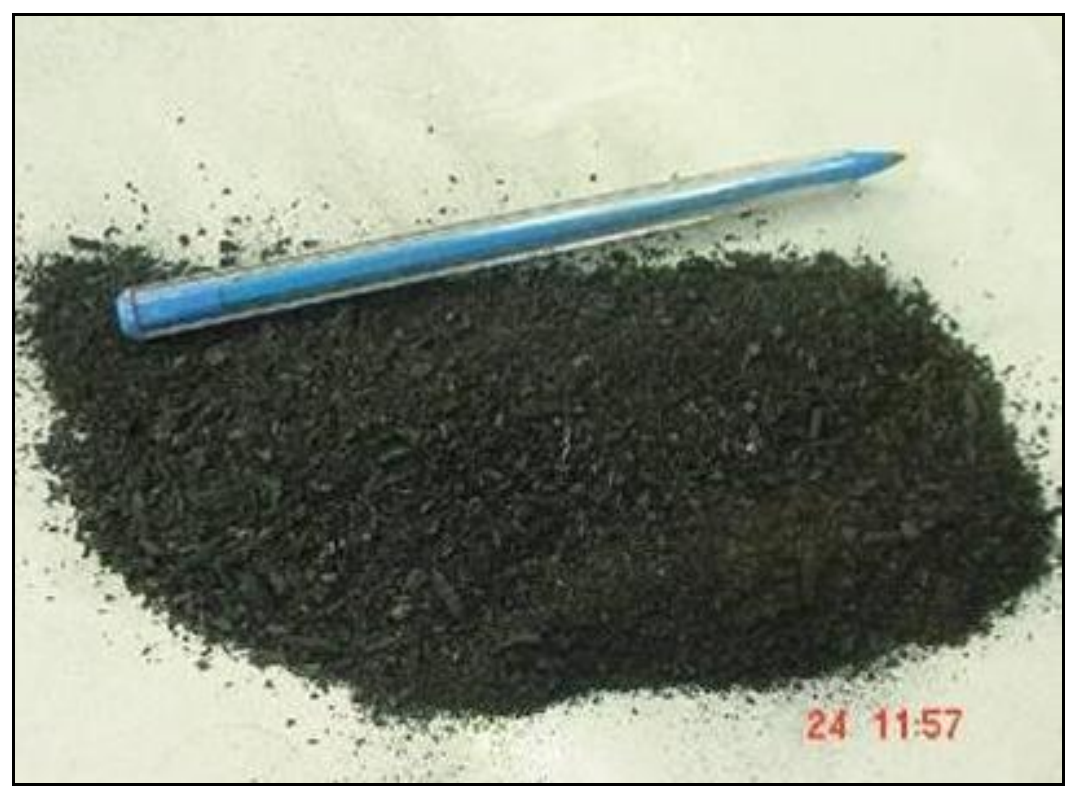

Figure 7: Biochar produced by BEST Energies Australia, Pty Ltd (BEST Energies Australia, 2008, p. 6)

The definition has been a dynamic one over the last years as it was initially restricted to the solid residue of slow pyrolysis that operates at low heating rates and a relatively low final residence temperature (Sohi, Lopez-Capel, Krull, \& Bol, 2009). The definition has extended to the solid residues of fast pyrolysis as well as new production technologies that use microwaves (Sohi, et al., 2009).

Fire-derived carbonaceous products of biomass comprise a wide range of materials and the use of terms in the literature often leaves the reader confused. To facilitate discussion in the following chapters, a definition of terms is provided here which follows that of Sohi and colleagues (2009).

'Char' describes any solid fire residue of organic material and encompasses black soot resulting from the incomplete combustion of fossil fuels as well as charred woody materials left after a natural forest fire (Sohi, et al., 2009).

The term 'charcoal' refers to the product of thermal decomposition of woody materials in a temperature range of $400-500^{\circ} \mathrm{C}$. The method deployed is traditional kiln technology, i.e. using earth mounds without capture of the liquid and gaseous reaction products (Sohi, et al., 2009). While traditional methods convert about $10 \%$ of the dry weight of the 
Introd | Method | Biochar | Institutions | Theory | Analys \& Disc | Concl

feedstock into biochar, controlled industrialised pyrolysis processes achieve about $35 \%$

(Sohi, et al., 2009). A distinguishing factor between biochar and charcoal is that the latter is primarily used for purposes other than soil enhancement. These include heating, cooking, filtration, industrial steelmaking or colouring in industrial or art applications (Lehmann \& Joseph, 2009).

Activated carbon is produced by two main methods. These are thermal or physical activation, e.g. with steam (Alaya, Girgis, \& Mourad, 2000) and chemical activation, e.g. with potassium hydroxide (Azargohar \& Dalai, 2006) or $\mathrm{CO}_{2}$ as the activation agent (Zhang, et al., 2004). Activation of carbonaceous material creates a value-added product that is used as an adsorbent in a variety of industrial and commercial applications such as water filtration, gas purification or adsorption of volatile organic compounds to prevent air pollution at source (Henning \& Schäfer, 1993; Ioannidou \& Zabaniotou, 2007). Activated carbons are characterised by a large internal surface area and a high surface reactivity with the majority of pores being in the order of micropores (Alaya, et al., 2000; Azargohar \& Dalai, 2006).

Black carbon (BC) is the product of incomplete combustion of fossil fuels and vegetation (Goldberg, 1985) and represents a spectrum of carbonaceous materials, chemically ranging from polyaromatic to elemental substances (Kuhlbusch, 1995). The chemical characteristic of aromaticity describes the proportion of organic content of a substance that is comprised of aromatic compounds. These are rings of six carbon atoms linked together without oxygen or hydrogen (Lehmann \& Joseph, 2009). The higher the treatment temperature during pyrolysis, the more aromatic rings are formed and are increasingly ordered. At $3,500^{\circ} \mathrm{C}$ (and for some biomass already at $2,000^{\circ} \mathrm{C}$ ) graphite is formed which is characterised by perfectly stacked and aligned sheets of carbon rings (Downie, Crosky, \& Munroe, 2009), as shown in Figure 8 below. 
Introd | Method | Biochar | Institutions | Theory | Analys \& Disc | Concl

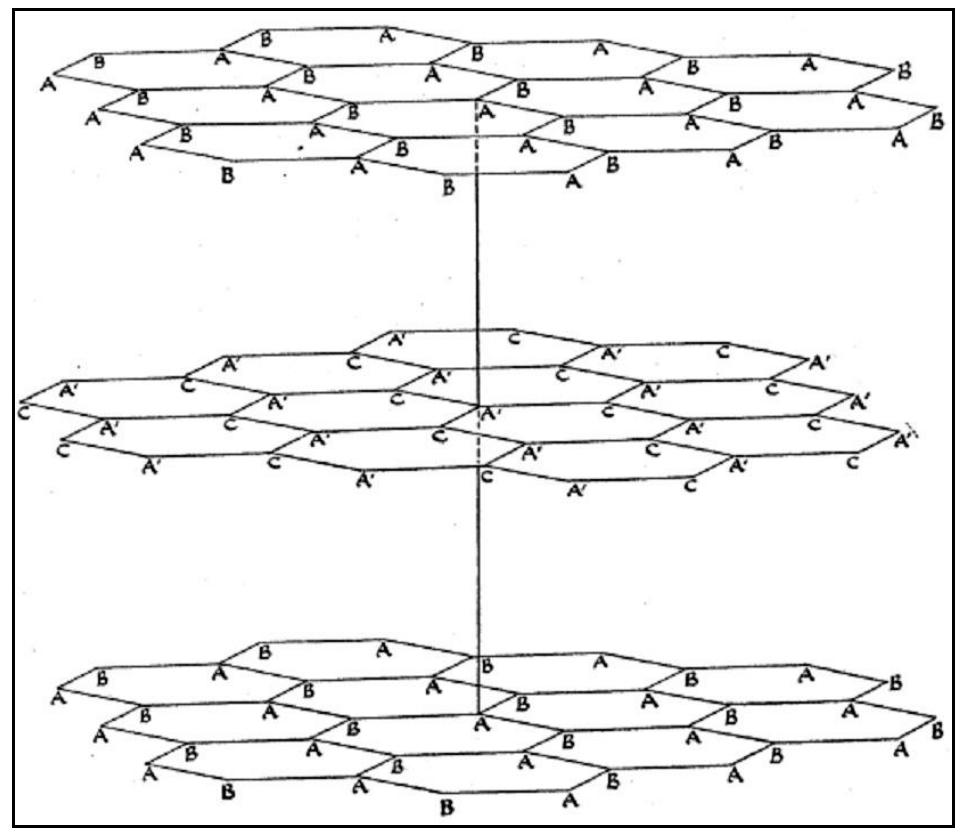

Figure 8: Structure of graphite as proven for the first time by Bernal in 1924 (Bernal, 1924, p. 767)

Ultimately, pyrolysis of all biomass-carbon will yield graphite. The gradual development of carbon rings and their increasing alignment as pyrolysis temperature increases is graphically shown in Figure 9 below.

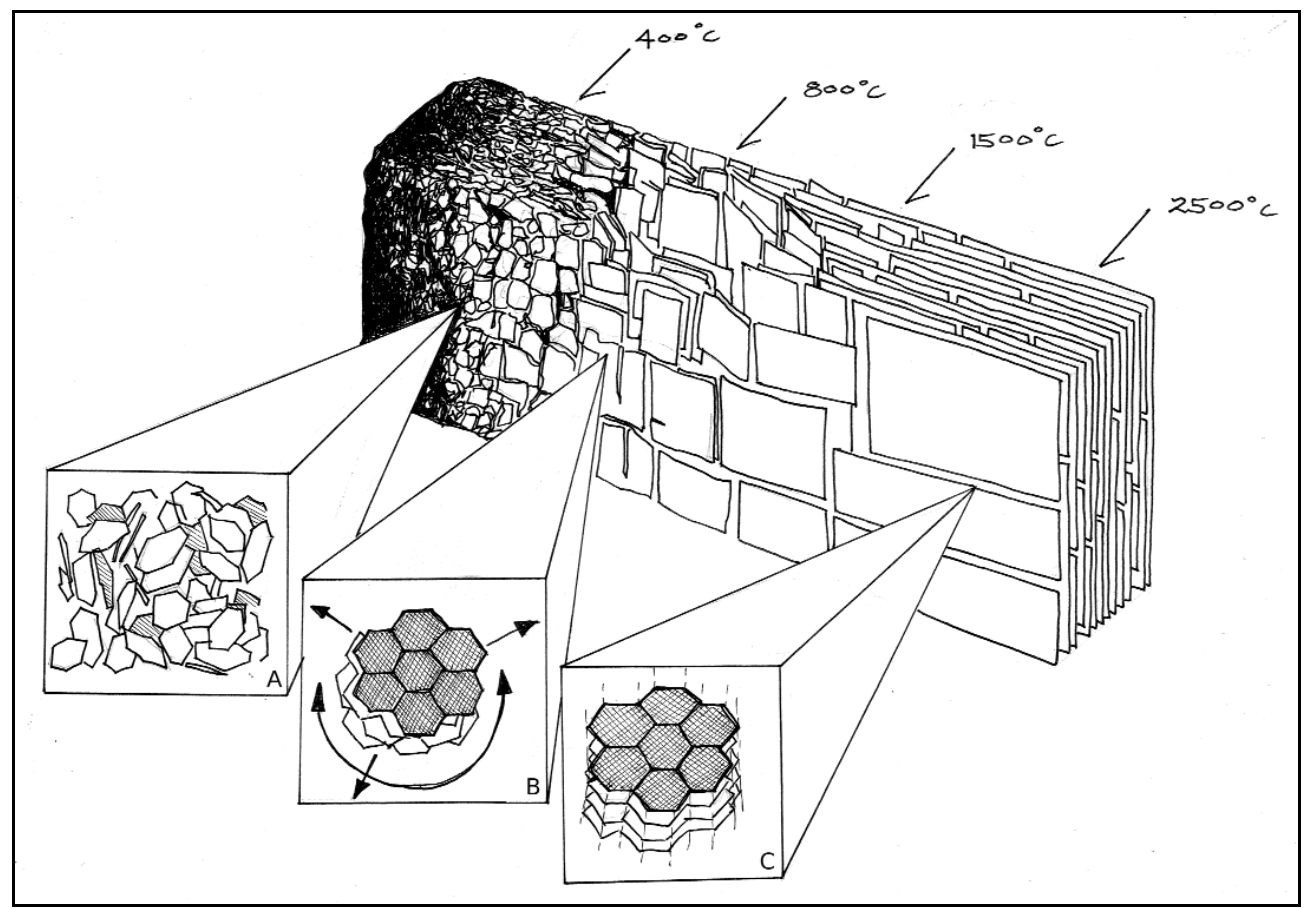

Figure 9: Ideal carbon ring structure development with highest treatment temperature (HTT): (a) Increased proportion of aromatic carbon, highly disordered in amorphous mass; (b) growing sheets of conjugated aromatic carbon; (c) structure becomes graphitic with order in the third dimension (Downie, Crosky, \& Munroe, 2009, p. 18) 
Introd | Method | Biochar | Institutions | Theory | Analys \& Disc | Concl

Figure 10 and Figure 11 illustrate BC's continuum character from partially charred plant material with a still intact physical structure, to charcoal, soot and ultimately graphite (Seiler \& Crutzen, 1980). There are no clearly defined boundaries between these carbonisation stages of biomass, and the particle size of the different compounds varies considerably (Schmidt \& Noack, 2000).

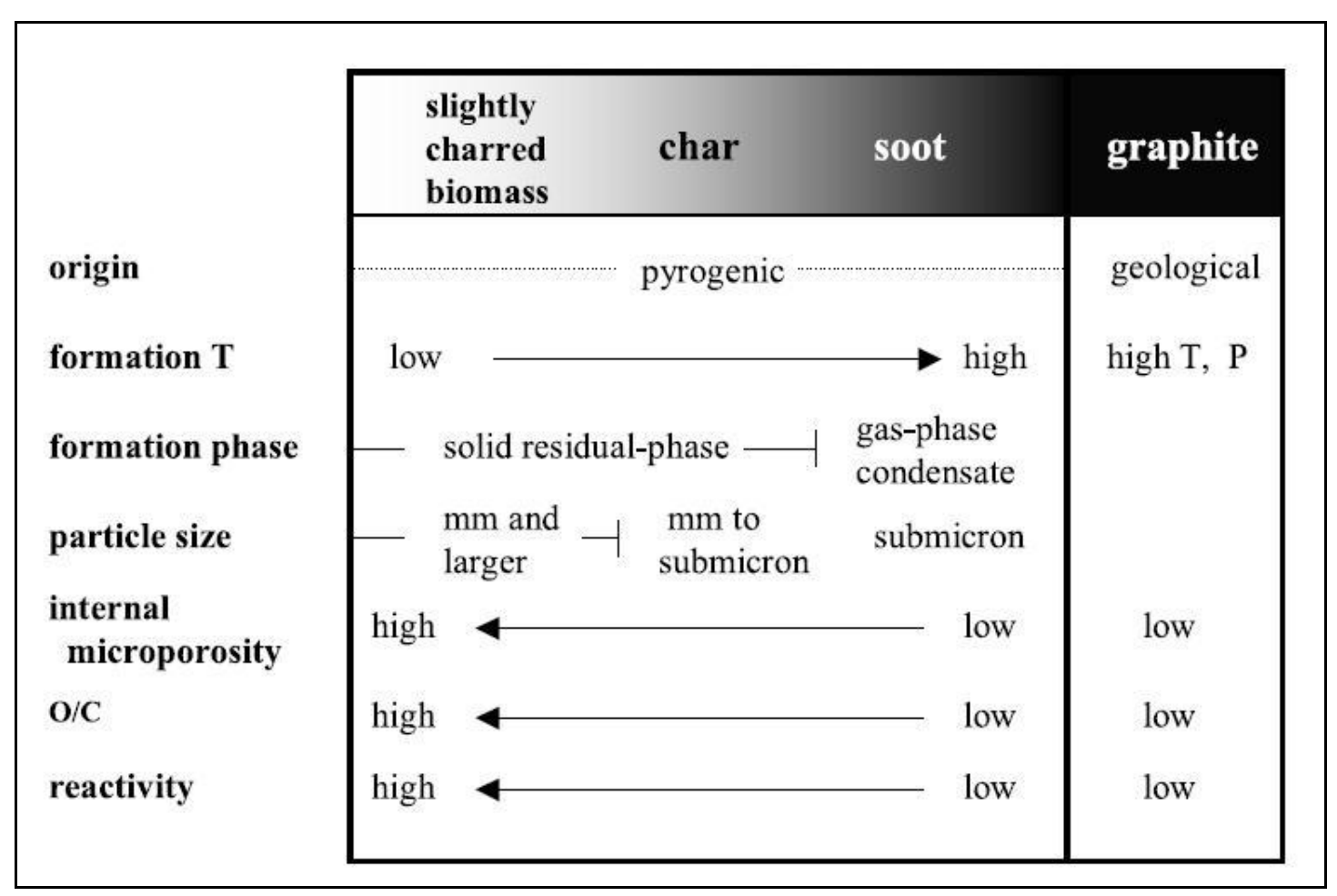

Figure 10: $\mathrm{BC}$ formation as a combustion continuum where $\mathrm{T}$ is temperature, $\mathrm{P}$ is pressure and $\mathrm{O} / \mathrm{C}$ is the atomic oxygen to carbon ratio (Elmquist, Cornelissen, Kukulska, \& Gustafsson, 2006, p. 2) 


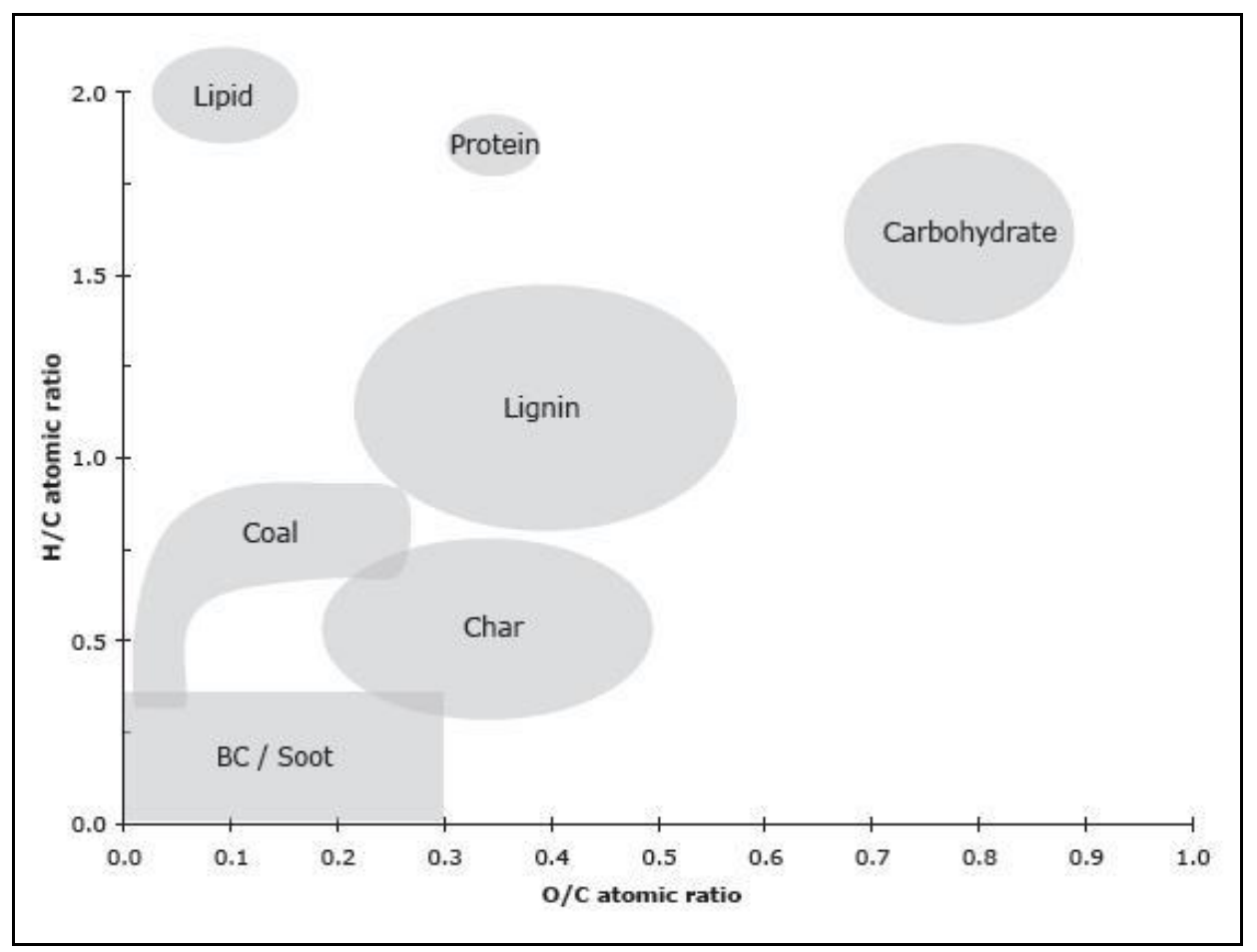

Figure 11: Process of biomass charring and associated changes in biomolecular components (grey shadings) (adapted from Hammes, et al., 2006, p. 1630)

Black carbon is ubiquitous in that it can be found in ocean sediments and ice as well as in soils and in the atmosphere (Kuhlbusch, 1998). BC formation occurs via two main pathways. While solid combustion residues form char-BC, soot-BC is formed from recondensed volatiles (Preston \& Schmidt, 2006; Schmidt \& Noack, 2000). The different $\mathrm{BC}$ formations are reflected in the chemistry and morphology of the $\mathrm{BC}$ particles. Charcoal particles feature basic characteristics of the chemistry and morphology of the plant material that they are derived from. These characteristics are absent in soot particles which identifies them as being derived from secondary condensation of combustion gases (Schmidt, Masiello, \& Skjemstad, 2003). BC is also discussed as a significant but relatively short-lived greenhouse gas (Hansen, et al., 2005; Ho, 2009; Molina, et al., 2009; Wallack \& Ramanathan, 2009).

Additionally, the term 'elemental carbon' appears in the literature. It is inconsistently used to refer to different materials and is often used synonymously with 'black carbon'. Elemental carbon is formed under aerobic conditions and refers to the carbon fraction that is oxidised above a particular temperature threshold. It is loosely used in the literature to 
Introd | Method | Biochar | Institutions | Theory | Analys \& Disc | Concl

describe material of near-elemental soot-carbon-like composition (Andreae \& Gelencsér, 2006).

Following the elaborations above, the terms biochar and black carbon are used interchangeably in this study.

Apart from the carbon sequestration aspect in the context of climate change mitigation, biochar has been suggested to provide agronomic benefits. Improved soil health and productivity have been associated with elevated soil carbon levels (Brady \& Weil, 2002; Troeh \& Thompson, 2005).

The soil carbon pool is also discussed in the context of climate change as a compartment of the global carbon cycle (see Figure 12), and land use management is targeted to reduce emissions from land use and land-use change (Commonwealth Scientific and Industrial Research Organisation (CSIRO), 2009; Scherr \& Sthapit, 2009; Wise, et al., 2009).

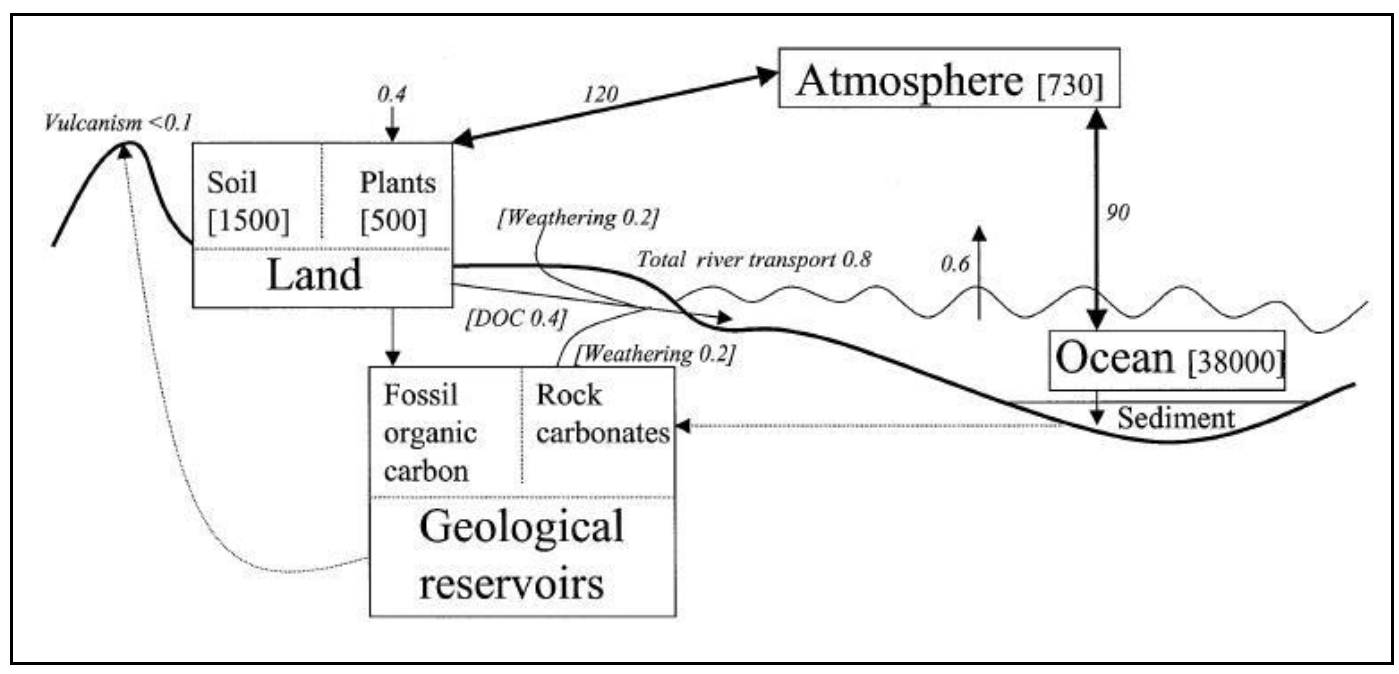

Figure 12: The global natural carbon cycle (without human perturbation) with pools and fluxes in Gt; $($ DOC $=$ dissolved organic carbon) $($ Smith, 2004, p. 213)

It has been estimated that globally, soils contain 1,500 Gt of organic carbon (Batjes, 1996) which is about three times the amount of carbon stored in vegetation and almost twice as much as in the atmosphere (IPCC, 2000b). Estimates for historic global soil 
Introd | Method | Biochar | Institutions | Theory | Analys \& Disc | Concl

carbon loss due to cultivation and other disturbances range from 40-90 GtC (Houghton, 1999; Houghton, Hackler, \& Lawrence, 1999; Lal, 1999; Schimel, 1995).

The BC fraction of the soil carbon pool is relatively inert or recalcitrant, thereby representing a terrestrial carbon sink (Kuhlbusch, 1998; Preston \& Schmidt, 2006;

Schmidt \& Noack, 2000; Schulze, Wirth, \& Heimann, 2000) with a much slower turnover time than other terrestrial sequestration options, such as afforestation and reforestation (Nguyen, et al., 2008; Schulze, et al., 2000).

Having introduced the wider context of climate change in which biochar is presented as a potential mitigation tool, the following chapter is concerned with the methodology deployed in this research. 
Introd | Method | Biochar | Institutions | Theory | Analys \& Disc | Concl

\section{Methodology}

This chapter presents the methodological approach deployed in this study to address the aim and objectives presented in the introduction. It seeks to answer the following questions:

- What are the underlying paradigmatic assumptions of this study?

- Which specific methods are employed for primary and secondary data collection and analysis?

The chapter is structured in three main sections. It first lays out the paradigms adopted for the purpose of this study. This is followed by an outline of the research design in the second subsection. The chapter concludes by detailing the specific methods used for empirical data collection, recording and analysis.

\subsection{Environmental Pragmatism}

What researchers observe and how they observe it is not neutral but carried out from within a paradigm (Kuhn, 1962). This study is framed under the paradigm of environmental pragmatism as one of the distinct and significant of the many and varied strands of pragmatism (Creswell, 2003; Mintz, 2004). The philosophical movement of pragmatism originated in the 1870s in the United States (Peirce, 1877; James, 1898). Among the foundational pragmatic scholars are Charles Sanders Peirce, William James, John Dewey, and George Herbert Mead.

The popular connotation of pragmatism as short-sighted, anthropocentric instrumentalism does not suggest any usefulness for informing environmental discourse and policy deliberation and decision-making (Weston, 2003; Parker 1996). Philosophical pragmatism, however, is genuinely compatible with environmental ethics (Weston, 2003) and some even argue that it is an environmental ethic (Rosenthal \& Buchholz, 1996). One of the fundamentals is the notion of society as a subsystem of and embedded in the 
environment (Parker, 1996). The environment is not 'out there' as separate from human beings and is not freely available, at our disposal for exploitation or preservation as we please. Instead, humans and any being are inextricably linked with the environment as the place where experience - in the most basic sense the interaction between organism and environment - occurs (Rosenthal \& Buchholz, 1996). All that can be felt, known, valued or believed in arises and takes place in the environment (Parker, 1996). Should our striving toward full domination and prediction of the environment ever be successful, we would have annihilated the ultimate source of our growth - further experience - and hence ourselves (Rosenthal \& Buchholz, 1996).

Philosophical pragmatism is subjective in the sense that only human beings $d o$ value, but this does not mean that only human beings have value. Pragmatism draws on a range of values and beliefs that compete with and at the same time complement each other, similar to the various species that coexist, interact and compete with each other in an ecological network (Weston, 2003). The problem in pragmatism is not to devise justifications for environmental values but to resolve the conflicts between them in the specific situations where they are applied (Weston, 2003). With regard to environmental policy, Norton (1996) argues for the integration of multiple values on three scales of human concern and valuation: local values that mirror individual preferences, community values that protect and sustain human and ecological communities and global values that represent a hope for humans' long-term survival (Norton, 1996). This pluralistic approach is built on pragmatism's rejection of the notion of an absolute truth or axiomatic belief upon which knowledge must be based (Minteer \& Manning, 2003; Rorty, 1979). Instead, true beliefs are those that continue to make sense of the world and are not contradicted in experience (James, 1907; 1909). Truth is what works at a time. Accordingly, environmental pragmatists "are not wedded to any particular theoretical framework from which to evaluate specific problems, but [they] can choose the avenue which best protects the longterm health and stability of the environment, regardless of its theoretical origin" (Light, 1996, p. 172).

Pragmatism is interested in 'workability'. It emphasises action and experimentation (Minteer \& Manning, 2003, p.320) and is ultimately most concerned with the research problem and the solution to it (Creswell, 2003; Mintz, 2004). This problem-centeredness implies that the choice of research methods is based on the goal of best understanding the 
problem. The attempt to derive successful actions, grounded in practical experience, enables researchers some freedom of choice in the use of multiple methods, drawing on the strengths of both quantitative and qualitative strategies of inquiry (Onwuegbuzie, Johnson \& Collins, 2010; Onwuegbuzie \& Teddlie, 2003). As such pragmatism provides a philosophical underpinning and epistemological justification for mixed methods research (Maxcy, 2003). Pragmatism “opens the door" (Creswell, 2003, p. 12) to mixed method research as the strategy of inquiry. The thesis of incompatibility of quantitative and qualitative methods is rejected for the sake of producing more informative, complete, balanced and useful research results (Onwuegbuzie, et al., 2010).

The implication of this for environmental policy, pragmatism sees "individuals as the source of genuine insight into what is needed, and accordingly tries to maximise participation in governing" (Parker, 1996, p. 31) with the aim of giving the public "a real voice in determining the kinds of environments we inhabit” (Parker, 1996, p. 31). It is hoped that this will contribute to achieving more informed, effective and equitable resolutions in environmental decision-making and policy formation (Minteer \& Manning, 2003).

\subsection{Research Design}

The research employs a mixed methods approach to data gathering. While still a nascent paradigm located in the middle of the continuum of qualitative and quantitative approaches (Johnson \& Onwuegbuzie, 2004; Sale, Lohfeld, \& Brazil, 2002), the mixed methods approach was chosen because it allows the researcher to draw on the strengths of both qualitative and quantitative methods and to minimise their respective weaknesses (Onwuegbuzie \& Teddlie, 2003). Including numeric as well as text information was considered to best address the aim and objectives of this research. For the purpose of this study, qualitative and quantitative data should be seen as complementary. The specific type of mixed methods strategy adopted in this research is termed concurrent nested strategy which nests the method that is given less priority within the dominant method (Creswell, 2003). For this study it means that the quantitative method (online surveys) is nested within the qualitative method (individual and small-group interviews). A visual 
representation of this design is given in Figure 13 where this study can be located in the bottom left square (circled). The concurrent nested model was chosen because it enables extending the perspective beyond what would have been possible by using the dominant (qualitative) method alone. During analysis the data collected via the different methods are converged so as to best analyse the problem under investigation (Creswell, 2003).

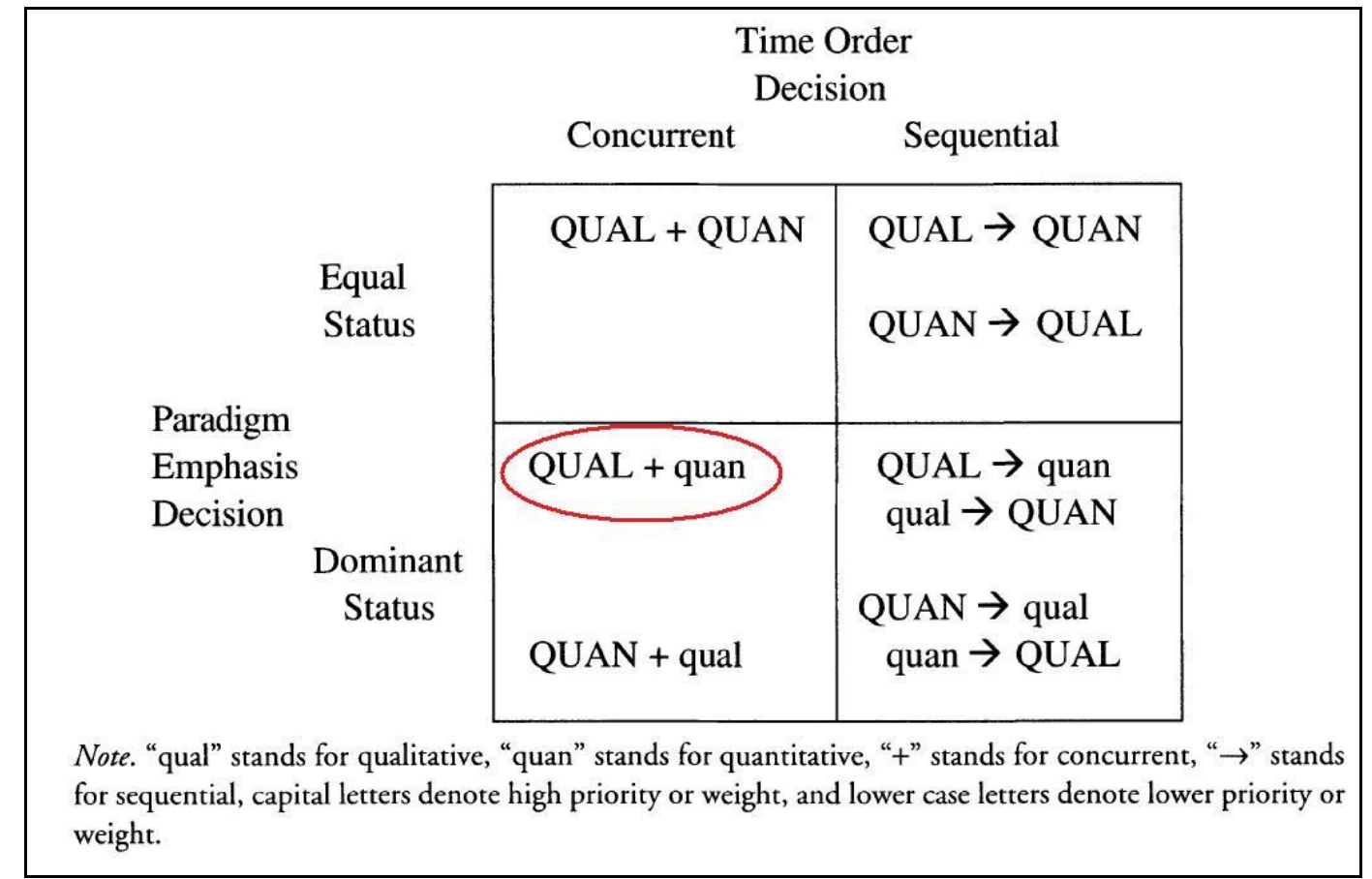

Figure 13: Matrix for mixed methods research design with design applicable to this study circled (Johnson \& Onwuegbuzie, 2004, p. 22)

This study does not adopt a purely pragmatic paradigm, which has been suggested to be the "philosophical partner" (Johnson \& Onwuegbuzie, 2004, p. 16) of mixed methods research, but aligns itself more closely with social constructionism as outlined in section Error! Reference source not found. above. This is in accord with the emphasis on a qualitative approach.

In locating the use of theory on the continuum between induction and deduction, this study adopts the mixed methods concept of theory as a "lens or perspective to guide the study" (Creswell, 2003, p. 136). This allows for determining a theoretical framework $a$ priori while being flexible enough to allow for the development of new propositions that emerge from the data (Lather, 1986). 
Introd | Method | Biochar | Institutions | Theory | Analys \& Disc | Concl

Specifically, this research combines semi-structured interviews (one-to-one and smallgroup interviews) and online surveys. An overview of the specific methods and their contribution to achieving the objectives of this research is given in Table 3. 
Introd | Method | Biochar | Institutions | Theory | Analys \& Disc | Concl

Table 3: Overview of mixed methods deployed in this study

\begin{tabular}{|c|c|c|c|}
\hline Method & Type of analysis & Procedure and outcome & $\begin{array}{l}\text { To meet } \\
\text { objective }\end{array}$ \\
\hline Literature review & $\mathrm{N} / \mathrm{A}$ & $\begin{array}{l}\text { Review of academic literature to determine } \\
\text { the current knowledge about climate change } \\
\text { and the role that biochar is deemed play } \\
\text { within that context }\end{array}$ & 1 \\
\hline Literature review & $\mathrm{N} / \mathrm{A}$ & $\begin{array}{l}\text { Review of academic literature to determine } \\
\text { the research design best suited to attain the } \\
\text { research aim as well as advantages and } \\
\text { disadvantages of specific methods }\end{array}$ & 2 \\
\hline Literature review & $\mathrm{N} / \mathrm{A}$ & $\begin{array}{l}\text { Review of academic literature to determine } \\
\text { the current knowledge about biochar in } \\
\text { general and its implications for NZ in } \\
\text { particular }\end{array}$ & 3 \\
\hline Literature review & $\mathrm{N} / \mathrm{A}$ & $\begin{array}{l}\text { Review of academic and policy literature to } \\
\text { provide an account of the institutional setting } \\
\text { that frames biochar deployment in NZ }\end{array}$ & 4 \\
\hline Literature review & $\mathrm{N} / \mathrm{A}$ & $\begin{array}{l}\text { Review of academic literature to establish the } \\
\text { theoretical lenses deployed for analysis of } \\
\text { empirical results }\end{array}$ & 5 \\
\hline Online surveys & $\begin{array}{l}\text { Quantitative \& } \\
\text { qualitative }\end{array}$ & $\begin{array}{l}\text { Surveying members of forestry/wood } \\
\text { processing and organic agriculture } \\
\text { organisations so as to elicit perspectives of } \\
\text { potential feedstock suppliers and biochar } \\
\text { demanders on a larger scale than would be } \\
\text { possible by individual interviews; basic } \\
\text { statistical analysis using MS Excel for } \\
\text { quantitative survey data; coding for } \\
\text { qualitative survey data }\end{array}$ & 6 \\
\hline $\begin{array}{l}\text { Individual } \\
\text { interviews }\end{array}$ & Qualitative & $\begin{array}{l}\text { Semi-structured face-to-face and telephone } \\
\text { interviews with stakeholders to establish a } \\
\text { picture of biochar deployment in NZ and to } \\
\text { explore perceptions about risks associated } \\
\text { with biochar and preferred risk management } \\
\text { strategies (data analysis by coding) }\end{array}$ & 6 \\
\hline $\begin{array}{l}\text { Small-group } \\
\text { interviews }\end{array}$ & Qualitative & $\begin{array}{l}\text { Semi-structured interview technique with the } \\
\text { added advantage of using group interactions } \\
\text { to increase depth and richness of the } \\
\text { discussion as participants are able to probe } \\
\text { each other's reasoning for holding a specific } \\
\text { perspective }\end{array}$ & 6 \\
\hline $\begin{array}{l}\text { Thematic coding; } \\
\text { comparison and } \\
\text { integration of } \\
\text { empirical findings } \\
\text { with theory }\end{array}$ & Qualitative & $\begin{array}{l}\text { Discuss categories identified via coding of } \\
\text { empirical data against the backdrop of } \\
\text { theories drawn fom the literature; highlight } \\
\text { specific implications for NZ }\end{array}$ & 7 \\
\hline
\end{tabular}


Introd | Method | Biochar | Institutions | Theory | Analys \& Disc | Concl

\subsubsection{Literature Reviews}

Various parts of this thesis are based on a review of academic and policy publications. The multidisciplinary nature of the research requires consultation of literature form sociology, psychology, economics and public policy as well as natural sciences.

Scientific studies concerned with climate science, chemistry, physics and soil science provide background information on the natural science aspects of climate change and biochar. This is complemented by quantitative data on soil types and land use which are relevant to assess the potential for biochar application in NZ.

The theoretical basis for exploration of motivational aspects and influences on individual decision making draws on academic work in psychology and sociology. For the policy and socio-economic implications of biochar deployment, relevant literature in policy and economics provides valuable insights into concepts and consequences of policy decision making.

\subsubsection{Empirical Research}

The empirical part of the research employs a two-tier data gathering technique. The quantitative strand comprises two separate online surveys to cover the feedstock supply and the biochar demand sides. To limit the scope of the study, the forestry and wood processing sectors, which together have been found to potentially provide up to $76 \%$ of biochar feedstock in NZ (Shrubsole, 2009), were chosen to cover the feedstock supply side. For the purpose of limiting the scope, the demand side was covered by targeting the organic agricultural sector, including horticulture and animal husbandry. An additional reason was the underlying assumption that people working in organic agriculture would be putting a relatively higher importance on environmental sustainability than conventional agriculturalists. Membership organisations in both forestry/wood processing and organic agriculture were asked to send out the survey link to their members. This was done by means of printed or online newsletters. The survey questionnaires (annexed in Appendix Two) include several open-ended questions so as to provide space for 
participants to articulate their underlying reasoning, motivations and rationales.

Therefore, the survey yielded quantitative and qualitative data which are complementary.

Due to a low response rate the study is not statistically representative of the groups surveyed. In the stakeholder group of forestry and wood processing, the survey request was published in newsletters of two forestry and one wood processing membership organisations with a combined number of about 1,850 members. One forestry organisation specifically sent the survey request to 16 of its members which together cover approximately $70-75 \%$ of the New Zealand plantation forest estate. Eight responses were received from the stakeholder group of forestry and wood processing, equating to a response rate of $0.48 \%$.

In the stakeholder group of organic agriculture, four organisations agreed to publish the survey request in newsletters as well as one magazine. The combined membership of these organisations is 3,900 . The survey yielded 25 responses, equating to a response rate of $0.64 \%$.

The membership numbers presented here may serve as a rough guide only when estimating how many people may have been reached by the survey request. Publications are typically read beyond the circles of members of a particular organisation. Overlapping readership, overlapping membership and readership by non-members suggest that these figures represent only an indication of the potential size of the respondent groups.

An issue related to the wider readership of organisational publications is that not all survey respondents and interview participants in the stakeholder group of agriculture identified as 'organic' in the sense of complying with a specific set of substances and practices permitted by a certifying authority. While the study targeted the organic farming community, an officially recognised certification was not a mandatory requirement for participation. All agricultural respondents were using farming practices that provided an alternative to conventional farming. They utilised organic and biological methods with the aim to minimise the use of synthetic fertiliser and other chemical inputs. 
As the survey was not intended to yield statistically significant data, it was considered more important to find out what opinions are held and what problems and benefits are identified by those whom the academic literature implicitly envisages to use biochar.

Consequently, analysis of the survey responses focuses on qualitative data and aims to integrate these with the qualitative data gathered in interviews. The general strategy of the research followed concurrent procedures, meaning that the two strands of online surveys and individual and small-group interviews were carried out simultaneously (Creswell, 2003). Notwithstanding, a sequential approach was integrated by giving respondents the option of providing their contact details at the end of the survey if they were willing to participate in a follow-up in-depth interview. There is thus an overlap of survey respondents and interview participants.

This study employed the technique of semi-structured interviews for individual as well as small-group interviews. This technique is best suited to reveal information about motivational aspects behind approaches taken by different actors. Semi-structured interviews are guided by predetermined essential questions that need to be answered and are formulated as open-ended questions, while additional questions arise from the conversation itself (DiCicco-Bloom \& Crabtree, 2006). The iterative nature of the qualitative research process and particularly the use of a semi-structured interview technique allow for redesigning the interview questions during and after each interview, in case they prove inadequate or unsuitable (Atkins, 1984). The interview themes are annexed in Appendix One.

Collection and analysis of data in qualitative research form a "repetitive interplay" (Bryman, 2004, p. 399) meaning that the strategy for data collection simultaneously constitutes the strategy for analysis (Charmaz, 2005). A semi-structured interview method tries to balance the influence of interviewer and interviewee on steerage of the conversation (Pawson, 1996). This enables coverage of topics and aspects that the researcher did not anticipate but which are important to the interview participant. This option is an integral part of the exploratory nature of the qualitative approach (Bryman, 2004). In addition to individual interviews small-groups interviews were conducted so as to tap into group interactions which enable participants to probe each other's reasons for holding a particular view (Flick, 2009). This adds depth and richness to the discussion as 
various views are articulated and participants are challenged to give their underlying rationales for why they think about the issue the way they do (Bryman, 2004). Moreover, it has been argued that group settings come closer to the real life situation where meaning is constructed collectively in a social context (Wilkinson, 1998).

The requirements for data processing, interpretation, representativity and validity in a qualitative study are different from quantitative approaches. A qualitative approach means limitations in terms of generalisability of findings and replication of the study (Creswell, 1994). While quantitative research projects often aim for objectivity, qualitative studies rely on the concept of intersubjectivity to validate the results of data analysis (Boyatzis, 1998). This means that different researchers, although they differ in their subjective views, should arrive at the same results when using the method employed in the study (Creswell, 1994). This highlights the importance of transparency and plausibility as criteria for qualitative data analysis. Including extended quotations from research participants alongside the researchers' interpretation makes the analysis understandable and open to scrutiny. While the reader can assess the validity of the researchers' interpretation of the raw data, it has the added benefit of giving participants a voice (Altheide \& Johnson, 1998; Clough \& Nutbrown, 2002).

The specific methods used in this study for the collection, recording and analysis of empirical material are detailed in the following section.

\subsection{Methods: Empirical Data Collection, Recording and Analysis}

Prior to empirical data collection, approval from Victoria University of Wellington's Human Ethics Committee was required and sought. This procedure is required for any research involving human subjects to ensure protection of people's privacy, rights and freedoms (Victoria University of Wellington (VUW), 2007). In the application for ethics approval, the nature and purpose of the research as well as procedures for data collection, storage, access, use and feedback are specified. This information is - in a condensed form - also provided to research participants by way of an information sheet. Participants are 
asked to sign a consent form that specifies privacy and feedback preferences. In the case of this study, participants will be provided with a summary of the results once the thesis has been marked.

\subsubsection{Methods for Surveys}

Six stakeholder groups were identified for the purpose of this study: organic agriculture, forestry/wood processing, bioenergy/biochar businesses, environmental non-government organisations (ENGO), academia and the public sector. The groups of forestry/wood processing and organic agriculture were chosen for a survey because they appeared to comprise the largest number of people out of the six stakeholder groups. Limits on the scope of the study necessitated some selection.

The form of an online survey instead of a paper-based one was chosen because of logistic ease and financial constraints. The researcher is aware that this limited the group of potential respondents to those with internet access.

A web-based survey was set up by subscribing to SurveyMonkey, a private online survey tool provider based in the United States. The two survey questionnaires (annexed in Appendix Two) were tested in a pilot study. Ten respondents filled in the survey and provided feedback which contributed to the amendment of the survey questionnaires. The pilot study participants did not belong to the particular groups targeted by the survey as they were not working in forestry/wood processing or organic agriculture. For this reason, the respondents' comments helped to improve the general design and wording of the questionnaire, but the suggestions regarding questions that were specific to the said sectors were limited.

A second pilot run of the survey was conducted yielding seven responses, enabling further refinement of the questionnaire. The same strengths and weaknesses apply as for the first pilot run in terms of the contribution that participants were able to make based on their experience and professional background. 
Introd | Method | Biochar | Institutions | Theory | Analys \& Disc | Concl

For the actual research survey, forestry/wood processing organisations and organic agricultural organisations in NZ forwarded the survey request to their individual members. Due to differing issue dates of newsletters, magazines or other publications by the various organisations involved, the time window for different groups to fill in the questionnaire also varied. The first notifications of the survey were sent out in December 2009 and successively followed by further announcements from January to March 2010 according to issue dates of organisations' publications. Data collection for all groups of respondents finished on 14 March 2010.

Responses were stored electronically on the server of the online survey tool provider and were analysed online as well as downloaded for further processing using Microsoft Excel. The qualitative survey material was processed along with the qualitative interview data for which the detailed analysis methods are described in the following section.

\subsubsection{Methods for Interviews}

Members of all six stakeholder groups described in section 2.3.1 above were interviewed. It was hypothesised that each stakeholder group would have distinguished interests and perspectives on the matter and it was the aim to elicit a variety of viewpoints. This is hoped to enable evaluation of pros and cons of biochar deployment from a variety of perspectives and that the insights will provide a starting point for thinking about the NZ policy approach towards biochar deployment. This approach to sampling based on predefined groups of interest aligns itself with the procedures outlined in Flick (2009). It was found to be an adequate method as the research is concerned with eliciting "the social distribution of perspectives on a phenomenon or a process" (Flick, 2009, p. 318) with the underlying assumption that different social groups hold different views on the matter under investigation (Flick, 2009).

Initial contacts for interviews were made using the researcher's own as well as her supervisor's networks. Additionally, in the course of the literature research and by keeping up-to-date regarding biochar issues in NZ further contacts who appeared interesting were contacted directly by email or phone. Furthermore, snow ball sampling 
was employed. This technique yields a statistically non-representative sample of respondents because the researcher establishes initial contacts with a group of people that is considered relevant to the research topic while further recruitment of participants relies on social contacts between individuals (Bryman, 2004).

The option of face-to-face interviews was preferred to that of phone interviews. Due to financial and time constraints 26 out of 44 interviews were done on the phone as participants were based throughout NZ. Interview duration ranged from 15 to 90 minutes. Three small-group interviews were conducted, two within the stakeholder group of academia (with two and three participants respectively) and one within the forestry/wood processing group (two participants). The group interview builds on the focused interview technique developed by Merton and Kendall (1946). While their discussion mainly centres on individual interviews, they also consider extending the method to group settings (Merton, Fiske, \& Kendall, 1956).

Seventeen of the 18 face-to-face interviews and two of the three small-group interviews were recorded with a Dictaphone and transcribed within three days after the interview. This was complemented by handwritten notes that were taken during the conversations. If participants did not approve of the interview being recorded or if it was a phone interview, only handwritten notes were taken which were subsequently written down in an electronic file. The interviews are considered the main data source and are augmented by survey responses which help to cover larger shares of the stakeholder groups surveyed.

Table 4 provides a summary of the number of interviews in each stakeholder group and indicates the type of interview (face-to-face vs. phone interview). The small number of ENGO members interviewed weakens the attempt to provide a balanced picture of stakeholder group perspectives. Nine New Zealand ENGO were contacted with two declining participation due to perceived insufficient knowledge on the subject, and five not responding to repeated attempts to make contact ${ }^{4}$. Unfortunately, time constraints precluded the researcher from further and insistent requests for ENGO statements.

\footnotetext{
${ }^{4}$ While of course not representative for ENGO in general, influential analyses and statements have been issued by the ENGO Biofuel Watch UK (Ernsting, Anderson, \& Maina, 2009; Ernsting \& Rughani, 2008; Ernsting \& Smolker, 2009; Paul, et al., 2009) and Rainforest Rescue (Rainforest Rescue, 2009). Both organisations highlight global rather than NZ-specific issues. A declaration published by Rainforest Rescue has been signed by 158 organisations (as of 26/03/2009) (Rainforest Rescue, 2009).
} 
Introd | Method | Biochar | Institutions | Theory | Analys \& Disc | Concl

Table 4: Overview of number of participants in each stakeholder group

\begin{tabular}{|c|c|c|c|}
\hline \multirow[b]{2}{*}{ Stakeholder group } & \multicolumn{3}{|c|}{ Number of participants in each interview category } \\
\hline & $\begin{array}{l}\text { Face-to-face } \\
\text { interview }\end{array}$ & $\begin{array}{c}\text { Phone } \\
\text { interview }\end{array}$ & Total \\
\hline Organic agriculture & 3 & 12 & 15 \\
\hline $\begin{array}{l}\text { Forestry \& wood } \\
\text { processing }\end{array}$ & $3^{*}$ & 5 & 8 \\
\hline $\begin{array}{l}\text { Bioenergy/biochar \& } \\
\text { fertiliser companies }\end{array}$ & 1 & 5 & 6 \\
\hline ENGOs & - & 2 & 2 \\
\hline Academics & $7^{\star *}$ & 1 & 8 \\
\hline Public sector & 4 & 1 & 5 \\
\hline Total & 18 & 26 & 44 \\
\hline \multicolumn{4}{|c|}{ * Of which two participants were interviewed in a small-group setting } \\
\hline \multicolumn{4}{|c|}{$\begin{array}{l}\text { ** Of which five participants were interviewed in small-group settings with two and } \\
\text { three participants respectively }\end{array}$} \\
\hline
\end{tabular}

The aim of qualitative data gathering is to explore participants' 'frameworks of meaning' and applies a more open-ended approach. This contrasts with quantitative approaches where the researcher determines the categories before data collection (Bryman, 2004; Creswell, 1994). The empirical materials collected for this study were analysed by thematic coding as developed by Flick (2009). It builds on the constant comparison method of grounded theory, originally designed by Glaser and Strauss (1967) and subsequently advanced by Strauss (1987).

Data collection and analysis occur simultaneously in a cyclic process (Glaser \& Strauss, 1967). Ongoing analysis of collected material via coding serves the purpose of organising and reducing data (Glaser \& Strauss, 1967). Codes are developed from the empirical material rather than imposed on it so that the data is not required to fit into preconceived, standardised categories (Flick, 2009).

Labelling, separating, compiling and fleshing out similarities and divergences between individual incidents are performed with the aim of grouping them in categories (Charmaz, 
Introd | Method | Biochar | Institutions | Theory | Analys \& Disc | Concl

2003, 2005; Huberman \& Miles, 1998). From these categories more abstract, higher-level concepts are then distilled (Glaser \& Strauss, 1967). After developing thematic codes from analysis of individual cases, comparison within and between stakeholder groups are made (Flick, 2009).

Flick's thematic coding procedure enables the development of categories by aggregating and comparing perspectives within and between the groups studied while simultaneously maintaining sensitivity and openness to the individual case in regard to the issue under investigation (Flick, 2009). 
Introd | Method | Biochar | Institutions | Theory | Analys \& Disc | Concl

\section{Biochar Science and Technology}

Building on the definition of biochar given in Chapter One, a more detailed discussion of scientific and technological aspects is provided here. The questions that this chapter seeks to answer are:

- What are the positives, negatives and unknowns about biochar in general and in the specific NZ context?

- Which potentially adverse side-effects may be anticipated?

The application of charcoal to agricultural land is not a new invention. Although anthrosols (soils that have been formed under anthropogenic influence) with historically carbon-enriched top layers can be found in several parts of the world, they are primarily associated with the Amazon region (Glaser, Balashov, Haumaier, Guggenberger, \& Zech, 2000; Marris, 2006) and are believed to have been created by Amerindian pre-Columbian civilisations (Glaser, Haumaier, Guggenberger, \& Zech, 2001; Smith, 1980; Sombroek, 1966).

These soils are termed Terra Preta do Índio or Indian Black Earth due to their dark colour derived from the anthropogenic addition of charcoal and various kinds of organic material (Glaser, et al., 2001; Smith, 1980). Other names are Anthropogenic Dark Earths or Amazonian Dark Earths (Lehmann, et al., 2003b). They are significantly more fertile than adjacent soils that are of the same type but do not contain anthropogenic charcoal and organic matter amendments. Amazonian Dark Earths feature relatively higher carbon content, cation exchange capacity, $\mathrm{pH}$ values and phosphorus contents as well as lower aluminium contents than adjacent soils ${ }^{5}$ (Major, Di Tommaso, Lehmann, \& Falcão, 2005).

\footnotetext{
${ }^{5}$ Even today, black carbon-enriched soils aged 600-8,700 years still exhibit significantly higher contents of chemically stable aromatic carbon as a component of their soil organic matter (SOM) than adjacent soils of the same type which have not been anthropogenically enriched with black carbon (Solomon, et al., 2007). Soil organic matter is defined here according to (Baldock \& Skjemstad, 1999) as "all organic materials found in soils irrespective of origin or state of decomposition" (Baldock \& Skjemstad, 1999, p. 160). However, measurement difficulties arise in regard to SOM content due to the range of elements that comprise $\mathrm{SOM}(\mathrm{C}, \mathrm{H}, \mathrm{O}, \mathrm{N}, \mathrm{P}$ and $\mathrm{S})$. In most cases, the SOM content is determined indirectly by analysing the soil organic carbon (SOC) content first and using a conversion factor to obtain the SOM content (Krull,
} 
Introd | Method | Biochar | Institutions | Theory | Analys \& Disc | Concl

In NZ charcoal soil application to increase fertility and retain heat during night time was part of traditional pre-European Maori agricultural practices (Furey, 2006; MacNab, 1969; Middleton, 2007).

Evaluating the potentials and challenges of biochar deployment in NZ is usefully grounded in an understanding of basic physical, chemical and engineering-related aspects. This chapter hopes to provide such an overview by drawing on the relevant scholarly literature. The first part of the chapter is concerned with the physico-chemical properties of biochar and their impacts on soil properties. Issues of nutrient cycling, GHG emissions, sorption of water and environmental pollutants as well as impacts on soil structure and soil biota are explored. The second part of the chapter outlines engineering-related aspects of biochar production technologies.

All these facets have economic and sustainability implications for biochar deployment. Such repercussions are considered in more detail in the Analysis and Discussion in Chapter Six.

\subsection{Biochar Impacts on Soil biophysical and biochemical Properties}

This section will look at the impact of biochar on the physical and chemical properties of soil as they affect nutrient retention, nutrient cycling, water holding capacity, soil structure, and soil biota. It has been proposed that biochar soil addition may enhance these parameters. That is, biochar may provide agronomic benefits as well as indirect GHG savings additional to the direct carbon sequestration in the biochar (Chan, Van Zwieten, Meszaros, Downie, \& Joseph, 2007; Gaskin, Steiner, Harris, Das, \& Bibens, 2008; Gaunt \& Lehmann, 2008; Van Zwieten, et al., 2009a).

Skjemstad, \& Baldock, 2004). In Amazonian terra preta soils 35\% of the soil organic matter (SOM) in the A horizon of the soil consists of black carbon. In adjacent Oxisols, however, BC was found only in the top few centimetres and constituted 14\% of the SOM (Glaser, et al., 2000). 
Auxiliary benefits include reduced emissions from fertiliser production and use, reduced need for tillage, avoided emissions from fossil fuels (through use of energy generated during pyrolysis) and avoided emissions from landfilled biomass (Cowie, 2009).

Biochar performance in soils varies significantly and is dependent on biochar properties as well as characteristics of the environment in which the biochar is applied. Feedstock ${ }^{6}$, manufacturing process and conditions - such as temperature, heating rate and heating time - soil type, degree of soil degradation, land management (crops, fertiliser, tillage etc.) and climate all have considerable influence on the impact of biochar on soil properties and hence on plant growth (Abdullah, et al., 2010; Chan \& Xu, 2009; Cheng \& Lehmann, 2009; Kimetu, et al., 2008).

Using the same biochar in an arid, low-carbonate soil under cereal cropping in south east Australia (Australian Government, 2007) and in a wet, acid brown soil in NZ under dairy pasture (Hewitt, 2009) will yield significantly different impacts on soil and plants. Therefore, the claims for biochar performance are very specific to the respective study and its materials and methods. Arguing from the particular to the general proves very problematic as research findings are virtually not generalisable.

In this section, studies of soil carbon in climatic regions similar to the temperate NZ region (Kottek, Grieser, Beck, Rudolf, \& Rubel, 2006; Peel, Finlayson, \& McMahon, 2007) are used where possible. Despite a growing body of literature with studies in temperate climatic zones, a large proportion of publications is concerned with the humid tropics or arid regions. Apart from the climate, one of the key differences is that soils in such regions have significantly lower carbon contents than NZ soils. The following sections aim to shed light on the materials and methods of the studies cited so as to put their findings in perspective and indicate their relevance to $\mathrm{NZ}$ conditions.

NZ's climate is classified as warm-temperate and humid throughout the year with cool summers (Kottek, et al., 2006; Peel, et al., 2007). Due to high diversity in annual means for rainfall, sunshine hours and daily average temperature (Figures 14 to 16) NZ can be

\footnotetext{
${ }^{6}$ Biochar characteristics depend heavily on the feedstock. Using leaf, bark or wood of the very same tree will yield biochars of very different properties because of differences in biological structure, such as oil glands in mallee eucalypt leaf that are not present in the bark of that tree (Abdullah, Mediaswanti, \& Wu, 2010).
} 
Introd | Method | Biochar | Institutions | Theory | Analys \& Disc | Concl

classified into a lot of different climatic sub-zones (Mackintosh \& NIWA, 2001). Given the abovementioned importance of climatic conditions for biochar performance, results from biochar soil application can be expected to vary considerably between those climatic sub-zones.

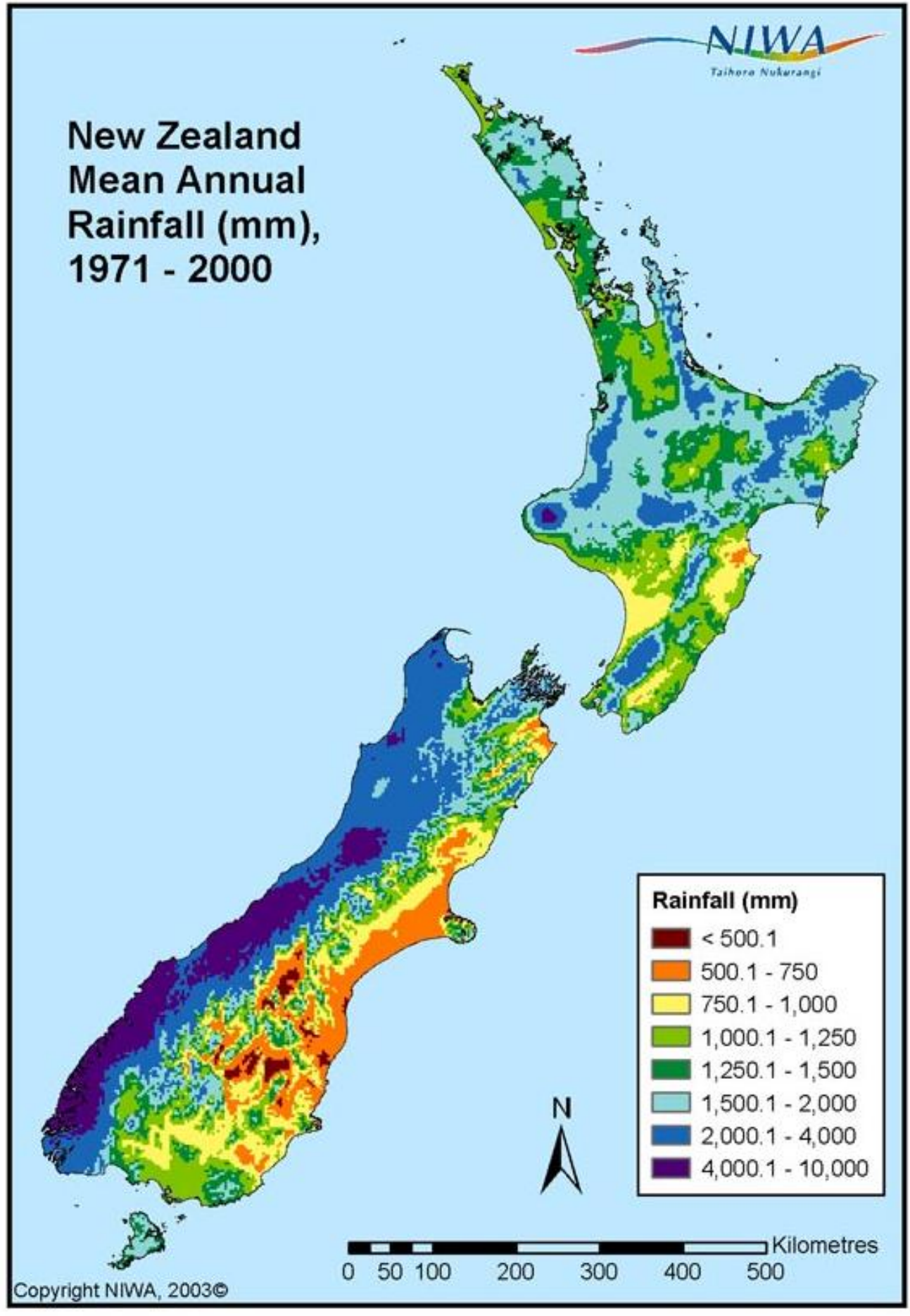

Figure 14: NZ mean annual rainfall $(\mathbf{m m})$ 1971-2000 (National Institute of Water and Atmospheric Research (NIWA), 2003: http://www.niwa.co.nz/our-science/climate/our-services/mapping) 
Introd | Method | Biochar | Institutions | Theory | Analys \& Disc | Concl

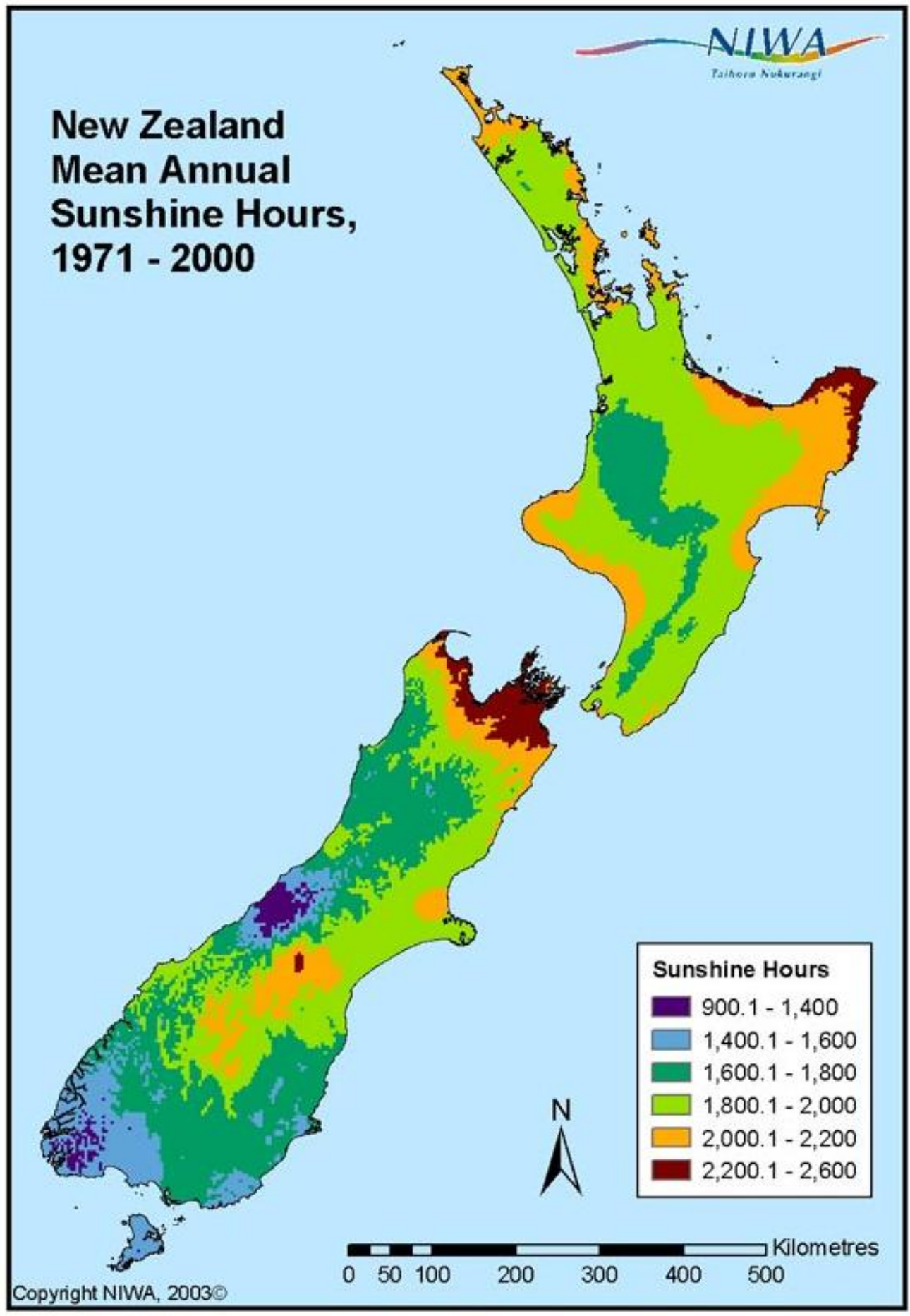

Figure 15: NZ mean annual sunshine hours 1971-2000 (NIWA, 2003: http://www.niwa.co.nz/ourscience/climate/our-services/mapping) 
Introd | Method | Biochar | Institutions | Theory | Analys \& Disc | Concl

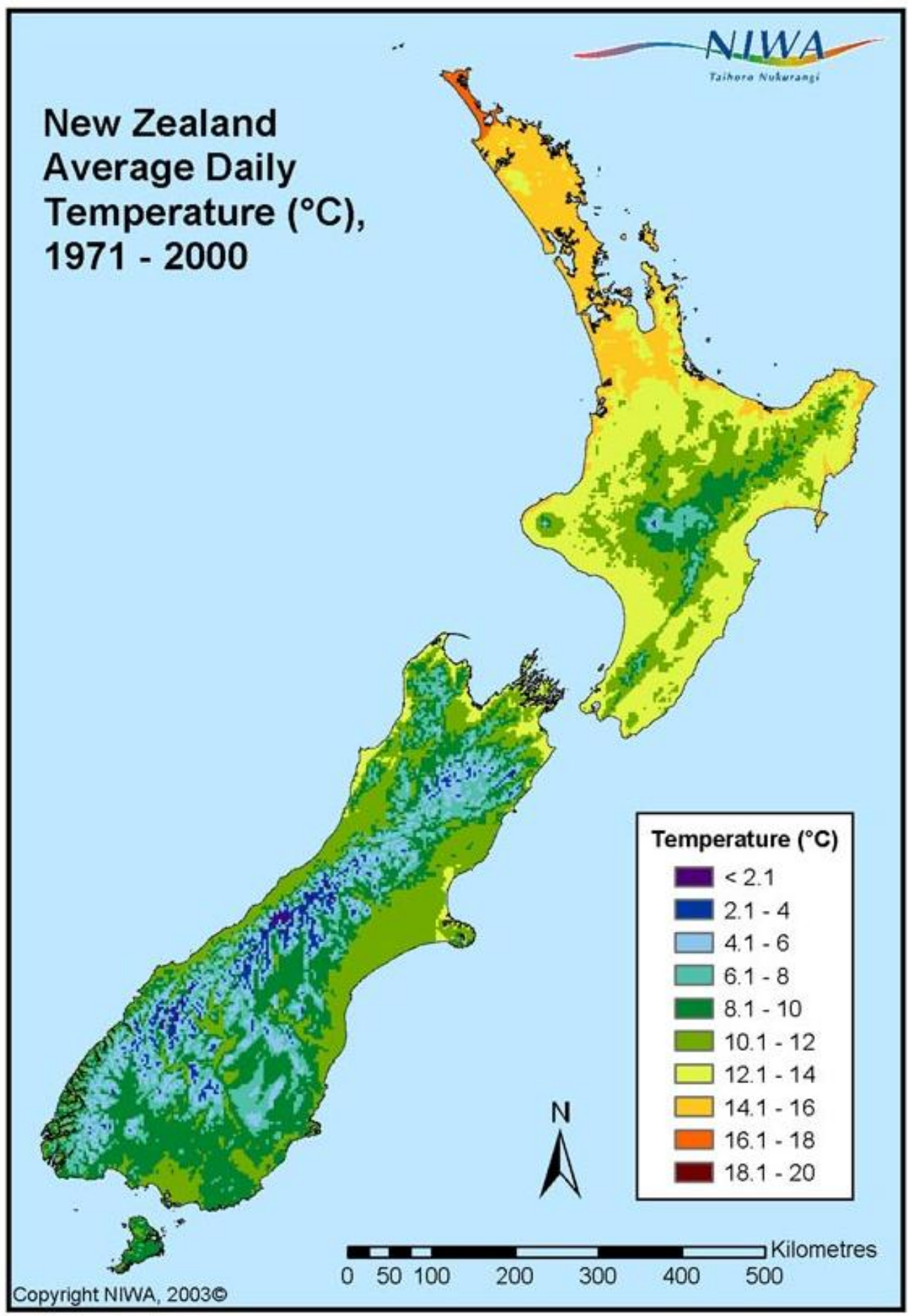

Figure 16: NZ average daily temperature $\left({ }^{\circ} \mathbf{C}\right)$ 1971-2000 (NIWA, 2003: http://www.niwa.co.nz/ourscience/climate/our-services/mapping) 
Introd | Method | Biochar | Institutions | Theory | Analys \& Disc | Concl

\subsubsection{Impacts on Nutrient Retention and Nutrient Cycling in Soils}

Biochar has a twofold effect on plant nutrition: (i) directly through nutrients contained in the biochar and (ii) indirectly through impacts on nutrient retention and availability (Chan $\& \mathrm{Xu}, 2009)$.

The nutrient content of biochar depends heavily on feedstock material and pyrolysis process conditions ${ }^{7}$. Of interest for agronomic performance are the elemental composition (carbon $(\mathrm{C})$, nitrogen $(\mathrm{N})$, phosphorus $(\mathrm{P})$, potassium $(\mathrm{K})$, available $\mathrm{P}$ and mineral $\mathrm{N})$ and the $\mathrm{pH}$ of biochar (Chan \& Xu, 2009).

Feedstock materials vary considerably in their $\mathrm{C}$, oxygen $(\mathrm{O})$ and hydrogen $(\mathrm{H})$ as well as mineral content and this is reflected in the biochar produced from it (Bourke, et al., 2007; Sohi, et al., 2009). High-carbon biochars are typically made from woody plant materials (wood, greenwaste, coconut shell, eucalyptus etc.) while biochars with a relatively higher content of the minerals $\mathrm{N}, \mathrm{P}$ and $\mathrm{K}$ are obtained from sewage sludge, animal manure and paper mill sludge (Chan \& Xu, 2009; Downie, Van Zwieten, Chan, Crosky, \& Munroe, 2008).

As a result of their higher mineral content such biochars have a higher $\mathrm{pH}$, making them suitable as liming agents (Downie, et al., 2008). This may balance the acidifying effect of $\mathrm{N}$ fertiliser and reduce the need for lime applications (Laird, 2008). Contrarily, elevated pH levels may adversely affect plant growth. Establishment of woody plants was inhibited on historical charcoal hearth sites due to high soil $\mathrm{pH}$ and reduced nutrient availability even 110 years after the charcoal hearths had been abandoned (Mikan \& Abrams, 1995). Adverse effects of high $\mathrm{pH}$ on nutrient availability were also documented in soybeans where biochar applications of 5-15t/ha resulted in yield decreases of $37-71 \%$ (Kishimoto \& Sugiura, 1985).

This highlights that the choice of feedstock is to be made with the desired change in soil properties in mind. The effect of biochar soil application may be detrimental or beneficial

\footnotetext{
${ }^{7}$ Unfortunately, these have not always been included in the reporting of agronomic studies of biochar soil application which complicates their comparative analysis (Chan \& Xu, 2009).
} 
depending on the chemical properties of the biochar, the soil it is applied to and specific interactions between them.

Mineral composition and $\mathrm{pH}$ of biochar do not only depend on the type of feedstock, but also on the processing conditions during pyrolysis. Relevant manufacturing parameters include heating rate, final temperature (or highest treatment temperature, HTT) and residence time of the biomass in the pyrolysis kiln (Cetin, Moghtaderi, Gupta, \& Wall, 2004; Chan \& Xu, 2009; Guerrero, Ruiz, Millera, Alzueta, \& Bilbao, 2008).

The total nutrient content of biochar is, however, not a useful indicator for assessing the suitability of a particular biochar for a particular soil. Not all nutrients present in biochar can be readily absorbed by plants. This means that plant-available rather than total nutrient contents of different biochars should be compared (Downie, Van Zwieten, Chan, Dougherty, \& Joseph, 2007; Glaser, Lehmann, \& Zech, 2002; Lehmann, et al., 2003a). From the limited number of studies investigating the plant-available fraction of biochar nutrient contents, it can be summarised that available $\mathrm{N}$ is very low, available $\mathrm{P}$ is highly variable and available $\mathrm{K}$ is $\operatorname{high}^{8}$ (Chan \& Xu, 2009).

A pot experiment with NZ soils found that biochar may promote $\mathrm{N}$ deficiency in plants because decreasing plant biomass was observed in biochar-amended soils. If $\mathrm{N}$ fertiliser was added to the biochar-soil mixture, biomass yields increased (Camps-Arbestain, et al., 2010). This illustrates the complexity of biochar-nutrient interactions and their contingency on the type of biochar used and the soil it is applied to. It also highlights that biochar itself is not a fertiliser. Instead, it needs conditioning with conventional fertiliser, manure or compost prior to addition to soil (Chan, et al., 2007; Steiner, et al., 2007).

Biochar's porous structure, large surface area and specific surface chemistry make it an adsorbent ${ }^{9}$ for nutrients such as N, P, Ca and $\mathrm{K}$ in soil systems (Glaser, et al., 2001). This may reduce leakage of $\mathrm{N}$ compounds and other nutrients into groundwater and hence may

\footnotetext{
${ }^{8}$ In tropical Colombian soils, for example, decreased plant uptake of $\mathrm{N}$ has been reported with increasing rates of biochar addition to soil (Lehmann, et al., 2003a; Rondon, Lehmann, Ramirez, \& Hurtado, 2007). On the other hand, plant uptake of $\mathrm{P}, \mathrm{K}, \mathrm{Ca}, \mathrm{Zn}$, and $\mathrm{Cu}$ was found to increase (Lehmann, et al., 2003a).

${ }^{9}$ It is important to note that biochar $a d$ sorbs but not $a b$ sorbs nutrients, water, organic compounds etc. These terms describe two different physico-chemical phenomena. Adsorption, on the one hand, denotes adhesion of one substance onto the surface of another. Absorption, on the other hand, describes the intake of particles of one material, especially a fluid, into another material, generally a liquid or solid.
} 
increase fertiliser use efficiency. As a result, overall fertiliser input requirements may be reduced (Chan, et al., 2007; Steiner, et al., 2007).

Additionally, ammonium bicarbonate $\left(\mathrm{NH}_{4} \mathrm{HCO}_{3}\right)$ is formed in biochar pores through a process called ammonium carbonation ${ }^{10}$. Therefore, biochar may be able to contribute to increased fertiliser use efficiency by two paths: by reducing leaching through surface sorption and by forming a fertilising substance in the biochar itself.

While the adsorbing properties of biochar may be beneficial in some circumstances, they may also mean that biochar competes with plants for nutrients. That is, the amount of nutrients available for plant uptake is reduced. This supports the argument for the abovementioned conditioning of biochar prior to soil addition.

Generally, NZ soils are acidic and low in nutrients which suits native vegetation but not the plant species introduced in the course of European colonisation (Hewitt, 2009; Schipper, et al., 2007). A significant relation of soil carbon content with soil $\mathrm{pH}$ was found under indigenous podocarp/hardwood forest in the Central North Island. Acid conditions under native forests are suggested to lead to chemical stabilisation of mineral soil carbon, which persist long after land use conversion to pine or pasture (Beets, Oliver, \& Clinton, 2002).

In NZ, large-scale land clearing for cultivation started in the 1850s. Intensification of agriculture and especially dairying meant that $\mathrm{P}$ and $\mathrm{N}$ fertiliser applications increased dramatically over time (Parfitt, Schipper, Baisden, \& Elliott, 2006; Schipper, et al., 2007). Ordering different land uses in NZ according to soil acidity results in a descending order of native forests, pine forests and pasture (Beets, et al., 2002). Application of lime lifts soil $\mathrm{pH}$ levels under pasture artificially. In these circumstances, biochar soil application may prove beneficial in that it may reduce liming requirements. However, for reversion to native shrub and forest and associated chemical stabilisation of soil carbon a liming effect from biochar may result in a suboptimal outcome. This again highlights the need to keep

\footnotetext{
${ }^{10}$ This chemical reaction of ammonia $\left(\mathrm{NH}_{3}\right)$, carbon dioxide $\left(\mathrm{CO}_{2}\right)$ and water $\left(\mathrm{H}_{2} \mathrm{O}\right)$ results in a nitrogenenriched biochar (Day, Evans, Lee, \& Reicosky, 2004; Li, Hagaman, Tsouris, \& Lee, 2003; Winsley, 2007a).
} 
Introd | Method | Biochar | Institutions | Theory | Analys \& Disc | Concl

in mind the desired outcome and the specific ecosystem in which biochar is to be introduced.

\subsubsection{Impacts on Soil Greenhouse Gas Emissions}

It has been suggested that biochar-amended soils emit less $\mathrm{N}_{2} \mathrm{O}$ and $\mathrm{CH}_{4}$ than their unamended control soils (Van Zwieten, et al., 2009b).

In 2008, agricultural soils accounted for $15.23 \%$ of NZ's total emissions and $95.5 \%$ of NZ's total $\mathrm{N}_{2} \mathrm{O}$ emissions (Ministry for the Environment (MfE), 2010b). Sources of $\mathrm{N}$ in soils are $\mathrm{N}$ fertilisers, $\mathrm{N}$-fixing bacteria (mutualistic, associative and free-living ones) and animal manure. Depending on $\mathrm{N}$ application rate, crop type, fertilizer type, soil organic carbon content, rainfall, temperature, soil $\mathrm{pH}$ and texture, the presence of $\mathrm{N}$ may lead to elevated $\mathrm{N}_{2} \mathrm{O}$ emissions from cultivated soils (Johnson, Franzluebbers, Lachnicht Weyers, \& Reicosky, 2007; Jones, Rees, Skiba, \& Ball, 2007). This is of significance as $\mathrm{N}_{2} \mathrm{O}$ is a GHG 310 times more potent than $\mathrm{CO}_{2}$ (IPCC, 2007c). Emissions of $\mathrm{N}_{2} \mathrm{O}$ from $\mathrm{NZ}$ agricultural soils increased by $21.3 \%$ over the period 1990 to 2008 (MfE, 2010b).

Especially poorly drained soils display high $\mathrm{N}_{2} \mathrm{O}$ emission rates leading to the conclusion that denitrifying conditions are strongly correlated with elevated $\mathrm{N}_{2} \mathrm{O}$ emission levels. Such conditions are particularly intense under grazed pastures because of animal excreta and hoof damage on wet soils. Denitrification is further intensified by high fertiliser application rates and high rainfall (Carran, Theobald, \& Evans, 1995). These findings are supported by a laboratory study that suggests soil moisture to be a major determinant of soil $\mathrm{N}_{2} \mathrm{O}$ emissions ${ }^{11}$ (Yanai, et al., 2007).

Soil $\mathrm{N}_{2} \mathrm{O}$ emissions can thus be expected to be high in areas in $\mathrm{NZ}$ that are characterised by intensive farming and poor soil drainage (Carran, et al., 1995). Furthermore, land use change contributes to increased soil $\mathrm{N}_{2} \mathrm{O}$ and $\mathrm{CH}_{4}$ emissions if forests are converted to

\footnotetext{
${ }^{11}$ Rewetting of dried soil at $73 \%$ and $78 \%$ of water-filled pore space (WFPS) that was amended with $10 \%$ of charcoal by weight suppressed $\mathrm{N}_{2} \mathrm{O}$ emissions by $89 \%$. In contrast, rewetting to $83 \%$ of WFPS resulted in a significant stimulation of $\mathrm{N}_{2} \mathrm{O}$ emissions from soil compared to the control soil (Yanai, Toyota, \& Okazaki, 2007).
} 
pasture (Allen, et al., 2009). Since the advent of colonisation, two thirds of NZ's native forest and grassland have been converted to predominantly pastoral agriculture (Schipper, et al., 2007).

It has been suggested that the emissions-inhibiting effect of charcoal addition is attributable to a complex interaction of changes in soil physico-chemical properties. These include reduced bulk density and hence increased soil aeration (reducing the time of anaerobic conditions in the soil, leading to decreased denitrification and an increased sink capacity of soil for $\mathrm{CH}_{4}$ ) and enhanced microbial activity (leading to a higher immobilisation rate of available N) (Van Zwieten, et al., 2008; Yanai, et al., 2007).

A loss of native soil carbon from upon charcoal addition has been found in a ten-year field experiment under boreal forests in northern Sweden. The effect was attributed to enhanced microbial respiration of native organic carbon and its release as $\mathrm{CO}_{2}$ (Wardle, et al., 2008a, 2008b). This indicates that charcoal addition to high organic matter soils may result in increased rather than reduced soil GHG emissions. As can be seen from Figure 17 , carbon content of $\mathrm{NZ}$ soils is in most areas higher than $2 \%$ and in some locales is even as high as 40\% (Ghani, Mackay, Clothier, Curtin, \& Sparling, 2009; Landcare Research Manaaki Whenua, 2010). It remains to be investigated to what extent the findings of Wardle and colleagues in Sweden are transferable to NZ. 


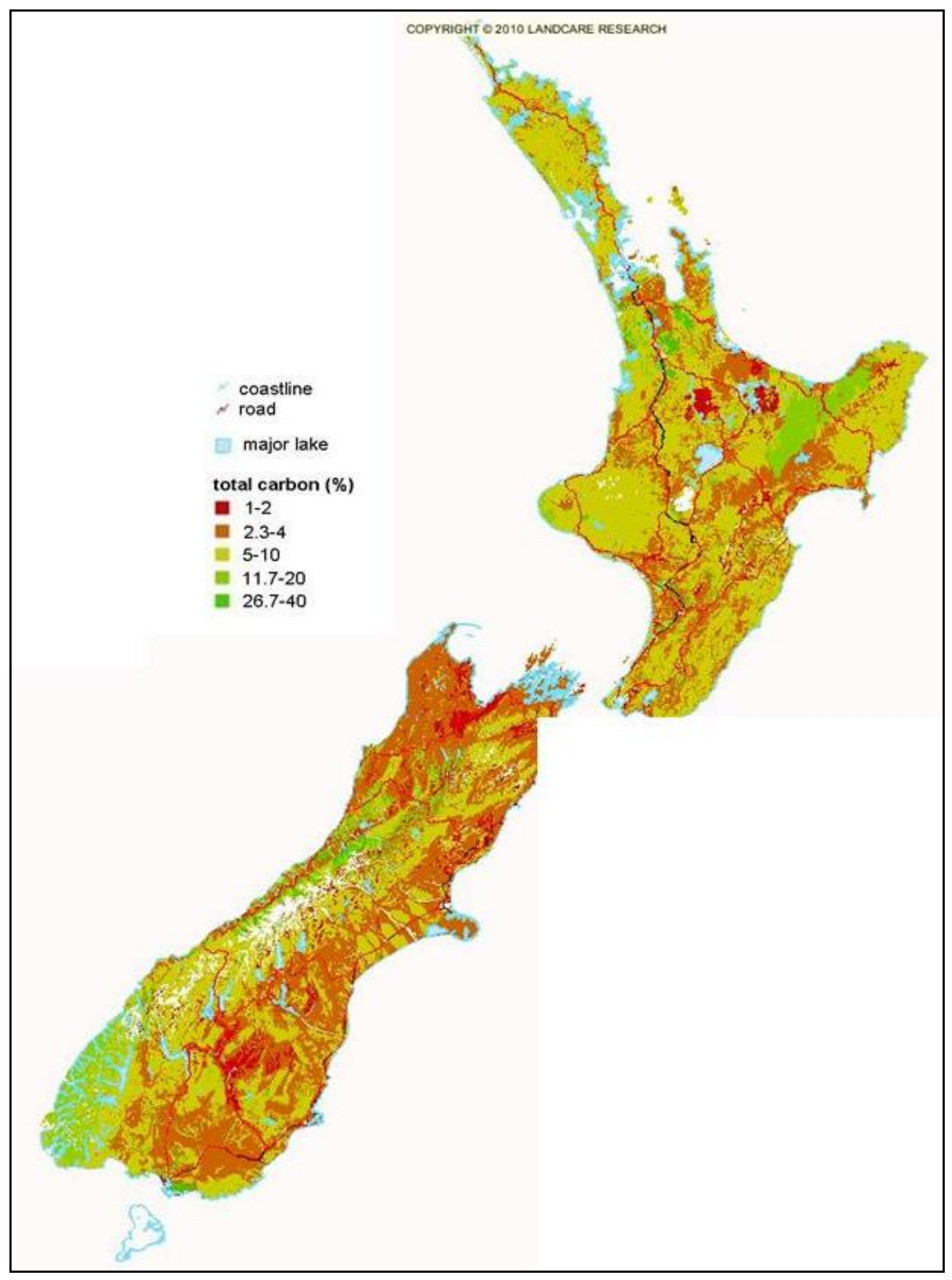

Figure 17: Carbon content of NZ soils (\%), scale 1:5M (Landcare Research Manaaki Whenua, 2010: http://gisportal.landcareresearch.co.nz/WebForms/map.aspx)

Several studies reported reductions in $\mathrm{CH}_{4}$ and $\mathrm{N}_{2} \mathrm{O}$ emissions upon biochar addition (Cowie, 2009; Rondon, et al., 2006; Rondon, Ramirez, \& Lehmann, 2005; Spokas, Koskinen, Baker, \& Reicosky, 2009). These studies were performed either in tropical soils or under laboratory conditions or both. This suggests very limited applicability of the results to NZ. Additionally, most of the studies cited above were of short duration. 
Long-term studies on behaviour and fate of biochar in soils beyond ten years have yet to be conducted (Verheijen, et al., 2009).

A recent NZ laboratory study found that unweathered (= fresh) pinus radiata wood biochar did not reduce but in fact stimulated soil $\mathrm{N}_{2} \mathrm{O}$ emissions from bovine-urineamended pasture soil. The treatments compared were soil + biochar + urine and soil + urine with corresponding controls (soil + biochar and soil only). During the first 30 days $\mathrm{N}_{2} \mathrm{O}$ fluxes from soil that was amended with biochar + urine were found to be generally higher that fluxes from soil that was treated with urine only. No significant difference was observable after 50 days. Cumulative $\mathrm{N}_{2} \mathrm{O}$ emissions of biochar + soil + urine equalled those of soil + urine over the 53 days of the experimentation period (Clough, et al., 2010).

The particular mechanisms through which biochar impacts on soil $\mathrm{CH}_{4}$ and $\mathrm{N}_{2} \mathrm{O}$ emissions have yet to be fully understood. It is suggested that determinants are both biotic and abiotic factors and that they show considerable variations according to climate, soil type, land use and biochar characteristics (Van Zwieten, et al., 2009b).

Considering the fact that $\mathrm{CH}_{4}$ is 21 times more potent a GHG than $\mathrm{CO}_{2}$, and that $\mathrm{N}_{2} \mathrm{O}$ has 310 times the global warming potential of $\mathrm{CO}_{2}$ (IPCC, 2007c), reducing emissions of these gases will improve the GHG balance of NZ agriculture. The agriculture sector contributed $96.0 \%$ of NZ's total $\mathrm{N}_{2} \mathrm{O}$ emissions and $90.6 \%$ of total $\mathrm{CH}_{4}$ emissions in 2008 (MfE, 2010b).

Significant agricultural $\mathrm{N}_{2} \mathrm{O}$ emissions in $\mathrm{NZ}$ are associated with dairying by multiple pathways: cow urine patches, tillage to establish winter crops, winter grazing and animals treading on water logged soil. $\mathrm{N}_{2} \mathrm{O}$ emissions were found to be highest under intensive tillage followed by minimum tillage and no tillage. If soils were trodden by animals, highest emissions were recorded when soil moisture content exceeded field capacity ${ }^{12}$ while least emissions were observed from soils with moisture content below field capacity. Largest $\mathrm{N}_{2} \mathrm{O}$ emissions occurred from intensively tilled urine-amended soil that

\footnotetext{
${ }^{12}$ Field capacity describes the moisture content of a soil that remains after drainage from wetting up to the saturation point where all soil pores are filled with water and no air remains in the soil pores (Hanks, Holmes, \& Tanner, 1954). A soil at field capacity has air and water in large soil pores while small pores are still saturated with water. This stage is usually reached 2-3 days after wetting (Brouwer, Goffeau, \& Heibloem, 1985).
} 
was exposed to animal treading. In contrast, reduced tillage intensity for establishing winter forage crops and limited grazing on waterlogged soil were identified as effective strategies to prevent high $\mathrm{N}_{2} \mathrm{O}$ soil emissions (Thomas, Beare, Francis, Barlow, \& Hedderley, 2008). These findings are supported by a study of Luo and colleagues (2008) who also found high soil moisture content to be a determining parameter for increased $\mathrm{N}_{2} \mathrm{O}$ emissions from irrigation of farm dairy effluent.

Considerable uncertainties remain about the underlying mechanisms of biochar impact on soil $\mathrm{CH}_{4}$ and $\mathrm{N}_{2} \mathrm{O}$ emissions. These are compounded by challenges of measurement and monitoring of these gas fluxes between land and atmosphere (Denmead, 2008; Giltrap, Saggar, Li, \& Wilde, 2008) which vary on a daily and seasonal basis and also fluctuate with rain and disturbance events (Saggar, Tate, Giltrap, \& Singh, 2008). As pointed out above, other strategies such as reduced tillage and restricted grazing on waterlogged soils in winter may prove to be effective ways of reducing soil $\mathrm{N}_{2} \mathrm{O}$ emissions. These options may also offer a lower-cost pathway compared to biochar production and application. Comparative studies of land management techniques, such as the above, versus biochar in terms of GHG reduction potential as well as costs are required. This will enable identification of the most effective and efficient pathway for agricultural soil emission reductions.

\subsubsection{Adsorption and Desorption Characteristics}

Biochar is a highly porous material with a large surface area (illustrated in Figure 18 to Figure 20 below). As a result, significantly increased water holding capacity in biocharamended soils has been observed (Gaskin, et al., 2007; Girgis, Yunis, \& Soliman, 2002; Marsh, 1987; Yu, Ying, \& Kookana, 2006). Biochar water holding capacity varies with feedstock and manufacturing conditions (Burrage, 1933; Chen, Zhou, \& Zhu, 2008). The effect on soil moisture is also greatly dependent on soil texture. This means biochar's potential to increase available moisture is greatest in sandy soils, zero in medium-textured soils and negative in clay soils (Sohi, et al., 2009). 
Introd | Method | Biochar | Institutions | Theory | Analys \& Disc | Concl
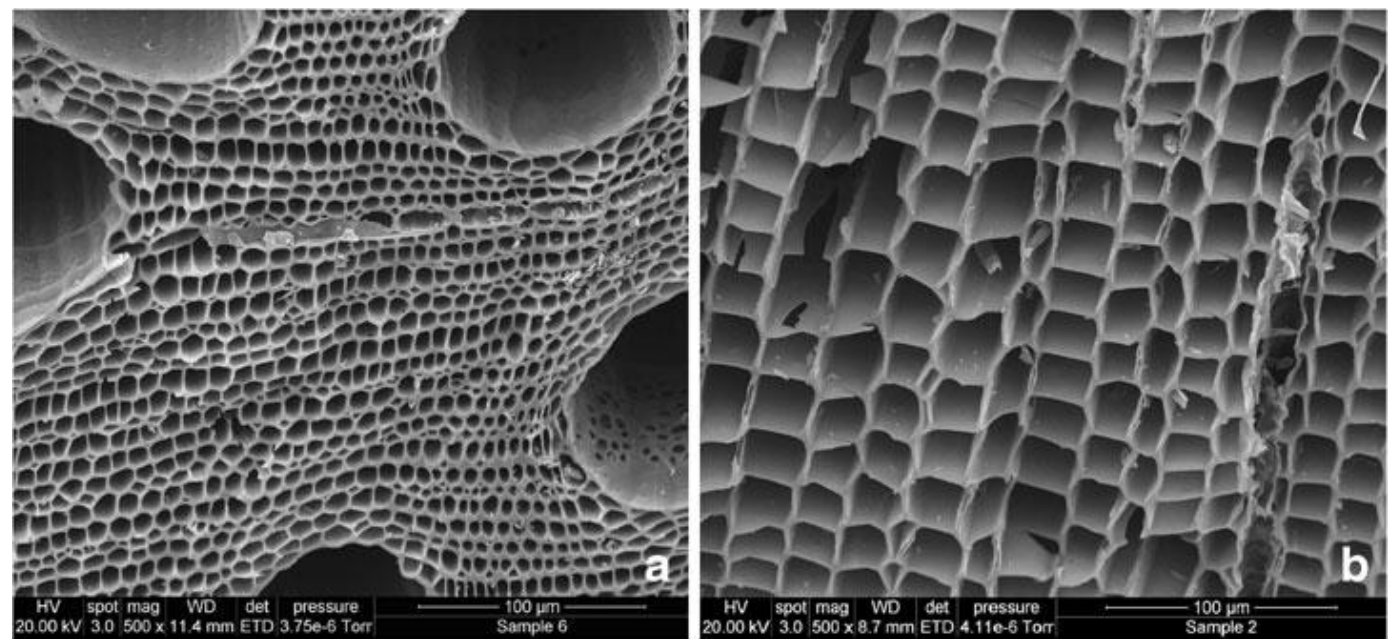

Figure 18: Scanning electron microscope (SEM) image of biochar from (a) eucalyptus bark and (b) pine bark (Macías \& Camps-Arbestain, 2010, p. 14)

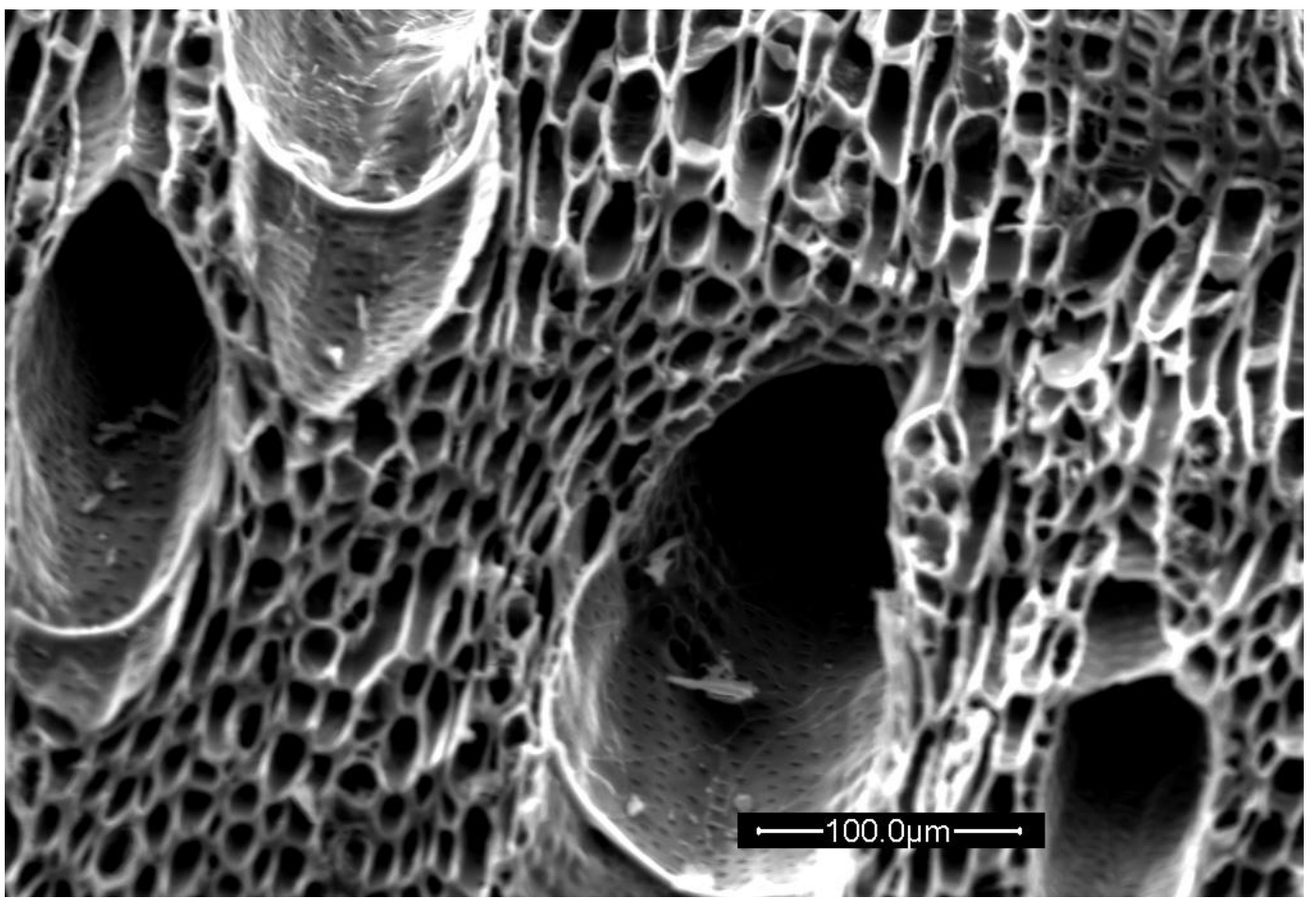

Figure 19: SEM image showing macroporosity of biochar produced by slow pyrolysis from wood (Downie, et al., 2009, p. 25) 


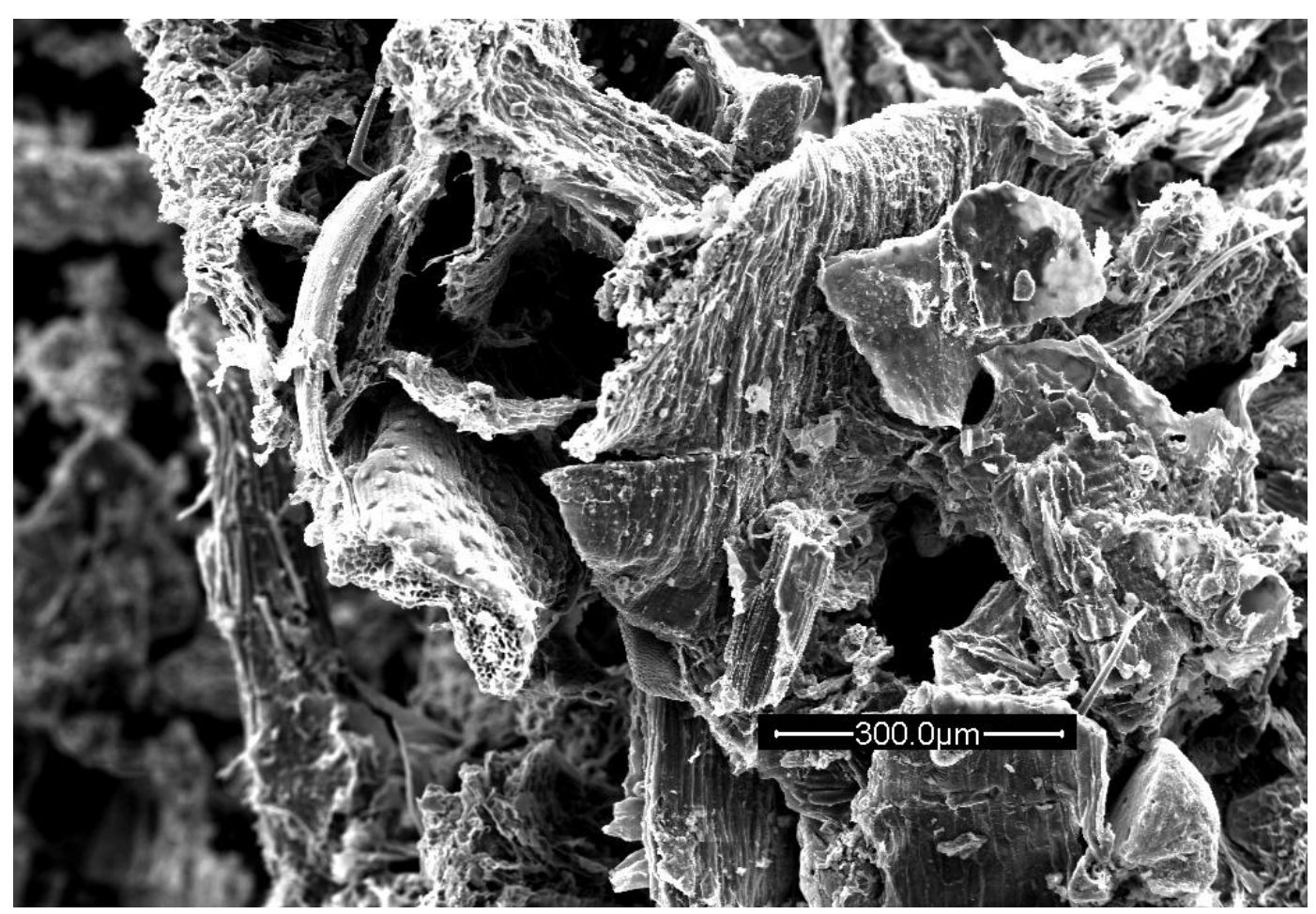

Figure 20: SEM image showing macroporosity of biochar produced by slow pyrolysis from poultry litter (Downie, et al., 2009, p. 26)

Enhanced water retention may be of interest at the east coasts of both the North and the South Island as these areas are already prone to soil moisture deficit over summer (Figure 21) and are projected to face decreased precipitation (NIWA, 2008) (Figure 22).

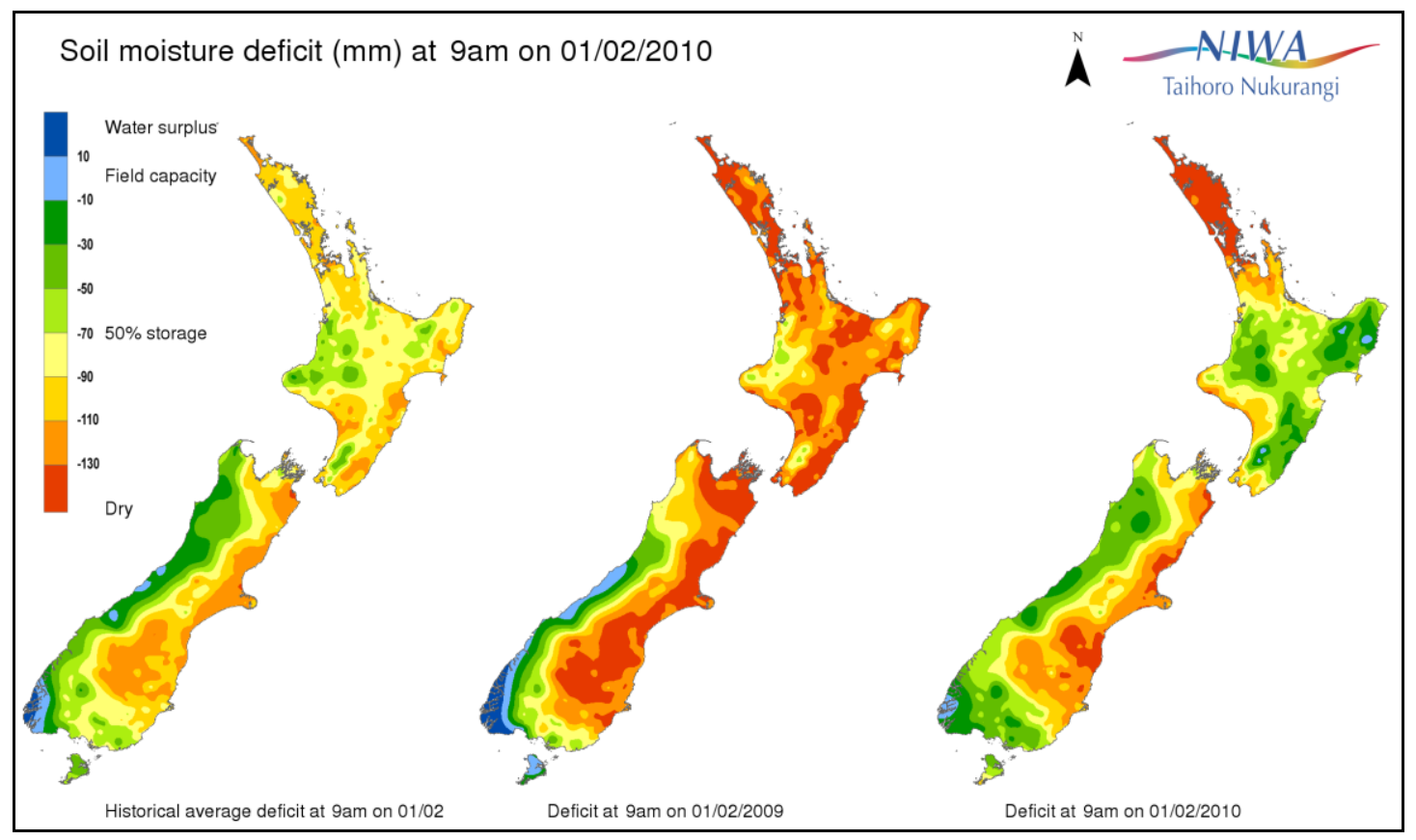

Figure 21: Soil moisture deficit on 01/02/2010 compared to historical average (NIWA, 2010: http://www.niwa.co.nz/our-science/climate/publications/all/cu/new-zealand-climate-update128-a-february-2010/current-climate---january-2010) 


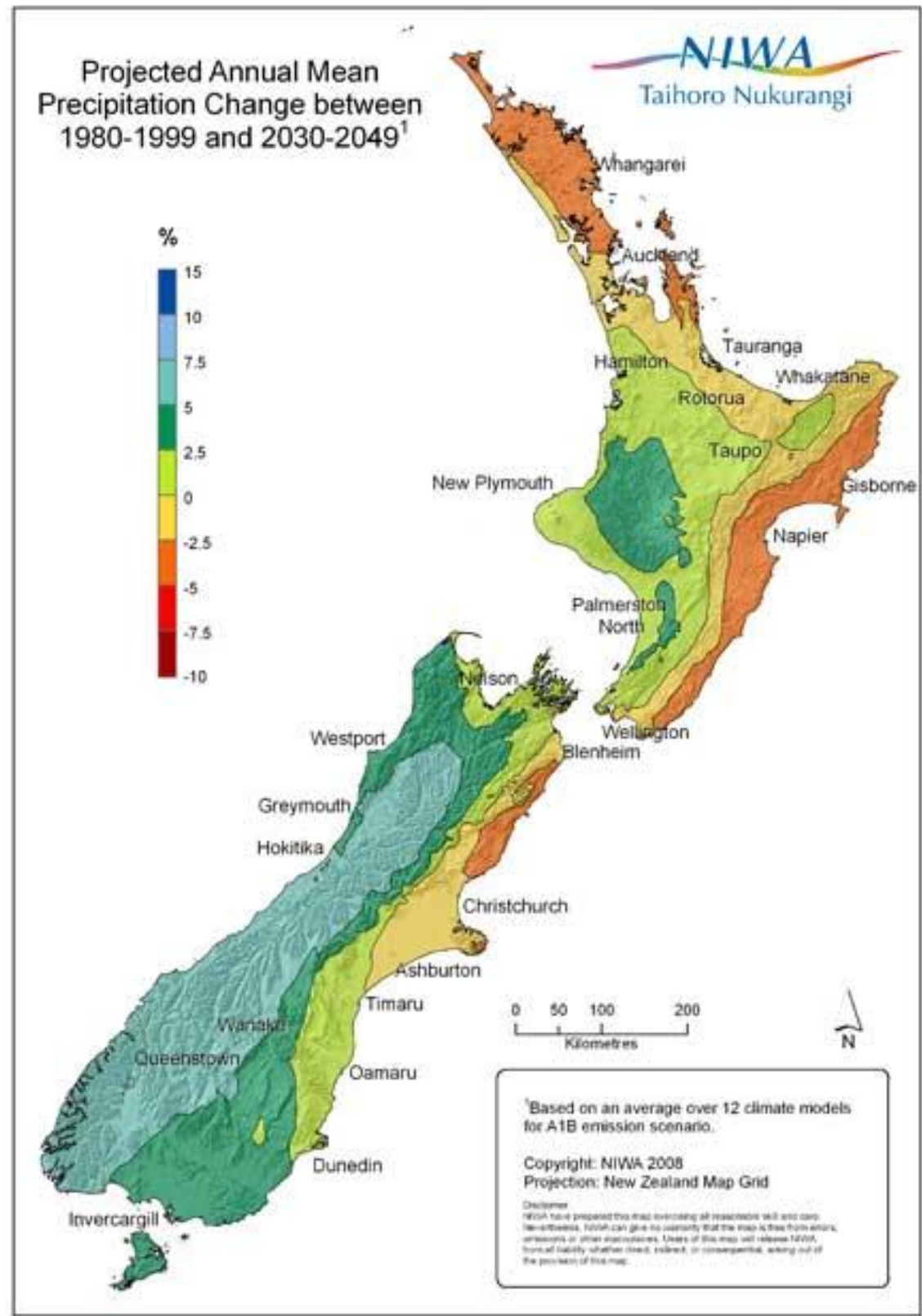

Figure 22: Projected annual mean precipitation change between 1980-1999 and 2030-2049 in NZ (NIWA, 2008:

http://www.niwa.co.nz/ data/assets/image/0007/71971/prann2040 hs2_450.jpg).

Biochar's high adsorption capacity may make it a useful agent in other applications where this property is important. Particularly after activation of biochar, which further increases surface area and adsorption capacity, biochar may be of use in pollution clean-up such as waste water treatment, exhaust gas scrubbing and remediation of contaminated soil ${ }^{13}$ (Cornelissen, Haftka, Parsons, \& Gustafsson, 2005; Newcombe, Drikas, \& Hayes, 1997).

\footnotetext{
${ }^{13}$ A variety of physical and chemical methods can be used to produce activated carbon from biochar as briefly described in Chapter One.
} 
On the downside, using charcoal or activated carbon in environmental remediation precludes its end use as an agricultural soil amendment. If the biochar is saturated with pollutants, it may instead represent a hazardous waste (Sohi, et al., 2009).

In NZ, environmental remediation potential may be of interest in the context of dairying. Steroid hormones such as estradiol and its primary metabolite estrone are used to synchronise estrus cycles in dairy cows (Cavalieri, Hepworth, Fitzpatrick, Shephard, \& Macmillan, 2006; Hanlon, et al., 1997; Lucy, McDougall, \& Nation, 2004). They present an environmental challenge as they are discharged with dairy manure into soil and aquatic environments (Gadd, Tremblay, \& Northcott, 2010). NZ farm soils display moderate to high retention of these hormones which helps limiting their vertical distribution in the soil profile (Sarmah, Northcott, \& Scherr, 2008). A study using biochar (not activated) as an adsorbent in a NZ dairy farm soil (Matawhero loam) suggests that biochar has potential to reduce the leaching risk for these hormones as well as for antibiotics (Srinivasan, et al., 2010).

Dairy wastewater treatment with a coagulant and activated charcoal enables recycling and reuse of the water for process use in the dairy operation (Sarkar, Chakrabarti, Vijaykumar, \& Kale, 2006). Given that the NZ dairy industry generates considerable amounts of wastewater, this option may be of interest to policymakers.

Given that NZ soils have elevated cadmium resulting from phosphate application, a study by Beesley and colleagues (2010) in the UK suggests remediation potential by using biochar as an adsorbent. Biochar soil addition resulted in a tenfold decrease of cadmium in soil pore water and hence decreased phytotoxicity (Beesley, et al., 2010).

Mitigation potential for pesticide contamination in aquatic environments has been shown by Zheng and colleagues (2010). Adsorption of the pesticides atrazine and simazine to greenwaste biochar (prepared at $450^{\circ} \mathrm{C}$ ) of various particle sizes was favoured by a low $\mathrm{pH}$. The saturation point for pesticide adsorption was reached earlier the smaller the biochar particles were. Effectiveness of adsorption increased with increasing amounts of biochar mixed into a given quantity of pesticide solution (Zheng, et al., 2010). Biochar was also found to reduce bioavailability and hence plant uptake of pesticides in contaminated agricultural soils (Yang, et al., 2010). 
Carbonaceous materials have been observed to have a capacity for adsorption of polycyclic aromatic hydrocarbons (PAHs), polychlorinated biphenyls (PCBs), pentachlorophenol (PCP) and other organic compound classes (Cao, Ma, Gao, \& Harris, 2009; van Noort, Jonker, \& Koelmans, 2004; Wen, et al., 2009; Zhu, Kwon, \& Pignatello, 2005). The adsorption of organic compounds was attributed to strong affinity between the aromatic ring structures of charcoal and those of PAH molecules (Sander \& Pignatello, 2005) and was highly irreversible (Braida, et al., 2003). Several hypotheses of desorption behaviour are being considered and further research into the pathways of organic compounds becoming bio-available again is needed (Sander \& Pignatello, 2007).

PAHs are carcinogens and quite ubiquitous as they result from combustion irrespective of whether the material is fossil fuels or biomass (Agency for Toxic Substances and Disease Registry (ATSDR), 1995). PCBs are classified as persistent organic pollutants (POPs). Internationally, the Stockholm Convention on Persistent Organic Pollutants (adopted in 2001 and entry into force in 2004), to which NZ is a party, obliges countries to reduce or eliminate their release into the environment (United Nations (UN), 2001).

While charcoal's adsorbing capacity may prove beneficial in some applications, potential adverse impacts and unintended side effects need to be considered. Highly adsorbent biochar in agricultural soil may imply reduced pesticide, herbicide and fertiliser efficiency. Furthermore, applying biochar in an already dry soil may result in yet less water being plant-available. For example, in situations where the farming cycle relies on an immediate impact of herbicide in order to enable sowing of seeds or where there are already dry conditions, biochar addition may aggravate problems (Haard, 2010).

In regard to environmental remediation, it is not only important to look at the adsorption behaviour of biochar and hence the immobilisation of a particular pollutant but also at desorption characteristics. A major area that remains to be investigated is how and under which circumstances toxins and contaminants may become bio-available again (Krull, 2010). Further research is needed to make the sorption behaviour of carbonaceous materials more predictable and to allow for assessing their potential for ecotoxicological risk management (Allen-King, Grathwohl, \& Ball, 2002; Cornelissen \& Gustafsson, 2004). 
Introd | Method | Biochar | Institutions | Theory | Analys \& Disc | Concl

\subsubsection{Effects on Soil Structure}

Reduced tensile strength and bulk density have been observed in biochar-amended soils which may in turn enhance drainage, aeration and root penetration (Chan, et al., 2007; Laird, 2008). Potentially some indirect GHG savings may result as tillage would require less force by farming equipment or would need to be practiced less frequently (Cowie \& Singh, 2008).

Carbon and its effect on soil tillage and workability have been investigated in long-term trials at Rothamsted, UK. Friability of soil is usually associated with high organic matter content. Low-organic matter soils are characterised by higher susceptibility to mechanical damage and have been observed to require more intensive tilling (Gregory, et al., 2009). It has also been found that a small increase in soil organic carbon leads to disproportionately large improvements in soil physical properties (Gregory, et al., 2009).

This suggests that improved soil structure can be attributed to soil carbon content in general and is not exclusively the result of biochar application, implying that any method that increases soil carbon will also improve soil structure. Comparative studies of current carbon farming practices and biochar land application scenarios will need to evaluate not only the contribution to soil carbon but also the overall impact on soil biota and soil processes.

\subsubsection{Impact on Soil Biota}

Soil microorganisms are essential to soil health and provide a wide range of ecosystem services. The microbial community plays a key role in organic matter decomposition, nutrient cycling, filtration, mobilisation and immobilisation of contaminants, suppression or triggering of plant diseases, GHG production, enhancement of soil porosity and with it soil aeration and water infiltration (Brady \& Weil, 2002; Paul, 2007). It therefore is important to understand the impact of biochar on soil microorganisms. 
Biochar acts like a coral reef for microorganisms in that it provides a high internal surface area for microbes to cling to (Downie, et al., 2009; Nishio, 1996). Extensive pore space offers shelter for microbes from their predators, fungal grazers (Saito \& Marumoto, 2002; Warnock, Lehmann, Kuyper, \& Rillig, 2007).

Addition of wood-derived charcoal enhanced root colonisation of plants with arbuscular mycorrhizal fungi ${ }^{14}$ resulting in an increased production of plant biomass (Ishii \& Kadoya, 1994; Ogawa, Yambe, \& Sugiura, 1983; Saito \& Marumoto, 2002). Apart from other benefits, mycorrhiza fungi facilitate the inorganic nitrogen uptake of plants which often represents a limiting factor for plant growth (Atul-Nayyar, Hamel, Hanson, \& Germida, 2009).

Conventional agriculture based on the use of various biocides kills nitrogen-fixing soil biota (Zahran, 1999) and hence requires the input of even larger amounts of synthetic fertiliser. If the colonisation of plant roots with nitrogen-fixing mycorrhiza fungi significantly increases with biochar addition, this may reduce the need for $\mathrm{N}$ fertiliser. Biochar addition would need to be accompanied by other practices such as direct drilling to ensure minimal disturbance of the fungal hyphae network (Graves, 2010).

On the downside, stimulation of microbial activity may also lead to increased oxidation of native soil organic carbon due to enhanced microbial respiration (Wardle, et al., 2008a, 2008b; Pietikäinen, Kiikkilä, \& Fritze, 2000). The implications for the mostly highorganic matter soils in NZ (see Figure 17) may be that biochar addition could potentially lead to soils being a net source rather than a sink for carbon. Further research is thus required to advance our understanding of the interactions and underlying mechanisms of living and non-living soil components.

Regarding soil macrofauna, earthworm density and activity are important to ecological soil processes. A study in the south-eastern US with poultry litter and pine chip biochar found a negative effect on earthworm survival (species Eisenia Fetida) when poultry litter biochar was applied at rates higher than $67 \mathrm{t} / \mathrm{ha}$. Generally, earthworm activity and hence

\footnotetext{
${ }^{14}$ Arbuscular mycorrhizal fungi are a type of mycorrhizae that develops arbuscules in the cortical cells of plant roots thereby increasing the surface area of the plant root that is in contact with the fungi. This facilitates the exchange of carbon from the plant for phosphorus from the fungi (Bever, Schultz, Pringle, \& Morton, 2001).
} 
Introd | Method | Biochar | Institutions | Theory | Analys \& Disc | Concl

respiration were higher with pine chip than with poultry litter biochar (Weyers, Liesch, Gaskin, \& Das, 2009).

In contrast, Merfield (2008) claims that earthworms such as Lumbricus species are more important to soil than generic compost worms such as Eisenia species. In a field trial in Québéc, Canada, generally higher earthworm density was found in biochar-amended soils than in the control plots but the species of worms is not specified (Husk \& Major, 2010).

A study on Pontoscolex corethrurus found that this earthworm species was important for incorporating charcoal into the soil matrix by physically mixing it with the soil but not ingesting the charcoal itself (Topoliantz \& Ponge, 2003). Elevated pH levels resulting from charcoal soil application were found to increase juvenile earthworm activity of Pontoscolex corethrurus (Topoliantz, Ponge, \& Ballof, 2005). Note that, these studies were concerned with tropical soils and the results should not be extrapolated to NZ conditions.

A study in south-west Germany in temperate deciduous forest found that earthworms ingested but did not digest charcoal particles, leading to a vertical relocation of the material within the soil profile (Eckmeier, Gerlach, Skjemstad, Ehrmann, \& Schmidt, 2007). This again highlights that different biochars impact differently on soil biota and care must be taken to not adversely affect soil life. For this reason it has been suggested that an earthworm avoidance test could be used to detect sub-lethal concentrations of toxins (Yeardley, Lazorchak, \& Gast, 1996).

\subsection{Production Process: Pyrolysis}

As evidenced from ancient Amazonian and NZ practices described in the introductory paragraphs to this chapter, the process of pyrolysis has been deployed by humans for several millennia. What distinguishes today's charring of biomass from ancient practices are the controlled process conditions under which it happens. They enable the capture of the gaseous and liquid fractions that emerge from biomass pyrolysis. 
The general concept of pyrolysis with biochar as a soil additive is illustrated in Figure 23 below. Up to $50 \%$ of the carbon in the feedstock biomass can be captured in biochar. Carbon yields in most cases hover at around 25-40\% (Lehmann, et al., 2006; Ogawa, Okimori, \& Takahashi, 2006).

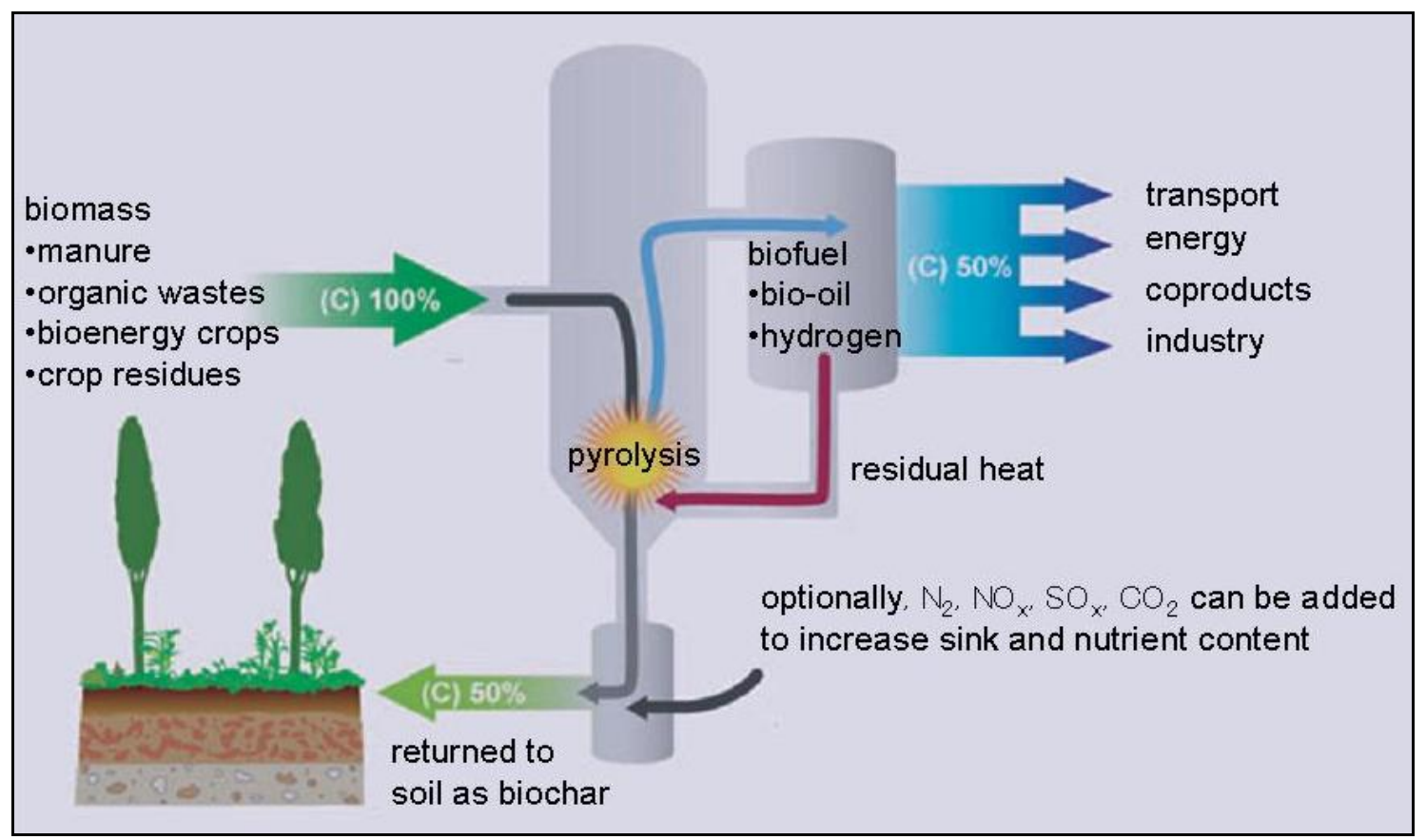

Figure 23: General concept of pyrolysis with biochar soil addition (Lehmann, 2007a, p. 382)

The conversion method of pyrolysis is an exothermic chemical reaction in which biomass is heated in the absence of oxygen (Bridgwater, 2003; Lehmann, 2007a). A schematic illustration of additional steps before and after the actual pyrolysis is given in Figure 24 .

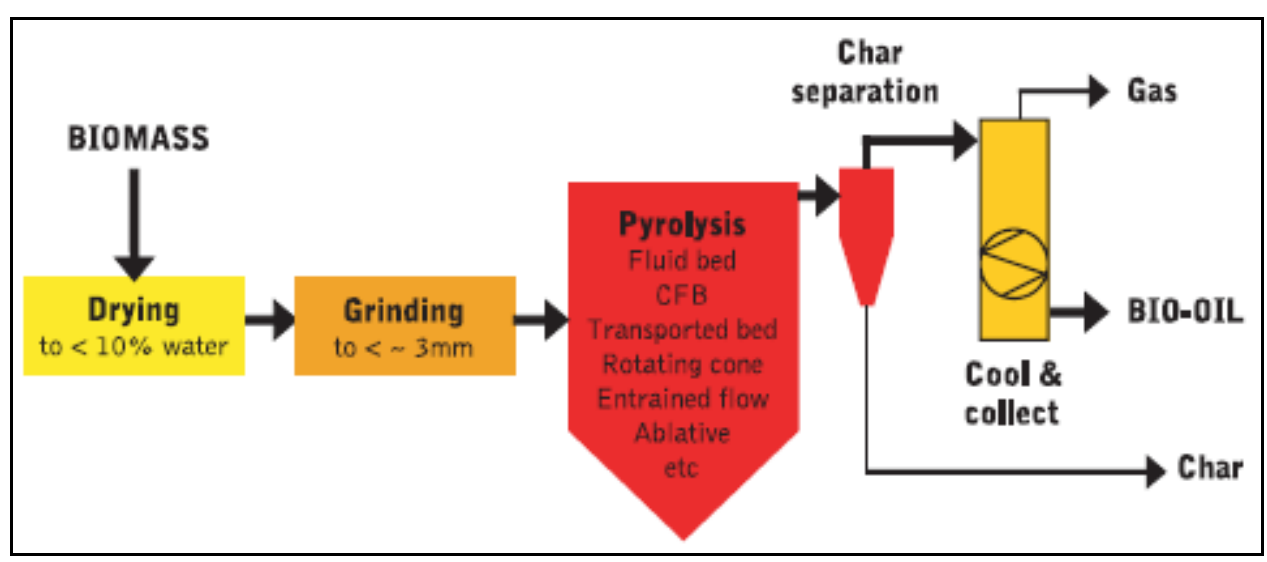

Figure 24: Schematic diagram of fast pyrolysis processing (Bridgwater, 2007, p. 5) 
Liquid (bio-oil), gas (synthesis gas or syngas) and charcoal (biochar) are obtained as reaction products and each can be utilized as a renewable fuel (Bridgwater, 2003). The process can be calibrated so as to obtain different proportions of liquid, gas or solid products (Figure 25) and this will largely be an economic decision (Mathews, 2008).

\begin{tabular}{|lllll|}
\hline Mode & Conditions & Liquid & Char & Gas \\
Fast & $\begin{array}{l}\text { moderate temperature, around } 500^{\circ} \mathrm{C}, \\
\text { short hot vapour residence time } \sim 1 \text { second }\end{array}$ & $75 \%$ & $12 \%$ & $13 \%$ \\
Intermediate & $\begin{array}{l}\text { moderate temperature, around } 500^{\circ} \mathrm{C}, \\
\text { moderate hot vapour residence time } \\
\text { Slow (carbonisation) }\end{array}$ & $\begin{array}{l}\text { low temperature, around } 400^{\circ} \mathrm{C}, \\
\text { very long solids residence time }\end{array}$ & $20 \%$ & $30 \%$ \\
Gasification & $\begin{array}{l}\text { high temperature, around } 800^{\circ} \mathrm{C}, \\
\text { long vapour residence time }\end{array}$ & $35 \%$ & $35 \%$ \\
\hline
\end{tabular}

Figure 25: Proportions of liquid, solid and gaseous products (on a dry wood basis) obtained from different kinds of pyrolysis of wood (Bridgwater, 2007, p. 4)

Slow pyrolysis with relatively lower temperature and longer processing time yields a higher proportion of biochar than fast pyrolysis, which is mainly used to obtain bio-oil that can be refined into a transportation fuel (Bridgwater, 2003). Syngas, consisting mainly of carbon monoxide (CO) and hydrogen $(\mathrm{H})$, can be converted to synthetic diesel by using the Fischer-Tropsch process (Daey Ouwens, den Uil, \& Boerrigter, 2001).

The combined production of biofuel and biochar has been claimed to potentially integrate the benefits of both a carbon-negative transport fuel and a carbon-sequestering and soilenhancing biochar (Laird, 2008). However, bio-oil needs substantial refinement before it can be used as a liquid fuel. It is not an off-the-shelf solution to the transport problem (Mullen, Boateng, Hicks, Goldberg, \& Moreau, 2010).

Typically, bio-oil has a moisture content of $25 \%$ and a pH of 2.5 (Hall \& Gifford, 2007) meaning it is very corrosive and special transport and storage equipment as well as additional health and safety provisions may be necessary leading to increased costs. In general, every additional step in refining also increases costs (Hall \& Gifford, 2007). Bio- 
oil is highly viscose and only boiler or bunker fuel applications are possible without major refinement (Bridgwater, 2003; Czernik \& Bridgwater, 2004).

Ideally, a pyrolysis plant is engineered as a closed loop system where the energy generated from the exothermic reaction is used to run the process. After initial firing by natural gas the process becomes energy self-sustaining. Such a design is depicted in Figure 26 below.

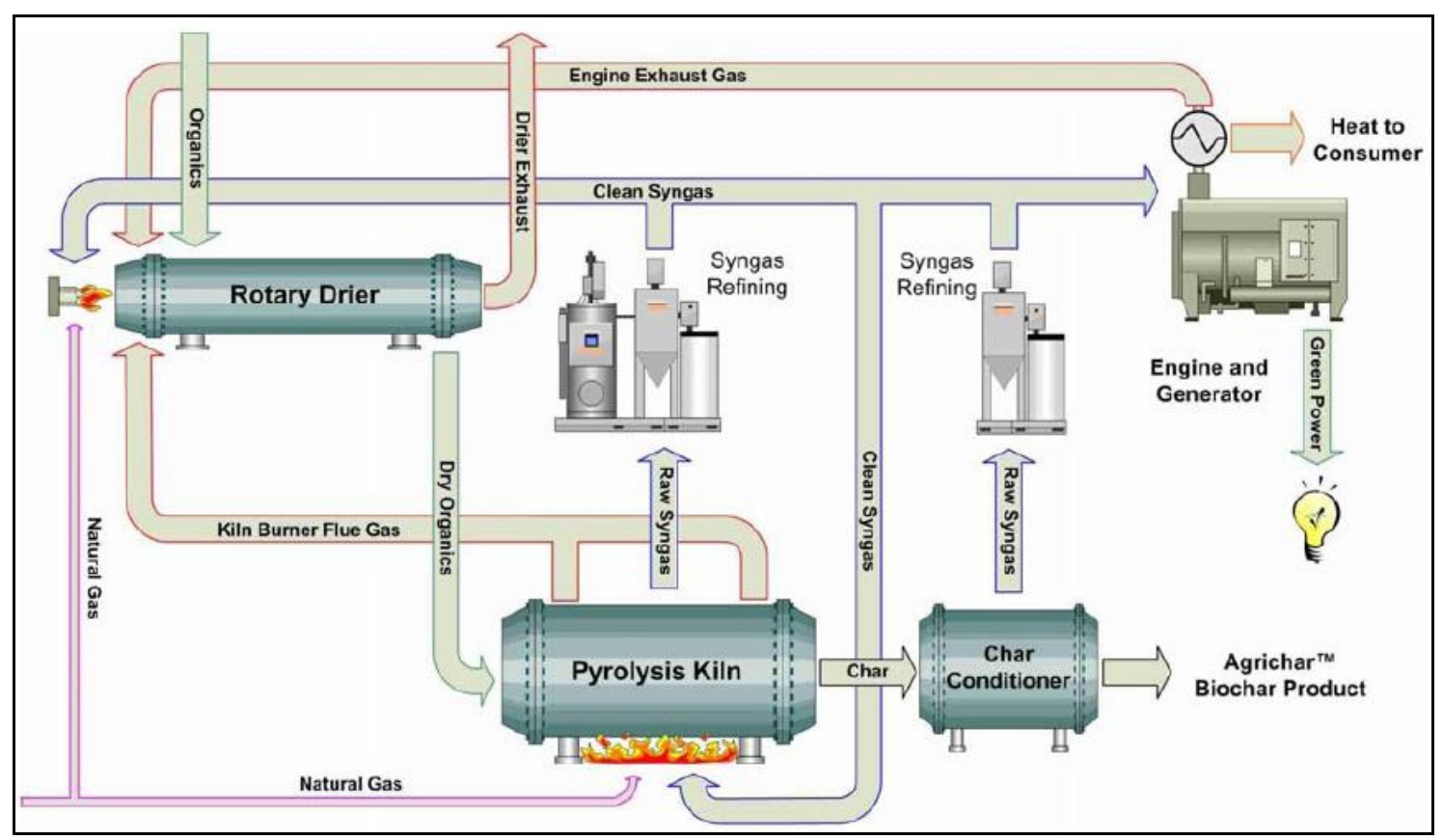

Figure 26: Schematic simplified slow pyrolysis process engineered by BEST Energies (Sohi, et al., 2009, p. 7)

The properties of biochar depend on several process parameters, meaning that the very same feedstock will yield biochars with very different properties if operating parameters are changed. Determinants in the pre-treatment include drying, comminution and chemical activation (Downie, et al., 2009). The actual pyrolysis process determines the properties of the resulting biochar through heating rate, highest treatment temperature, pressure and residence time of the biomass in the reaction vessel (Schenkel, 2001). Engineering design of the reaction vessel itself also has a bearing on pyrolysis products. These include the vessel's orientation, dimensions, stirring regime and catalysts. Flow rates of additional inputs such as $\mathrm{N}, \mathrm{CO}_{2}$, air or steam further affect biochar properties. Finally, post-treatment such as crushing, sieving or activation of the biochar has an effect on its properties (Downie, et al., 2009; Schenkel, 2001). 
Figure 27 provides an overview of plant engineering-related as well as processing-related factors that determine the pyrolysis conditions and hence, the quantity and quality of biochar produced.

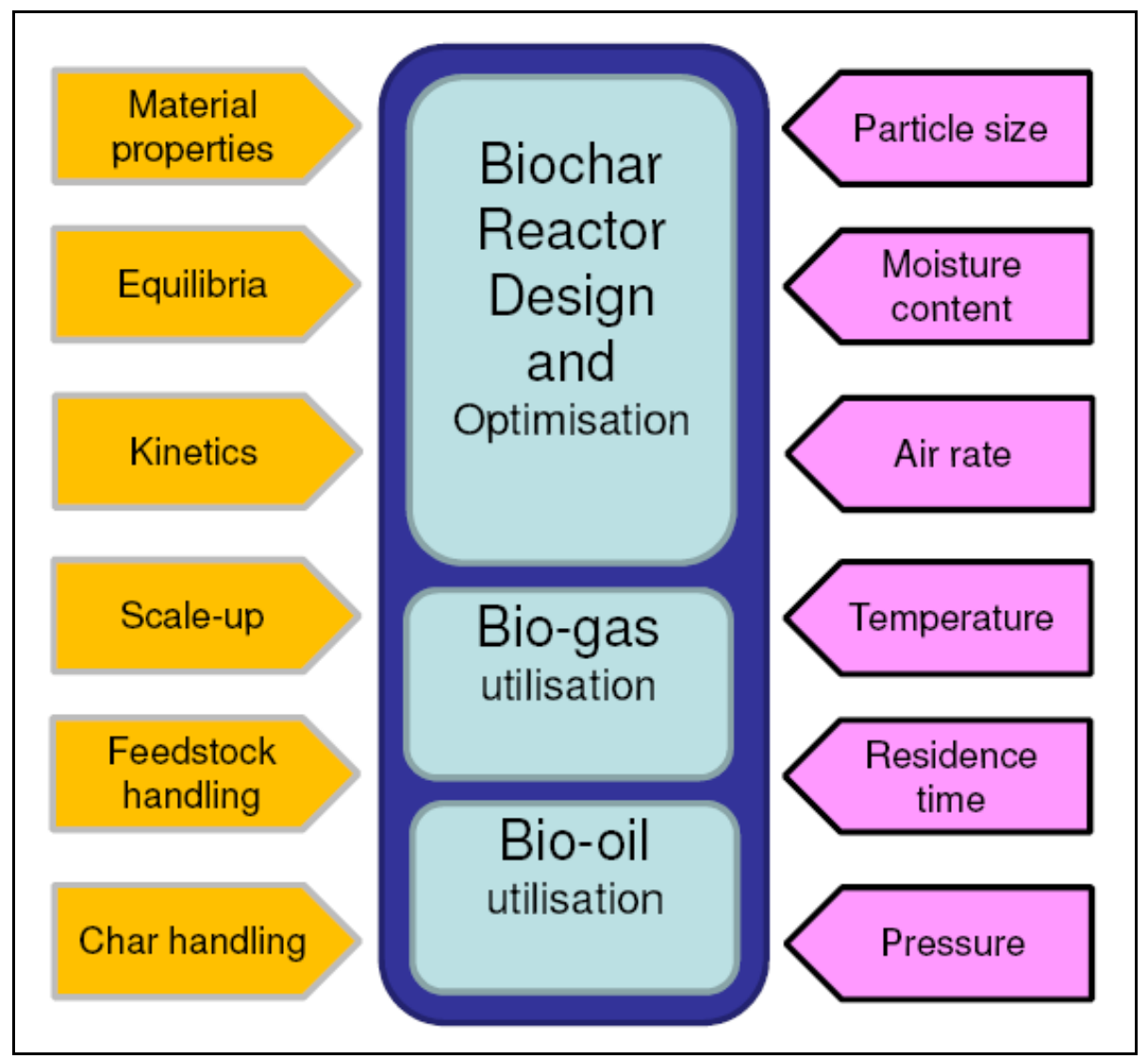

Figure 27: Factors affecting pyrolysis (factors that affect the engineering are depicted in orange, and those that affect the pyrolysis products are shown in purple) (Jones, 2010, p. 15)

The highest treatment temperature is believed to be the most influential one followed by heating rate and pressure (Antal \& Gronli, 2003; Boateng, 2007; Lua, Yang, \& Guo, 2004) as they determine volatilisation and hence aromaticity of the biochar (Sharma, et $a l ., 2004)$. The effect of the highest treatment temperature on selected biochar properties is presented in Figure 28. 


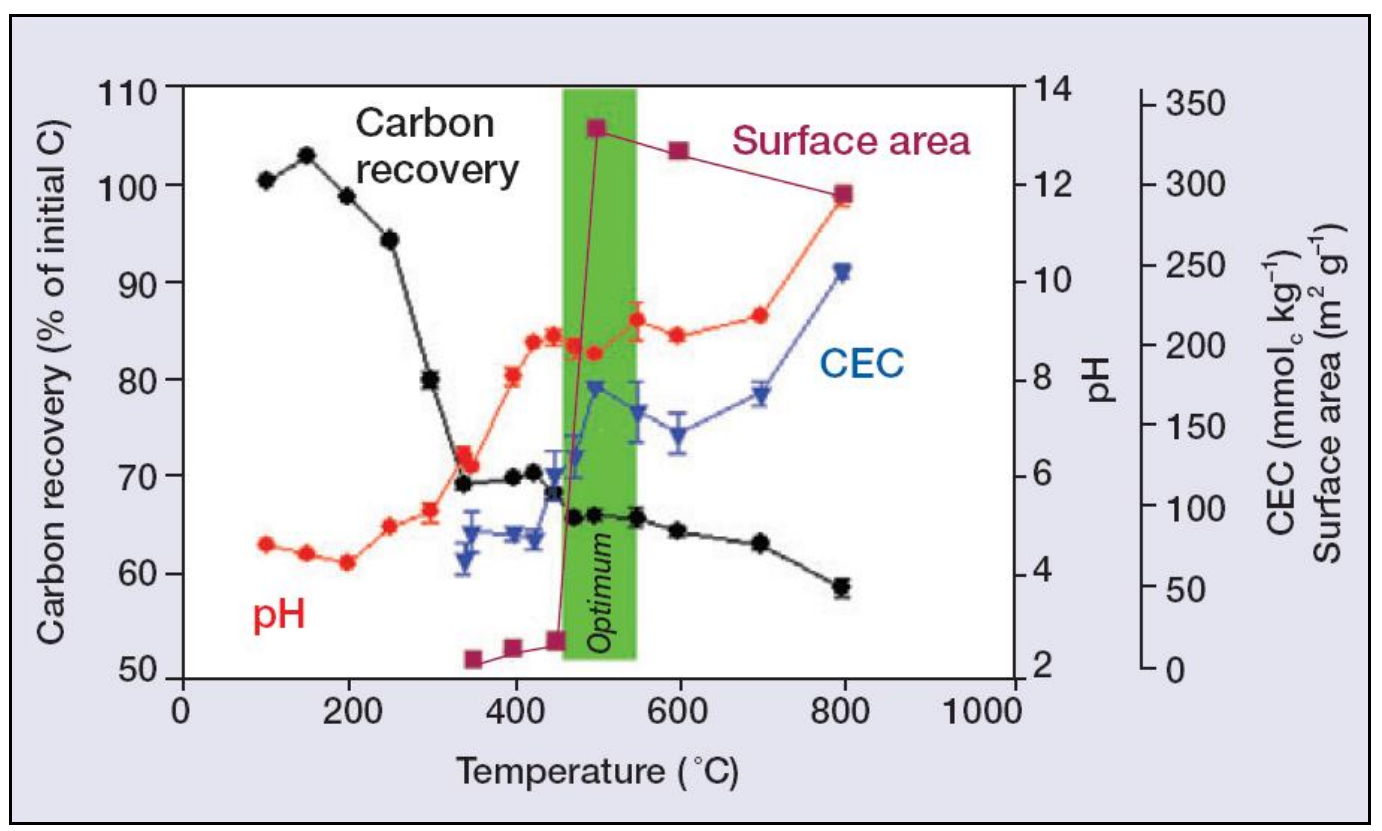

Figure 28: Effect of pyrolysis temperature on carbon recovery, cation exchange capacity (measured at pH 7), pH and surface area (Lehmann, 2007a, p. 385)

Oil and gas from biomass pyrolysis provide one of many options for generating bioenergy. An analysis of the NZ context shows that even if all available biomass residues were to be used for bioenergy, they could only meet 6-7\% of NZ's primary energy demand. Any larger contribution would need to rely on purpose-grown bioenergy crops (de Vos, et al., 2009). Producing dedicated bioenergy crops may be counterproductive to the extent that fossil fuels are directly and indirectly (e.g. through fertiliser production) involved in cropping $\operatorname{practices}^{15}$ (Melillo, et al., 2009; Tilman, Hill, \& Lehman, 2006).

Effects of land use change, for example through conversion of forest and grassland to crop production, as well as displacement of food crops to less productive soils, further exacerbate the pressure on soils and add to their depletion of carbon and nutrients (Searchinger, et al., 2008). Care must be taken even if only crop residues are used for bioenergy production because their diversion makes them unavailable for in situ addition

\footnotetext{
${ }^{15}$ Calculating the additional emissions from fertiliser application would need to include emissions from fossil fuel for running farm equipment as well as direct and indirect emissions form the fertiliser itself. Emission factors used in NZ's GHG Inventory for 1990-2008 (Ministry for the Environment (MfE), 2010b) are as follows: direct emissions from nitrogen input to soil: $0.01 \mathrm{~kg} \mathrm{~N}_{2} \mathrm{O}-\mathrm{N} / \mathrm{kg} \mathrm{N}$ (Kelliher \& de Klein, 2006); indirect emissions from volatising nitrogen: $0.01 \mathrm{~kg} \mathrm{~N}_{2} \mathrm{O}-\mathrm{N} / \mathrm{kg} \mathrm{NH}_{\mathrm{x}}-\mathrm{N}$; indirect emissions from leaching nitrogen (IPCC, 2000a, both figures from Table 4.18); total synthetic fertiliser emitted as $\mathrm{NO}_{\mathrm{x}}$ or $\mathrm{NH}_{3}: 0.1 \mathrm{~kg} / \mathrm{kg}$ of synthetic fertiliser N applied (IPCC, 1996, Table 4.19; Sherlock, Jewell, \& Clough, 2009).
} 
Introd | Method | Biochar | Institutions | Theory | Analys \& Disc | Concl

to soil (e.g. for ploughing under) and adversely impacts soil carbon stocks (Reijnders, 2008).

In terms of continuity of energy supply, outputs from pyrolysis depend on the feedstock biomass; especially its carbon and moisture content. Energy yields of cattle manure, greenwaste and wheat straw are 2.5, 3.7 and 4.5 GJ per tonne of dry matter (Gaunt \& Cowie, 2009). This suggests that in order to hold energy outputs at a consistent level over time, a feedstock stream of stable composition is needed.

Synthetic liquid fuels created from bio-oil or syngas could be used in existing infrastructure which may make the change to a low-carbon economy less disruptive. It would enable continued use of expensive and long-lived infrastructure. On the downside, such an approach may prove disadvantageous in the long term because it perpetuates rather than breaks the existing lock-in of liquid fuel dependency (Unruh \& CarrilloHermosilla, 2006). That is, the shift in technology infrastructure would remain far below the necessary rate given the immediacy of the threat posed by climate change.

In sum, the biophysical, biochemical and engineering aspects of biochar deployment are all important for determining the potential, suitability, applicability and relevance of the technology for NZ. A comprehensive assessment must go beyond the essential scientific background. Ultimately, biochar deployment occurs in a social and institutional setting. This means that interests and considerations other than purely science-based ones play a role in policymaking.

Additional to the environmental issues outlined in this chapter, legal, ethical, economic and social considerations need to be taken into account. The following chapter attempts to add such aspects to the discussion. It investigates the international and domestic institutional framework in which biochar deployment may be realised. 
Introd | Method | Biochar | Institutions | Theory | Analys \& Disc | Concl

\section{Institutional Framework}

This chapter is dedicated to the international and domestic institutional framework in terms of legislation, policies, agreements and strategies as well as the respective agencies involved in their formulation, implementation, monitoring and enforcement.

This study adopts the definition of institutions from Vatn (2005) as being "the conventions, norms and formally sanctioned rules of a society. They provide expectations, stability and meaning essential to human existence and coordination. Institutions regularize life, support values and produce and protect interests" (Vatn, 2005, p. 60). Institutions can be of formal as well as informal nature and serve the purpose of structuring interactions and creating certainty about their course and outcome (North, 1991). Institutions set the structure of incentives and determine the development of an economy toward growth, stagnation or recession (North, 1991).

Formal institutions are of both underlying and specific character. Underlying institutions include the constitution and rule of law which provide a general framework for political stability, protection of property rights and prevention of corruption. Specific institutions comprise legislation, regulation and the organisations concerned with their creation and enforcement such as public sector agencies and the legal system (Frances, 2004).

Borner and colleagues (2004) distinguish between political and economic formal institutions. The former serve to structure the state and the procedures of the political decision-making (Borner, Bodmer and Kobler 2004); the latter establish property and contract rights which reduces transaction costs (Coase, 1960; North, 1994). Institutions regulate access, withdrawal, management and exclusion by allocating different types of property rights. A property right is a bundle of rights and obligations to access, use, enhance, manage, or dispose of a resource (Guerin, 2003). Importantly, one can only own the property right but not the resource itself (Alchian \& Demsetz, 1973).

Different types of property are specified within a matrix of excludability and rivalness as presented in Chapter Five. Allocating and enforcing property rights along with opportunities, privileges and obligations are at the heart of institutional functions (Guerin, 
Introd | Method | Biochar | Institutions | Theory | Analys \& Disc | Concl

2003; Young \& McColl, 2002). Further, institutions are part of and shape the social context in which biochar deployment ultimately occurs.

The questions that this chapter seeks to answer are:

- What is the existing framework in terms of legislation, policies and agencies into which biochar would need to be integrated?

- What repercussions and effects on climate change as well as other policy areas would a decision in favour of biochar entail?

The chapter briefly presents the most relevant international agreements in regard to climate change that have repercussions for NZ's domestic policy. Some of these international institutions are legally binding (hard law), some cannot be legally enforced (soft law). Within the domestic institutional framework, regulating agencies and legislation pertinent to biochar deployment are highlighted. This includes not only climate change but also resource use, waste management, hazardous substances and new organisms as well as energy-related portfolios.

\subsection{International Agreements pertinent to Climate Change Policy}

This section will only very briefly introduce the major international agreements in relation to climate change. A more detailed overview is given in Appendix Four.

\subsubsection{United Nations Framework Convention on Climate Change 1992}

Adopted in 1992 and entered into force in 1994, the United Nations Framework Convention on Climate Change (UNFCCC) provides the major footing for global climate change policy, with 194 parties to date (as of 09/06/2010) (United Nations Framework Convention on Climate Change (UNFCCC), 2010b). 
Introd | Method | Biochar | Institutions | Theory | Analys \& Disc | Concl

The Convention's ultimate objective is the "stabilization of greenhouse gas concentrations in the atmosphere at a level that would prevent dangerous anthropogenic interference with the climate system" (United Nations (UN), 1992, p. 4). While declaring an intent, no prescriptive rules on how to achieve the objective are specified. The phrase "dangerous anthropogenic interference" escapes a unanimously agreed definition and is subject to much scientific and probably even more political debate.

Annex I of the Convention lists 41 parties that committed to returning their anthropogenic GHG emissions to a level at or below that of 1990 (Article 4.2(b)). Quantified and legally binding responsibility targets have been established in the Kyoto Protocol attached to the Convention, which is the focus of the following section.

\subsubsection{Kyoto Protocol 1997}

Under the UNFCCC, the Kyoto Protocol (KP) is attached as a legally binding agreement and has been ratified by 191 parties (as of 09/06/2010) (UNFCCC, 2010c). The six gases regulated under the Protocol are carbon dioxide $\left(\mathrm{CO}_{2}\right)$, methane $\left(\mathrm{CH}_{4}\right)$, nitrous oxide $\left(\mathrm{N}_{2} \mathrm{O}\right)$, hydrofluorocarbons (HFCs), perfluorocarbons (PFCs) and sulphur hexafluoride $\left(\mathrm{SF}_{6}\right)(\mathrm{UNFCCC}, 1998)$.

Collectively, parties listed in Annex B of the KP agreed to a 5\% overall reduction of anthropogenic GHG emissions in the 2008-2012 first commitment period compared to 1990 levels (UNFCCC, 1998). Annex B parties are largely identical with Annex I parties under the UNFCCC. NZ's obligation under the Kyoto Protocol is to keep emissions in the commitment period 2008-2012 at 1990 levels (UNFCCC, 1998). The NZ GHG situation and Kyoto challenge will be further commented on in section 4.2.1 below.

The KP provides the mechanisms of emissions trading (ET), joint implementation (JI) and clean development mechanism (CDM) for countries to fulfil their responsibility targets (UNFCCC, 1998). Appendix Four provides a more detailed outline of each of these mechanisms. 
The main point to establish for the purposes of this study is the obligation to reduce GHG emissions as well the stock of GHG already in the atmosphere. Amongst various pathways to achieve this is a quest for sinks and reservoirs of GHG components, notably carbon.

A reservoir is defined as "a component of the climate system, other than the atmosphere, which has the capacity to store, accumulate or release" GHG or their precursors (IPCC, 2007c, p. 951). Oceans, soils and forests are considered reservoirs of carbon. A sink is defined as "a process, activity or mechanism that removes" GHG or their precursors form the atmosphere (IPCC, 2007c, p. 952). The definition of both reservoirs and sinks does not include permanence, and both may turn into net sources of GHG or their precursors due to, for example, climate change impacts such as ocean warming or forest fires (IPCC, 2007c). In this context, biochar can be treated as a carbon reservoir and its production as a sink (Manning, 2010, pers. communication). The permanence of the biochar carbon reservoir then needs long-term monitoring.

Article 3.4 of the Kyoto Protocol equips the Conference of the Parties with the decisionmaking power regarding inclusion or exclusion of anthropogenic activities that change emission sources and sinks in the categories of agricultural soils and the land-use change and forestry (UNFCCC, 1998). Biochar could thus theoretically be acknowledged as a carbon reservoir but no government is presently using this option (Gaunt \& Cowie, 2009).

In the absence of recognition of biochar in international GHG accounting rules, inclusion of biochar in the NZ Emissions Trading Scheme (ETS) implies that no financial benefit can be obtained on the international GHG market from sale of biochar offsets. In environmental terms there may still be a climate benefit from biochar as a carbon reservoir. The potential for long-term carbon storage through biochar in the NZ context will become clearer as domestic research efforts progress. 
Introd | Method | Biochar | Institutions | Theory | Analys \& Disc | Concl

\subsubsection{Copenhagen Accord 2009}

The most recent of the major climate change-related international agreements is the Copenhagen Accord agreed upon in 2009. Similar to the 1992 UNFCCC, the Copenhagen Accord is intent-based but not prescriptive in nature. Article 2 specifies the outcome of holding "the increase in global temperature below 2 degrees Celsius" (UNFCCC, 2009a, p. 2) but no precise rules on how to achieve it.

Major weaknesses of the Accord are the absence of emission caps and that even the Accord itself does not have diplomatic consensus and is not legally binding. Annex I parties of the UNFCCC were required to submit their 2020 targets by 31 January 2010, but even this was made non-mandatory. In contrast to the Kyoto Protocol, individual countries are free to choose the base year against which emission reductions are measured. The targets that have been announced so far are listed in Table 5. 
Introd | Method | Biochar | Institutions | Theory | Analys \& Disc | Concl

Table 5: Quantified economy-wide emissions targets for 2020 (UNFCCC, 2010a: http://unfccc.int/home/items/5264.php)

\begin{tabular}{|c|c|c|}
\hline Annex I Parties & Emissions reduction in 2020 & Base year \\
\hline Australia & $5 \%$, up to $15-25 \%$ & 2000 \\
\hline Belarus & $5-10 \%$ & 1990 \\
\hline Canada & $17 \%$ & 2005 \\
\hline Croatia & $5 \%$ & 1990 \\
\hline $\begin{array}{l}\text { EU1 and its Member States (Belgium, } \\
\text { Bulgaria, Czech Republic, Denmark, } \\
\text { Germany, Estonia, Ireland, Greece, } \\
\text { Spain, France, Italy, Cyprus, Latvia, } \\
\text { Lithuania, Luxembourg, Hungary, } \\
\text { Malta, Netherlands, Austria, Poland, } \\
\text { Portugal, Romania, Slovenia, } \\
\text { Slovakia, Finland, Sweden, United } \\
\text { Kingdom) acting in common }\end{array}$ & $20-30 \%$ & 1990 \\
\hline Iceland & $30 \%$ & 1990 \\
\hline Japan & $25 \%$ & 1990 \\
\hline Kazakhstan² & $15 \%$ & 1992 \\
\hline Liechtenstein & $20-30 \%$ & 1990 \\
\hline Monaco & $30 \%$ & 1990 \\
\hline New Zealand & $10-20 \%$ & 1990 \\
\hline Norway & $30-40 \%$ & 1990 \\
\hline Russian Federation & $15-25 \%$ & 1990 \\
\hline Switzerland & $20-30 \%$ & 1990 \\
\hline Ukraine & $20 \%$ & 1990 \\
\hline United States of America & $17 \%{ }^{3}$ & 2005 \\
\hline \multicolumn{3}{|c|}{$\begin{array}{l}1 \text { Currently, not all EU Member States are Annex I Parties. } \\
2 \text { Kazakhstan is a Party included in Annex I for the purposes of the Kyoto Protocol in } \\
\text { accordance with Article 1, paragraph 7, of the Protocol, but Kazakhstan is not a Party } \\
\text { included in Annex I for the purposes of the Convention. }\end{array}$} \\
\hline \multicolumn{3}{|c|}{$\begin{array}{l}3 \text { Pending legislation would entail a } 30 \% \text { reduction in } 2025 \text { and a } 42 \% \text { reduction in } \\
2030 .\end{array}$} \\
\hline
\end{tabular}

NZ's target falls short of the IPCC's recommendation of a $25-40 \%$ emissions reduction needed from developed nations by 2020 in order to stabilise atmospheric GHG concentration levels at 450ppm CO $\mathrm{CO}_{2}$-e (IPCC, 2007a). Further elaborations on NZ's 2020 target are presented in Appendix Five. 
The world may be put on a path towards $3^{\circ} \mathrm{C}$ of warming not only due to insufficient reduction commitments but also due to the retention of offsetting practices in the Copenhagen Accord. Acknowledging carbon sinks from land use, land-use change and forestry (LULUCF), avoided emissions from reduced emissions from deforestation and forest degradation (REDD), reductions from $\mathrm{CDM}$ projects and unused allowances from the first Kyoto commitment period may well lead to rising emissions in real terms and at best slow down their increase (German Advisory Council on Global Change, 2009). All of these mean real cuts in emissions are further pushed into the future. It also suggests that the acknowledgement of biochar as an offset in international carbon markets may actually do more harm than good in the long term in terms of overall emissions.

Notwithstanding such concerns, 14 African nations ${ }^{16}$, Australia and Costa Rica (International Biochar Initiative (IBI), 2009c) as well as the UN Convention to Combat Desertification (UNCCD, 2008, 2009) made submissions to the UNFCCC in the lead-up to the Copenhagen Climate Conference, seeking recognition of biochar in a post-Kyoto framework.

The Copenhagen Accord lacks any reference to agriculture and correspondingly includes neither soil carbon nor biochar. This seems prudent given that a global code of best practice for biochar is still absent. Minimum specifications of such a code should include acceptable and unacceptable land-use policies, for example for plantations so as to avoid repeating the mistakes made in the context of biofuels (Heffernan, 2009; Searchinger, et al., 2008; Smolker, Tokar, Petermann, \& Hernandez, 2009; Thorlby, 2009). Further, a minimum limit on carbon sequestration by certified projects in order to ensure a truly sustainable implementation of biochar systems is suggested (Heffernan, 2009).

If global and large-scale deployment is envisaged, it is crucial to establish international standards and quality controls for different biochars (Sohi, et al., 2009). At the same time, such standards and best practice codes should allow for flexibility so that refinements can be made and specific regulations be adapted as the knowledge on biochar and its impacts broadens (Heffernan, 2009).

\footnotetext{
${ }^{16}$ Micronesia, Belize, Swaziland, Gambia, Ghana, Lesotho, Mozambique, Niger, Senegal, Swaziland, Tanzania, Uganda, Zambia, Zimbabwe
} 
Impact assessments should have regard to all dimensions of sustainability, that is, environmental, social and economic ones so as to achieve the best possible outcome for all three aspects. Considering the highly specific performance of biochar (dependent on climate, soil type, feedstock, manufacturing conditions etc.) and nationally unique socioeconomic circumstances, it may prove beneficial to have such codes and standards designed and adopted on a national and perhaps even sub-national level. Nonetheless, internationally agreed guiding principles are necessary to ensure a minimum benchmark.

In the absence of both biochar product standards, that enable predictability and extrapolation of yield impacts, and biochar best practice codes, that ensure a sustainable life cycle performance of the biochar product, it seems premature to introduce biochar as a globally recognised carbon offset. Prior to large-scale and global deployment, incentive structures on international and national levels need to be carefully crafted so as to avoid perverse behaviour. A premature inclusion of biochar into global carbon markets may result in unwanted side-effects, economically as well as ecologically, and may put biochar on a similar pathway to first generation biofuels.

While global climate policy agreements provide overarching direction, their goals are ultimately implemented by individual parties to the UNFCCC and the Kyoto Protocol. The goals become enshrined in national law and manifest themselves in domestic legislation and regulation. They lead to establishment and allocation of responsibilities to particular agencies and determine public policy priority setting. Ramifications of international agreements are cascading down from a global to a national and eventually local level. The following section introduces the NZ context of climate change policy, key agencies and legislation. 


\subsection{Domestic Climate Change Policy and Institutions}

\subsubsection{New Zealand's Kyoto Challenge}

Although contributing only $0.2 \%$ of global emissions, NZ was the $5^{\text {th }}$ highest emitter on a per-capita basis of 27 OECD countries in 2005 (MfE, 2009b). With emissions of about $18.5 \mathrm{t} \mathrm{CO}_{2}$-e per person per year (see Figure 29) $\mathrm{NZ}$ has also been classified within the group of countries with high per capita GHG emissions by global standards (World Resources Institute, 2009).

\section{Per capita emissions}

Source: World Resource Institute (WRi)

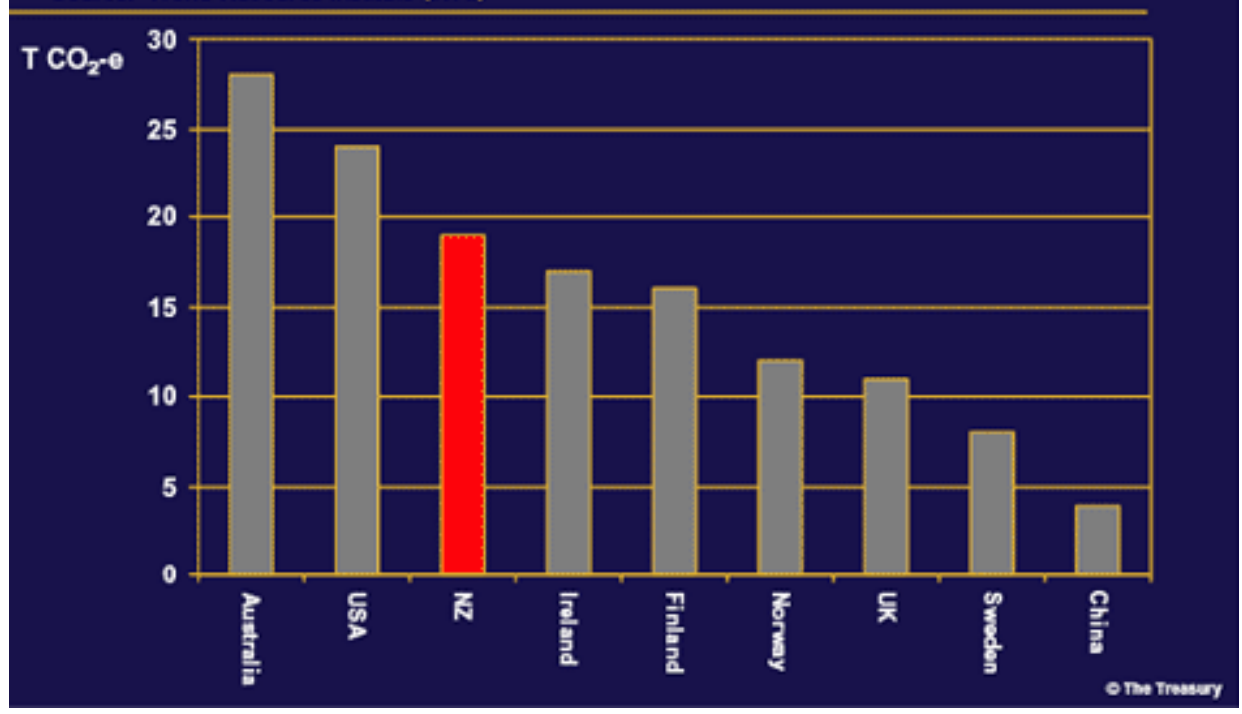

Figure 29: NZ per-capita emissions in international comparison (Ministry for the Environment (MfE), 2009a)

Fulfilling its reporting obligations under the UNFCCC and the Kyoto Protocol, the Ministry for the Environment issued the latest GHG Inventory for the 1990-2008 period in April 2010 (MfE, 2010b). As can be seen from Figure 30, total gross emissions from all six Kyoto gases have been reported to be 74.7 million tonnes $\mathrm{CO}_{2}$-e $\left(\mathrm{Mt} \mathrm{CO}_{2}\right.$-e $)$ in 2008 , with the agricultural sector contributing 46.6\%, the energy sector (including 
electricity generation, heat production and transportation) contributing $45.3 \%$, industrial processes $5.7 \%$ and the waste sector $2.2 \%$. Subtracting the net removals from the LULUCF sector results in total net emissions of $48.5 \mathrm{Mt} \mathrm{CO}_{2}$-e (MfE, 2010b).

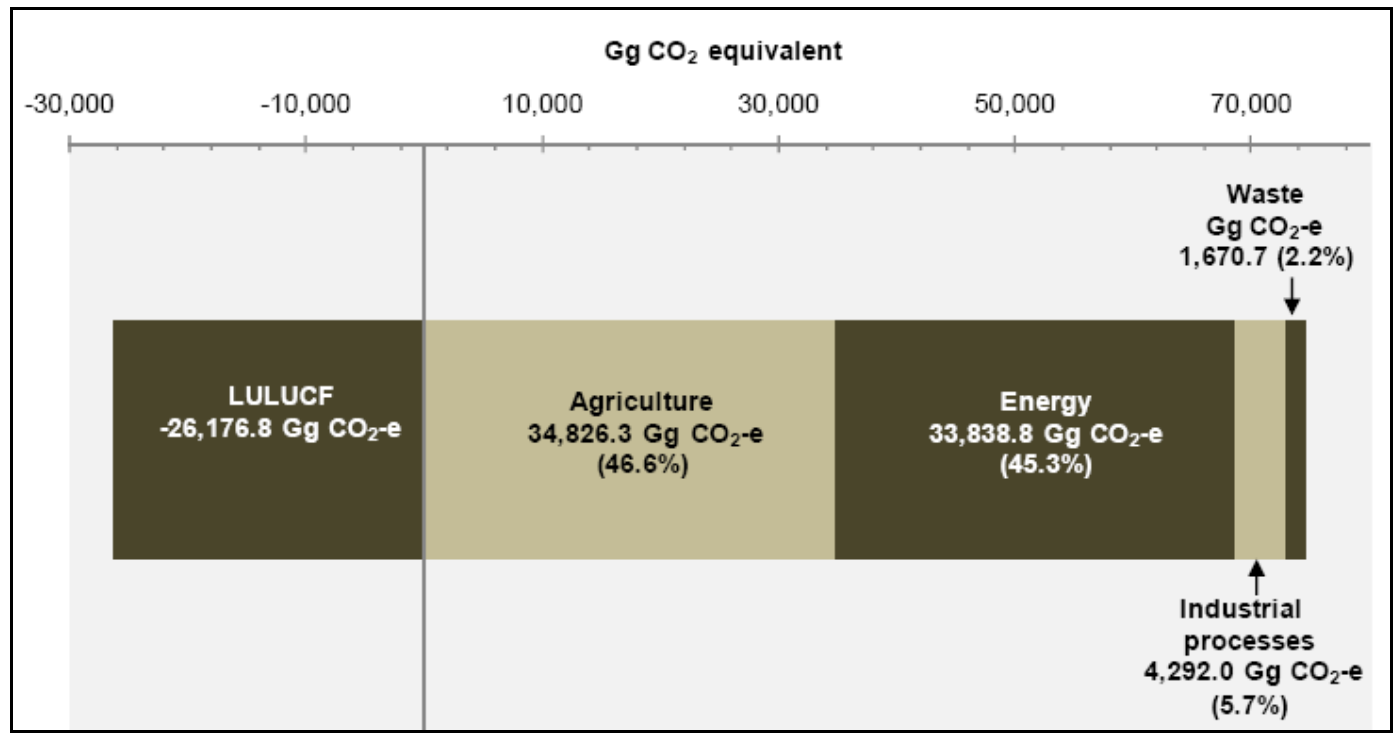

Figure 30: NZ's total GHG emissions by sector in 2008 (MfE, 2010b, p. viii)

Almost $47 \%$ of NZ's total emissions accrue from the agricultural sector yet this share is usually less than 10\% for other Annex I countries (MfE, 2010b). The sector with the highest growth from 1990 to 2008 was the energy sector (see Figure 31), with electricity generation, heat production and transport categories being the main contributors to rising emissions in this category (MfE, 2010b).

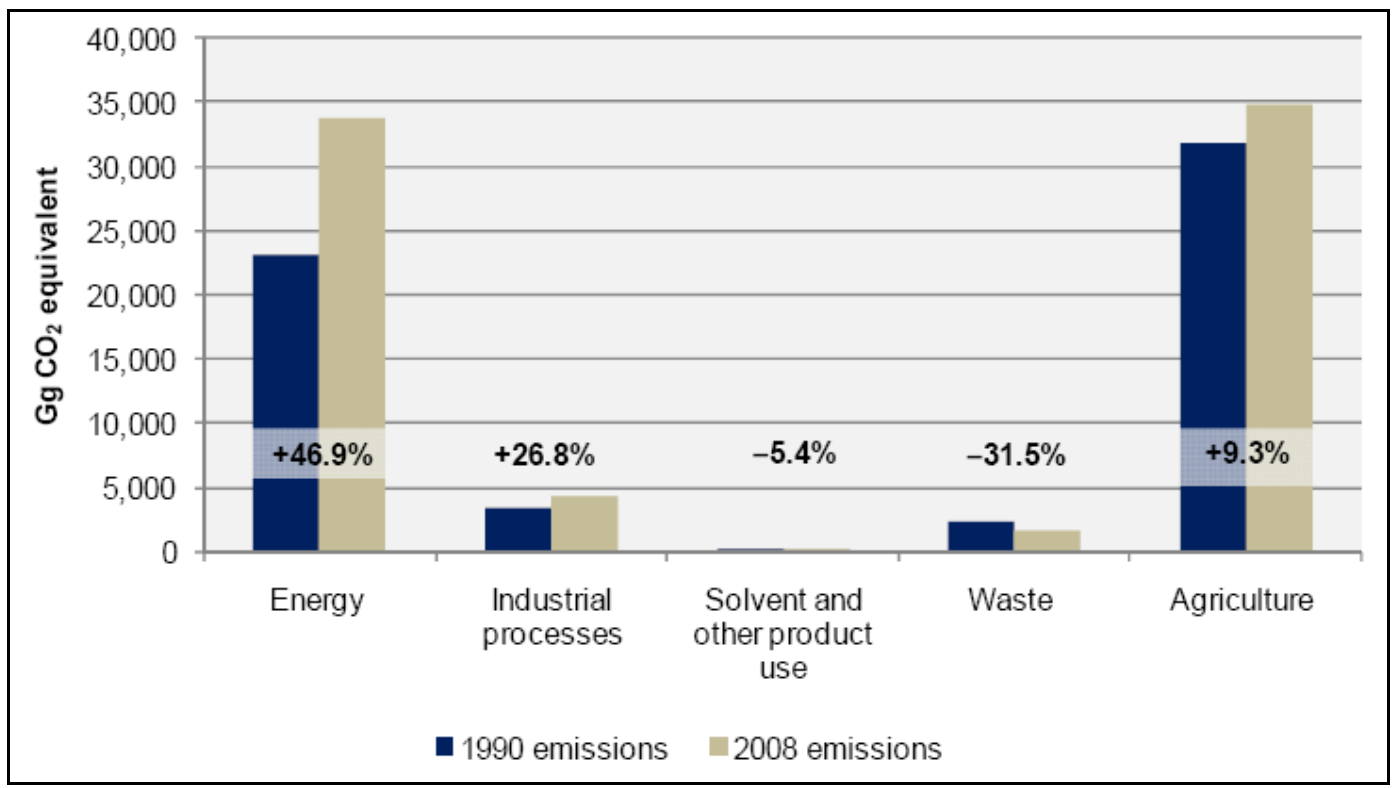

Figure 31: Change in NZ's emissions by sector from 1990 to 2008 (MfE, 2010b, p. ix) 
Under the Kyoto Protocol, NZ's responsibility target is to not let average total gross emissions per year over the period 2008 to 2012 exceed those of 1990 (UNFCCC, 1998). Such commitment notwithstanding, the country's gross emissions rose by $13.9 \mathrm{Mt} \mathrm{CO}_{2}-\mathrm{e}$ or $22.8 \%$ from 1990 to 2008 . Table 6 shows that over the same period, net removals from the LULUCF sector decreased from $31.1 \mathrm{Mt} \mathrm{CO}_{2}$-e 1990 to $26.2 \mathrm{Mt} \mathrm{CO}_{2}$-e in $2008^{17}$ (MfE, 2010b). Despite this reduction, LULUCF removals still more than compensate for the $22.8 \%$ increase in total gross emissions since 1990 . What is more, even a net surplus of 11.4 Mt $\mathrm{CO}_{2}$-e is projected for the first commitment period 2008-2012 of the Kyoto Protocol $^{18}$ (MfE, 2010c).

Table 6: NZ's emissions by sector in 1990 and 2008 (MfE, 2010b, p. viii)

\begin{tabular}{|c|c|c|c|c|}
\hline \multirow[b]{2}{*}{ Sector } & \multicolumn{2}{|c|}{$\mathrm{Gg} \mathrm{CO}$-equivalent } & \multirow[t]{2}{*}{$\begin{array}{l}\text { Change from } \\
1990 \text { (Gg CO}{ }_{2-}^{-} \\
\text {equivalent) }\end{array}$} & \multirow[t]{2}{*}{$\begin{array}{c}\text { Change from } \\
1990(\%)\end{array}$} \\
\hline & 1990 & 2008 & & \\
\hline Energy & $23,042.7$ & $33,838.8$ & $+10,796.1$ & +46.9 \\
\hline Industrial processes & $3,385.8$ & $4,292.0$ & +906.2 & +26.8 \\
\hline Solvent and other product use & 41.5 & 31.0 & -10.5 & -25.4 \\
\hline Agriculture & $31,865.4$ & $34,826.3$ & $+2,960.9$ & +9.3 \\
\hline Waste & $2,438.2$ & $1,670.7$ & -767.5 & -31.5 \\
\hline Total (excluding LULUCF) & $60,773.6$ & $74,658.7$ & $+13,885.1$ & +22.8 \\
\hline LULUCF & $-31,066.3$ & $-26,176.8$ & $+4,889.5$ & +15.7 \\
\hline Net Total (including LULUCF) & $29,707.3$ & $48,482.0$ & $+18,774.6$ & +63.2 \\
\hline
\end{tabular}

Within the LULUCF sector, emissions and removals by forests vary with planting and harvesting rates each year and are difficult to predict with certainty. Especially considering that international accounting rules have yet to be specified for a post-Kyoto period, it is prudent to not rely too heavily on these offsets (The Treasury, 2009).

\footnotetext{
${ }^{17}$ This represents a decrease by $15.7 \%$ or $4.9 \mathrm{Mt} \mathrm{CO}_{2}$-e. It is partly due to increased emissions from deforestation and partly due to harvesting and replanting of plantation forests. This replacement of older with younger stands entails a lower average age and lower $\mathrm{CO}_{2}$ absorption capacity of the forests (MfE, 2010b).

${ }^{18}$ Under the Vote Climate Change in the Budget 2010, announced on 20 May 2010, a total of about \$1bn is allocated to buying forestry emission units for allocation to the NZ economy (Government of New Zealand, 2010).
} 
Changes between 1990 and 2008 with significance for above- and below-ground carbon pools are increased emissions from forest land and grassland ${ }^{19}$ (see Figure 32). In the forest land category, these are primarily due to harvesting and replanting along with direct emissions from deforestation. In the grassland category, deforestation and conversion of plantation forests to grassland are the main reasons (MfE, 2010b).

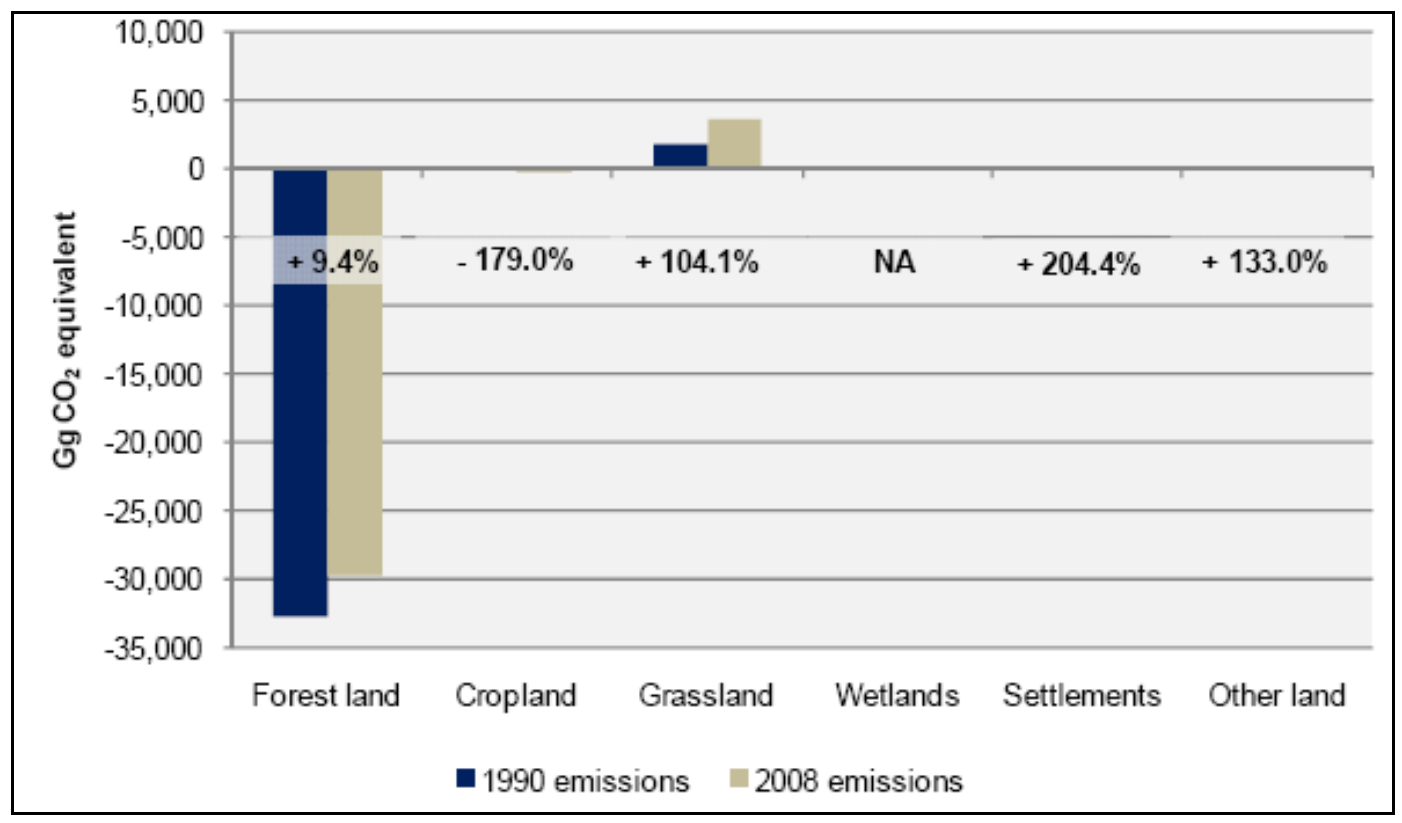

Figure 32: Change in NZ's emissions and removals from the LULUCF sector from 1990 to 2008 (MfE, 2010b, p. 112)

Having established the background on international climate policy obligations and NZ's challenge to meet them, the following section introduces key agencies in NZ, translating international decisions into the domestic context.

\subsubsection{New Zealand Lead Agencies}

Climate change requires action on multiple levels and affects a wide-range of policy portfolios. The following section briefly presents relevant domestic institutions and their respective role in the context of climate change policy development and implementation.

\footnotetext{
${ }^{19}$ The introduction of Land Use and Carbon Analysis System (LUCAS), a new data collection and modelling programme, has enabled more precise mapping of land-use and land-use change. The data have been made publicly available for electronic download by MfE with the release of the land use map database on 22 April 2010. This can be found under http://koordinates.com/.
} 
The Ministry for the Environment (MfE) links international and domestic climate policy as it serves as the official communication channel to the UN body and is in charge of reporting under the UNFCCC and the Kyoto Protocol. On a domestic level, it administers the NZ ETS as well as issues in relation to waste management (MfE, 2010a).

The Ministry of Transport (MoT) coordinates issues on the interface of climate change and energy and with the NZ Transport Strategy has a legally binding plan for the domestic transport future and hence the option of prescribing a sustainable path forward (MoT, 2008). The Strategy is complemented by the first Government Policy Statement on Land Transport Funding (MoT, 2009) issued under the Land Transport Management Act (New Zealand Parliament, 2010c). Road transport is one of the categories having the largest relative influence on NZ's emissions trend from 1990 to 2008 (MfE, 2010b). High per-capita emissions are due to a transport system reliant on the car which in turn can be attributed to low population densities and inadequate public transport and public transport capacity (MoT, 2008).

The Ministry of Agriculture and Forestry (MAF) is the lead authority for land-based activities in the primary sector. It administers a range of climate change-related initiatives. Both agriculture and forestry are significant for NZ's Kyoto balance. While the former contributes $46.6 \%$ of the country's 2008 gross GHG emissions (mainly from enteric fermentation) (MfE, 2010b), the latter is heavily being relied upon to make up for NZ's shortfall in meeting its Kyoto obligations (cf. section 4.2.1) (The Treasury, 2009). MAF administers sustainable land management projects such as the Permanent Forest Sink Initiative, the East Coast Forestry Project and various other projects (MfE, 2007).

The Ministry of Economic Development (MED) oversees the energy sector and implements the NZ Energy Strategy. Concerning the NZ ETS, MED's role is to manage the NZ Emission Unit Register (NZEUR) (MfE, 2010a).

The Ministry of Foreign Affairs and Trade (MFAT) works closely with MfE in regard to international climate policy. While MfE's role includes domestic implementation as well as communication and reporting to the international level, MFAT's role focuses on negotiating these implementation, communication and reporting requirements (MfE, 2010a). 
Introd | Method | Biochar | Institutions | Theory | Analys \& Disc | Concl

The Energy Efficiency and Conservation Authority (EECA) supports the strive for an overall reduction in demand for energy by providing households, businesses and public sector organisations with advice and funding (EECA, 2010).

While also promoting an efficient use of electricity, the Electricity Commission's tasks are concerned with regulation of the electricity industry and markets.

The Treasury's role is to provide advice for decision-making by investigating public finance and economic implications of climate change and related policy (MfE, 2010a).

Further relevant agencies include the Ministry of Research, Science and Technology (MoRST) with the key roles of providing policy advice on research, science and technology, managing government investments in these areas and encouraging innovation and commercialisation in science and technology (MoRST, 2010)

One of the relevant agents apportioning MoRST's environment- and innovation-related funding budget is the Foundation for Research, Science and Technology (FRST). Amongst other target areas, it provides financial support to scientific and technological capacity building regarding climate change and its mitigation and adaptation (FRST, 2010; MoRST, 2008).

The Department of Conservation (DoC) comes into play where climate change is actually or potentially affecting NZ's natural and historic heritage (MfE, 2010a).

Local Authorities are required by the Resource Management Act 1991 to have particular regard to the efficiency of the end use of energy (s7(ba)), the effects of climate change (s7(i)) and the benefits to be derived from the use and development of renewable energy (s7(j)) (New Zealand Parliament, 2009b). While GHG emissions are not directly under the control of Local Authorities, indirect influence can be exerted via regulation of land use. Councils can also participate voluntarily in the Communities for Climate Protection New Zealand (CCP-NZ) programme which aims to support Local Authorities in areas such as energy savings, transport, urban design and waste management (CCP-NZ, 2008). 
The position of the Parliamentary Commissioner for the Environment (PCE), established under the Environment Act 1986 (New Zealand Parliament, 2008b), is endowed with the power to investigate matters where an adverse environmental impact is suspected. While the PCE's opinion may be sought by the Parliament or Parliamentary Select Committees, the PCE may only make recommendations but has no authority to issue legally binding rules or repeal decisions of public authorities (Office of the Parliamentary Commissioner for the Environment, 2010; Young, 2007).

In 2009, amendments to the Resource Management Act (RMA) 1991 established the Environmental Protection Authority (EPA) as a statutory office within MfE with the purpose of streamlining and centralising decision-making in resource consent processes of national significance (Environmental Protection Authority (EPA), 2009). These have so far been handled by Local Authorities. Diversion of the decision-making power to a more centralised agency with ensuing reduced public participation is a major concern. In the future, the EPA's role may be broadened to include environmental responsibility for NZ's exclusive economic zone, oversight of hazardous substances and new organisms and administrative functions of the Emissions Trading Scheme (EPA, 2009).

Having established the organisational part of the institutional framework, the following section looks at the legislative and regulatory structure that these policy and regulating bodies create and enforce. The laws and regulations introduced below present a selection of policy areas for which biochar deployment is anticipated to have implications.

\subsubsection{Legislative Framework pertinent to Biochar Deployment}

The policies, laws and regulations covered in this section may have implications for biochar deployment. The list is not exhaustive but highlights key areas where interrelations may be anticipated. The section begins with an overview of the climate change legislation that established a domestic emissions trading scheme. Further statutes concerned with resource management, waste management, biofuels as well as energy generation and its efficient use are discussed. 
Introd | Method | Biochar | Institutions | Theory | Analys \& Disc | Concl

\subsubsection{Climate Change Response Act 2002}

While the Labour Government had passed the Climate Change Response Act in 2002, a subsequent review by the National Government elected in 2008 resulted in an amended version, passed in December 2009 (New Zealand Parliament, 2009a).

The purpose of the Act is to enable NZ to meet its international obligations under the UNFCCC and the Kyoto Protocol. The Act also establishes the NZ Emissions Trading Scheme (ETS) in order to reduce net GHG emissions below business-as-usual levels (New Zealand Parliament, 2009a).

In order to evaluate the impacts of amendments to the initial Act the National Government commissioned two key reports: one by the NZ Institute of Economic Research and Infometrics (Stroombergen, Schilling \& Ballingall, 2009) on the macroeconomic impacts of climate change policy and one by a dedicated Parliamentary Select Committee (Emissions Trading Scheme Review Committee, 2009).

Amendments to the NZ ETS, made in September 2009 through an agreement between National and the Maori Party, aim to cushion the market price increase for electricity and petrol resulting from the internalisation of the GHG externality. Stationary energy, industrial processes and liquid fossil fuels all enter into the ETS on 1 July 2010. In order to cut the resulting price increase to half, $\$ 400$ million will be sourced from tax revenue and redistributed to businesses within a transition period for these sectors (1 July $2010-1$ January 2013). A 50\% obligation in this period means that companies have to surrender only one emission allowance (worth $1 \mathrm{t} \mathrm{CO}_{2}$-e) per $2 \mathrm{t} \mathrm{CO}_{2}$-e emitted (New Zealand Parliament, 2009a), the resulting effect being a redistribution of welfare from consumers and small to medium sized enterprises to larger producers because half of the marginal external costs are borne by taxpayers (Bertram, et al., 2009).

The entry of agriculture into the scheme was pushed back by two years and is now the 1 January 2015 (see Table 7), implying that the trade-exposed and emissions-intensive dairy sector will have an additional two years of 'liability holidays'. Further amendments, watering down any potential environmental effectiveness of the NZ ETS, include a cap on the carbon price at NZ\$25 during the transition period from 1 July 2010 - 1 January 2013. 
The capping gives polluters the option of paying this fixed amount rather than purchasing additional units on the market (Jacoby \& Ellerman, 2004), effectively sheltering the NZ industry from a carbon market price that would reflect the true cost of the GHG production externality (Environmental Defense Fund, 2007b).

Table 7: Timetable of sector entry dates into the NZ ETS pre- and post-2009 amendments (own table based on New Zealand Parliament, 2009a and MfE, 2009c)

\begin{tabular}{|l|c|c|}
\hline \multirow{2}{*}{ Sector } & \multicolumn{2}{|c|}{ date of entry into ETS } \\
\cline { 2 - 3 } $\begin{array}{l}\text { Stationary Energy } \\
\text { (includes electricity) }\end{array}$ & was & now \\
\hline $\begin{array}{l}\text { Industrial Processes } \\
\text { (steel, cement, aluminium) }\end{array}$ & 1 Jan 2010 & 1 July 2010 \\
\hline Liquid Fossil Fuels 2010 \\
\hline $\begin{array}{l}\text { Agriculture } \\
\text { (cattle, sheep, deer, poultry) }\end{array}$ & 1 Jan 2011 & 1 July 2010 \\
\hline
\end{tabular}

In terms of permit allocation to the industry, changes include a production-based allocation calculated from the industry average rather than a fixed allocation based on 2005 emissions. Also, the single threshold for grandparenting of units based on $\mathrm{CO}_{2}$-e per annum has been scrapped in favour of a scaling of companies according to their emissions intensity $\left(\mathrm{CO}_{2}\right.$-e per \$million).

Only big polluters (i.e. moderately or highly emissions-intensive companies) will be eligible to apply for free permit allocations. Moderately emissions-intensive activities will receive a $60 \%$ free allocation and highly emissions-intensive activities $90 \%$ (New Zealand Parliament, 2009a), implying that the subsidy increases with pollution intensity (emissions generated per dollar of a firm's output). While after the Act's amendment more companies are liable for carbon payments (65 instead of 21$)$, this intensity approach will allow for absolute emissions to increase as the value of production increases.

The phase-out of industry support in the form of grandparented units has been aligned with the proposed Australian emissions trading scheme, called the Carbon Pollution 
Introd | Method | Biochar | Institutions | Theory | Analys \& Disc | Concl

Reduction Scheme, and is now only $1.3 \%$ per year starting in 2013 as opposed to the previously planned 8\% per year (New Zealand Parliament, 2009a).

This means that a reduction of industry support from $90 \%$ to $50 \%$ will be achieved 20 years later, i.e. in 2050 rather than 2030. Transitional support for the fishing industry was raised from 50\% to $90 \%$. Significantly, applications for allocation to industry and agriculture will not be processed by the Ministry for the Environment but by the fledgling Environmental Protection Authority (MfE, 2009c).

\subsubsection{Resource Management Act 1991}

The Resource Management Act (RMA) 1991 governs the management of the natural and physical environment with the purpose of promoting sustainable management (s5). Key features of the RMA are that it includes the sustainability principle, acknowledges the intrinsic value of ecosystems, is future-regarding, effects-based and pursues an approach of integrated management through a vertically and horizontally integrated policy-making, planning and decision-making structure (Grinlinton, 2002). However, no precautionary principle is included. The Act provides for public participation although deficits in implementation exist (Heitzmann, 2007; Office of the Parliamentary Commissioner for the Environment, 1998).

Activities are grouped in six classes: permitted, controlled, restricted discretionary, discretionary, non-complying or prohibited (s87A). Unless an activity is permitted or prohibited, resource consent has to be obtained. Decision-making power in the consent process is devolved to Local Authorities that are required to have particular regard to the efficiency of the end use of energy (s7(ba)), the effects of climate change (s7(i)) and the benefits to be derived from the use and development of renewable energy (s7(j)) (New Zealand Parliament, 2009b).

An amendment to the Act in 2004 resulted in the control of GHG emissions being removed from the local to the national level (New Zealand Parliament, 2004). Section 3(b) of the amending Act requires Local Authorities to plan for the effects of climate 
change, but not to consider the effects of GHG emissions on climate change (New Zealand Parliament, 2004). This prevents direct control of GHG-generating activities by Local Authorities, for example, through rules in regional plans or requirements in air discharge consents. Only indirect influence can exerted through regulation of land use (New Zealand Parliament, 2009b).

Resource consent applicants are required to prepare an Environmental Impact Assessment (EIA). This represents a useful attempt to lift regard for environmental costs to the same level as conventional costs, the latter often being treated as primary (Grinlinton, 2002; Office of the Parliamentary Commissioner for the Environment, 1998).

The relevance of the RMA to biochar deployment may be diverse. The main issue is likely to be an interaction with the National Environmental Standards for Air Quality (MfE, 2008). Practitioners may want to consider potential discharges to air of particulate matter during biochar production, handling, transport and application. The sustainability principle must be adhered to with regard to feedstock sourcing and biochar impacts on soil ecology. The sustainability principle in the RMA may also be invoked to require a carbon-negative life cycle performance of specific biochar projects. A National Environmental Standard for Assessing and Managing Contaminants in Soil is in development (MfE, 2010d). It needs to be evaluated whether potential toxins in biochar may prevent its use in soil or whether the adsorbing properties of biochar may prove helpful for remediation of contaminated land.

Resource consent may also be required if the intention is to build larger-scale pyrolysis plants. Building heights may interfere with local specifications and interpretations of the Building Act 2004, Building Regulations 1992 and the Building Code. Further overlaps of the RMA with other legislation include the areas of storage, use, minimisation and disposal of waste and hazardous substances. Relevant acts that cross over and are of significance within the context of this study are the Waste Minimisation Act 2008 and the Hazardous Substances and New Organisms (HSNO) Act 1996. Classifications and regulations set out in these acts have twofold relevance to biochar: potential feedstocks may be classified as wastes or the biochar product itself may be considered a hazardous substance if contaminated. In both cases this will have implications for biochar production, storage and use, particularly if its application to soil is intended. The 
Introd | Method | Biochar | Institutions | Theory | Analys \& Disc | Concl

following section presents an overview of relevant waste management regulations and some reflection on their implications for biochar deployment.

\subsubsection{Waste Management}

Waste regulations influence biochar systems on both ends: production and application. Careful consideration needs to be given to the choice of feedstock. This has to be done with the application in mind. It would be counterproductive if biochar was produced from sewage sludge or old tyres, representing a hazardous waste rather than a valuable soil amendment. To shed light on such issues, this section is dedicated to a brief overview of waste management legislation and regulation as it potentially affects biochar deployment.

Key documents of the regulatory framework for waste management in NZ are the NZ Waste Strategy 2002, the Waste Minimisation Act 2008 and the Waste Minimisation (Calculation and Payment of Waste Disposal Levy) Regulations 2009. Some waste management aspects cross over with regulations in the Hazardous Substances and New Organisms Act (HSNO) 1996, presented in the subsequent section.

A potentially beneficial facet of pyrolysis is its use as a waste management tool for organic materials. A sustainable pathway has to be ensured by limiting feedstock sourcing to biomass that would otherwise be landfilled or burned. It is important that biomass is not diverted from any other more environmentally benign use. Choosing a feedstock biomass may depend on economic aspects (e.g. wastes that incur a tipping fee) or waste management aspects. These include obligations to reduce the overall amount of waste that is being landfilled, to reduce emissions from landfills or to dispose of wastes for which currently no adequate management option exists, such as sewage sludge or old tyres.

Although not a legal act as such, the NZ Waste Strategy identifies long-term goals for improved waste management, waste minimisation and resource efficiency. Policy criteria for prioritising action are volume and harm, achievability, public concern and costeffectiveness (MfE, 2002). At the time of writing of this thesis the Strategy was under review and an updated version to be released later in 2010 (MfE, 2010e). 
The Waste Minimisation Act 2008 introduces a \$10 levy per tonne of landfilled waste from 1 July 2009. The entire waste levy revenue is allocated to territorial authorities and a Waste Minimisation Fund, which was established under the Act, to support waste minimisation initiatives (New Zealand Parliament, 2008d, 2009c).

The availability of feedstocks, such as a woody biomass and some types of municipal waste, in NZ has been evaluated in collaborative studies by NIWA and SCION (de Vos, et al., 2009; Hall \& Gifford, 2007; Hall \& Jack, 2008) and Shrubsole (2009) and will not be rehearsed here. Other waste streams that may provide suitable biochar feedstocks are putrescible wastes generated by households and council greenwaste. Diverting these materials from landfill will reduce methane emissions and will save the waste levy (New Zealand Parliament, 2008d).

These cost-benefit considerations in regard to composting ${ }^{20}$ may be taken into account when assessing the potential of diverting this waste stream to biochar production. Aspects such as location of the processing facility, collection costs, market size and distribution to end users affect the viability of biochar production.

\subsubsection{Hazardous Substances and New Organisms Act 1996}

The Hazardous Substances and New Organisms (HSNO) Act 1996 establishes the Environmental Risk Management Authority (ERMA) and its responsibilities for processing applications relating to the introduction of hazardous substances and new organisms into NZ. The Act sets out procedures for application, assessment, testing, approval, control, restrictions and enforcement. In giving effect to international

\footnotetext{
${ }^{20}$ A cost benefit analysis of commercial organics composting recommends kerbside collection instead of a drop-off system where households and businesses individually deliver organic wastes to transfer stations (Denne, Irvine, Atreya, \& Robinson, 2007). It has been estimated that 760,000t of commercial and domestic organic waste were landfilled in NZ in 2006 (Denne, et al., 2007). Wood waste only has been estimated to be 520,000t in 2005 (de Vos, et al., 2009). However, municipal organic waste streams may be contaminated by other household rubbish and chemically treated timber from demolition (de Vos, et al., 2009). These waste streams also have alternative uses in commercial composting, mulching, particle board manufacturing or bioenergy (de Vos, et al., 2009). Additionally, transport requirements may render procurement of organic material and the final product distribution economically infeasible. Compost, for example, is a low-density and low-value product, meaning that its transport becomes unprofitable beyond $100-150 \mathrm{~km}$ from the processing facility (Denne, et al., 2007).
} 
obligations, the Act also regulates persistent organic pollutants following NZ's ratification of the Stockholm Convention. It contains a precautionary approach in that decision-makers "shall take into account the need for caution in managing adverse effects where there is scientific and technical uncertainty about those effects" (s7 in New Zealand Parliament, 2008c). Similar to the RMA, the HSNO also embraces the sustainability principle, acknowledges the intrinsic value of ecosystems and is future-regarding (sections 5 and 6 in New Zealand Parliament, 2008c).

The Act may be relevant to biochar deployment if plant species are introduced to NZ in order to produce purpose-grown feedstocks; particularly if these plants are intended to be genetically modified in order to breed feedstock plants with particular characteristics. Further, presence of contaminants in the biochar may lead to it being subjected to the Act's regulations. If, on the other hand, biochar is found to be suitable for soil remediation purposes on contaminated sites such as mining land, it may help to fulfil the purpose of the Act. It remains to be assessed whether biochar's adsorbing properties may be used to immobilise persistent organic pollutants, regulated under the Stockholm Convention.

\subsubsection{Biofuels Policy}

While bio-oil from pyrolysis can be upgraded to a liquid transport fuel, its high viscosity and acidity require considerable refinement (see Chapter Three, section 3.2); an efficient pathway for which has yet to be determined. Nonetheless, a brief look at NZ's biofuel policy may be justified on the basis of bio-oil potentially becoming part of this sector in the future.

The Energy (Fuels, Levies, and References) Act 1989 (New Zealand Parliament, 2010b) was amended in 2008 so as to include a biofuel sales obligation. This obligation came into force on 1 October 2008 but was repealed in December 2008 after the NZ General Election in November which changed the power in Government from Labour to National. 
A Sustainable Biofuel Bill that proposes to amend the Energy Act is currently before the Select Committee on Local Government and Environment (as of 09/06/2010). The aim of this Members Bill is to ensure that biofuels sold in NZ from 1 May 2010 are sourced and produced sustainably (New Zealand Parliament, 2010e). Submissions on the Bill closed in September 2009 and the Select Committee's report is due on 29 July 2010 (New Zealand Parliament, 2010d). In the absence of a biofuel sales obligation with a quantified and scheduled phase-in of biofuels into the liquid transport fuel supply it remains to be seen whether biofuels will gain ground.

\subsubsection{Electricity: Small-Scale, Distributed Generation}

The main challenges concerning energy are meeting a growing demand whilst reducing GHG emissions, and securing energy supply (IPCC, 2007a). Fossil fuel combustion for electricity and heat generation accounted for 26\% of global GHG emissions in 2004 (IPCC, 2007a) and 15.8\% of NZ total net GHG emissions in 2008 (MfE, 2010b). Displacement of fossil fuels in electricity generation is one significant lever for GHG emission reductions.

From an environmental and energy security perspective, it appears desirable to develop domestically available renewable energy (RE) sources for increased energy selfsufficiency and reduced environmental impact. Biomass presents a RE resource which can be processed in different ways, one of which is pyrolysis. Industrial-scale pyrolysis equipment is being used and developed in various places around the world ${ }^{21}$. The focus here is on small-scale, distributed generation. It is assumed that feedstock sourcing, energy and biochar use all occur in close proximity to the pyrolysis facility.

Small-scale pyrolysis projects are likely to face the same issues as other small-scale, distributed RE projects. This justifies a closer look into the institutional and regulatory framework for RE in general and small-scale, distributed generation in particular.

\footnotetext{
${ }^{21}$ For example, Dynamotive Energy Systems Corporation in Canada http://www.dynamotive.com/, Pacific Pyrolysis in Australia http://pacificpyrolysis.com/index.html, Biochar Engineering in the USA http://www.biocharengineering.com/, 3R Agrocarbon in Hungary http://www.3ragrocarbon.com/ or Swiss Biochar in Switzerland http://www.swiss-biochar.com/. For an overview of companies involved in biochar and pyrolysis see here http://terrapreta.bioenergylists.org/company.
} 
Introd | Method | Biochar | Institutions | Theory | Analys \& Disc | Concl

\section{Renewable Energy in New Zealand}

In 2008, 65\% of NZ's electricity was generated from renewable sources (Ministry of Economic Development (MED), 2009). Figure 33 shows that the relative share of renewables follows a downward trend over the past 35 years.

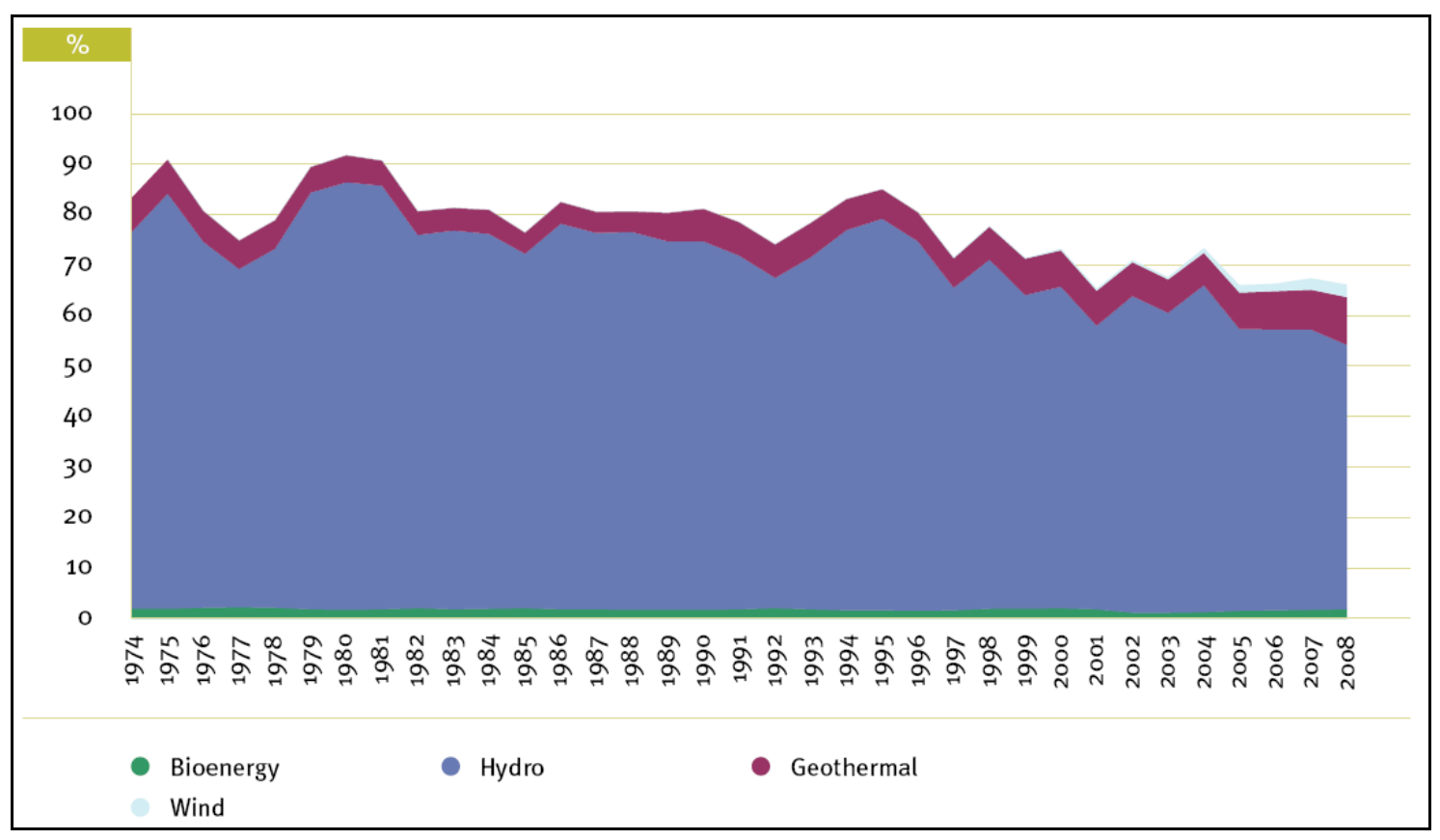

Figure 33: Percentage of electricity generation from renewable sources in NZ, 1974-2008 (MED, 2009, p. 98)

This is primarily due to more gas and coal based power generation coming online in order to balance supply insecurities in dry years when hydroelectricity generation is limited (MED, 2009). Figure 34 shows that the marginal increase in energy generation is mainly realised by fossil fuel (coal and gas). 


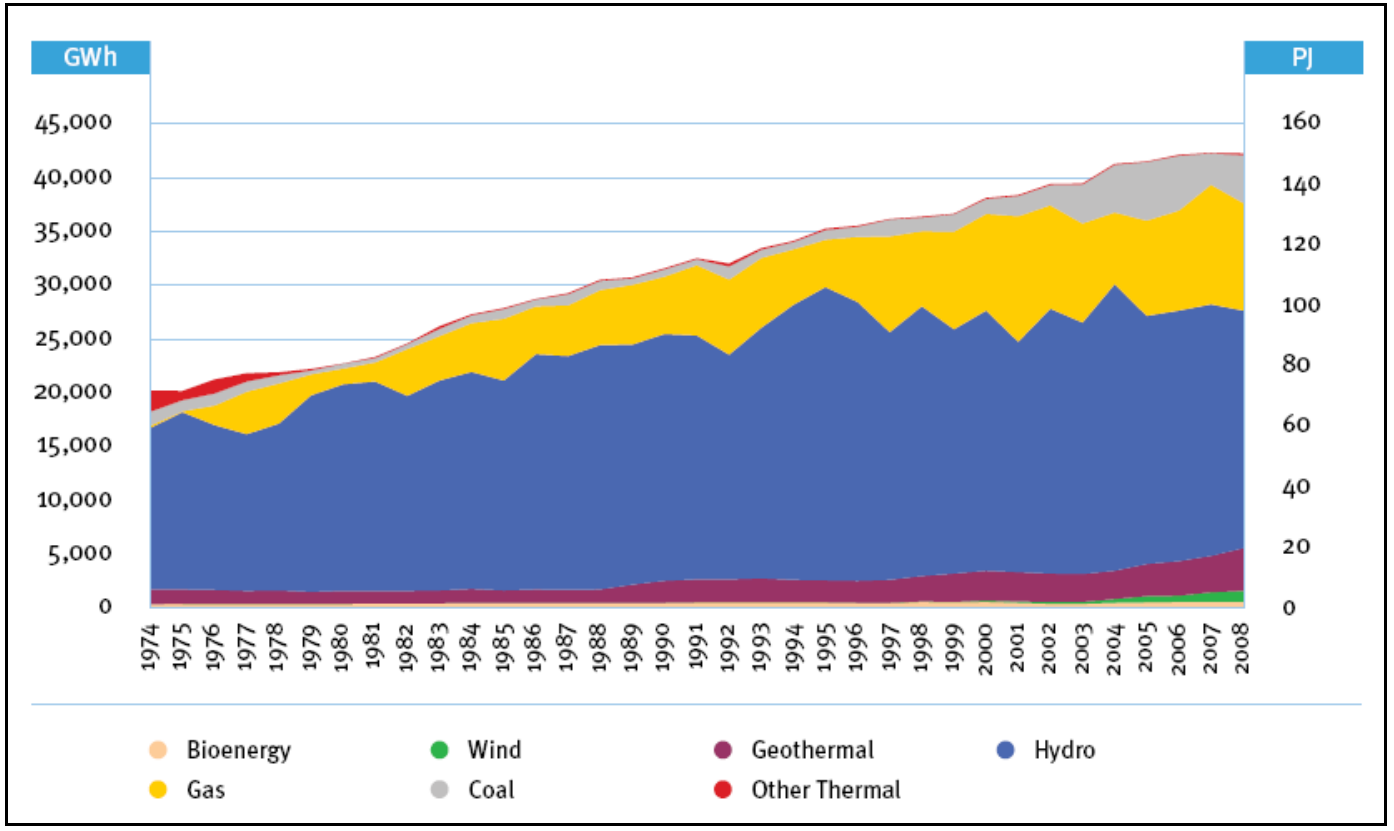

Figure 34: Annual electricity generation by fuel type 1974-2008 (MED, 2009, p. 102)

Within the category of RE sources, the share of bioenergy is of particular interest in the context of this study. Bioenergy includes wood biomass as well as biogas, from both wastewater treatment plants and landfills (MED, 2009).

A total of $1.3 \%$ of electricity is generated from wood and biogas (MED, 2009). Wood is used for cogeneration (also known as combined heat and power generation) at several wood processing factories around NZ (MED, 2009). Cogeneration is more environmentally benign than electricity-only generation because of higher energy conversion and efficiency rates (Eyre, 1997; MED, 2009). If pyrolysis is to be adopted instead, it will need to have a superior energy and GHG balance. For pyrolysis to measure up against other RE and specifically other bioenergy pathways, the 'energy returned on energy invested' (EROEI) over the life cycle will have to be favourable (Gonçalves da Silva, 2010; Mason, Page, \& Williamson, 2010). Mason and colleagues (2010) ranked RE in $\mathrm{NZ}$ according to the net EROEI in a descending order of hydro, wind, geothermal and biomass.

Singling out the category of biomass, Hall and Jack (2008) compare potential scale, GHG impacts, EROEI and economic viability of various bioenergy pathways for NZ as summarised in Table 8. Combined heat and power (CHP) from straw shows a relatively 
high EROEI and also a reasonably large resource base. In contrast, reject Kiwifruit to biogas via anaerobic digestion outperforms CHP from straw in terms of EROEI but has an only limited biomass resource. Sustainability implications of diversion of vast quantities of straw from agricultural lands deserve further in-depth analysis of long-term nutrient cycle and ecosystem impacts but are outside the scope of this study.

Table 8: Summary of biomass energy pathways (Hall \& Jack, 2008, p. 7)

\begin{tabular}{|c|c|c|c|c|}
\hline Pathway & & Potential scale & $\begin{array}{l}\text { GHG emissions and } \\
\text { environmental sustainability }\end{array}$ & Economic viability \\
\hline $\begin{array}{l}\text { Straw to combined } \\
\text { heat and power } \\
\text { (CHP) }\end{array}$ & $\sqrt{ }$ & $\begin{array}{l}\text { Significant } \\
\text { contribution at the } \\
\text { regional level. }\end{array}$ & $\begin{array}{l}\sqrt{ } \text { Significant GHG reductions } \\
(\times 95 \%) \text { when compared to } \\
\text { grid electricity and heat } \\
\text { from coal. The EROEI is } 18: 1 \text {. }\end{array}$ & $\begin{array}{l}\text { X Currently not competitive. } \\
\text { Carbon price will influence } \\
\text { economics. }\end{array}$ \\
\hline $\begin{array}{l}\text { Canola crops } \\
\text { to biodiesel }\end{array}$ & $x$ & $\begin{array}{l}\text { Land use competition } \\
\text { reduces potential } \\
\text { scale. }\end{array}$ & $\begin{array}{l}\sqrt{ } \text { Reduces GHG emissions } \\
(60 \%) \text { compared to fossil } \\
\text { diesel; EROEI is } 2.2: 1 . \\
\text { Requires arable land. }\end{array}$ & $\begin{array}{l}\sqrt{ } \text { Currently economically } \\
\text { competitive. }\end{array}$ \\
\hline $\begin{array}{l}\text { Reject kiwifruit } \\
\text { to biogas via } \\
\text { anaerobic digestion }\end{array}$ & $x$ & $\begin{array}{l}\text { Small resource } \\
\text { ( } 1.5 \mathrm{PJ}) \text { nationally. }\end{array}$ & $\begin{array}{l}\sqrt{ } \text { Significant GHG reductions } \\
(995 \%) \text { compared to } \\
\text { natural gas. EROEI is } 27.1 \text {. }\end{array}$ & X Currently not competitive. \\
\hline $\begin{array}{l}\text { Industrial effluent } \\
\text { to CHP via } \\
\text { anaerobic digestion }\end{array}$ & $\mathrm{x}$ & Resource is limited. & $\begin{array}{l}\sqrt{ } \text { Significant reductions } \\
\text { in waste }(80 \%) \text { and } \\
\text { GHG emissions (200\%), } \\
\text { compared to land disposal } \\
\text { and grid electricity. }\end{array}$ & $\begin{array}{l}\sqrt{ } \text { Economic at favourable } \\
\text { sites, increase in } \\
\text { electricity prices } 15 \text { to } \\
20 \% \text { would make it viable } \\
\text { at a greater range of sites. }\end{array}$ \\
\hline $\begin{array}{l}\text { Forest residues } \\
\text { to heat via } \\
\text { combustion }\end{array}$ & $\sqrt{ }$ & $\begin{array}{l}20 \% \text { of demand. Can } \\
\text { meet demand in some } \\
\text { regions. }\end{array}$ & $\begin{array}{l}\sqrt{ } \text { Reduces } \mathrm{GHG} \text { emissions } \\
\text { by a factor of ( } 90 \% \text { ) } \\
\text { compared to coal. } \\
\text { Energy return on energy } \\
\text { investment (EROED) is } 6.4: 1 \text {. }\end{array}$ & $\begin{array}{l}\sqrt{ } \text { Future economics will be } \\
\text { influenced by the price } \\
\text { of carbon. }\end{array}$ \\
\hline $\begin{array}{l}\text { Forest residues } \\
\text { to ethanol via } \\
\text { enzymatic } \\
\text { conversion }\end{array}$ & $\mathrm{x}$ & $10 \%$ of demand. & $\begin{array}{l}\sqrt{ } \text { Significant GHG reductions } \\
(\sim 80 \%) \text {. Even low } \\
\text { percentages blends provide } \\
\text { environmental gains. EROEI } \\
\text { is } 3.5: 1 .\end{array}$ & $\begin{array}{l}X \text { Currently only } 30 \% \text { more } \\
\text { costly than petrol. }\end{array}$ \\
\hline $\begin{array}{l}\text { Purpose-grown } \\
\text { forest to ethanol }\end{array}$ & $\sqrt{ }$ & $\begin{array}{l}\text { Sufficient low to } \\
\text { moderate value land } \\
\text { exists to make } N Z \\
\text { self-sufficient in } \\
\text { transport fuels. }\end{array}$ & $\begin{array}{l}\sqrt{ } \text { Significant GHG reductions } \\
(60-90 \%) \text {. Even low } \\
\text { percentage blends provide } \\
\text { environmental gains. EROEI } \\
\text { is } 4.5 .1 \text {. }\end{array}$ & X Currently not competitive. \\
\hline
\end{tabular}

Hall and Jack (2008) analyse pyrolysis only in regard to bio-oil for liquid fuel production as can be seen from rows seven and 14 in Table 9 below. The energy conversion efficiencies for woody biomass converted to liquid fuels via pyrolysis range from $56 \%$ to $58 \%$ and are far below the $88 \%$ conversion efficiency of straw used for heat generation 
Introd | Method | Biochar | Institutions | Theory | Analys \& Disc | Concl

(row 15 in Table 9). A similar analysis of conversion efficiency, GHG impact and EROEI of pyrolysis with the syngas used for electricity generation may be worth investigating in further studies ${ }^{22}$.

Table 9: Comparison of bioenergy pathways according to energy efficiency (defined as total energy outputs divided by total energy inputs) (Hall \& Jack, 2008, p. 50)

\begin{tabular}{|c|c|c|c|c|c|c|}
\hline Pathway & Description & $\begin{array}{l}\text { Energy } \\
\text { efficiency }\end{array}$ & $\begin{array}{l}\text { Heat } \\
\text { (GJ) }\end{array}$ & $\begin{array}{l}\text { Electricity } \\
\text { (GJ) }\end{array}$ & $\begin{array}{l}\text { Diesel } \\
\text { (GJ) }\end{array}$ & $\begin{array}{c}\text { Ethanol } \\
\text { (GJ) }\end{array}$ \\
\hline 1 & Wood to Heat & $67 \%$ & 0.7 & & & \\
\hline 2 & Wood to CHP & $46 \%$ & 0.35 & 0.13 & & \\
\hline 3 & Wood to EtOH & $41 \%$ & & 0.12 & & 0.325 \\
\hline 4 & Wood-Gas Heat & $57 \%$ & 0.60 & & & \\
\hline 5 & Wood-Gas-CHP & $47 \%$ & 0.26 & 0.231 & & \\
\hline 6 & Wood to gas to $\mathrm{FT} * *$ liquids & $52 \%$ & & 0.186 & 0.41 & \\
\hline 7 & Wood to Pyrolys is to LF*** & $56 \%$ & & & 0.013 & $0.46^{*}$ \\
\hline 8 & PGF to Heat & $63 \%$ & 0.7 & & & \\
\hline 9 & PGF to CHP & $43 \%$ & 0.35 & 0.13 & & \\
\hline $10 a$ & PGF to EtOH & $43 \%$ & & 0.12 & & 0.325 \\
\hline $10 \mathrm{~b}$ & PGF to Biodiesel & $43 \%$ & & 0.12 & 0.325 & \\
\hline 11 & PGF-gas-heat & $60 \%$ & 0.60 & & & \\
\hline 12 & PGF-gas-CHP & $49 \%$ & 0.26 & 0.23 & & \\
\hline 13 & PGF to gas to FT liquids & $54 \%$ & & 0.186 & 0.413 & \\
\hline 14 & PGF to Pyrolysis to LF & $58 \%$ & & & 0.13 & $0.46^{*}$ \\
\hline 15 & Straw to Heat & $88 \%$ & 0.9 & & & \\
\hline 16 & Straw to CHP & $61 \%$ & 0.45 & 0.17 & & \\
\hline 17 & WVO to Biodiesel & $84 \%$ & & & 0.99 & \\
\hline 18 & Tallow to Biodiesel & $64 \%$ & & & 0.73 & \\
\hline 19 & Rapeseed to Biodiesel & $69 \%$ & & & 0.81 & \\
\hline 20 & Coal to Heat & $74 \%$ & 0.75 & & & \\
\hline 21 & Coal to gas to FT liquids & $53 \%$ & & 0.186 & 0.43 & \\
\hline
\end{tabular}

${ }^{22}$ The EnergyScape ${ }^{\mathrm{TM}}$ Basis Review produced by NIWA and Scion suggests that while gasification and pyrolysis have potential for liquid fuel production, they are not fully commercialised but emerging technologies as yet (de Vos, et al., 2009). Also, liquid fuels are seen as relatively higher-value products with a broad demand base and therefore attract much more capital investments than, for example, gaseous energy products (de Vos, et al., 2009). 
Small-scale renewable projects cannot capture economies of scale and hence, incur higher generating costs per kWh (Bolinger, 2001, p. 6). On the other hand, distributed generation with end-use located in close proximity means fewer transmission losses and reduced non-energy costs of transmission (Siddiqui, Marnay, Firestone, \& Zhou, 2006).

Distributed off-grid generation may also increase energy security for remote communities in rural areas (Kanase-Patil, Saini, \& Sharma, 2010).

The National Party's electricity policy focuses on security of supply, part of which is to minimise transmission and distribution losses (Brownlee, 2009). This may be a useful step given those current losses from transmission and distribution together account for 3.1 Terawatt (TW) or $7.3 \%$ of total net generation. This is twice as high as the combined total share of bioenergy, waste heat and wind with $1.6 \mathrm{TW}$ or $3.8 \%$ of total net generation (MED, 2009). Local and small scale electricity generation can reduce transmission losses and increase local energy security which would be further supported by community ownership of the generating facility (Barry \& Chapman, 2009).

Location matters not only for feedstock proximity reasons and costs but also in regard to aesthetics, recreation and amenity. Impacts may result from noise, odour or outer appearance of the plant. Higher population densities aggravate the situation, especially as it concerns human health, e.g. discharge of particulate matter from biochar handling and transport (Husk \& Major, 2010).

\section{New Zealand Agencies}

The main agencies exercising regulatory functions concerning NZ's electricity sector are MED (policy development and implementation; monitoring of competition and pricing and monitoring of the Electricity Commission), the Electricity Commission (ensuring security of supply, monitoring competition, developing transmission grid standards and investment guidelines) and the Commerce Commission (monitoring market performance and competition in transmission and distribution) (MED, 2009).

In its decisions, MED is guided by the Government Policy Statement on Electricity Governance. Further parts of the regulatory framework controlling the electricity sector are legislation (specific and generic) and regulations. Specific pieces of legislation are the 
Introd | Method | Biochar | Institutions | Theory | Analys \& Disc | Concl

Electricity Act 1992, the Electricity Reform Act 1998 and Part 4A of the Commerce Act 1986. Generic legislation comprises the Commerce Act 1986, Fair Trading Act 1986, Consumer Guarantees Act 1993, Resource Management Act 1991 and the Energy Efficiency and Conservation Act 2000.

An exhaustive in-depth exploration of all legislation and regulation pertinent to the $\mathrm{NZ}$ electricity sector is outside the scope of this study. Generally, prospects for increased electricity generation from RE sources in NZ were diminished in November 2008 when the newly elected National Government repealed Part 6A of the Electricity Act 1992. This part was included just two months prior to the election by the Electricity (Renewable Preference) Amendment Act 2008. It restricted new fossil-fuelled thermal electricity generation (New Zealand Parliament, 2010a). The repeal opened the door for new baseload thermal electricity generation from fossil fuels. Additionally, the National Party plans a revision of the NZ Energy Strategy to centre it on security of supply with the “overriding goal of maximising economic growth" (Brownlee, 2009). It can be expected that the review will result in a version with much reduced emphasis on environmental sustainability.

In terms of regulation of distributed generation, the Electricity Governance (Connection of Distributed Generation) Regulations 2007 is a key regulatory document. It specifies processes and pricing for the connection of distributed generation to local lines networks and lays out information requirements for generators seeking approval by distributors to be connected. The regulations further contain the rights and obligations of distributors and generators in case of non-contractual connection, a default dispute resolution process and pricing principles. Additionally, maxima for fees to be paid by the generator are prescribed as the generator must pay the distributor when making an application and for observing the testing and inspection of the generating facility (New Zealand Parliament, 2008a).

These regulations mean that individuals willing to sell excess energy to an electricity retailer will have to negotiate individually with the distributor. In NZ, 29 independent distribution companies exist (as of April 2009) (MED, 2009). This is a fairly large number by international comparison. Different pricing policies in various regions may lead to different prices being paid to generators despite them using the same technology. 
Introd | Method | Biochar | Institutions | Theory | Analys \& Disc | Concl

Further barriers to small-scale, distributed RE development in NZ are high upfront development costs, the lack of a stable market for the electricity generated and an investment risk in the form of market price insecurity (Barry \& Chapman, 2009; EECA, 2006).

\section{Policy Design to increase the Uptake of small-scale, distributed Renewable Energy}

\section{Projects: The Option of a Feed-in Tariff?}

A policy instrument suggested for dealing with these costs and pricing barriers is a feedin tariff (FIT). This is a tariff paid on energy from renewable sources over and above the market price for electricity (Cory, Couture, \& Kreycik, 2009). A FIT represents a Pigovian subsidy on production so as to internalise the positive production externality of reduced GHG emissions from energy generation (Sawin, 2004).

Figure 35 below illustrates this economic theory. In the presence of a positive production externality marginal private costs (MPC) exceed marginal social costs (MSC). As a result, it is 'irrational' for an individual to produce the good or service in question because the marginal costs of doing so (MPC) are higher than the benefit that the individual would derive from production (the marginal private benefit or MPB). This situation is represented by point E1 in Figure 35. The quantity of RE supplied does not exceed Q1 due to the abovementioned higher MPC. The difference between MPC and marginal social costs (MSC) is represented by the vertical distance between the two supply curves S1 and S2. MPC are represented by S1 which is the sum of MSC and the MEB of reduced GHG emissions. In contrast, S2 reflects the MSC only and hence, disregards the positive externality. 


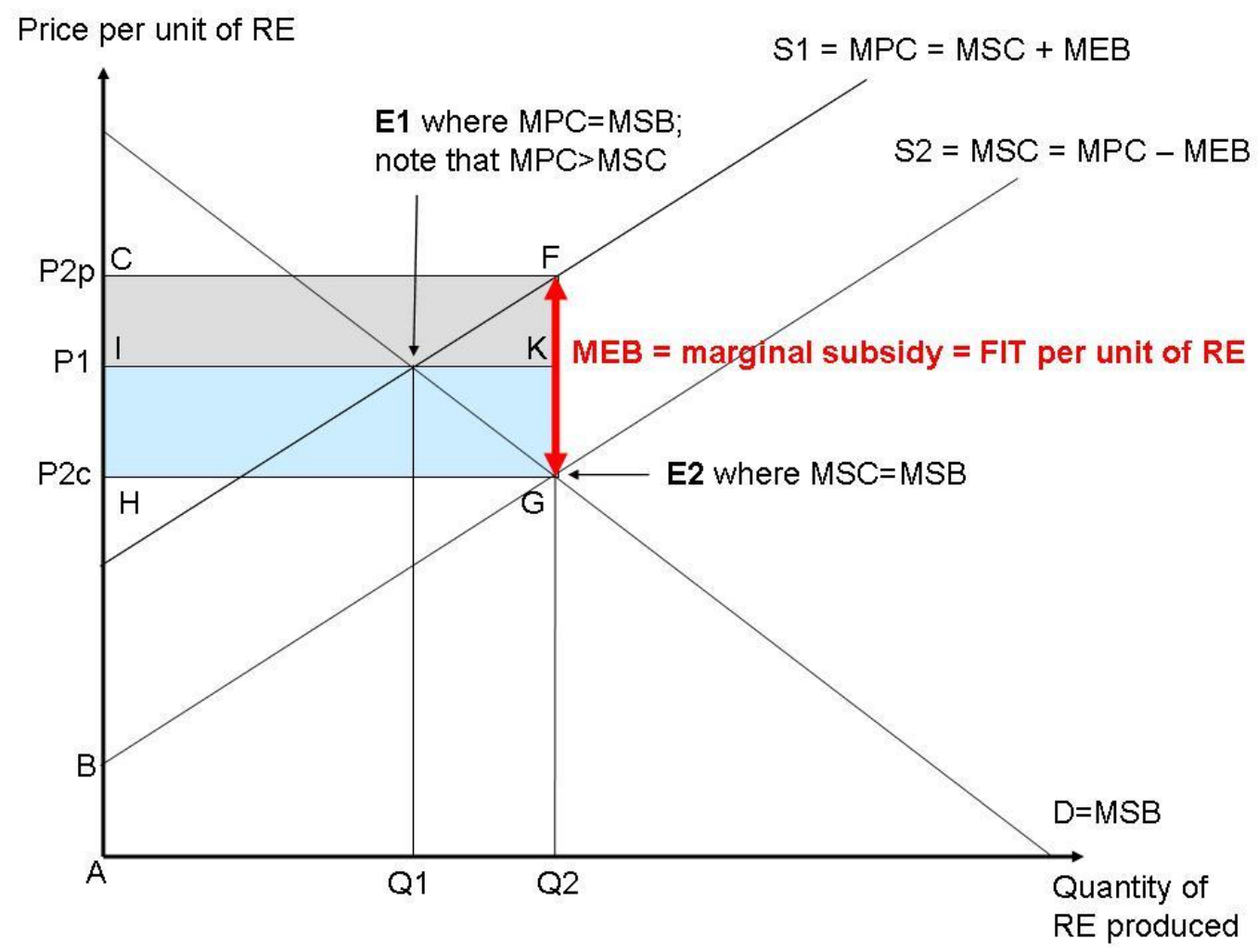

Figure 35: Feed-in tariff as a subsidy on production of renewable generation so as to internalise the external benefit of reduced GHG emissions (own chart)

Key:

E1: $\quad$ competitive equilibrium with $\mathrm{P} 1$ and Q1

E2: $\quad$ social optimum/allocative efficiency with P2c and Q2

MEB: $\quad$ marginal external benefit $=$ subsidy to move to the social optimum where allocative efficiency is represented by MSB=MSC

P1: $\quad$ market price at competitive equilibrium

P2p: $\quad$ price to producers at $\mathrm{E} 2$ (i.e. after implementation of subsidy)

P2c: price to consumers at E2 (i.e. after implementation of subsidy)

CFGH: total amount of subsidy paid at Q2

CFKI: share of subsidy paid out to producers

IKGH: share of subsidy paid out to consumers

The competitive market equilibrium E1 with quantity supplied Q1 and competitive market price P1 does not reflect the socially optimal price and quantity. The socially efficient point is defined where MSC equal marginal social benefit (MSB). This is represented by point E2 in Figure 35. Here, the vertical distance between point $G$ and $F$ marks the marginal external benefit (MEB) or FIT paid per unit of RE generated. This internalises the positive externality and leads to an increase of the quantity supplied up to 
Q2 and has a twofold impact on price. Firstly, the price paid to producers per unit of RE supplied increases from P1 to P2p. Secondly, the price paid by consumers per unit of RE used decreases from $\mathrm{P} 1$ to $\mathrm{P} 2 \mathrm{c}^{23}$. This leaves both producers and consumers better off than without the FIT and internalises the environmental benefit of reduced GHG emissions.

In sum, the marginal subsidy paid is the FIT per unit of RE generated while the total subsidy paid at the socially efficient point $\mathrm{E} 2$ is represented by the rectangle $\mathrm{CFGH}$ (i.e. quantity supplied times per-unit subsidy). This total subsidy is shared by producers (gaining area CFKI) and consumers (gaining area IKGH).

A FIT can be determined based on either electricity generation costs or avoided external costs. In the first case, power generation costs include upfront investment in the technology, other expenses such as for licensing (or, in NZ circumstances, costs for obtaining resource consent, for example), operation and maintenance cost, feedstock cost, inflation and interest rates as well as profit margins (Klein, et al., 2008).

The second option of determining the tariff level considers avoided external costs such as physical damage to the natural and built environment (including GHG emissions, damage to health from air pollutants), effects on security of supply or impacts on recreational, aesthetic and amenity value of the environment (Eyre, 1997; Klein, et al., 2008).

FIT can be designed as a fixed tariff with a guaranteed price per $\mathrm{kWh}$ or as a premium tariff where the subsidy is tied to the market price of electricity, e.g. $120 \%$ of the electricity market price (Mendonça, 2007). Fluctuations in the market price then affect the premium paid and may lead to either windfall profits if the market price skyrockets or to drastic losses as the market price falls (Klein, et al., 2008). The fixed-price model has the advantage of providing investment security in that investors can calculate when the costs will have amortised, i.e. the break-even point (de Jager \& Rathmann, 2008).

\footnotetext{
${ }^{23}$ It is noted that a reduction in consumer electricity prices may send the wrong signals leading to a rebound effect (Eyre, 1997; Liou, 2010). Nonetheless, a FIT has been proven very successful in stimulating RE development, for example in Germany (Saidur, Islam, Rahim, \& Solangi, 2010; Sawin, 2004).
} 
A FIT essentially alters the position of the RE technology fostered by relocating the technology along a marginal abatement cost curve. When considering the criterion of economic efficiency, marginal abatement costs (MAC) of various technologies can be compared to determine the highest GHG reduction for each additional dollar spent. Figure 36 gives a global MAC curve for different GHG-reducing measures and activities.

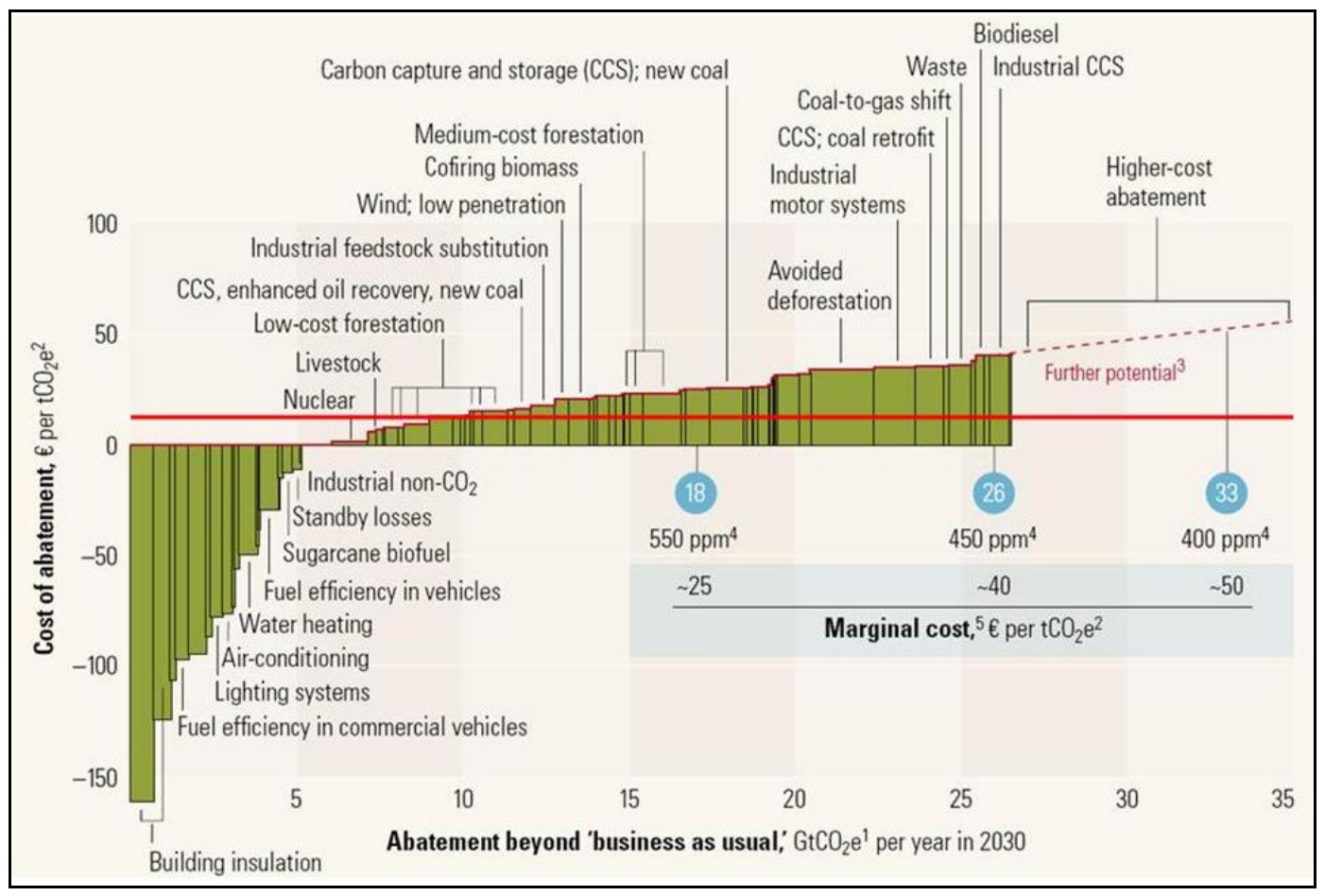

Figure 36: Global marginal abatement cost curve of different abatement measures (Enkvist, et al., 2007). The red horizontal line indicates the NZ\$25 (or about 12.50€) price cap of the NZ ETS to demonstrate which abatement options it would cut off.

Significantly, several measures, such as building insulation or increased vehicle fuel efficiency, show negative values, meaning that they come at no net cost and confer a benefit. That is, the financial savings from increased energy efficiency will result in net gains. Altogether, measures with zero or net negative life cycle cost account for almost

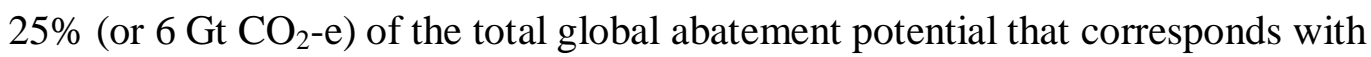
450ppm $\mathrm{CO}_{2}$-e and MAC of $40 € / \mathrm{t} \mathrm{CO}_{2}$-e (Enkvist, et al., 2007).

The chart also correlates abatement costs with atmospheric GHG concentrations. It can be seen that achieving $400 \mathrm{ppm} \mathrm{CO}_{2}$-e, requiring $33 \mathrm{Gt} \mathrm{CO}_{2}$-e to be abated annually by 2030 , would come at MAC of about $50 €$ per $\mathrm{C}_{2}$-e which equates to about NZ\$98. For 
comparison, the carbon price in the EU ETS since its start in 2005 has ranged from a few cents to $30 € / \mathrm{t} \mathrm{CO}_{2}$-e with a current price of $12.30 €$ (as at 08/01/2010) (European Energy Exchange (EEX), 2009). Lehmann (2007c) estimates that biochar carbon sequestration with bioenergy production from pyrolysis can become economically viable in the US at a carbon price of US\$37/t $\mathrm{CO}_{2}$-e or about $26 €$ and $\mathrm{NZ} \$ 50 / \mathrm{t} \mathrm{CO}_{2}$-e respectively. Given current price structures, this seems to be still a long way off. Added difficulties arise from a capping of the carbon price at NZ\$25 in the transition period ending 31 December 2012 which will discourage innovation and incentives for abatement projects.

Successful policy design of FIT starts with offering this support to all levels/scales of renewables generators, from the household to large-scale commercial utilities (Mendonça, 2007). Another essential aspect is financial security. Tariffs must be high enough and paid for long enough to not only cover costs of installation and development but also to have a reasonable return on investment (Klein, et al., 2008). Long-term certainty also implies easier access to financing as banks appreciate a guaranteed return.

It proves beneficial to build trust amongst investors by removing barriers to grid connection. Guaranteeing access to the national grid as well as planning to strategically develop the national grid so as to accommodate further expansion of distributed generation increase trust and provide certainty for investors in the long-term (de Jager \& Rathmann, 2008). Within the NZ regulatory framework for the electricity sector, signalling readiness for adequate grid development could come from the Electricity Commission because it develops transmission grid upgrade guidelines and reliability standards (MED, 2009).

Transparent administration of application procedures as well as clearly specified eligibility criteria for types and scales of technologies, time frames, mid- and long-term RE targets, tariff levels and duration of payment make the policy instrument of FIT attractive and accessible to potential participants, i.e. potential generators (Klein, et al., 2008).

It is important to work towards increased public acceptance of small-scale, distributed generation projects. This may be aided by keeping costs to end users low and by demonstrating policy success through ease and benefit of participation, e.g. facilitating 
Introd | Method | Biochar | Institutions | Theory | Analys \& Disc | Concl

connection to the grid (Mendonça, 2007). In the NZ context, RE development must have regard to cultural and spiritual significance of landscapes (EECA, 2006) and must ensure that intrinsic and non-market values of landscapes are taken into account.

\subsection{New Zealand's Biochar 'Landscape'}

The NZ Government promoted biochar as one of its climate change solutions in the area of agricultural and forestry land management (MfE, 2007). In sum, the Ministry of Agriculture and Forestry (MAF) invests NZ\$10m from 2007 to 2012 in research, development and commercialisation of biofuels, biochar and energy efficiency (MfE, 2007; MAF, 2007b). Additionally, the 'Sustainable Land Management and Climate Change Plan of Action' envisages biochar as a means of climate change mitigation while providing business opportunities (MAF, 2007b). Biochar is seen as having potential to suppress $\mathrm{N}_{2} \mathrm{O}$ emissions, reduce nitrate leaching into waterways, create a carbon sink and 'green' business opportunities (MAF, 2007a, 2007b). Further information needs for policy decision-making have been identified as regards the amount of biochar needed to improve soil health and increase soil productivity and crop yield (Winsley, 2007a, 2007b). Other research areas identified by policy are the implications of biochar soil application for water quality, fertiliser use and nitrate leaching as well as costs of production and utilisation as a soil amendment (Horgan, 2008).

To foster research on these topics, MAF funds two professorial chairs at Massey University: 'Biochar and Bioenergy Pyrolysis Engineering' and 'Biochar and Soil Science Research' (Massey University, 2007; Pigneri \& Hedley, 2008). Governmental funding is provided for four years, after which Massey has to seek other financial sources (MAF, 2007a). From 2007-2011 NZ\$10.325 million will be allocated to bioenergy and biochar research and development (MAF, 2007b), almost one third of which (NZ\$3.125m) has been designated for the two professorships at Massey University (MAF, 2007a). MAF's expectations in the two professorial chairs include commercialisation of the technology and the establishment of industry links (Winsley, 2007b). 
Additional funding from MAF under the Sustainable Farming Fund has been granted for the establishment of the NZ Biochar Network as a one-year project from 2008-2009 (Hedley, 2010). This initiated knowledge transfer on domestic and international biochar research findings from the research community to stakeholders in agriculture and forestry. Information transfer from primary sector stakeholders to the research community included stakeholders' practical and operational requirements in regard to biochar soil application. The project-based funding enabled hosting of seminars, issuance of newsletters and establishment of a website (Hedley, 2010).

Research activity on biochar is not limited to Massey University. Other universities include Lincoln (Anderson \& Condron, 2010; Clough, et al., 2010), Waikato (Bourke, et al., 2010), Canterbury (Pang, et al., 2010) and a collaborative project between Otago and Victoria (Dickinson, et al., 2010). Crown Research Institutes investigating biochar include Scion (Wang, 2010), Landcare (Srinivasan, et al., 2010) and Plant and Food Research (Simpson, et al., 2010; Sivakumaran, et al., 2010).

In the Manawatu-Wanganui region, Palmerston North is assessing the technical and economic feasibility of a pyrolysis facility to process organic waste streams under the Council's management (Downie \& Pepper, 2010). Other commercial biochar production includes AES in Pukekohe ${ }^{24}$ and CarbonScape in Blenheim ${ }^{25}$.

\footnotetext{
${ }^{24}$ The pyrolysis plant in Pukekohe plant focuses on bio-oil production and is a joint venture between NZ company Alternative Energy Solutions (AES), Malaysia-based forest owner Ernslaw One, and the Energy Efficiency and Conservation Authority (EECA) (http://www.carbonnews.co.nz/story.asp?storyid=2802; http://www.bioenergy.org.nz/documents/publications/Liquid\%20Biofuels/KeyPlayers\%20in\%20NZ\%20Li qBio/AES.pdf)

${ }^{25} \mathrm{http}: / /$ carbonscape.com/
} 
Introd | Method | Biochar | Institutions | Theory | Analys \& Disc | Concl

\section{Theoretical Framework}

This chapter presents the theoretical lenses deployed in this research through which the primary and secondary data are analysed. It helps to address the study's aim and objectives, set out in Chapter One, by seeking to answer the following questions:

- What considerations for GHG policy design are suggested by theory and which policy criteria and principles can be applied when decisions have to be made in the face of risk and uncertainty?

- Which theoretical perspectives offer useful insights when biochar is framed as a new climate change mitigation tool?

The chapter begins with reflections on economic aspects and further policy criteria for designing pollution control instruments. In economic terms, GHG emissions are an externality and biochar is a possible tool to internalise that externality. Importantly, biochar deployment itself comes with positive or negative externalities. Uncertainty and risk arise from two facts: current scientific understanding may not be able to anticipate all possible externalities, and the very same environmental impact of biochar production or use may represent a positive or a negative externality, depending on the specific situation.

As established in the previous chapter, the newness of biochar as a climate change mitigation tool implies that for $\mathrm{NZ}$ only limited guidance is available by policy experience in other countries. This compounds the scientific uncertainty mentioned above. Biochar is an innovation with which both public policy and the economy are relatively unfamiliar as yet. The dynamics of adoption of innovations within an economy are looked at through the lens of Diffusion of Innovations Theory.

The chapter proceeds by suggesting environmental policy principles as guidance for policy decision-making under conditions of uncertainty and risk. The concluding section reflects on public participation in policy decision-making processes. The validity and importance of perspectives of those affected by a decision is highlighted. An imperative for extensive and intensive public participation is derived, not despite but because of uncertainty and risk. 
Introd | Method | Biochar | Institutions | Theory | Analys \& Disc | Concl

\subsection{Policy Design Considerations for Pollution Control}

Climate change mitigation in the form of carbon sequestration has been cited as a prime reason for biochar deployment (Bruun, El-Zahery, \& Jensen, 2009; Joseph, et al., 2009; Lehmann, 2007b; Ogawa, Okimori, \& Takahashi, 2006). The following sections introduce policy considerations and economic aspects in GHG pollution control policy design by drawing on neoclassical and ecological economic approaches.

Ecological Economics addresses the inextricable linkages between the environmental, social and economic realm. It is concerned with the operation of an economy within the physical limits of the Earth's resources that determine the limits of economic growth (Daly \& Farley, 2004). Ecological economics questions the commensurability of valuing ecosystem goods and services and particularly future, uncertain or irreversible negative externalities in an orthodox economic sense, that is, in monetary terms. The idea of equating human well-being with material growth is rejected (Costanza, Hart, Posner, \& Talberth, 2009). Special regard is given to distributional issues and equity, in an intra- as well as intergenerational sense, and between humans and the non-human world (Martinez-Alier, 1998).

Any economic activity benefits from and impacts on the natural environment and its resources. The impacts and uses on resources can be characterised within a matrix of rivalness and excludability as discussed in the following.

\subsubsection{A Taxonomy of Uses and Benefits of Resources: Rivalness and Excludability}

Rivalness and excludability do not refer to the resource itself but to the use benefits from and impacts on the resource (see Table 10). Rivalness prevails where one person's benefit from the resource reduces the benefits that others can derive from that resource (Samuelson, 1954). 
Introd | Method | Biochar | Institutions | Theory | Analys \& Disc | Concl

Table 10: Taxonomy of resources (according to Musgrave, 1959; Samuelson, 1954)

\begin{tabular}{|l|l|l|}
\hline & rival & non-rival \\
\hline excludable & $\begin{array}{l}\text { private good } \\
\text { or service }\end{array}$ & $\begin{array}{l}\text { mixed good } \\
\text { or service }\end{array}$ \\
\hline non-excludable & $\begin{array}{l}\text { common pool } \\
\text { resource }\end{array}$ & $\begin{array}{l}\text { pure public good; } \\
\text { open access }\end{array}$ \\
\hline
\end{tabular}

In the context of biochar, examples of rival uses of environmental resources include biomass used for pyrolysis, which reduces the remaining stock of biomass available for other uses, or land dedicated to bioenergy cropping which is consequently unavailable for food production ${ }^{26}$.

Accordingly, non-rivalness means that one person's benefit from a resource does not diminish the benefit that others can derive from the same resource (Callan \& Thomas, 2007). Air purification by indigenous forests, the ozone layer's protection from UV radiation or water purification by wetland areas are examples for non-rival environmental resource use benefits.

Excludability means that use benefit from and impact on a resource are restricted to the owner of a legal entitlement to access and use the resource. Others are excluded from a stream of benefits derived from the resource (Musgrave, 1959). Correspondingly, nonexcludability implies that it is not technically, legally or financially feasible to exclude others from sharing the benefits of a particular resource or preclude them from impacting on the resource (Ostrom, 2003). For example, while it is theoretically conceivable to own a street light, it would be impractical or impossible to exclude others from 'using' that light.

Excludability introduces the anthropocentric concept of access controls implemented by institutions. Excludability is an extrinsic attribute and exists only by social convention. Contrarily, rivalness is an inherent characteristic of use or benefit from a resource as it exists independently of human institutions (Daly \& Farley, 2004). Without institutions

\footnotetext{
${ }^{26}$ This is essentially an extension of the biofuels debate about various displacement effects and competing uses of biomass. It is more extensively discussed in Chapter Six.
} 
that assign and manage excludability open access would exist with resources freely available to anyone (Ostrom, 2003; Vatn, 2005). Classic examples of global common pool resources in regard to the natural environment are the atmosphere and oceans (Lipietz, 1995).

Such public good resources are prone to overuse because all users have an incentive to maximise their benefits derived from the resource. That is, public good resources suffer from the free-rider problem ${ }^{27}$ (Hardin, 1968; Samuelson, 1954). This is because no one has a guaranteed property right of access to or benefit from a given amount of the resource in the future (Ostrom, 2003). It is in these situations of global commons that difficulties in management of many environmental resources arise. Issues such as overfishing and GHG emissions document the failures of institutions to effectively govern the global commons (Carraro, 1999; Clark, 1999).

In the case of the atmosphere there is no incentive to reduce GHG emissions in the absence of GHG pricing. In economic terms, GHG emissions are a negative externality of economic activity. Pricing of GHG emissions aims to internalise that externality.

The following section endeavours to shed light on the GHG externality and biochar as a tool to mitigate that externality. Additionally, the various positive and negative environmental externalities that may arise from biochar deployment itself are explored.

\subsubsection{The Greenhouse Gas and other Externalities in the Context of Biochar}

Externalities are costs or benefits of an economic activity that accrue to parties not directly involved in the market transaction in question (Pigou, 1912). Pollution represents an externality (Jaffe, Newell, \& Stavins, 2005). The common aim of all GHG policy instruments is to internalise the costs imposed on society through the polluting activity.

\footnotetext{
${ }^{27}$ Further discussion of origins, consequences and potential solutions to the free-rider problem is, for example, provided by Chari and Jones (2000), Grossman and Hart (1980), Groves and Ledyard (1977) and Kim and Walker (1984).
} 
Externalities are not reflected in the market price and can arise from production or consumption. Positive externalities are benefits to society, arising from a market transaction, which do not accrue to either producers or consumers involved in that transaction (Common \& Stagl, 2005; Engel, Pagiola, \& Wunder, 2008). Negative externalities include damage to the natural and built environment as well as adverse impacts on recreational and aesthetic value of landscapes (Eyre, 1997).

Acknowledging biochar as a carbon offset may be conceptualised as a mitigation measure used to correct the market failure of the GHG externality. However, biochar deployment itself has associated environmental externalities.

While making no claims of being complete, Table 11 below lists potential positive and negative externalities of biochar. In many instances, the very same feature can be a positive or negative externality. This highlights the need for further research and thorough case-by-case assessment of the costs and benefits of biochar deployment.

Table 11: Potential externalities associated with biochar soil application and technology development (own table). Note: While the attempt was made to relate positive to negative externalities the horizontal alignment should not be interpreted as strictly corresponding. Also, this table is not intended to be exhaustive.

\begin{tabular}{|c|c|}
\hline Potential positive externalities & Potential negative externalities \\
\hline $\begin{array}{l}\text { Carbon sequestration (Joseph, et al., 2009; } \\
\text { Lehmann, 2007b; Ogawa, et al., 2006) }\end{array}$ & $\begin{array}{l}\text { Acknowledgement as a carbon offset would } \\
\text { not change overall emissions (Downie, } \\
\text { 2007; Environmental Defense Fund, } \\
\text { 2007a). } \\
\text { Duration problem may arise if carbon } \\
\text { storage is impermanent (Reijnders, 2009; } \\
\text { van Kooten, 2009). }\end{array}$ \\
\hline $\begin{array}{l}\text { Renewable energy/electricity (Bridgwater, } \\
\text { 2003, 2007; Demirbas, 2008a, 2008b) }\end{array}$ & $\begin{array}{l}\text { Potentially carbon-positive and energy } \\
\text { intensive life cycle (Gaunt \& Cowie, 2009; } \\
\text { Roberts, Gloy, Joseph, Scott, \& Lehmann, } \\
\text { 2010a). }\end{array}$ \\
\hline $\begin{array}{l}\text { Reduced soil } \mathrm{CH}_{4} \text { and } \mathrm{N}_{2} \mathrm{O} \text { emissions } \\
\text { (Cowie, 2009; Rondon, et al., 2006; } \\
\text { Spokas, et al., 2009; Van Zwieten, et al., } \\
\text { 2008) }\end{array}$ & $\begin{array}{l}\text { Accelerated decomposition of native soil } \\
\text { organic matter upon biochar addition } \\
\text { (Wardle, et al., 2008a; 2008b; Pietikäinen, } \\
\text { et al., 2000); increased soil } \mathrm{N}_{2} \mathrm{O} \text { emissions } \\
\text { (Clough, et al., 2010) and no effect on soil } \\
\mathrm{CH}_{4} \text { emissions (Simpson, et al., 2010) }\end{array}$ \\
\hline $\begin{array}{l}\text { Better retention and availability of water } \\
\text { and nutrients (Chan \& Xu, 2009; Major, }\end{array}$ & $\begin{array}{l}\text { High sorption affinity (Braida, et al., 2003; } \\
\text { Sander \& Pignatello, 2007) may also mean }\end{array}$ \\
\hline
\end{tabular}


Introd | Method | Biochar | Institutions | Theory | Analys \& Disc | Concl

\begin{tabular}{|c|c|}
\hline Steiner, Downie, \& Lehmann, 2009) & $\begin{array}{l}\text { suboptimal desorption characteristics for } \\
\text { water and nutrients, i.e. very strong } \\
\text { adsorption of nutrients and water, making } \\
\text { them unavailable to plants) (Krull, 2010) }\end{array}$ \\
\hline $\begin{array}{l}\text { Reduced bulk density and tensile strength } \\
\text { resulting in better soil tilth, soil porosity } \\
\text { and aeration as well as reduced need for } \\
\text { tillage (Chan, et al., 2007; Cowie \& Singh, } \\
\text { 2008; Laird, 2008) }\end{array}$ & $\begin{array}{l}\text { Soil compaction when spreading biochar } \\
\text { with heavy equipment and from very fine } \\
\text { biochar particles may fill up soil pore } \\
\text { spaces (Verheijen, et al., 2009) }\end{array}$ \\
\hline $\begin{array}{l}\text { Increased cation exchange capacity (Cheng, } \\
\text { Lehmann, Thies, Burton, \& Engelhard, } \\
\text { 2006; Liang, et al., 2006) }\end{array}$ & $\begin{array}{l}\text { High pH may reduce availability of trace } \\
\text { elements and result in reduced plant growth } \\
\text { (Kishimoto \& Sugiura, 1985; Mikan \& } \\
\text { Abrams, 1995) }\end{array}$ \\
\hline $\begin{array}{l}\text { Habitat provision for mycorrhizae fungi } \\
\text { and other beneficial soil microbes as well } \\
\text { as increased earthworm abundance (Husk } \\
\text { \& Major, 2010; Ishii \& Kadoya, 1994; } \\
\text { Ogawa, Yambe, \& Sugiura, 1983; Saito \& } \\
\text { Marumoto, 2002) }\end{array}$ & $\begin{array}{l}\text { Decreased earthworm abundance (Weyers, } \\
\text { et al., 2009); unclear impact on other soil } \\
\text { macrofauna and soil biodiversity in general } \\
\text { (Verheijen, et al., 2009) }\end{array}$ \\
\hline $\begin{array}{l}\text { Knowledge externality and adoption } \\
\text { externalities }{ }^{28} \text { (Arrow, 1994; Jaffe, et al., } \\
\text { 2005) }\end{array}$ & $\begin{array}{l}\text { Appropriation and privatisation of } \\
\text { indigenous knowledge through } \\
\text { development of patentable technology } \\
\text { (Beddoe, et al., 2009; Bronson, Mooney, \& } \\
\text { Wetter, 2009) }\end{array}$ \\
\hline $\begin{array}{l}\text { Land use reduction through productivity } \\
\text { increase (Downie \& Lau, 2010) }\end{array}$ & $\begin{array}{l}\text { Diversion of land from other uses; large } \\
\text { scale monocultures for biochar feedstock } \\
\text { production (Ernsting, et al., 2009; Ernsting } \\
\text { \& Rughani, 2008; Ernsting \& Smolker, } \\
\text { 2009) }\end{array}$ \\
\hline $\begin{array}{l}\text { Reduced waste to landfill (Di Marian \& } \\
\text { Fantozzi, 2004; Ibarrola, 2009) }\end{array}$ & $\begin{array}{l}\text { Diversion of biomass from other uses, } \\
\text { especially residue removal instead of in situ } \\
\text { use, e.g. for mulching or composting } \\
\text { (Ernsting \& Smolker, 2009; Holmes, } \\
\text { Rahman, Saunders, \& Mowat, 2010) }\end{array}$ \\
\hline $\begin{array}{l}\text { Increased plant biomass production (Chan, } \\
\text { et al., 2007; Major, Rondon, \& Lehmann, } \\
\text { 2007; Major, Rondon, Molina, Riha, \& }\end{array}$ & $\begin{array}{l}\text { Decreased plant biomass production } \\
\text { (Camps-Arbestain, et al., 2010; Rondon, } \\
\text { Lehmann, Ramirez, \& Hurtado, 2007) }\end{array}$ \\
\hline
\end{tabular}

\footnotetext{
${ }^{28}$ Knowledge externality: R\&D activities create new knowledge which is a public good. Therefore, innovating firms have a disincentive to invest in R\&D when others, too, benefit from that knowledge while incurring no costs for its creation (Arrow, 1994; Jaffe, et al., 2005). Adoption externalities: Users of the innovation are better off the more people adopt the innovation. On the demand side, users benefit from new knowledge generated by those who have already adopted the innovation. On the supply side, production cost tend to decrease over time as experience with manufacture of the new product increases (Jaffe, et al., 2005)

${ }^{29}$ Note that the simple statement of increase or decrease in plant biomass upon biochar addition needs to be qualified by the experimental conditions, such as type of biochar, rate of application and additional fertiliser application. Effects on plant biomass are however included in this list of externalities to illustrate that both positive and negative outcomes are possible depending on the particular conditions of the experiment. Please refer to Chapter Three for a more detailed discussion of biochar properties affecting plant biomass production.
} 


\begin{tabular}{|c|c|}
\hline Lehmann, 2010) & \\
\hline $\begin{array}{l}\text { Dietary supplement for animals: increasing } \\
\text { feed intake due to better digestibility (de- } \\
\text { tannification and adsorption of } \\
\text { phytochemicals) (Rogosic, Pfister, } \\
\text { Provenza, \& Grbesa, 2006; Van, Mui, \& } \\
\text { Ledin, 2006); }\end{array}$ & $\begin{array}{l}\text { Unclear long-term animal health and } \\
\text { welfare implications (Verheijen, et al., } \\
\text { 2009; Condron, 2010, pers. } \\
\text { communication) }\end{array}$ \\
\hline $\begin{array}{l}\text { Activated charcoal is also used as a } \\
\text { gastrointestinal decontaminant for animals } \\
\text { and humans (Bond, 2002; Decker \& Corby, } \\
\text { 1970; Huwig, Freimund, Käppeli, \& } \\
\text { Dutler, 2001) }\end{array}$ & \\
\hline $\begin{array}{l}\text { Soil albedo: faster increase of soil } \\
\text { temperature and longer heat retention } \\
\text { favouring earlier germination and longer } \\
\text { growing periods (Verheijen, et al., 2009) }\end{array}$ & $\begin{array}{l}\text { Soil albedo: darkening of soil colour leads } \\
\text { to increased heat absorption and hence } \\
\text { further warming of the Earth's surface } \\
\text { (Verheijen, et al., 2009) }\end{array}$ \\
\hline $\begin{array}{l}\text { Improved fertiliser use efficiency and } \\
\text { reduced need for fossil fuel in fertiliser } \\
\text { production and application (Van Zwieten, } \\
\text { et al., 2009a) }\end{array}$ & $\begin{array}{l}\text { Public health hazard: dust spreading } \\
\text { (particulate matter) resulting in adverse } \\
\text { respiratory health effects (Husk \& Major, } \\
\text { 2010) }\end{array}$ \\
\hline $\begin{array}{l}\text { Risk mitigation in forestry: removal of } \\
\text { large slash piles }{ }^{30} \text { from skid sites }{ }^{31} \text { that } \\
\text { would otherwise risk instability of skid } \\
\text { sites (Haddon, } 2010 \text {, pers. communication) }\end{array}$ & $\begin{array}{l}\text { Occupational health and safety: fire hazard } \\
\text { in forests when using mobile pyrolysis } \\
\text { equipment; special care needed for bio-oil } \\
\text { storage, handling and transport as it is } \\
\text { highly acidic (Bridgwater, 2003; Hall \& } \\
\text { Gifford, 2007) }\end{array}$ \\
\hline $\begin{array}{l}\text { Bioremediation: adsorption of PAHs, heavy } \\
\text { metals, pesticides and herbicides (Beesley, } \\
\text { et al., 2010; Braida, et al., 2003; Cao, Ma, } \\
\text { Gao, \& Harris, 2009; Sander \& Pignatello, } \\
\text { 2005; Yang, et al., 2010; Zheng, et al., } \\
\text { 2010) }\end{array}$ & $\begin{array}{l}\text { Risk of contaminants in the biochar such as } \\
\text { heavy metals and PAHs (Verheijen, et al., } \\
\text { 2009). } \\
\text { High sorption affinity for pesticides and } \\
\text { herbicides may also mean that more of } \\
\text { these substances need to be applied because } \\
\text { their efficiency is reduced due to their } \\
\text { adsorption by biochar (Haard, 2010). }\end{array}$ \\
\hline
\end{tabular}

Designing mechanisms to internalise all these externalities may prove challenging due to uncertainties about many of the aspects listed in the table. In the particular NZ context, biochar performance under local conditions as well as overall GHG savings assessed on a

\footnotetext{
${ }^{30}$ Slash refers to unmarketable woody debris resulting from thinning or harvesting which is piled up (Seymour \& Tecle, 2004).

${ }^{31}$ Skid site (also called landing) describes an area that is cleared of vegetation and is established for forest harvesting purposes. It is the area where logs are hauled into and processed (debarking, cutting off branches, base and tip of logs) before being dispatched (Hall \& Gifford, 2007; Dyck, 2009, pers. communication).
} 
project basis are areas requiring further research (Anderson \& Condron, 2010; CampsArbestain, et al., 2010; Clough, et al., 2010; Downie \& Pepper, 2010; Pigneri, 2010).

Many of the externalities identified relate to environmental goods and services for which no market exists, for example potentially beneficial pollutant adsorption or potentially adverse impacts on soil macrofauna or biodiversity. Therefore, a holistic approach that takes not only economic costs into account, but gives consideration to non-market goods and services may be recommended here. Given that the natural environment provides a multitude of unpriced goods and services that are important now and in the future, policy decision-making about biochar needs to give consideration to impacts on the non-human world as well as implications for inter- and intragenerational equity. These and other policy criteria are presented in the following section.

\subsection{Policy Criteria}

When designing or assessing policy instruments for environmental impact mitigation or internalisation of externalities it is useful to have a set of basic criteria with which to determine the appropriateness of various options. As policy is a multi-level and multistakeholder process, the challenge is to integrate various concerns and interests into policy design.

One of the basic criteria for environmental policy is environmental effectiveness of the policy instrument. That is, ensuring that the policy implementation will result in the desired outcome, such as reduced GHG emissions (Gupta, et al., 2007). To this end, interactions with and effects on other policies need to be anticipated. The impacts may result in synergistic, neutral or negating effects on the new policy and may potentially undermine its effectiveness (Young, et al., 1996).

Achieving a policy goal in the most efficient manner, that is, at a minimum cost to society, is a further criterion (Common \& Stagl, 2005; Zhang \& Baranzini, 2004). Careful consideration needs to be given to the time dimension when assessing cost and benefits. A policy option may fulfil the conditions for static efficiency and maximise benefits over 
costs at a particular time. When considering costs and benefits over time, a different policy solution may be more advantageous. The economic method of cost-benefitanalysis is used to evaluate the effects of policies and projects over time in order to find the dynamically efficient solution (Eyre, 1997; Harris, 2006). This often entails discounting and links dynamic efficiency to the criterion of equity. Equity concerns relate not only to equity between members of the present generation, but also between the present and the future as well as between humans and the non-humans world (Brown Weiss, 1989; Lind, 1995).

Applying a high discount rate in cost-benefit-analyses will inevitably discriminate against future generations because benefit is maximised and cost minimised for the present generation only (Brennan, 1995; Newell \& Pizer, 2004). The concept of cost benefit analysis is inherently anthropocentric, meaning that the non-human world is easily disregarded. The implications for biodiversity or the carbon cycle, for example, may be overlooked since the non-human world has no voice that would make their 'interests' heard and cannot 'vote' through market decisions (Eckersley, 2005). Distributional inequities of environmental benefits and costs may undermine efficiency of a policy instrument (Gupta, et al., 2007).

Any new policy must accord with domestic judicial rules principles (Crabbé \& Leroy, 2008) as well as international laws and obligations (Cohen, 1999; Gupta, et al., 2007). In regard to climate change, this is exemplified by the UNFCCC 1992 and the Kyoto Protocol 1997 (entry into force 2005) with legally binding responsibility targets. International laws determine the scope and direction of domestic policy. Biochar in international GHG accounting is explored in Chapters Four and Six. Concerning the particular NZ situation, policy must also comply with the Treaty of Waitangi (Grinlinton, 1996).

A further criterion is adjustability as it enables amendment of the policy in the face of new information (Daly \& Farley, 2004). Flexibility over time allows for amendments to be made as learning occurs in the economic and policy realms (Dodgson \& Bessant, 1996). While it may be wise to keep open an option of reversibility, policy should be of considerable durability to provide certainty and stability for investment decisions (Young, et al., 1996). 
Institutional feasibility which includes social, cultural and political acceptability as well as support by the respective domestic legal system will also determine the policy choice (Gupta, et al., 2007). Good governance is reflected in policymaking that is transparent, inclusive and provides for public participation. Accountability of decision-makers and responsibility to explain and justify the decision-making process as well as implementation and outcomes of the new policy, are essential for exercising authority with integrity (United Nations Economic and Social Commission for Asia and the Pacific (UNESCAP), 2007).

Consideration must be given to the fiscal burden if the policy involves the payment of incentives. The incentive structure must not encourage perverse behaviour that runs counter to the actual policy goal (Young, et al., 1996).

When determining the diffusion potential of innovations in the renewable energy sector, such as pyrolysis systems with biochar production, policymakers may wish to take into account a country's resource and energy system characteristics (Dinica, 2010). Availability, quality, distribution and other particularities of the renewable resource, that is intended to be used for energy generation, need to be considered (Dinica, 2010). A pyrolysis plant capable of processing several hundred tonnes of biomass per hour will run under capacity if the required quantity of biomass is simply not available. Pyrolysis plant designs with ever-larger processing capacity do not necessarily indicate an increased contribution of renewable energy from pyrolysis to the overall share of renewables in a national energy system.

Similarly, pyrolysis systems need to match grid characteristics. The scale of the pyrolysis plant would need to be different according to whether the net exploitable biomass energy potential is below or above the technically possible grid integration for energy from pyrolysis (Dinica, 2010). If below, more efficient pyrolysis systems would need to be developed and adopted. If above, pyrolysis systems that have higher grid-friendliness and are more compatible with the grid infrastructure are to be prioritised. This would lift the technically feasible ceiling of grid integration of renewable energy from pyrolysis systems (Dinica, 2010). 
Introd | Method | Biochar | Institutions | Theory | Analys \& Disc | Concl

\subsection{Pollution Control Theory}

Pollution Control Theory provides a framework for assessing costs of pollution damage and abatement. Policy instruments to control GHG emissions can broadly be categorised as either direct regulation (also known as 'command-and-control') or market-based solutions. The former include, for example, environmental or technology standards while the latter may be a per-unit-tax on emissions or a cap-and-trade system (Common \& Stagl, 2005).

This study focuses on market-based instruments. They achieve reductions in nonuniformly mixed pollutants, such as GHG, emitted by point and non-point sources more economically efficient than direct regulation (Tietenberg, 2006; Zhang \& Baranzini, 2004). Within the category of market-based instrument, this research focuses on cap-andtrade because it is the system implemented in $\mathrm{NZ}$ as well as internationally. By making use of varying marginal abatement costs among polluters, emissions will be reduced where the costs for doing so are lowest (Harris, 2006; Jaffe, et al., 2005).

The efficient level of pollution is not zero but defined by the quantity of pollution where marginal damage cost (MDC) equals marginal abatement cost (MAC), shown as point E in Figure 37 with the efficient price $\mathrm{P}$ and quantity Q. At this point, polluters emit quantity AQ and abate quantity QB. The area under the MAC (triangle EBQ) represents the total cost of abatement. The area under the MDC curve (triangle PEQ) represents the total cost of damage. Price P may be a tax per tonne or a permit price per tonne emitted. 


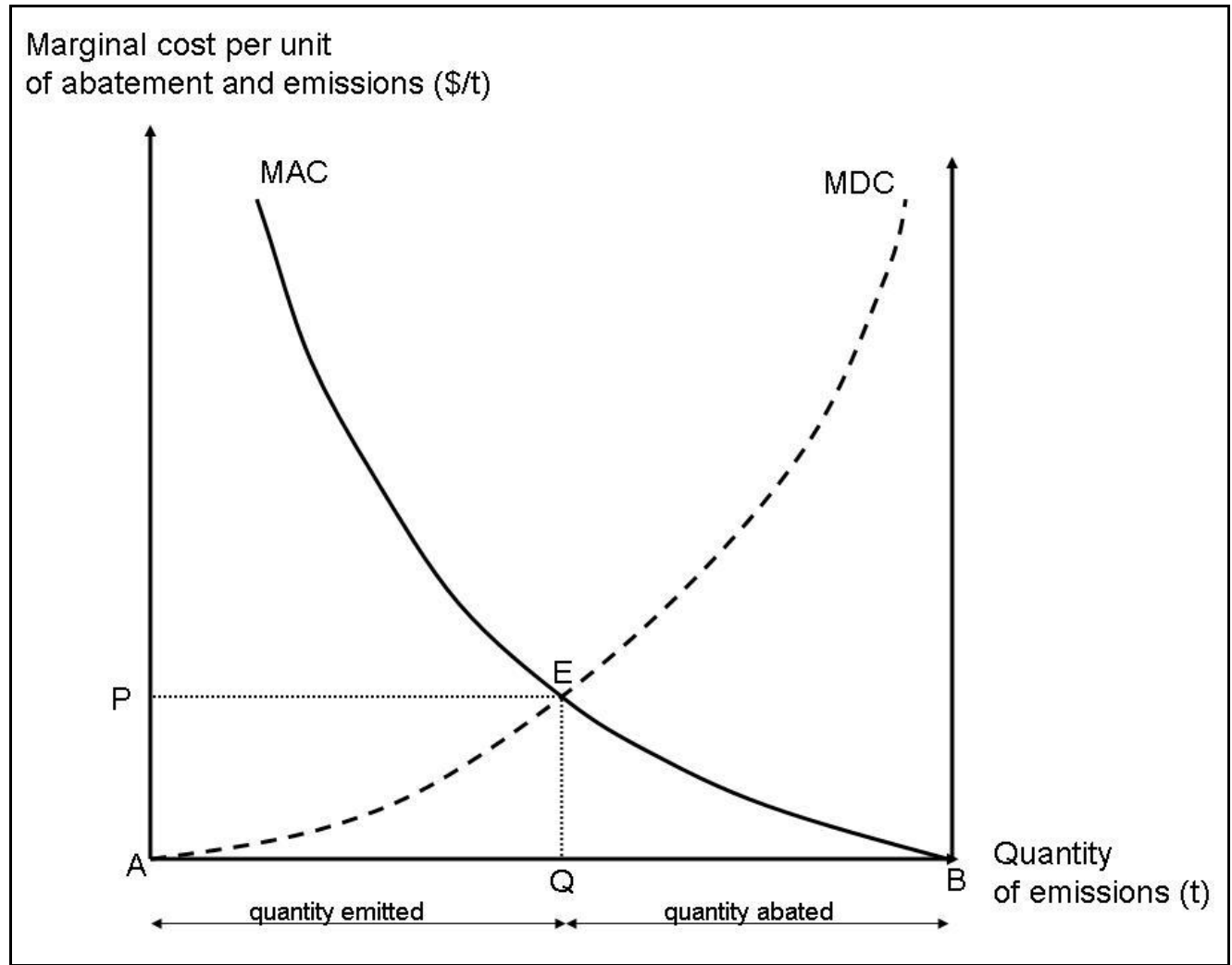

Figure 37: Marginal abatement and marginal damage costs and the efficient level of pollution under certainty about MAC and MDC (own diagram based on theory presented in Common \& Stagl, 2005; Harris, 2006; Tietenberg, 2006).

In most cases policymakers have to decide under incomplete information because the MACs of firms are not known to the government. To minimise net welfare loss to society a tax is preferred if the MAC curve is very steep and marginal damage increases only slightly with each additional unit of emissions (Harris, 2006). In contrast, if MDCs rise very steeply and MACs increase only moderately a quantity limit on emissions (a cap) is preferable (Harris, 2006; Jacoby \& Ellerman, 2004). In either case, the total revenue generated from the tax or the cap-and-trade system is represented by the area PEQA. In case of a tax, the revenue can be recycled by the government and used to lower other, distorting, taxes or to invest in low-carbon technology (Zhang \& Baranzini, 2004). By contrast, emissions permits, which could be auctioned to provide revenue, in NZ are issued free, as grandparented allocations (New Zealand Parliament, 2009a).

A tax provides certainty about the price, but no guarantee of a particular quantity of emissions that will be reduced upon imposition of the tax. It is vice versa for a cap-and- 
Introd | Method | Biochar | Institutions | Theory | Analys \& Disc | Concl

trade system: certainty is provided about the quantity of emissions reductions while the price fluctuates (Harris, 2006).

As outlined in Chapter Four, NZ decided on an ETS which is neither one nor the other. Formally disguised as a cap-and-trade arrangement, it is actually a form of carbon 'tax' because no cap exists. That is, emission permits can be bought from the international carbon market without a limit on the proportion of liabilities that can be met by these additional permits. Formally, the NZ system is however not a tax because the revenue does not go to Government.

To reduce costs to the NZ economy accruing from implementation of the NZ ETS, a certain percentage of the liability can be met by carbon offsets instead of actual emissions reductions. Biochar comes into play as a proposed tool to generate such carbon offsets. The issues associated with acknowledgement of biochar as a carbon offset pathway are further explored in Chapter Six. The following section frames biochar as an innovation and investigates dynamics of adoption through the theoretical lens of Diffusion of Innovations Theory.

\subsection{Biochar as an Innovation}

The innovation of biochar may be framed within a larger paradigm shift (Kuhn, 1962). Economies worldwide become increasingly aware of a carbon-constrained future. Pricing of GHG emissions, increased use of renewable energies and various other policy and technological changes illustrate the transition toward low-carbon economies. Attempts are made to decouple economic growth from environmental degradation and to reorient culture from consumerism to sustainability (Worldwatch Institute, 2010).

Overarching global challenges for this transition are fossil fuel dependency, climate change, soil degradation and waste management problems (IPCC, 2007b). Biochar has been suggested to assist in tackling all of these (Lehmann, 2009; Lehmann \& Joseph, 2009) and as such emerges as a new tool on the political radar. 
Biochar production and use with the primary purpose of carbon sequestration can be identified as an innovation ${ }^{32}$ which is broadly defined as a new combination of existing equipment, resources and other inputs (Schumpeter, 1934). The term innovation may refer to new products, processes, markets, supply sources as well as changes to the structural organisation of industries' competitiveness (Schumpeter, 1934) ${ }^{33}$.

Biochar deployment fits into several categories of that definition. It is a new product, unfamiliar to most practitioners who are envisaged to supply feedstock material or to use biochar, for example forestry and agriculture. Pyrolysis as a thermochemical conversion process of biomass is not a novelty as such. Nonetheless, considerable challenges for research, development and demonstration still exist. These include the development of industrial-scale technology and the fine-tuning of pyrolysis plant parameters to optimise the integrated production of biochar and bioenergy (Bridgwater, 2007; Brownsort, 2009; Cetin, et al., 2004; Jones, 2010; Sadhukhan, Gupta, \& Saha, 2008).

Biochar deployment may also open up new markets. These may include commercialisation of various pyrolysis technology designs and their use as a new waste management tool. Pyrolysis technology may also be used to generate green electricity for sale to the national grid and biochar as a marketable soil additive. There is lobbying for acknowledgement of biochar within the UNFCCC framework as a new pathway for carbon sequestration and offsetting (UNCCD, 2008, 2009), but no such recognition exists at this stage (Gaunt \& Cowie, 2009).

Biochar feedstocks can be very diverse. Preferably, existing waste streams are used instead of deliberately created input material (Roberts, Gloy, Joseph, Scott, \& Lehmann, 2010a). It has to be ensured that those existing raw materials are not competing in their use for biochar with potentially more beneficial uses. They must not lead to displacement

\footnotetext{
${ }^{32}$ Schumpeter argues for an analytical distinction between invention and innovation. The term invention describes the discovery or generation of new knowledge which can happen outside the business sphere (e.g. at universities or other research institutions), is not tied to commercialisation (Schumpeter, 1934). Invention as the production of information constitutes a public good (Gomulka, 1990). Innovation describes a social activity and emphasises the intention of commercialisation (Graf, 2006; Schumpeter, 1934). Although several authors emphasise this two-step procedure (e.g. Gomulka, 1990; Zaltman, Duncan, \& Holbek, 1973), the term innovation is often used to include the meaning of invention and refers to the "qualitative change of an economy" (Gomulka, 1990, p. 11) that results from an invention's production and adoption.

${ }^{33}$ For a wider discussion of the field of innovation studies and its relation to Schumpeter's evolutionary approach to economic development see, for example, Fagerberg (2003) and Fagerberg and Verspagen (2009).
} 
effects. Such raw materials need also to be extracted and converted to biochar in an economically and environmentally efficient and effective manner. Biochar produced must have characteristics that match the intended use.

Biochar deployment may have implications for various industries in $\mathrm{NZ}$ as it concerns feedstock supply and use of bioenergy and biochar. Depending on whether research can demonstrate benefits from biochar for NZ and the resulting scale of deployment, repercussions are conceivable for forestry, agriculture and waste management, as well as for the electricity and fertiliser industries.

Uncertainty prevails in many aspects, such as biochar performance in NZ soils (Anderson \& Condron, 2010; Camps-Arbestain, et al., 2010; Clough, et al., 2010) or actual GHG reductions over the whole life cycle (Downie \& Lau, 2010; Gaunt \& Lehmann, 2008; Ibarrola, 2009; Pigneri, 2010; Roberts, et al., 2010a). As illustrated in Chapter Three and Table 11 above (this chapter), many potential benefits and drawbacks of the innovation biochar are still subject to further research.

Innovation studies highlight the importance of science in enabling innovation and its relevance for technological change. Science might not always result in directly measurable innovation in the form of spin offs or spill overs, but it is generally a central part of an economy's knowledge base (Mytelka \& Smith, 2001).

Besides the necessary research, an important driver of innovation is businesses' interest in commercial applications of a new process or product. Entrepreneurship of individuals who pioneer change is performed within a socio-institutional context that may change at considerably lower speed (Schumpeter, 1934).

"Governments are just lacking the willingness to do anything or to really do something about climate change. After 20 years in promoting solar water heating I'm just very disillusioned about the political arena. John Key doesn't think that climate change is happening... So my only expectation or what I hope for in regard to government is that they don't interfere and don't obstruct. Getting the research underway ... is already the best thing that they could have possibly done. So I don't want government to be involved just from my experience with solar 
water heating." (Don Slater, scientist by training, renewable energy project developer)

In other words, economic activity is embedded in social systems (Granovetter, 1973) where peoples' decisions and actions are contingent on one another (Midgley \& Dowling, 1978). The institutional context and the social interactions within it influence and shape economic activity in general and innovative activity in particular $^{34}$ (Granovetter, 1985).

Institutions and policy play a key role in determining the 'if' and 'how' of the evolution of a biochar industry (Damsgaard \& Lyytinen, 1997). As demonstrated in Chapter Four, the main aspects of NZ's institutional framework in regard to biochar are climate change policy and other environmental legislation as well as public funding for biochar research (Hedley, 2010; MfE, 2007; MAF, 2007a; Pigneri \& Hedley, 2008; Winsley, 2007b).

Essential for the explanation of economic development is the role of learning which is an interactive, i.e. socially embedded process (Lundvall, 1996). In the learning process, different kinds of knowledge are transmitted and complement each other ${ }^{35}$. The spread of information and knowledge in social networks is pivotal to the diffusion of innovations. The quality and quantity of interactions and linkages determines the flow of information and the spread of knowledge (Arrow, 1994; Granovetter, 1973). The implications for policy-makers are that they should enable and expand learning capacity by competence building $^{36}$ (Dodgson \& Bessant, 1996; Lundvall, Johnson, Andersen, \& Dalum, 2002).

The entire system comprising the social and cultural context, institutions and organisations, regulation as well as infrastructure in both the tangible and non-tangible sense, is important in driving and shaping local outcomes of policy instruments. That is, the diffusion of a given innovation follows a different pattern in locales with different

\footnotetext{
${ }^{34}$ For further discussion of changes in the social and institutional context, the regulatory environment and economic implications of technological innovations see for example Boyer (1990), Freeman and Perez (1988) and Perez (1983).

${ }^{35}$ Codified knowledge, on the one hand, is knowledge about facts and principles, physical as well as social ones. Tacit knowledge, on the other hand, refers to skills and know-how on a more practical level. It also includes the ability to establish and effectively use the expertise of particular social groups and networks (Lundvall, 1996; Polanyi, 1958, 1966).

${ }^{36}$ While this thesis puts more emphasis on the diffusion of biochar rather than on innovation policy, more detailed information on innovation policy issues and on specific innovation policy instruments can be found in Dodgson and Bessant (1996).
} 
socio-economic and institutional infrastructure, including education systems and government policies ${ }^{37}$ (Granovetter, 1985; Lyytinen \& Damsgaard, 2001). This implies that the same policy instrument may yield a different outcome if implemented under different framework conditions (Lundvall, 1992).

But how exactly does the social context affect the fate of an innovation? What determines adoption or rejection of innovations? A theoretical lens that is used here to shed light on these aspects is the Diffusion of Innovations Theory, outlined in the following section.

\subsection{Diffusion of Innovations Theory}

Diffusion of Innovations Theory contributes a social science perspective, emphasising behavioural and social contextual information. In so doing it contrasts with the neoclassical economic assumption of rational, self-maximising individuals with independently formed preferences. Diffusion research acknowledges the vital role of the social system and its networks ${ }^{38}$.

Most importantly, the theory acknowledges that stakeholders' perceptions of innovations are drivers of diffusion and hence crucial for understanding the diffusion process (Rogers, 1995a). Individual perceptions are derived from subjective evaluation of an innovation, personal experiences and other people's experiences conveyed by interpersonal networks (Rogers, 1995a).

Diffusion is defined as a "process by which an innovation is communicated through certain channels over time among the members of a social system. It is a special type of communication, in that the messages are concerned with new ideas" (Rogers, 1995a, p. 5). Communication as an exchange of information is nothing exclusively attributable to diffusion. The specific feature of diffusion is the "newness" (Rogers, 1995a, p. 6) of the

\footnotetext{
${ }^{37}$ For an in-depth discussion of temporal and spatial aspects of diffusion see Hägerstrand (1966, 1967).

${ }^{38}$ The perspective of diffusion theory was also deemed suited for this study as the largest part of diffusion studies was undertaken in rural sociology. This discipline is concerned with the spread of agricultural innovations in rural communities as well as unintended consequences of these innovations, for example, carcinogenic pesticides (Rogers, 1995a). Increasing awareness of environmental degradation led the discipline to focus on animal, human and environmental health issues and resource conservation (Rogers, 1995a).
} 
idea that is communicated. This newness is associated with uncertainty in that the relative probability of different outcomes of adoption cannot be predicted.

Information exchange can reduce uncertainty, but much information needed to reduce uncertainty about biochar does not yet exist, or cannot be conclusively verified. Such includes the long-term impacts on soil biology or mechanisms by which biochar affects soil GHG emissions (Verheijen, et al., 2009).

Communication channels are the means by which information is exchanged between individuals and can range from mass media to interpersonal channels. The former are more efficient in distributing information widely and quickly while the latter is more persuasive (Rogers, 1995a). In personal networks, some people act as opinion leaders who are able to exert influence on other people's opinion, attitude and behaviour (Katz \& Lazarsfeld, 1955; Valente \& Davis, 1999). The strong association with peers and the importance of opinion leadership for knowledge spread and diffusion of an innovation is also reflected in research participants' comments such as:

"Me and some others we had taken a great interest in New Zealand joining Kyoto. When I say 'we', I mean people thinking like myself. Partly because we do accept that $\mathrm{CO}_{2}$ levels are rising and we do accept that as a prima facie case that that is caused by human action." (Max Purnell, farmer trustee of AGMARDT)

"I'm trying to get it [the scientific background] so that I can use it and can demystify it quickly for my people which are farmers ... I really see that as my role to represent the farming community, land practitioner. Hands in the soil!" (Max Purnell, farmer trustee of AGMARDT)

Adoption of an innovation by some people presents a new situation and a new basis for decision making for those who have not yet adopted the innovation (Granovetter, 1978). Behaviour of individuals is receptive and responsive to other people's behaviour ${ }^{39}$ (Midgley \& Dowling, 1978). Particularly important for persuasion are socio-economic

\footnotetext{
${ }^{39}$ On individual drivers of innovation adoption by consumer see Hirschman (1980) and Wood and Swait (2002). Organisational learning, skill development and knowledge barriers are discussed by Attewell (1992). Adaptive emulation of innovations by businesses and the importance of successful peer firms in promoting further adoption are suggested by Strang and Macy (2001).
} 
similarities between the communicating individuals. One is more likely to adopt an innovation that has already been successfully adopted by a peer who is of similar socioeconomic status, education and beliefs (Rogers \& Shoemaker, 1971; Strang \& Macy, 2001). This is the principle of homophily meaning that exchange of information occurs most frequently between similar (or homophilous) individuals (Lazarsfeld \& Merton, 1954).

A high degree of heterophily can render knowledge transfer ineffective. This may be the case if a technical expert and a layperson talk past each other. Differences in understanding of the technical complexities involved, in underlying beliefs and social norms as well as in education and social status may result in ineffective communication (Rogers, 1995a).

The importance of communication and social networks at various stages of the individual decision-making process is schematically illustrated in Figure 38 below.

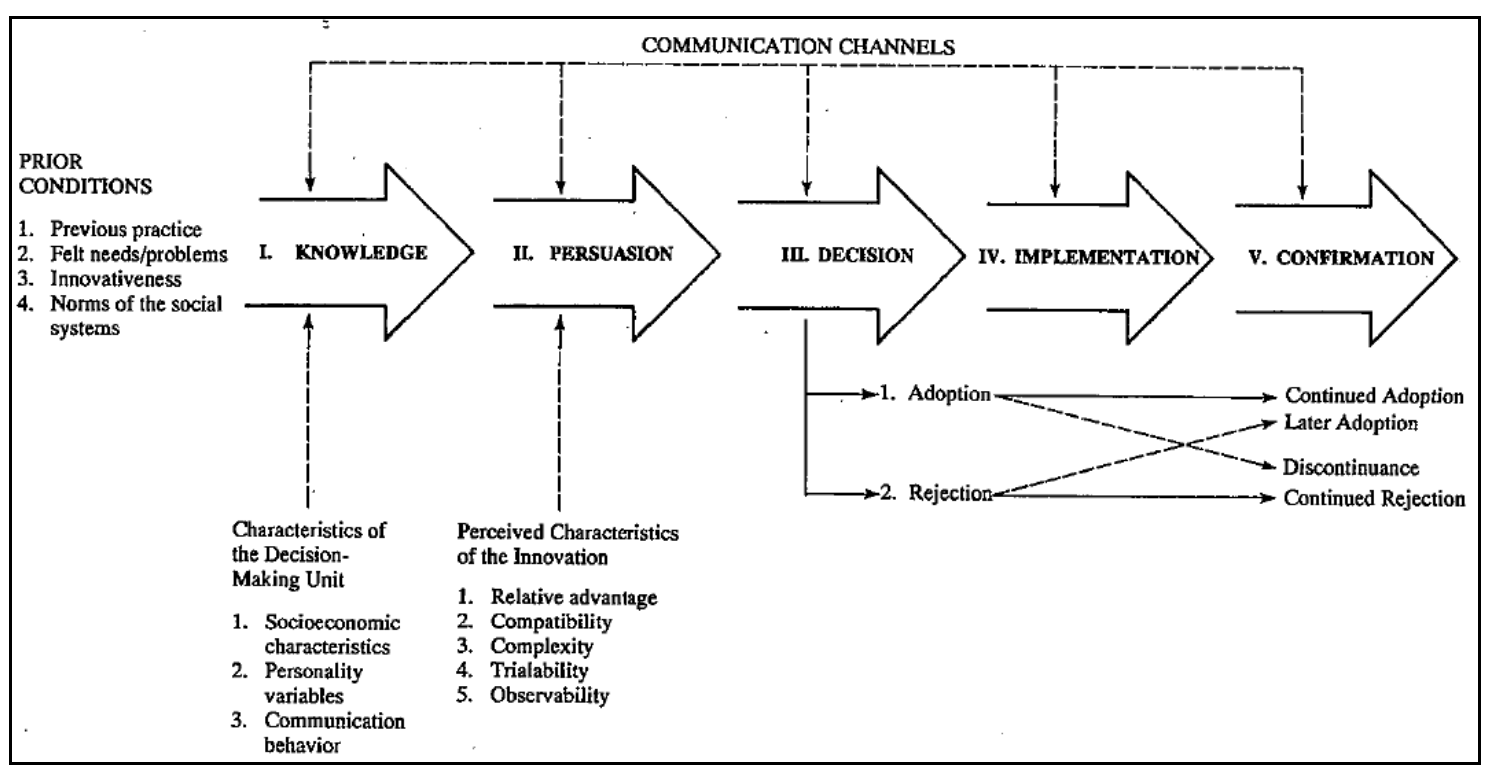

Figure 38: Stages in the innovation-decision process (Rogers, 1995a, p. 163)

The social context shapes the overall pattern of diffusion. Empirical observations by Ryan and Gross (1943) found that actual diffusion patterns diverge from the expected normal distribution function. Frequency of adoption is greater in early stages and lower in later stages than in a normal distribution model. Observed adoption rates are highest at the 
mode and in the two years thereafter (Ryan \& Gross, 1943). This pattern reflects the influence of social context, especially where competition and pressure to adopt are prevalent (Abrahamson, 1991; Abrahamson \& Rosenkopf, 1993; Ryan \& Gross, 1943).

Cumulative adoption rates over time generally follow the pattern of a sigmoid growth curve (Pemberton, 1936; Tarde, 1890). A theoretical model for forecasting the rate of adoption of a product innovation by consumers is the Bass model ${ }^{40}$ (Bass, 1969) presented in Figure 39.

Biochar in NZ can be thought of as being at the very early stages of diffusion. No commercial-scale production or established market for the product exists. Although some NZ companies are producing limited quantities of biochar (as outlined in section 4.3), it is not a main stream product with a firmly established demand on the private market.

Biochar is mainly applied to land in individual back yard trials or on a farm-scale in cooperation with research institutions.

\footnotetext{
${ }^{40}$ For detailed discussion of the Bass model and suggestions for its refinement see Mahajan, Muller and Bass (1990) as well as Mahajan, Muller and Srivastava (1990).
} 


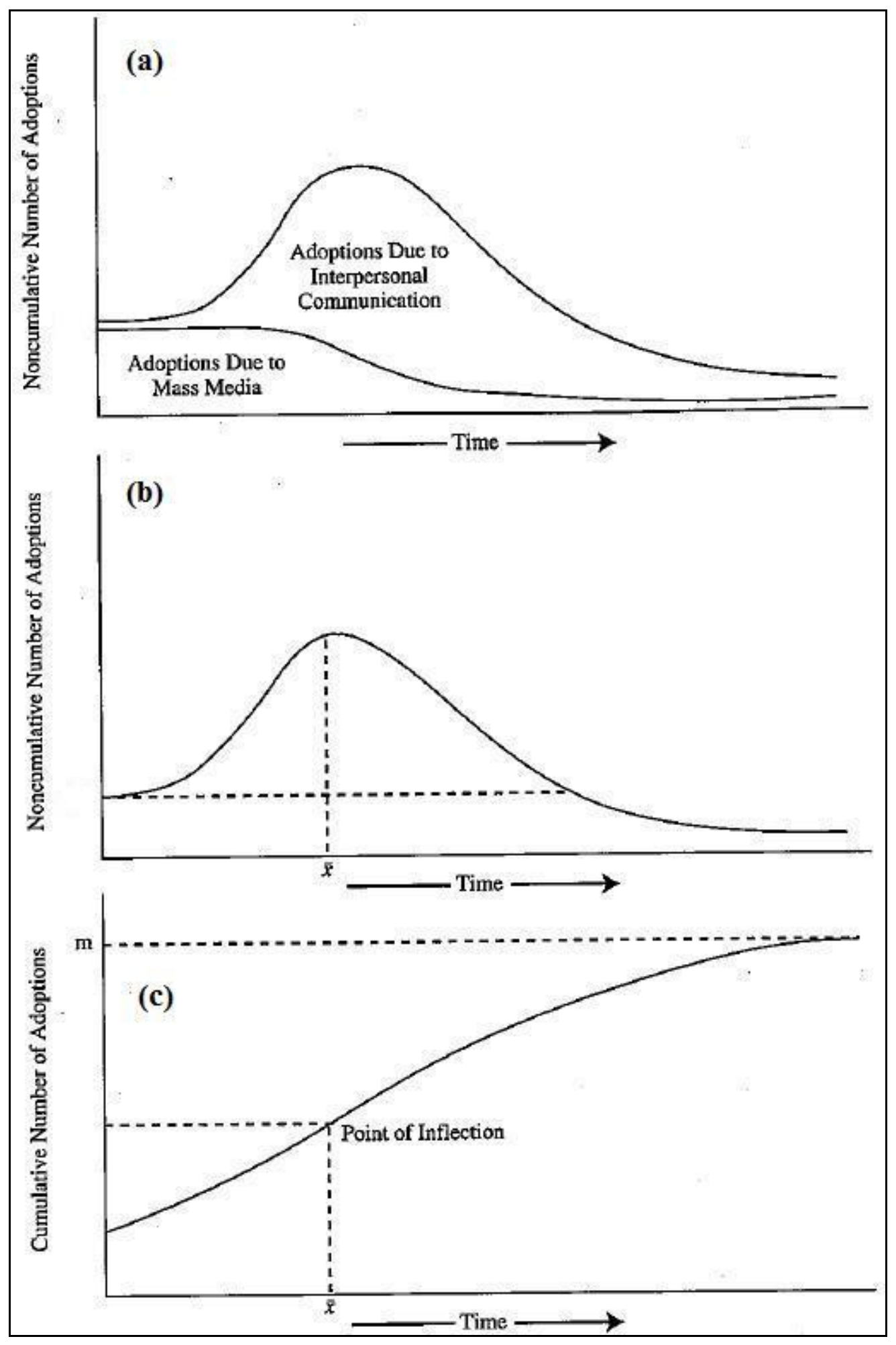

Figure 39: Bass model for forecasting adoption rates (Rogers, 1995a, p. 80)

(a) Adopters per unit of time due to media messages and to interpersonal communication channels, with the latter being more important.

(b) The critical variable is the mean time of adoption $(\overline{\mathrm{x}})$ where an inflection occurs in the diffusion curve.

(c) The S-shaped diffusion curve shows the cumulative number of adopters and is symmetrical around the mean year of adoption. Beyond the inflection point the rate of adoption slows down while the overall number of adopters in a given system continues to increase until the market potential $(\mathrm{m})$ is reached where $100 \%$ of the potential adopters did indeed adopt the innovation (Bass, 1969; Rogers, 1995a). 
The underlying and idealised assumptions of the model are that the market potential $(\mathrm{m})$ is constant, that the diffusion of the innovation in question occurs independently of other innovations, that the innovation itself remains constant over time, that the diffusion occurs independently of marketing strategies such as price change or increased advertising and that there are no restrictions in supply that could limit the rate of adoption $^{41}$ (Bass, 1969).

Consequences of adoption may be positive or negative. Outcomes of adoption can be differentiated into the categories of desirable vs. undesirable, direct vs. indirect, and anticipated vs. unanticipated (Rogers, 1995a). Given the direct and indirect impacts of biochar deployment and the risks and uncertainties associated with them (see for example Table 11 above), policymakers may wish to carefully consider the costs and benefits of each of these impacts.

In the context of externalities, outcomes of adoption can also usefully be classified into public vs. private and costs vs. benefits (Wejnert, 2002). The first category refers to "the impact of an innovation's adoption on entities other than the actor (public consequences) versus that on the actor itself (private consequences)" (Wejnert, 2002, p. 299). The category of costs vs. benefits related to the outcome of an adoption includes "monetary and nonmonetary direct and indirect costs, or risks associated with the adoption of an innovation" (Wejnert, 2002, p. 301).

As policy shapes the framework in which diffusion of innovations takes place, policymakers may wish to evaluate potential outcomes of adoption within the framework of the categories suggested by Rogers (1995a) and Wejnert (2002). An integrated policy approach may further be facilitated by invoking policy criteria, such as distributional equity, environmental effectiveness or dynamic efficiency as described in section 5.2 above. When considering the encouragement or discouragement of the adoption of the innovation biochar, specific environmental policy principles may provide additional guidance. The following section suggests possible criteria and principles that may assist in decision-making under uncertainty.

\footnotetext{
${ }^{41}$ For a critique of these simplifying assumptions see, for example, Coombs, Saviotti and Walsh (1987), Griliches (1957) or Metcalfe (1981, 1988).
} 
Introd | Method | Biochar | Institutions | Theory | Analys \& Disc | Concl

\subsection{Decision-making under Conditions of Risk and Uncertainty}

Decision-making is in many instances not based on full information. Information might not be available or if so, cannot be absorbed and processed in its entirety. In many situations decisions have to be made in the face of uncertainty, risk and ignorance ${ }^{42}$ (Wynne, 1992).

In modern society, risks arise from technology that is increasingly used to provide the amenities of a modern lifestyle (Beck, 1992b; Giddens, 1990, 2009; Perrow, 1984). These technologies are increasingly complex, such as nuclear power or genetic manipulation (Alario, 2000; Beck, 1992b; Matten, 2004). In deploying them, modern society generates its own manufactured risks that result from unwanted side-effects, or negative externalities, and include human health problems and environmental pollution (Beck, 1996; Giddens, 1999). Assigning responsibility and accountability for self-made risks is not straightforward and, as argued by Beck (1988, 1992a, 1992b, 1995, 1996), is often deliberately obscured. The risk society is characterised by 'organized irresponsibility' where the following questions remain unanswered:

- Who determines how harmful are activities or substances?

- What side-effects do they entail?

- What level of risk and uncertainty is acceptable?

- At what point is their safety sufficiently proven $?^{43}$

- Is compensation for harm to be paid, and if so by whom and to whom?

- Which forms of future control or regulation are appropriate?

\footnotetext{
${ }^{42}$ Risk refers to a situation where the range of outcomes is known and probabilities can be assigned to them. The term uncertainty is used where the range of outcomes is known but probabilities of occurrence are unknown. Indeterminacy describes a lack of knowledge regarding outcomes or how a system works. That is, causal chains or networks cannot be fully determined. Ignorance is characterised by unknown unknowns, i.e. we do not know what we do not know, usually because of highly complex systems and interactions (Wynne, 1992).

${ }^{43}$ Compounding problems are scientific uncertainty as well as contested and contesting knowledge claims and probabilities.
} 
Risks have both a subjective and an objective dimension (Hansson, 2010; Zinn \& TaylorGooby, 2006). Risks are in part socially constructed, not least by the very institutions which are meant to manage and control them. It follows that "the magnitude of the physical risks is therefore a direct function of the quality of social relations and processes" (Beck, 1992b, p. 4). Consequently, the primary source of risk is "that of social dependency upon institutions and actors who may well be - and arguably are increasingly - alien, obscure and inaccessible to most people affected by the risks in question" (Beck, 1992b, p. 4).

A telling example cited in Beck (1992b) is the rejection by the British government of farm workers' claims that a particular herbicide caused harm to environmental and human health. The government commissioned the Pesticides Advisory Committee to investigate. It concluded that there was no danger. After public concerns were voiced repeatedly, the Committee returned to the issue and qualified its conclusion by saying that the scientific literature did not suggest any harmful effect so long as production and use of the herbicide occurred under correct conditions. Farm workers, on the other hand, had the practical insight to know that these 'correct' conditions were hardly ever present. Instructions for use were lost, appropriate spraying equipment unavailable, protective clothing not worn and adverse weather conditions ignored in order to press ahead with the spraying.

While the risks cited in the example above may be different from those in relation to biochar, the constellation may nonetheless be similar. Practitioners' experience and knowledge may render the laboratory scientific understanding inadequate. The example also emphasises the sensitivity of findings to specific conditions and assumptions, making extrapolation from one locality to another highly questionable, which is applicable to biochar, too. The issue highlights the need for 'reflexive learning' by institutions (Beck, Giddens, \& Lash, 1994); calling for the acknowledgement of the benefits of knowledge held by groups other than scientists (Blaikie, 1996).

The existence and persistence of risk, uncertainty and ignorance must be explicitly acknowledged. While the scientific knowledge base is growing, uncertainties and gaps remain at the boundaries of knowledge (O'Riordan \& Rayner, 1991). Both science and policy must proceed with due humility when faced with highly complex systems and 
systems behaviour. Paradoxically, they must not be paralysed but rather have the audacity to make decisions in the face of ever-present uncertainties (Dovers \& Handmer, 1992).

How can institutions or, more specifically, environmental policy deal with such situations? What guidance can be suggested? On what premises can decision-making be based?

Understanding and managing the complex interactions of biophysical and socioeconomic systems over time and space requires far-sighted and holistic approaches. The following sections suggest the Precautionary Principle and the sustainability principle as guidance for environmental policy.

\subsubsection{Precautionary Principle}

The Precautionary Principle is defined in the United Nations' Rio Declaration adopted at the Earth Summit in $1992^{44}$ as follows: "Where there are threats of serious or irreversible damage, lack of full scientific certainty shall not be used as a reason for postponing costeffective measures to prevent environmental degradation" (United Nations Environment Programme (UNEP), 1992). The Principle is based on the premise "that prevention is better than cure" (Mayer \& Stirling, 2002, p. 60). It is invoked by authorities to help resolve the dilemma of the need for decision-making under conditions of scientific uncertainty (Graham, 2001).

Uncertainty may render decisions incorrect in two ways: false-negative (a technology is deemed safe but it is not) or false-positive (a technology is deemed unsafe but is in fact safe) (Page, 1978). A false-negative decision results in potentially serious and long-term or irreversible harm. A false-positive decision, on the other hand, entails foregone benefits of the technology to the environment, health or economy. Importantly, a false-

\footnotetext{
${ }^{44}$ For an analysis of this and other examples of the rhetoric of precaution in various international agreements and the underlying theoretical basis of the principle that is revealed through them see Adams (2002). Additional decision rules and refinements to the general framework of the Precautionary Principle are put forward by Graham (2001), Keeney and von Winterfeldt (2001) and Kheifets, Hester and Banerjee (2001) while Lewens (2010) argues in strong and unconditional support for the principle in the context of a critical discussion of progress and its meaning.
} 
negative error results in much larger or irreversible damage than a false-positive error (foregone benefits), making a strong case for a precautionary approach in order to reduce false-negative errors (Page, 1978).

The Precautionary Principle is valued for its protective function in that it may require action to avoid the risk of serious or irreversible harm. It also builds trust in and credibility of regulatory public institutions that are expected to deal with risks. By applying the Precautionary Principle, policymakers can demonstrate interest in public concerns and be seen to take the initiative (i.e. precautionary action) where science cannot conclusively demonstrate the absence of risks. Thereby the Precautionary Principle also serves to strengthen the public's feeling of protection (Burgess, 2002; Hom, Plaza, Feijóo, \& Palmén, 2009).

\subsubsection{Sustainability Principle}

Sustainability includes the three dimensions of environment, society and economy. The environment provides a multitude of goods and services which cannot be substituted by human-made capital. The notion of non-substitutability of manufactured capital for natural capital is known as strong sustainability. That is, depletion of natural resources and natural systems cannot be compensated for by increased accumulation of manufactured capital, even if the overall value of the capital stock, consisting of natural, social, cultural and manufactured or human-made capital, is maintained (Ekins, Simon, Deutsch, Folke, \& De Groot, 2003). In contrast, weak sustainability assumes substitutability provided the overall capital stock - in monetary terms - is maintained ${ }^{45}$ (Daly \& Farley, 2004).

The notion of strong sustainability conceptualises the environment as the very basis of any human activity. The natural environment provides for our basic needs, such as those for clean air and water as well as food, shelter and clothing (Maslow, 1943). Society is

\footnotetext{
${ }^{45}$ The concept of sustainability, its underlying anthropocentric assumptions and its usefulness in decisionmaking processes is discussed in further depth by Ehrenfeld (2005) and Newton and Freyfogle (2005a, 2005b). It is suggested that an updated version of Aldo Leopold's concept of 'land health' (Leopold, 1949) may be a more helpful in enhancing conservation of natural resources.
} 
dependent on and therefore shown as embedded in the natural environment (see Figure 40). The economy in turn is a subsection of society and reliant on the environment through use and transformation of natural resources (Daly \& Farley, 2004).

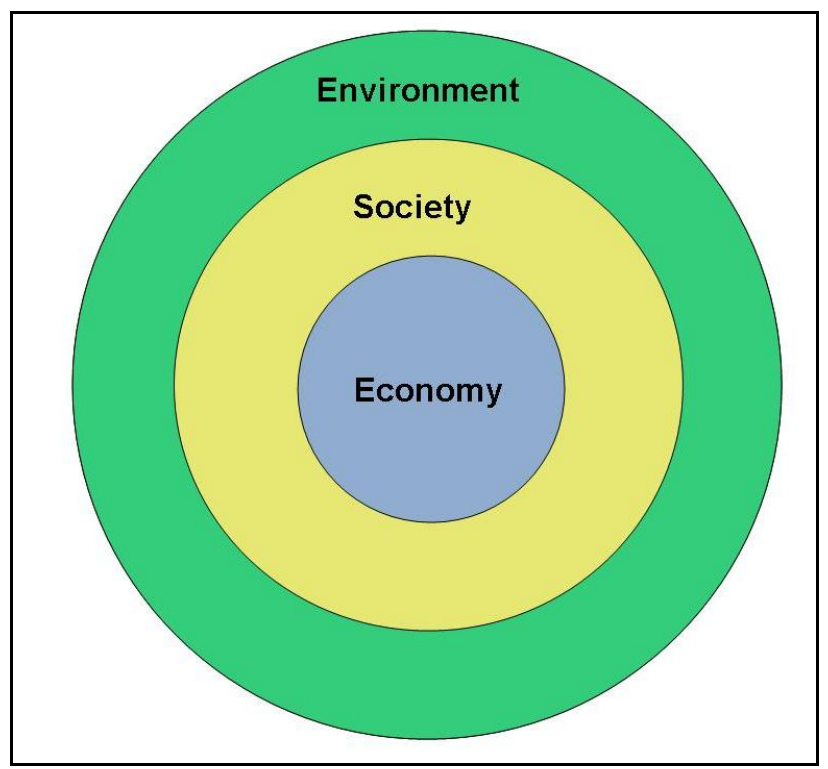

Figure 40: Schematic representation of the concept of strong sustainability (own diagram based on theory presented in Ekins, et al., 2003)

The concept of sustainability and more precisely of sustainable development includes a future-regarding aspect (Brown Weiss, 1989) in that it requires us to sustain natural resources over time in a quantity and quality that will enable future generations to provide for their needs (World Commission on Environment and Development (WCED), 1987). This implies using natural resources in a way that is consistent with the "carrying capacity of supporting ecosystems" (International Union for Conservation of Nature (IUCN), United Nations Environment Programme (UNEP), \& World Wide Fund for Nature (WWF), 1991).

When considering in whose interests decisions are made, it becomes clear that only those with a voice are being heard. This means that future generations as well as the non-human world are likely to being excluded or at least disadvantaged (Brown Weiss, 1989; Page, 1997) unless policy measures specifically provide for recognition of their interests. 
Pure time preference and discounting prove detrimental to the interests of future generations as the present is considered to be of the highest value (Brennan, 1995; Lind, 1995). Achieving static efficiency may thus not imply the simultaneous realisation of dynamic efficiency. In this context ethical, cultural and social criteria are important in determining the allocation of environmental costs and benefits. While a particular policy, for example, may maximise benefits to the largest proportion of the present generation, the long-term result, becoming apparent in 50 to 100 years' time, may very well be detrimental.

Environmental goods and services are particularly prone to inefficient allocation because most of them are not traded in a market and it is not desirable to do so. It seems that only by way of commercialisation of nature, is its value is taken into account, although in an anthropocentric sense only. Moving beyond a purely instrumental valuation toward an appreciation of intrinsic environmental values is needed to overcome decision-making that aims to maximise short-term economic gains.

\subsection{Institutions and Public Participation}

Following from the above, the social dependency of risks as well as trust in and credibility of institutions are major factors in public acceptance of policy decisions. If this is to be taken seriously, any policy decision-making, including environmental issues, should involve participatory processes; especially when dealing with highly technical and potentially hazardous technologies (Beck, 1992b; Hom, et al., 2009).

Democratic procedures are required to overcome purely technocratic risk management and create transparent and inclusive decision-making processes (Hom, et al., 2009; UNESCAP, 2007). This suggests a democratic imperative for including various stakeholders in environmental policymaking. Laird particularly argues "that ordinary citizens both have a stake in the outcomes of such policy-making and have important views and insights to contribute to it" (Laird, 1993, p. 341). 
If citizens are to express their preferences for policies in a truly democratic way, they must be knowledgeable about the consequences of their choices. An uninformed choice is not an expression of democracy (UNCESCAP, 2007). Contrary to the general public, scientific experts traditionally enjoy a privileged position as policy advisors (Blaikie, 1996). Laird (1993) emphasises the importance of an independent and open mind of participants when evaluating information about scientific and technological policy issues provided by experts. While expert knowledge is vital for informed decision-making, it is equally important to understand the limits of scientific knowledge and the values with which scientific statements are inevitably infused. The informed public must maintain its ability to question and critique asserted facts as well as the problem definition itself (Laird, 1993).

In combination with the above-mentioned importance of risk perception, this calls for a shift from purely technocratic to participatory risk management (Hom, et al., 2009). Eliciting and incorporating various stakeholder perspectives in the decision-making process is crucial (Young, et al., 1996). A policy decision in regard to biochar deployment for climate change mitigation must take account of both inherent physical risks and risks as perceived by stakeholders. As Chapter Two has outlined, the methods employed in this study were chosen so as to provide for the inclusion of individual perspectives and perceptions. The following chapter analyses and discusses stakeholder views on biochar based on the empirical material gathered for this research. 
Introd | Method | Biochar | Institutions | Theory | Analys\&Disc | Concl

\section{Stakeholder Perspectives on Biochar: Analysis and Discussion of Empirical Material}

As set out in Chapter One, the main questions that this chapter seeks to answer are:

- What do stakeholders identify as positives, negatives and unknowns about biochar?

- What does the literature suggest in regard to the issues identified by stakeholders?

- What public policy approach can be suggested based on stakeholder concerns and the literature review? Should biochar deployment in NZ be encouraged or discouraged, and under what conditions?

The themes and issues that emerged from the empirical material are put in the context of academic literature so as to answer the second question. The third question is answered by deriving suggestions for the role of public policy in relation to the issues identified. The chapter concludes with suggestions of possible policy approaches to address these issues.

The agriculture and forestry/wood processing surveys yielded 25 and eight responses respectively, equating to a response rate of $0.64 \%$ and $0.48 \%{ }^{46}$. As these numbers are below the general requirement of a sample size of 30, no statistical analysis is presented in this chapter. As described in Chapter Two, it was not the aim to obtain a statistically significant sample size. Rather, the emphasis is on the qualitative survey data gathered through open-ended questions.

Not all survey respondents and interview participants in the stakeholder group of agriculture identified as 'organic' in the sense of complying with a specific set of substances and practices permitted by a certifying authority ${ }^{47}$. For this reason, participants' statements in this chapter are not labelled 'organic agriculture survey

\footnotetext{
46 These response rates are calculated based on the membership numbers of organisations that published the survey request in a news item. The membership numbers indicate an upper range of the potential sample size.

${ }^{47}$ A more detailed description of this and other issues of empirical data gathering can be found in Chapter Two.
} 
respondent' but 'agriculture survey respondent'. It is acknowledged that the agricultural community reflected here uses farming practices that provide an alternative to conventional practices. All participants utilise biological methods with the aim to minimise the use of synthetic fertiliser and other chemical inputs.

The main themes that emerged from the analysis of the interview material and qualitative survey answers are presented in the following sections. Six major themes have been identified. Sections 6.1 to 6.6 present these themes and their subcategories.

\subsection{The Big Picture}

Participants embedded the debate pro and contra biochar into a broader picture, concerning not only NZ-specific, but international issues. The first emerging theme presented here is termed the 'big picture'. It includes issues that relate to our current 'way of doing things' on a global societal level. It includes some philosophical sub-points and wider concerns about the dimensions and interactions of the human and the non-human world.

\subsubsection{Holistic and long-term View}

A holistic and long-term view and the need for systems thinking were diagnosed by respondents as crucial for dealing with environmental, social and economic issues. Participants identified the wider background in challenges to global society posed by climate change, an increasing world population and ecosystem degradation and exploitation for short-term economic gains. Many survey respondents and interviewees diagnosed a lack of holistic thinking. They deplored people's disregard of repercussions of human activities on a full systems scale. These sorts of reflections are illustrated by comments such as the following.

"I think these things are always complicated and you need to know the whole, you need a systems approach. So what is the whole, what is the effect on the local 
ecosystem? And until you know that you can't answer that question [whether biochar deployment could be of benefit or disbenefit]." (David Wright, Secretary, Bio Dynamic Farming and Gardening Association in New Zealand, Inc.)

"The problem is that energy is seen separate from land, food, water etc. There is no holistic perspective." (forestry interview participant)

Considering the big picture, participants also emphasis the need to re-think the way we treat the environment in terms of using its resources to provide for our needs. In fact, we do not only provide for our needs but even more so for our wants, resulting in serious resource depletion. Participants called for a change in practices and a will to tackle the cause rather than merely the symptoms of environmental problems. Some people working in the primary sector are concerned that there is little hope that environmental issues will be solved unless a fundamental change in practices occurs. Two participants expressed this in the following way.

"It may be that biochar has agronomic benefits but we should start at a different point and stop putting shitloads of fertiliser, pesticides and what not on our land and don't think that we can heal all that by applying yet another substance." (forestry interview participant)

"We have done so many band aids already and usually just messed it up even more. Will biochar be another asbestos?" (Steffan Browning, Co-chair and Spokesperson, Soil and Health Association of NZ)

Interviewees and survey respondents also raised concerns in the context of ever increasing pressure on land and soil productivity. The 'limits to growth debate' shines through the comments of many participants when pondering natural resources as the basis for our very survival. Essential questions are to what use we put limited natural resources and whether this is the best use or whether different allocations may be more socially efficient. These considerations are illustrated in the following quotes.

"Even second generation biofuels that don 't displace food crops still need the same land to grow on. The whole system cannot continue to grow! There are too 
many people and always competition for land and resources." (forestry interview participant).

"Generally, there is the issue of land use: available productive land is limited and land use change is dynamic, and related to demand for forest versus agricultural products. The real problem is population growth but no one talks about that in Copenhagen." (Dean Satchell, forester)

“We will have 'peak soil' as much as we have peak oil." (Vicki Buck, CarbonScape)

\subsubsection{Green or Greenback?}

A major concern of research participants was the question for what reasons biochar research and deployment are pursued. Riding on the green economy wave and capitalising on environmental issues was perceived as pursuing an honourable goal for the wrong reason. That is, the main motivation being economic profit rather than genuine environmental concern. Fears about a techno-fix that serves corporate interests by generating intellectual property rights and patent options were aired in this context. The following comments reflect the underlying question whether biochar is pursued to become a more sustainable society or whether it is an extension of the industrial paradigm under which biochar presents an economic opportunity.

"I see the whole genetic engineering issue as an analogy to biochar. If they would be really interested in getting the best of the genes or making the most of them, then they would massively fund seed banks that aim to maintain our species diversity by keeping all the old varieties alive. But no, they put money into research on engineering new hybrids and manipulating their genes and selling these as the solution. And why do they do it? Because they can make money out of it!" (Max Purnell, farmer trustee of AGMARDT) 
"I am fascinated by how rapidly the government and universities have embraced this limited technology of questionable sustainability and value; seems like another 'quick fix' from a research community desperate to create patents." (agriculture survey respondent)

"The biggest scam yet to emerge." (forestry interview participant)

Asked about their general interest in biochar, the 25 agriculture survey respondents articulated highly diverse perspectives. On the one hand, the need for and usefulness of biochar was questioned. On the other hand, biochar was perceived as having potential to help mitigate climate change while improving soil fertility and do so sustainably.

A selection of answers to the question 'what interests you about biochar?' is provided below so as to reflect the range of views both sceptical and supportive.

"How the greed for Intellectual Property moves faster than the necessary knowledge/research."

"Misuse of climate change issue for poorly understood entrepreneurial technology."

"How the industrial paradigm is ever pervasive."

"Biochar is just a gimmick for people to make money out of sustainability."

"A possible method to increase soil carbon utilising local waste wood from prunings."

"A self sustaining soil fertility product that can be made on farm, hence low carbon footprint."

"Primarily climate change, with secondary interest in the possibility of carbon negative heat and power to justify carbon sequestration." 
Introd | Method | Biochar | Institutions | Theory | Analys\&Disc | Concl

"Pre-European practice for improvement of soil structure and biological fertility."

"Fertilising and enhancing the soil organically as in ancient times"

\subsection{Environmental Sustainability}

Sustainability includes the three dimensions of environment, society and economy, and in $\mathrm{NZ}$ also the cultural dimension. As outlined in Chapter Five, the notion of strong sustainability conceptualises society and the economy as dependent on the natural environment (Daly \& Farley, 2004). Natural capital provides unique benefits which cannot be substituted for by human-made capital (Ekins, et al., 2003).

The concept of sustainability also includes equity considerations - intragenerational, intergenerational and between the human and the non-human world (Brown Weiss, 1989; Page, 1997).

An interview participant working in the agricultural sector expressed his understanding of sustainability the following way:

"If you ask me what I understand under 'sustainability' I'd say that I care about my grandchildren and their children and I want my great great grandchildrenand hopefully many more generations - to be able to live here and to live a good life in a world where natural resources are available to them and are not depleted. So yeah, that's probably not the most academic definition but it's what sustainability means to me. I can just look two generations into the future, my children and grand children, they matter most to me. Beyond that it's difficult to grasp but we need to have a long-term view, especially in policy." (Max Purnell, farmer trustee of AGMARDT)

The following sections focus on the environmental dimension of sustainability because biochar technology is concerned with the production and transformation of biomass as a 
natural resource. An important part of any potential future biochar deployment will be the feedstock sourcing. This was a major concern of stakeholders whose thoughts on availability and different types of potential feedstocks are presented in the following.

\title{
6.2.1 Feedstock Potential
}

This section focuses on sustainability considerations about biochar feedstocks. Economic aspects of various feedstocks are explored in section 6.4.

The farming community was mainly concerned about on-farm feedstock sourcing because it was felt that biochar was often promoted in the context of vast amounts of agricultural waste that had no other use and would be available for biochar production. Some potentially available feedstocks on-farm as suggested by agriculture survey respondents are presented later in this section. However, the question asked what kind of biomass would potentially be available for biochar production. It did not ask about the current use of this biomass and whether it would be diverted from this use. Neither beef and sheep farmers nor horticulturalists identified large quantities of biomass that would not be put to other uses. Within the stakeholder group of agriculture, eight out of 15 interview participants emphasised that large quantities of spare biomass were simply not existent in agricultural operations ${ }^{48}$. The gist of the matter is summarised by an interviewee working in the agricultural sector in the following way.

\begin{abstract}
"To me this whole feedstock issue is really the elephant in the room. There is just no such thing as 'waste' on a farm." (Charles Merfield, horticultural researcher and consultant)
\end{abstract}

This was mainly attributed to existing agricultural practices. Direct drilling, for example, requires a continuous soil cover with crop residues (Merfield, 2008). Another practice is

\footnotetext{
${ }^{48}$ A specific question about waste biomass availability on-farm was not part of the survey. However, the question 'which kind(s) of biomass would you use or are you using as a feedstock and where would you source it from?' was included. Fifteen survey respondents identified own or neighbours' resources that they could be using as biochar feedstock. These include tree prunings, grape skins, stalks and winery sludge, orchard prunings, reject fruit, grass clipping and wheat and linseed stubble. Five respondents emphasised that they would use any spare biomass for composting rather than for biochar.
} 
green manuring where cover crops are being incorporated into the soil in situ. Not least, composting is a well-established and cost-effective practice (Harris \& Hill, 2007). This illustrates that several pathways of biomass utilisation are already established and widely used. Participants emphasised that these techniques are effective, yet simple. The following statement reflects the view of many participants by summarising:

"If I had a lot of spare biomass anywhere in the vicinity of me I'd simply be composting it and getting a result." (Max Purnell, farmer trustee of AGMARDT)

In this context, biochar may simply be another amendment or method among many alternatives and these alternatives might be more effective in many aspects such as cost, energy, yields, ease of handling or familiarity with the method. The comment also illustrates the issues highlighted in the Theory of Diffusion of Innovation (Chapter Five). An individual's experience with and perception of an innovation are important in determining the diffusion process. Individual perception is in turn shaped by the social context in which information is exchanged. Uncertainty inherent in any decision-making about adoption or rejection of an innovation can be reduced through such information exchange (Rogers, 1995a). The comment above reflects the higher certainty attached to the established practice of composting than to biochar land application in terms of agronomic benefit. Further, the participant's fellow members within the stakeholder group of agriculturalists use compost rather than biochar. Long-term familiarity with the technique and widespread use in the social group relevant to the participant create a bias toward the familiar in the initial stages of diffusion of an innovation (Rogers, 1995a).

This is also reflected in participants' frequent emphasis that practices to accumulate soil carbon and maintain or restore nutrient levels already exist and that they are deployed successfully. Participants cited examples such as cover cropping, green manuring, composting as well as land management techniques, e.g. rotations with $\mathrm{N}$-fixing legumes and adequate grazing management, to enhance soil carbon levels and plant nutrient availability.

Evidence in the literature suggests that the use of these and other techniques, helps to accumulate soil carbon as well as to mitigate $\mathrm{CO}_{2}, \mathrm{CH}_{4}$ and $\mathrm{N}_{2} \mathrm{O}$ emissions in the agricultural sector (Johnson, et al., 2007; Smith, et al., 2007). Participants stressed the 
importance of these methods not only for soil carbon accumulation but for a holistic approach to agricultural land management. Closed loop systems where biomass is generated and used on-farm, thereby retaining nutrients and carbon in an on-site cycle, were the preferred option of all agricultural stakeholders. This may be illustrated in the following quotes.

"Single focused carbon issues miss the point. A holistic natural systems approach restoring soil fertility using closed systems should be the aim not techno quick fix band-aids." (agriculture survey respondent)

"If you import organic matter, you deplete the organic matter where you source it from. So terra preta would be something like 'robbing Peter to pay Paul'. It all needs to be within the same system" (Charles Merfield, horticultural researcher and consultant)

Notwithstanding such concerns, some agricultural stakeholders as well as academics identified the option of purpose-grown feedstock on-farm. The following thought experiment reflects on how sustainability could be merged with dedicated biochar feedstock production.

"The other one I'm thinking of is where perhaps trees or bush, bushes could be grown to produce wood that's then charred and then added to your productive areas. So you'd have an amenity or bush area which is also producing some fertility for the productive areas. I think there is a case for that ... The similarity is making compost where you have an area that you're just taking grass from ... to make compost to use on your highly productive area ... To me, I see that as a similarity and it possibly is sustainable." (Seager Mason, Technical Director, BioGro)

The option of small-scale on-farm feedstock and biochar production using a simple onfarm unit or a mobile pyrolysis plant is also contemplated by Leo Condron as in the deliberations below. 
"Say, on a dairy farm where you would have an area, there are always areas on farms that are not very productive for some reason, whether because they are in awkward places or whatever. In those areas, you could set aside some land and actually growing a woody crop for char, willow for example” (Leo Condron, Professor of Biogeochemistry, Bio-Protection Research Centre, Lincoln University)

Agriculture survey responses support the notion of a rather small-scale on-farm system where feedstock is sourced on-site. When asked for potentially available feedstocks, respondents identified exclusively biomass sources generated from own operational activities. It was emphasised that the first choice would be waste biomass. Potential feedstocks identified from own operations are orchard and vineyard prunings where participants noted that the absence of copper and chlorine contaminants would need to be demonstrated first.

Moving from the unit of a single agricultural operation to a country-wide context, caution has been urged so as to not embrace large-scale land-use changes for purpose-grown bioenergy and biochar crops. With an established production forestry in the country, participants were concerned about further expansion of exotic plantation forests. Studies in NZ found a decrease in soil carbon levels when pasture was converted to pine plantation (Beets, et al., 2002; Oliver, et al., 2004; Parfitt, Percival, Dahlgren, \& Hill, 1997; Scott, Tate, Ford-Robertson, Giltrap, \& Smith, 1999; Tate, et al., 2004). While soil carbon loss may be cancelled out by pine litter accumulation, other observed conversion effects are soil acidification and decreased soil nitrogen levels (Parfitt, et al., 1997). Concerns about adverse impacts of land-use change are highlighted by policymakers in comments such as the following.

"If this land use shifted, for example by land being cleared of indigenous forests and turned it into a monoculture to produce biochar that would be a major environmental downside. It is, therefore, important that biochar production uses land sustainably - this should be easy to achieve in New Zealand where we have a lot of marginal land that could be used, and where our indigenous forests are protected." (Peter Winsley, formerly MAF, now MED) 
Cynically, participants considered this situation as already being present as pointed out by a MAF policy analyst.

"Let's face it: we have that already. All the radiata pine forests are large monocultures." (Gerard Horgan, MAF)

In the context of NZ plantation forestry, removal of residues that diverts biomass and associated carbon and nutrients was of concern to participants from the agricultural sector and is reflected in the following statement.

"If the slash on hills is removed, it also removes the carbon and the nutrients in there and hence depletes the soil. Pines and eucalypt are already mining our soils anyway. Moreover, if we did produce biochar from the slash it would most likely not being put back in the same spot from where the slash was taken." (agriculture survey respondent)

Participants from the forestry sector, on the other hand, did not deem nutrient removal to be a problem because of the generally low nutrient content of wood. This fact notwithstanding, the literature suggests an adverse impact on soil organic carbon levels and overall soil quality when forestry residues are continuously removed (Brandão, Milà $i$ Canals, \& Clift, 2010; Schlamadinger, Spitzer, Kohlmaier, \& Lüdeke, 1995; Smolander, Levula, \& Kitunen, 2008). Comparisons between different harvesting intensities showed reduced nutrient input to soils, lower pools of exchangeable $\mathrm{K}, \mathrm{Ca}, \mathrm{Mg}, \mathrm{Mn}$ and $\mathrm{Zn}$, lower effective cation exchange capacity per unit area as well as an acidifying effect on the soil in situations where logging residues had been extracted (Olsson, Bengtsson, \& Lundkvist, 1996; Smolander, et al., 2008). Additionally, residue recovery alters soil moisture and temperature due to the physical protection provided by the residues being removed (Smolander, et al., 2008).

Five out of eight forestry and wood processing survey respondents stated that their residues are entirely or mostly left on site to rot. They commented that smaller branches are left across the harvested area so as to minimise erosion and retain nutrients on-site. Extraction of larger pieces would become economically feasible at increased pulp log prices and low transport cost. Otherwise, residues would be stacked up in slash piles and 
left on skid sites. This would come at the risk of skid instability and stream obstruction if the amounts of accumulated residues are very large. Forestry survey respondents indicated that the forestry industry could be interested in removal of residues from a risk mitigation point of view rather than only from a carbon sequestration point of view. All forestry stakeholders identified the use of residues as a biochar feedstock as a potential means of accruing value from an otherwise unused or low-value resource.

Agriculture survey respondents identified potentially available biomass in the form of wheat and linseed stubble, grass clippings, grain straw, timber waste from trees harvested for firewood, hops bines and polythene twine, unbleached cardboard, orchard and other tree prunings, grape vine prunings as well as grape skins, stalks, seeds and winery sludge. Additionally, it was suggested to use invasive species, particularly wilding pines.

The use of pyrolysis as a tool in invasive species management was also suggested by Graeme Woodhouse of the Environmental Non-Government Organisation (ENGO) TerraNature. He had previously explored the option of pyrolysing poplars, willows and other non-native trees in areas of native habitat restoration where reinstatement of the historic landscape is desired. He also points out that these non-native trees would provide a temporary feedstock only as he hopes that they will all be finally removed at some point. Graeme identified other biomass as available, e.g. from weed control and removal of dead native vegetation shaded or crowded out when restored large trees become established. The biochar produced would be returned to the soil carbon sink.

An academic participant further suggested exploring the option of integrating pyrolysis systems on a municipal level for greenwaste management. Willow clearing along rivers and in other areas where native habitat is restored is under council responsibility. Pyrolysis was identified an option to manage such greenwaste streams, particularly in situations where burning is prohibited and the alternative of landfilling incurs a tipping fee. When pondering over pyrolysis applications on a local government level, Jim Jones, Professor at Massey University, described the following setting.

"I just drove past an area yesterday which is being returned to natural swamp which was covered in willow until about ten years. They've gone through and killed off all this willow and all the weeds and the natural swamp grass is back- 
growing and you can see that in time it's going to look like a real natural swamp of the original appearance. So willow clearing is something councils are into ... Burning it off is allowed but because the general public is starting to be restricted on what they can do in their own homes while you still got councils burning things off as well as some orchardists when they replace old varieties with new varieties, they basically stockpile and burn. And so there is certainly in some places in NZ some animosity between the general public and these groups who do the burning when one group isn't allowed and other groups are." (Jim Jones, Professor of Biochar and Bioenergy Pyrolysis Engineering, NZ Biochar Research Centre, Massey University)

In conclusion, the environmental impacts of biochar deployment in terms of feedstock procurement could be positive or negative, depending on scale of deployment and type of feedstock. Potentially negative aspects include nutrient removal or adverse impacts on biodiversity if exotic plant species are cultivated as purpose-grown feedstock on a large scale. On the other hand, using invasive plant species that are cleared for restoration of native habitat may prove to be a sustainable pathway. In any case, competing uses of biomass are to be considered. Established techniques such as composting, mulching, green manuring and other in situ uses are likely to enjoy higher familiarity and acceptance among agricultural practitioners. Comparative studies that evaluate the carbon mitigation benefit provided by these techniques versus biochar land application are needed to enable informed decision-making. It needs to be clarified whether replacing the aforementioned current practices with biochar deployment would yield any significant increase in GHG abatement.

Feedstock considerations other than environmentally-related ones are discussed in section 6.4 below. The subsequent section investigates energy and GHG life cycle issues of biochar production and utilisation. 
Introd | Method | Biochar | Institutions | Theory | Analys\&Disc | Concl

\subsubsection{Greenhouse Gas and Energy Life Cycle Assessment}

The previous section examined the issue of feedstock availability independently from carbon sequestration. To evaluate the environmental sustainability of biochar it is vital to apply an integrated approach that assesses the net energy and GHG performance of biochar over its entire life cycle.

Participants across all stakeholder groups stressed the need of case-specific life cycle assessments (LCA) as crucial for informed decision-making. Participants questioned whether LCA would show a net benefit of biochar production and utilisation in terms of energy as well as GHG. They suspected biochar to be a detour for what could be achieved more efficiently with existing techniques that use the biomass in situ and do not require time and energy for transport, conversion, handling and spreading of biomass and biochar.

Participants' need for information did not only concern biochar LCA in isolation but also a comparison with existing practices that aim to deliver soil carbon accrual. Survey respondents frequently articulated the need for such comparative studies of biochar with the use of compost or mulch. A comprehensive appraisal of biochar versus existing practices in relation to their impact on soil carbon storage, humus levels and cation exchange capacity, as well as technical feasibility and financial viability, was seen as pivotal.

It was also emphasised that such LCA would be highly case-sensitive and that findings would not be generalisable. This is due to factors such as transport distances, feedstocks, biochar manufacturing technique and conditions. Carbon recovery from the feedstock is also specific to the technology used and its particular calibrations. Jim Jones from Massey University summarises as follows.

"Bringing it all together, life cycle analysis, that sort of thing has to go in there, systems analysis for particular case studies. But it will be specific to the case study." (Jim Jones, Professor of Biochar and Bioenergy Pyrolysis Engineering, NZ Biochar Research Centre, Massey University). 
The following paragraphs present three such case studies on biochar life cycle performance. These indicate which factors and assumptions affect LCA outcomes and how changing these assumptions may yield very different results.

A recent study investigates the energy, GHG and economic net impact of biochar in the United States. The hypothetical study assesses the feedstocks corn stover (as an agricultural residue), yard waste (or garden waste) (as a waste stream with a tipping fee) and switchgrass (as a bioenergy crop) processed in a slow pyrolysis facility (Roberts, et al., 2010a).

The switchgrass scenario ${ }^{49}$ provides the highest net energy benefit, but is also a net source of emissions mainly due to indirect land-use change (see Figure 41). Pyrolysis of all feedstocks generates surplus energy. Energy consumption for feedstock drying varies with feedstock moisture content and is higher for early than for late stover, and highest for yard waste. Other energy consuming processes for stover and switchgrass are agrochemicals and field operations. Switchgrass also requires the highest energy input for production and collection due to the use of agrochemicals and field operations. The contribution analysis also shows that avoided fossil fuel production (4.6\% of total energy generated), biomass transport (2-3\%) and pyrolysis plant construction (2-4\%) have only minor influence on energy consumption.

In terms of the GHG balance, all feedstocks except switchgrass B show a net reduction in GHG emissions. Yard waste yields the largest reduction primarily due to the fact that only transport emissions are considered while no emissions are assigned to production and collection. The switchgrass analysis highlights the importance of direct and indirect landuse change resulting from purpose-grown bioenergy crops on existing agricultural land (Roberts, et al., 2010a).

\footnotetext{
${ }^{49}$ Late and early stover refer to the time of harvest which results in a different moisture contents (30\% for early stover and $15 \%$ for late stover on a wet basis) which in turn has repercussions on the pyrolysis process. Switchgrass scenarios A and B use two different underlying models. Both account for direct and indirect land-use change but vary in accounting methods for indirect land-use change resulting in net GHG emissions of $406.8 \mathrm{~kg} \mathrm{CO}_{2}-\mathrm{e} \mathrm{t}^{-1} \mathrm{DM}$ in scenario A and $886.0 \mathrm{~kg} \mathrm{CO}_{2}-\mathrm{e} \mathrm{t}^{-1} \mathrm{DM}$ in scenario $\mathrm{B}$. Yard waste is assumed to be diverted from a commercial composting facility which is reflected in the 'avoided composting' category (Roberts, et al., 2010a).
} 


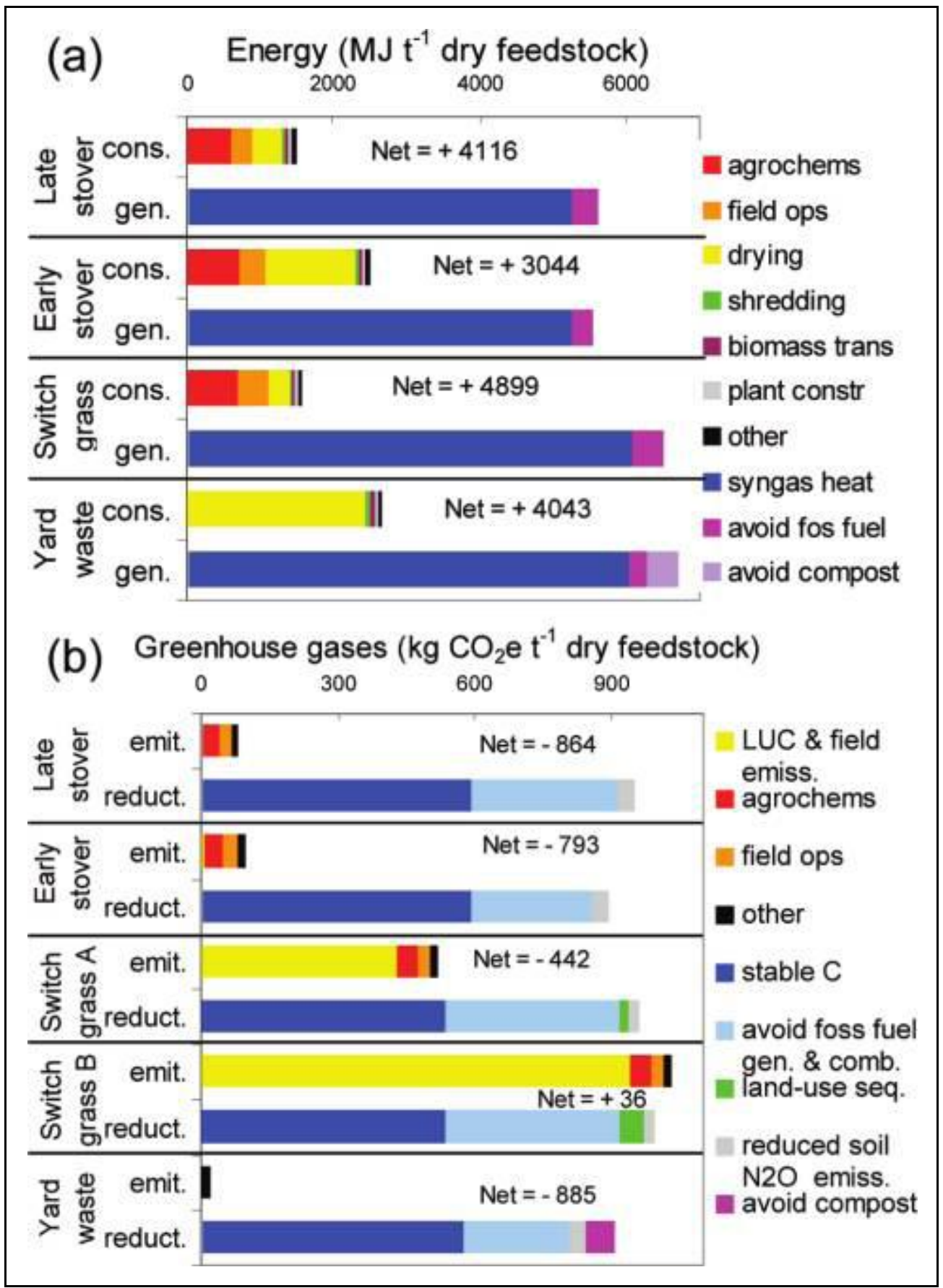

Figure 41: Contribution analysis of net energy and net GHG impact per tonne of feedstock dry matter (DM) for slow pyrolysis optimised for biochar production with use of co-products for bioenergy (Roberts, et al., 2010a, p. 830)

(a) Contribution analysis of net energy per t DM with top bar representing energy consumption and bottom bar energy production. The difference is the net energy and is stated adjacent to the bars. Switchgrass A and B have the same energy contribution profile, and only scenario A is shown.

(b) Contribution analysis for net GHG impact per t DM with top bar representing GHG emissions and bottom bar GHG reductions. The difference is the net GHG balance and is stated adjacent to the bars. (LUC = land-use change; other = biochar transport, plant dismantling, farm equipment, biochar application, avoided fertiliser production) (Roberts, et al., 2010a, p. 830) 
Pyrolysis is an exothermic reaction, meaning that the process becomes self-sustaining in energy terms after some energy input for the start-up phase has been provided. A model of energy flows of slow pyrolysis using late stover (15\% moisture content) is depicted as an example in Figure 42 below. It shows that in this particular case the 58MJ energy input needed in the form of natural gas are a fraction of the overall energy flows.

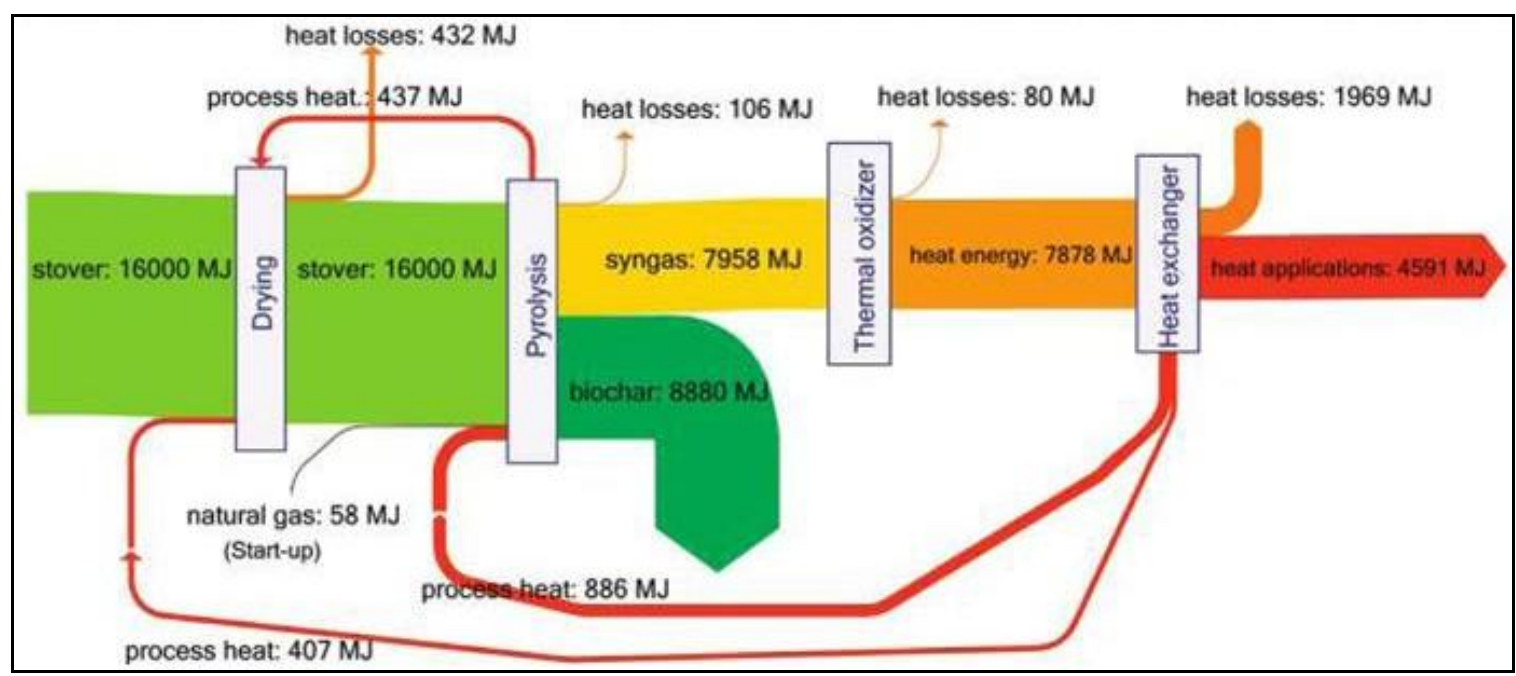

Figure 42: Energy flows (MJ per tonne of dry feedstock) of a pyrolysis system for late stover (Roberts, et al., 2010a, p. 828)

A GHG LCA for a pyrolysis plant intended to process the council-managed greenwaste in Palmerston North indicates $83 \%$ GHG savings when current practices are replaced with a proposed pyrolysis project. The sequestration potential, specific to the scenario, is estimated to be $1.8 \mathrm{t} \mathrm{CO}_{2}$-e for each $\mathrm{t} \mathrm{CO}_{2}$-e produced. That is, the difference between the emission from the project (using the specific assumptions for feedstock, pyrolysis technology etc.) and the carbon sequestered in the biochar product is not only zero but negative. In other words, the quantity of overall emissions reduction from the project is $180 \%$ of the project's emissions (Downie \& Lau, 2010).

A case study in Glasgow and Clyde Valley, Scotland comparing three waste management options (landfill, anaerobic digestion, pyrolysis) for biodegradable municipal waste concludes that pyrolysis offers the largest abatement potential. This is mainly due to multiple abatement pathways for the waste treatment options investigated. Anaerobic digestion and pyrolysis were each assigned three abatement pathways: fossil fuel displacement, carbon storage in the treatment product and the use of the product as either 
fossil fuel displacement or soil amendment. Landfilling was assigned only one abatement pathway: fossil fuel displacement (Ibarrola, 2009).

While these case studies may give a general idea of biochar systems performance over their life cycle, it must be acknowledged that any LCA is subject to the specific assumptions underlying its calculation. Especially the minor contribution of biomass transport to the overall energy consumption found by Roberts and colleagues in the US (2010a) may substantially differ in the NZ context ${ }^{50}$. They may be much higher due to longer distances than the $15 \mathrm{~km}$ assumed in the study and are also dependent on truck configuration, loading efficiency and the nature of the road network ${ }^{51}$ (Hall \& Gifford, 2007). Furthermore, Roberts and colleagues investigated the locally most abundant agricultural residue, corn stover, as one potential feedstock. In contrast, the dominant land uses in NZ's primary sector are pastoral grazing and plantation forestry rather than arable cropping. Therefore, available feedstocks differ from the US context. Different feedstock characteristics will have a bearing on overall LCA results. That is, energy and GHG balances of $\mathrm{NZ}$ agricultural and forestry residues can be expected to differ from those of corn stover. An exact quantification of the life cycle costs and benefits for biochar scenarios with NZ-specific feedstocks is an area requiring further investigation.

The impact of locally specific circumstances on the outcome of LCA is strikingly demonstrated by Chiaramonti and Recchia (2010). Even their LCA of a small-scale, welldefined local biofuels system shows high sensitivity to underlying assumptions. Modifying only one element (field input) of the GHG LCA changes the results for emissions (in $\mathrm{kgCO}_{2}$-e per MWh) by $300 \%$, and even more so when different utilisation options are assumed for the co-products.

The findings of Chiaramonti and Recchia (2010) highlight the limitations of LCA in assessing the quantitative GHG emissions associated with particular biofuels. The authors also question the suitability of LCA where policy has established threshold values that

\footnotetext{
${ }^{50}$ Roberts and colleagues (2010a) base their assumptions for biomass hauling on those calculated by McCarl and colleagues (2009). This means that transport costs are evaluated for mid-western US states where about $20 \%$ of the total land area is under maize cropping. Further assumptions are a service area of $19,600 \mathrm{ha}$ of cropland and an average hauling distance of $14.8 \mathrm{~km}$ with a cost of US $\$ 6.86 \mathrm{t}^{-1}$. The calculation accounts for $5 \%$ yield losses from transport and storage (McCarl, et al., 2009; Roberts, Gloy, Joseph, Scott, \& Lehmann, 2010b).

${ }^{51}$ Transport costs of wood residues in NZ are explored in section 6.4 .3 below.
} 
determine the eligibility of biofuels for regulatory support (Chiaramonti \& Recchia, 2010). Both the EU Renewable Energy Directive and the NZ Biofuel Bill specify such a threshold in the form of a minimum GHG reduction target. Biofuels have to reduce GHG emissions by at least $35 \%$ over their life cycle compared to fossil fuels to be marketed as a biofuel (European Union (EU), 2009; New Zealand Parliament, 2010e). A variability of $300 \%$ in LCA results even in a small-scale, well-defined case study indicates that the deployment of LCA to determine such thresholds at a much more aggregated level - in terms of larger geographical area and technological variability - is at best a very challenging task.

Determining the boundaries of LCA is in itself a difficult exercise (Feng, Rubin, \& Babcock, 2010). Further, the use of weighting factors such as human health, resource depletion and ecosystem quality also has a significant bearing on LCA results. A compounding problem is the change in such weighting sets over time and space (Monti, Fazio, \& Venturi, 2009). LCA may be considered a tool that identifies trade-offs rather than providing a simple answer for ranking different alternative pathways. Truly holistic assessments require identification of indirect effects, such as various displacements, and their environmental and social consequences (Brandão, et al., 2010).

\subsubsection{Recognition of Biochar as a Carbon Offset?}

\subsubsection{The Bioenergy Problem}

Biochar with associated bioenergy production is often promoted as a carbon-negative pathway, i.e. sequestering more carbon than is released over the life cycle, thereby drawing down atmospheric $\mathrm{CO}_{2}$ levels (Lehmann, 2007c). As has been pointed out by Searchinger and colleagues (2009), a crucial assumption is that the carbon released during biomass combustion is considered neutral in GHG terms because it was initially sequestered by and stored in plants.

In the long run this is true and biomass carbon may be considered free. In the short term increased emissions from land-use change are the result if previously uncultivated land is 
put into bioenergy crop production. Notwithstanding such concerns, Kyoto accounting rules give credit for the GHG benefits of displacing fossil fuels with bioenergy but do not subtract credits for the emissions resulting from land conversion to biofuel production (Searchinger, et al., 2009).

This problem arises because Kyoto accounting rules treat all biomass carbon as equal regardless of its source ${ }^{52}$. The Kyoto Protocol caps energy emissions only from Annex B countries, while no limits are imposed on non-Annex B countries' emissions, including those from land-use change (Searchinger, et al., 2009). This effectively provides a perverse incentive that allows Annex B countries to meet their increased bioenergy demand with supply from non-Annex B countries that may have resulted from land clearing for biofuels.

The emissions resulting from land conversion include carbon released from soil as well as from vegetation clearing for cultivation purposes. Soil organic carbon (SOC) changes are an often disregarded factor when assessing the life cycle performance of different bioenergy land uses. Even if SOC changes are considered, no uniform methodology for their calculation is applied (Brandão, et al., 2010). In sum, emissions from land conversion lead to a carbon debt of biofuels (Fargione, Hill, Tilman, Polasky, \& Hawthorne, 2008). If instead of purpose-grown crops a waste stream was used, this would not be associated with land-use change and resulting emissions, and is suggested to be more beneficial in GHG terms (Searchinger, et al., 2008).

\subsubsection{The Practice of Offsetting}

If biochar projects are to be included as offsetting activities, the usual criteria for offsets need to apply (Kollmuss, Lazarus, Lee, \& Polycarp, 2008a; Kollmuss, Zink, \& Polycarp, 2008b; UNFCCC, 1998). Credits must be:

\footnotetext{
${ }^{52}$ Searchinger's argument is supported by the Global Forest Coalition, an international Environmental NonGovernment Organisation. It issued a report criticising wood-based bioenergy, including pyrolysis and its byproduct biochar, as a false solution to climate change. Increased demand for woody biomass would lead to genetically engineered purpose-grown bioenergy crops with corresponding land grabbing for large monoculture plantations, displacement of indigenous peoples, displacement of food crops for bioenergy crops and land conversion from forest to food production with associated emissions (Global Forest Coalition, 2010).
} 
- Real: measurable and quantifiable;

- Verifiable: by an independent party;

- Additional: project activities shall go beyond business as usual;

- Exclusive: credits are counted and sold only once on either the voluntary or the compliance market;

- Eligible: type of projects or country of origin may be restricted;

- Permanent: reductions shall have duration over a specified amount of time.

A methodology to quantify the net GHG impact of biochar production and soil application has been submitted by the company Carbon Gold ${ }^{53}$ to the Voluntary Carbon Standard (Voluntary Carbon Standard Association (VCSA), 2009), but has not yet been approved. The VCS is an international offset standard for the voluntary market that is broadly accepted throughout the carbon offset industry (Kollmuss, et al., 2008b). The standard applies the criterion of additionality of a project in GHG terms but does not require environmental or social benefits beyond an offset project. Concerns about public participation arise from the fact that decision-making about information disclosure and the degree of stakeholder involvement in the country where the project is implemented are largely devolved to the project developer. The VCS only requires compliance with the local and national environmental law. Offset buyers who value environmental and social co-benefits may choose to buy offsets from a different programme (Kollmuss, et al., 2008a).

Under the VCS a lot of responsibility is devolved to the project developer and the auditor which in combination with the lack of an accreditation board may be seen as a weakness (Kollmuss, et al., 2008a, 2008b). A report reviewing the potential for generation of soil carbon offsets in NZ and their sale on the voluntary carbon market diagnoses social and

\footnotetext{
${ }^{53}$ Carbon Gold Ltd is a UK company set up by Craig Sams, founder of several wholefood and organic food companies, among them Green \& Black's chocolate, and Dan Morrell, founder of The Carbon Neutral Company, Global Cool and the Carbon Advisory Service (Carbon Gold Ltd, 2009a). In July 2009 Carbon Gold published a methodology aimed at standardising the accounting of GHG emissions associated with the production and soil application of biochar in agricultural and forest management systems (Carbon Gold Ltd, 2009b).

The methodology was open to public consultation from 30 July to 29 August 2009 (Voluntary Carbon Standard Association (VCSA), 2009) and nine submissions have been received, including from the NZ Biochar Research Centre. The proposed methodology and submissions can be downloaded from the following website: http://www.v-c-s.org/methodology gmfatgger.html

For an audiovisual impression of Carbon Gold's trials in the UK and concerns of the ENGO Biofuelwatch UK see here: http://www.youtube.com/watch?v=DVFRaCFXYwo (posted: 05/06/2010, retrieved: 06/06/2010).
} 
Introd | Method | Biochar | Institutions | Theory | Analys\&Disc | Concl

institutional conditions in NZ that would facilitate such efforts. Farmers' familiarity with GHG accounting and soil testing as well as the selection of the TZ1, NZ's carbon market operator, as a global registry for the VCS were rated as favourable (ICF International, 2008).

\subsubsection{The Issues of Measurability and Impermanence}

Measurement of GHG benefits from carbon offset projects and especially for soil carbon comes with its own intricacies (Fynn, et al., 2009; Grace, et al., 2003). The requirement for permanence in particular poses challenges for assessment and crediting (Dutschke, 2002; van Kooten, 2009). Furthermore, the practice of offsetting as a whole is questioned as it does not necessarily entail a reduction in GHG emissions (Downie, 2007;

Environmental Defense Fund, 2007a). Biochar carbon offsets could potentially provide a loophole for emissions to continue.

It has been suggested that offsetting fossil fuel emissions with biological terrestrial sinks in the form of LULUCF acknowledgement as carbon sinks is inappropriate as they vary in durability, measurability, reversibility, and long-term controllability and are subject to interannual fluctuation (German Advisory Council on Global Change, 2009).

Biological sinks, such as forests and purpose-grown crops that are landfilled are no adequate offset for fossil carbon emissions as they provide only limited durability (maximum 100 years) and suffer from leakage because of land-use change. While biochar may be more durable, uncertainties surround its life cycle emissions, leading to similar problems as those with biofuels (Reijnders, 2009). The impermanence of biotic sinks and reservoirs was also stressed by a participant working in the forestry sector:

"Putting trees, wood and even biochar in the same equation as fossil fuels just doesn't work in the long-term because 'offsets' in trees and biochar are only temporary and not in perpetuity. It's not a valid offset for emitting fossil fuel carbon, a permanent source. It just means that we are handing on liabilities to future generations for people to make money now. I think carbon trading should 
exclude biotic sources and sinks and be strictly for fossil fuels only." (Dean Satchell, forester)

While there may be potential for the energy generated from pyrolysis to replace fossil energy sources, only true waste streams should be used as feedstocks to prevent land-use change. A participant from the stakeholder group of academics suggests viewing biochar from a different angle, seeing it as a waste management tool only rather than focusing on the financial gain from carbon credits. He also emphasises that using biochar merely to enable continued business-as-usual and associated emissions elsewhere misses the point. He explains his view as follows:

"The way that I think of it is really as a waste management issue. You've got to have a feedstock. And that feedstock has got to have, what is it? It's a waste or it's a problem that exists at the moment. Whether it's saw dust or whether it's wood waste or whatever. I think you've got to avoid that biofuels argument where you actually start cutting down forests. And even forests in NZ and I have heard some discussion about the fact of forest conversion to pasture and that they could use biochar as a way of equalising, which is fair enough, but is that really what biochar technology is all about? Because from my perspective anyway, I look at it as a waste management thing." (Leo Condron, Professor of Biogeochemistry, BioProtection Research Centre, Lincoln University)

"A lot of people I have talked to dismiss biochar because they can't get over the thing that, they keep thinking that 'oh, you just got to grow plants instead of growing crops, you're going to grow a woody plant and make biochar from it'. To me that's not the point. The point is that it's not replacing land use but to use a waste." (Leo Condron, Professor of Biogeochemistry, Bio-Protection Research Centre, Lincoln University)

Using pyrolysis primarily as a waste management tool would be in line with the policy goal of reduced waste to landfill set out in NZ's Waste Strategy and Waste Minimisation Act (MfE, 2002; New Zealand Parliament, 2008d). 
If policy was to decide to advance the uptake of pyrolysis and biochar it has to be ensured that the framework of rules is carefully crafted and does not incentivise large scale landuse change. Instead, policy may wish to limit biochar production from feedstocks grown on marginal existing farmland or to the use of agricultural and forestry residues only. Such residues should then have demonstrably no other in situ use, e.g. physical soil protection form erosion or nutrient retention via mulching, composting or in situ decomposition. Other conceivable rules may restrict the use of biochar to in situ soil improvement so as to ensure a closed loop system.

On a larger scale and in an international context, it also has to be ensured that, should biochar at some point in the future be recognised as a carbon offset, its large-scale production and sale do not lead to a carbon price crash due to oversupply of cheap offsets. Caution has been urged that economic incentives for soil carbon sequestration and biochar will result in land grabbing by large corporations, especially in developing countries, for monoculture no-till crops, potentially genetically engineered ${ }^{54}$. This may further weaken and detract from efforts of true emissions reductions (Ernsting, Anderson, \& Maina, 2009; Rainforest Rescue, 2009).

\subsection{Carbon Accounting}

Policy decision-making concerning the potential of biochar as a pollution control instrument for climate change mitigation necessarily needs to take into account issues around biochar carbon sequestration and its permanence over time.

The following sections aim to highlight the key issues as they relate to carbon sequestration and their implications for carbon accounting based on the literature review and stakeholder perspectives.

\footnotetext{
${ }^{54}$ Such as in the US where in 2009 the planting of 250,000 genetically engineered, cold-resistant eucalypts was approved (Global Forest Coalition, 2010). For further information see http://www.triplepundit.com/2009/07/plan-to-plant-gmo-eucalyptus-trees-stirs-up-hornets-nest-of-protest/ (posted: 17/07/2009; retrieved: 06/06/2010) and http://www.aphis.usda.gov/brs/biotech_ea_permits.html (updated: 12/05/2010; retrieved: 06/06/2010).
} 
Introd | Method | Biochar | Institutions | Theory | Analys\&Disc | Concl

\subsubsection{Half-life of Biochar}

Although the half-life ${ }^{55}$ of biochar is still subject to further research (Cheng \& Lehmann, 2009; Cheng, et al., 2008), common estimates in the literature assume a figure of more than 1,000 years (Laird, 2008) and a study by Kuzyakov and colleagues indicates a halflife of 1,400 years (Kuzyakov, Subbotina, Chen, Bogomolova, \& Xu, 2009). The stability of charcoal is attributable to its constituting high molecular weight aromatic rings ${ }^{56}$, most of which are highly resistant to physical and chemical decomposition and are known to persist in soils for thousands to millions of years (Kuhlbusch, 1995; Kuhlbusch \& Crutzen, 1996).

Residence time of biomass-derived charcoal in soils varies according to climate zone, soil type and production procedure of the biochar (Baldock \& Smernik, 2002; Lehmann, et al., 2006). Amazon soils feature carbon aged several thousand years (Lehmann, et al., 2006) and deep-sea sediments indicate an age of up to 13,900 years (Masiello \& Druffel, 1998). Even today, Black Carbon-enriched soils aged 600-8,700 years still exhibit significantly higher contents of chemically stable aromatic carbon as a component of their soil organic matter than adjacent soils of the same type which have not been enriched with Black Carbon (BC) (Schmidt \& Noack, 2000; Solomon, et al., 2007).

As a very recalcitrant form of carbon, $\mathrm{BC}$ has a decomposition rate of $0.5 \%$ per year under laboratory conditions (Kuzyakov, et al., 2009). Taking into account that the decomposition rate under field conditions is ten times slower, it is estimated that the mean residence time of $\mathrm{BC}$ in soils of temperate climate zones is about 2,000 years (Kuzyakov, et al., 2009). Charcoal in soils was found to be more than 9,000 years old which is older than the humin fraction that is usually considered to contain the oldest carbon in soils (Pessenda, Gouveia, \& Aravena, 2001; Preston \& Schmidt, 2006). Preservation of BC in

\footnotetext{
${ }^{55}$ Half-life, turnover time, decay rate and mean residence time (equivalent to mean life time) are terms used for the quantification of biochar decay. While not synonymous, the terms are mathematically related (Lehmann, Czimczik, Laird, \& Sohi, 2009). The following definition is taken from Lehmann and colleagues (2009).

Decay rate: is the exponent ( $\mathrm{k}$, as a function of environmental conditions) in the exponential decay function and has a unit of 1/time: $\operatorname{Biochar}_{(\mathrm{at} \text { time } \mathrm{t})}=\operatorname{biochar}_{(\mathrm{at} \text { time } 0)} \mathrm{e}^{-\mathrm{kt}}$

Mean residence time: is the inverse of the decay rate $(1 / \mathrm{k})$ and is the average time that biochar is present. Half-life: is the time that elapses before half of the biochar decomposes and can be obtained by multiplying the mean residence time by the natural logarithm of 2 .

Turnover time: is calculated by dividing the stock of biochar at equilibrium by the loss per unit of time.

${ }^{56}$ Aromaticity of carbonaceous materials is explained in section 1.6 in Chapter One.
} 
soils and sediments over several millenia suggests carbon storage over geological time scales and effectively a permanent reservoir of carbon (Forbes, Raison, \& Skjemstad, 2006; Schmidt \& Noack, 2000).

For carbon accounting purposes it is vital to know the stability of biochar in soil over time in order to account for the stored carbon. This is not without challenges. It is wellestablished that charcoal is very recalcitrant, but exact mechanisms of stabilisation as well as accounting methods for the fixed versus volatile carbon content of biochar, warrant further research (Lehmann, et al., 2009). This is reflected in a comment from a NZ researcher when saying:
"Another issue from the policy viewpoint at least to account for carbon or from the Kyoto viewpoint is that we need to account for the recalcitrant carbon, so the carbon that will not be decomposed within 100 years, because the global warming potential of $\mathrm{CO}_{2}$, methane and other $\mathrm{GHG}$ is accounted for over 100 years. So we need to make sure that we have a method to account for that fraction of the biochar that will stay in the soil without decomposing in 100 years. And this is a real challenge." (academic interview participant)

A compounding problem is that stability of biochar-carbon in the environment is dependent on a raft of parameters such as feedstock, manufacturing conditions and characteristics of the physical environment in which the biochar is used. An academic interviewee expressed this the following way.

\footnotetext{
“We don't know the exact mean residence time of biochar in different pedoclimatic conditions, and of different types of biochar. Some biochars might be more aromatic than others, so we need to investigate this." (academic interview participant)
}

Policy development concerning biochar as a means for sequestering carbon must also have regard to auditing and monitoring aspects. These are highlighted by Mike Hedley from Massey University who remarks: 
"How are you going to assess, when somebody has made a char, whether that should get a credit because it's not going to decompose for thousands of years? So there is an auditing aspect associated with char production. All chars are not the same. So if you're going to enable people to start using it, you have to be able to distinguish between chars. And part of it is doing research to work out what the criteria are for the pyrolysis part of it and whether they consistently yield a char that meets the recalcitrant criteria." (Mike Hedley, Professor, Director of Fertilizer and Lime Research Centre, Massey University)

Overall, scientists emphasised the degree of uncertainty regarding long-term behaviour of biochar in the environment as reflected in the following comment.

“We don't know what it is going to do [with regard to changes in soil biology and biochemistry]. I mean if you start adding tonnes and tonnes of biochar to the soil we could end up doing what humans often do, which is shooting ourselves in the foot. If we go ahead with large scale application of biochar, in ten years time we may say 'crap, we shouldn't have done that!'”(Craig Anderson, Postdoctoral Research Fellow, Bio-Protection Research Centre, Lincoln University)

This raises questions of intergenerational equity. Environmental costs and benefits may be distributed unevenly across generations. Large-scale biochar land application now may imply a short-term benefit, while long-term adverse environmental impacts become apparent at a much later stage. Such ethical implications warrant further research but are outside the scope of this thesis.

\subsubsection{Stabilisation Mechanisms of Biochar-Carbon in Soil}

Interview participants in the stakeholder group of academics highlighted the need for exact quantification and understanding of mechanisms that underlie biochar-carbon stabilisation. Two main pathways of stabilisation are proposed in the literature and ongoing research in $\mathrm{NZ}$ is investigating which of those is the predominant one and which one is more effective in stabilising biochar-carbon. 
One stabilisation pathway is to produce biochar at high temperatures which results in a chemically very stable aromatic ring structure of the carbon, making it recalcitrant to mineralization and decomposition (Elmquist, et al., 2006). High stability comes at the expense of carbon recovery rate. That is, a lower proportion of the biomass carbon is stabilised in biochar when high temperatures are used compared to relatively lowtemperature pyrolysis (Cowie, 2009; Sohi, et al., 2009). This is schematically illustrated in Figure 43 below where increasing temperature indicates higher aromaticity of the biochar.

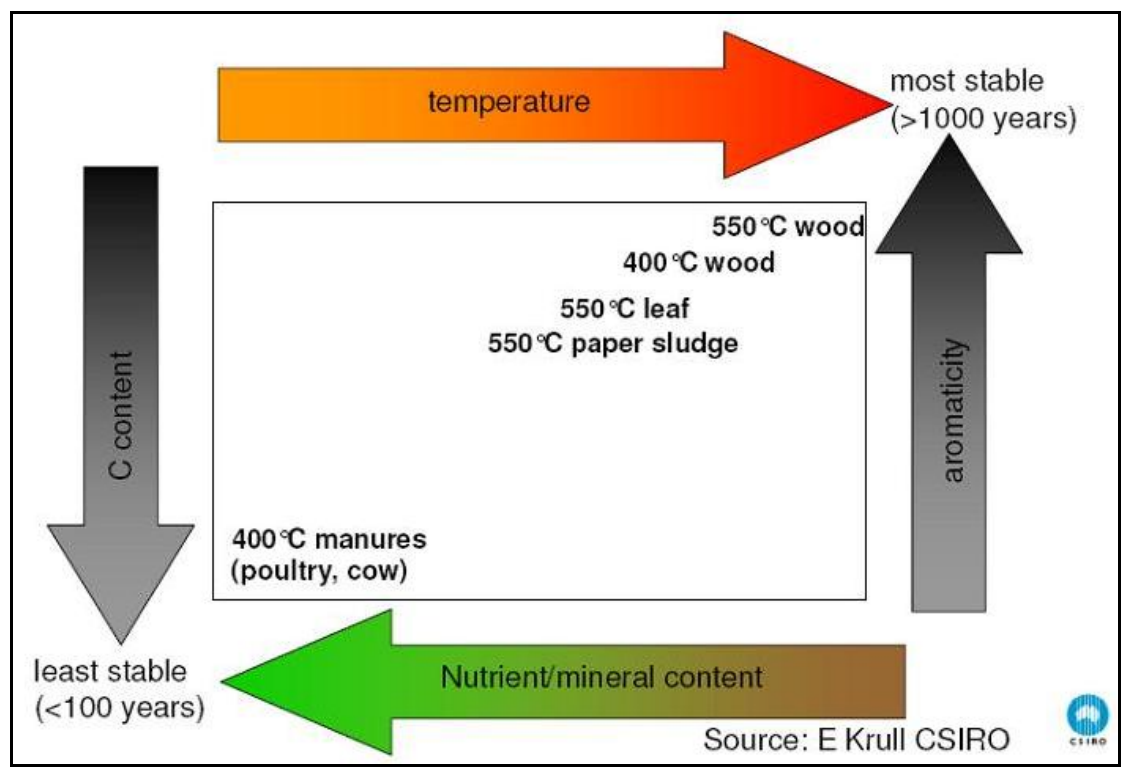

Figure 43: Stability of different biochars as affected by type of feedstock and pyrolysis conditions (Cowie, 2009, p. 7)

The other stabilisation pathway accrues from biochar-soil interaction where biochar-C forms bonds with organic minerals in the soil (Hockaday, Grannas, Kim, \& Hatcher, 2006, 2007; Lehmann, et al., 2009; Marschner, et al., 2008). Using relatively low pyrolysis temperatures of about $450^{\circ} \mathrm{C}$ instead of $700-1000^{\circ} \mathrm{C}$ increases the carbon recovery from the feedstock. The biochar is, however, chemically less stable, i.e. has lower aromaticity (as shown in Figure 43 above). There is a trade-off between producing a chemically stable biochar with relatively lower carbon recovery from the feedstock and producing a less-aromatic biochar but recovering a larger share of the biomass-carbon. A $\mathrm{NZ}$ researcher highlights the implications of scientific complexity for the policy issue of carbon accounting when saying: 
"It's two different opinions which are good to think about, but the organo-mineral pathway makes things more complicated. Because it is quite easy to just produce biochar at $550^{\circ} \mathrm{C}$, add it to the soil and account for it. But maybe it's not best for the soil but best for the Kyoto Protocol. There are many questions on the table that need to be answered." (academic interview participant)

The literature suggests that very little is known about black carbon (BC) loss processes and "almost nothing about biotic or abiotic agents of BC decomposition" (Masiello, 2004, p. 202). For carbon accounting, it is relatively straightforward to account for the carbon initially incorporated into the soil as biochar. Since biochar is not entirely inert and does ultimately decay (Baldock \& Smernik, 2002; Forbes, et al., 2006), it is necessary to determine the stable and labile (or fixed and volatile) fractions of biochar-carbon. Additional to mineralisation, microbial breakdown (or decay) will also affect the stability of biochar-carbon. It is, therefore, crucial to understand and account for changes to the chemical structure of biochar resulting from interaction with soil minerals as well as microbes (Camps-Arbestain, et al., 2010; Hockaday, Grannas, Kim, \& Hatcher, 2006).

Uncertain half-life estimates and stabilisation pathways also have implications for the life cycle analysis. A relatively lower carbon recovery from the feedstock but higher stability (in case the interaction with organic minerals provides a robust stabilisation pathway) may or may not be better than a high carbon recovery rate but with less stability over time.

The following section introduces some economic considerations on feedstocks and transport as identified by research participants. This is followed by some general reflections on marginal abatement costs of biochar and other abatement options based on scholarly literature. 
Introd | Method | Biochar | Institutions | Theory | Analys\&Disc | Concl

\subsection{Economic Considerations on Feedstocks}

\subsubsection{Forestry and Wood Processing Residues}

As established in section 6.2 waste streams provide the most environmentally benign feedstock option. They access only biomass carbon that is not put to any other use which would need to be replaced prior to its decay (Searchinger, et al., 2008). One potential waste stream identified by participants was forestry residues. The technically available quantities may differ substantially from those that can be collected cost-effectively. The collection cost may be restrictive, meaning that it is more economic to leave the residues on site to decompose. Six out of eight survey respondents indicated that this is indeed the current practice. Only price increases for pulp wood or woodchips would make it viable to extract and remove some of the higher-grade residues. The economic barriers to forest residue recovery are highlighted by a stakeholder working in the forestry sector when saying:

"The stumbling blocks are still the economics of materials handling. There is often the false assumption that it's doing good on all levels of the production chain but it is overlooked that this may not apply to forest management. The benefits don't flow back to the forest producer who incurs the cost of removing the residues. It is of no benefit to the forest manager or to the forest health." (forestry interview participant)

This also shows concern that continuous removal of residues may lead to adverse impacts on long-term soil productivity. Foresters commented that they were encouraged to leave smaller stable branches across the harvested site so as to prevent or limit soil erosion and to retain nutrients onsite. Research participants identified a problem with slash piles that accumulate on harvesting sites and may pose problems such as skid instability and stream obstruction. A forestry survey respondent determines the implication as follows: 
"Issues with slash piles left on skid sites/landings means the industry could be interested in removal of residues from a risk mitigation point of view rather than to sequester carbon solely." (forestry survey respondent)

Infrastructure for collecting logging residues from landings for energy generation purposes, mainly in wood processing facilities, is already in place and recovers 250,000t/year of residues (Hall \& Gifford, 2007). This represents $27 \%$ of landing residues and $7 \%$ of total forest harvest residues (Hall \& Gifford, 2007).

All forestry research participants identified the use of residues as a biochar feedstock as a potential means of accruing value from an otherwise unused or low-value resource. An added benefit highlighted by stakeholders was that the material would be removed from the price volatility of the export market for woodchips or chip-grade logs.

Assuming the technically and economically available quantities of forestry residues are determined, a third factor needs to be taken into account which is their quality or condition. As Peter Weir, involved in forestry as well as biochar production trials, points out:

"Some forestry residues are just too dirty. We are trying to get a feedstock that is as clean as possible; otherwise it clogs the plant" (Peter Weir, Ernslaw One Ltd.).

This indicates that quantitative and economic assessments of residue availability need to be complemented by an evaluation of the practicalities associated with their intended use. Policymaking may wish to reflect potential constraints accruing from the quality of biochar feedstock materials rather than assuming quantitative and economic assessments to be sufficient.

\subsubsection{Waste Streams with Tipping Fee}

A second option suggested by participants is waste that incurs a tipping fee. Diversion of such waste streams from landfill would also further the aim of the Waste Minimisation 
Act 2008 of reducing the amount of waste, especially organic waste, that is landfilled. Such cost considerations are reflected in a comment by Mike Hedley from Massey University who says:

"We are trying to combat the economic costs of biochar production by focusing on some wastes that have got a tipping fee, for example sewage sludge, biosolids, green wastes. Such wastes not only have a tipping fee but also environmental costs associated with them, for example, in the form of methane emissions resulting from their decomposition or adverse impacts on the marine environment when sewage sludge is discharged into the sea." (Mike Hedley, Professor, Director of Fertilizer and Lime Research Centre, Massey University).

Participants also suggested using invasive plant species as a biochar feedstock where clearing of exotic vegetation and restoration of native habitat occurs. Private land owners or public authorities would face costs when landfilling greenwastes such as non-native pines or willows that are cleared to restore native habitat.

When evaluating a suitable waste stream for biochar production, it also has to be considered from which current use the waste is diverted. Some waste streams are managed through well-established other recycling pathways, such as greenwaste that is used for composting or mulching (see section 6.2). Other waste streams may be more abundant but less suitable for biochar production. For example, sewage sludge could provide a large-scale feedstock of continuous supply, but other difficulties arise, including moisture content and potential contamination ${ }^{57}$.

\subsubsection{Transport and Handling Costs, Plant Size and Type}

Assuming a suitable feedstock has been found, other economic considerations include the transport costs of both biomass and biochar. These have been identified by many participants as being a major cost factor that may even be prohibitively high. Participants' comments as well as the literature suggest that forestry residues, for example, can be quite

\footnotetext{
${ }^{57}$ For an example of a NZ City Council considering treatment options for currently landfilled dewatered sewage sludge, including pyrolysis and biochar production, see Mendonça (2009).
} 
dispersed when not stacked up in slash piles, making it difficult to estimate collection and delivery costs (de Vos, et al., 2009). In a NZ study, transport cost ranges for wood processing residues have been estimated as follows (de Vos, et al., 2009, p. 37):

- Sawdust $\$ 0.18$ to $\$ 0.25$ per tonne-km

- Off-cuts $\$ 0.18$ to $\$ 0.27$ per tonne-km

- Dry shavings $\$ 0.54$ to $\$ 0.81$ per tonne-km (shavings are very low density)

Table 12 below shows the cost estimates for forest residue recovery for 2007 , ranging from $\$ 24 / \mathrm{m}^{3}$ to $\$ 91 / \mathrm{m}^{3}$ for solid wood that is delivered from forests to points of use between 25 and 100km (Hall \& Gifford, 2007).

Table 12: Delivered costs of forest residues to a user $\left(\$ / \mathbf{m}^{3}, 2007\right.$ costs) (Hall \& Gifford, 2007, p. 18)

\begin{tabular}{|l|cc|cc|cc|}
\hline $\begin{array}{c}\text { Transport distance } \\
\text { (one way) }\end{array}$ & \multicolumn{2}{|c|}{ Landing residues } & \multicolumn{2}{|c|}{$\begin{array}{c}\text { Rolling cutover } \\
\text { Ground based harvest }\end{array}$} & \multicolumn{2}{c|}{$\begin{array}{c}\text { Steep terrain } \\
\text { Hauler harvest }\end{array}$} \\
& Low & High & Low & High & Low & High \\
$25 \mathrm{~km}$ & $\$ 24$ & $\$ 34$ & $\$ 36$ & $\$ 50$ & $\$ 63$ & $\$ 78$ \\
$50 \mathrm{~km}$ & $\$ 27$ & $\$ 39$ & $\$ 39$ & $\$ 55$ & $\$ 67$ & $\$ 83$ \\
$75 \mathrm{~km}$ & $\$ 30$ & $\$ 43$ & $\$ 42$ & $\$ 59$ & $\$ 70$ & $\$ 87$ \\
$100 \mathrm{~km}$ & $\$ 33$ & $\$ 47$ & $\$ 45$ & $\$ 63$ & $\$ 72$ & $\$ 91$ \\
\hline
\end{tabular}

Of the total costs presented in Table 12, 60-70\% accrues from transport, processing and loading of forest residue ${ }^{58}$ (Hall \& Gifford, 2007).

Forestry interview participants highlighted that in regard to the size of a pyrolysis plant, a balance must be struck between competing cost factors. The larger the plant, the larger the area will have to be that supports this plant in terms of feedstock supply which in turn entails higher transportation costs. On the other hand, the higher throughput of a largerscale plant implies decreasing processing costs per unit of throughput. The literature suggests that the equilibrium between those competing cost factors represents the

\footnotetext{
${ }^{58}$ Additional to distance, transport costs are determined by truck configuration, loading efficiency and the nature of the road network, and hence very much case-specific (Hall \& Gifford, 2007). Cost estimates for 2007 range from $\$ 0.18$ to $\$ 0.25$ per tonne per kilometre (Hall \& Gifford, 2007).
} 
Introd | Method | Biochar | Institutions | Theory | Analys\&Disc | Concl

optimum plant size where the total cost of the pyrolysis products (biochar, syngas and bio-oil) generated is lowest (Searcy \& Flynn, 2010).

\subsubsection{Global Analysis}

Given the range of available GHG abatement options, policy needs to evaluate and compare different pathways and technologies. Several mitigation options may have a high technical potential for abating large quantities of emissions, but their costs per $\mathrm{C}_{2}-\mathrm{e}$ reduced differ. Applying the policy criterion of cost-effectiveness, or (static and dynamic) economic efficiency, policy can assess and rank different mitigation options by comparing their marginal abatement cost (MAC); that is the incremental cost for an additional unit of emissions reduced. Relatively inexpensive mitigation options should be implemented first (Callan \& Thomas, 2007; Common \& Stagl, 2005; Tietenberg, 2006).

Results of a study on the global mitigation potential of biochar by 2030 using the criterion of dynamic cost-effectiveness are presented in Figure 44 and Figure 45 below (Pratt \& Moran, 2010). The study by Pratt and Moran (2010) assumes deployment of large-scale biochar processing plants in developed countries, using both slow and fast pyrolysis. For the purpose of analysis the developed world is split into the three geographic areas of North America, Europe and the Developed Pacific. For developing countries (split into Africa, Asia and Latin America) it was assumed that existing stoves and charcoal kilns were modified to produce biochar. Feedstock availability was not considered a limiting factor in any of the regions. 


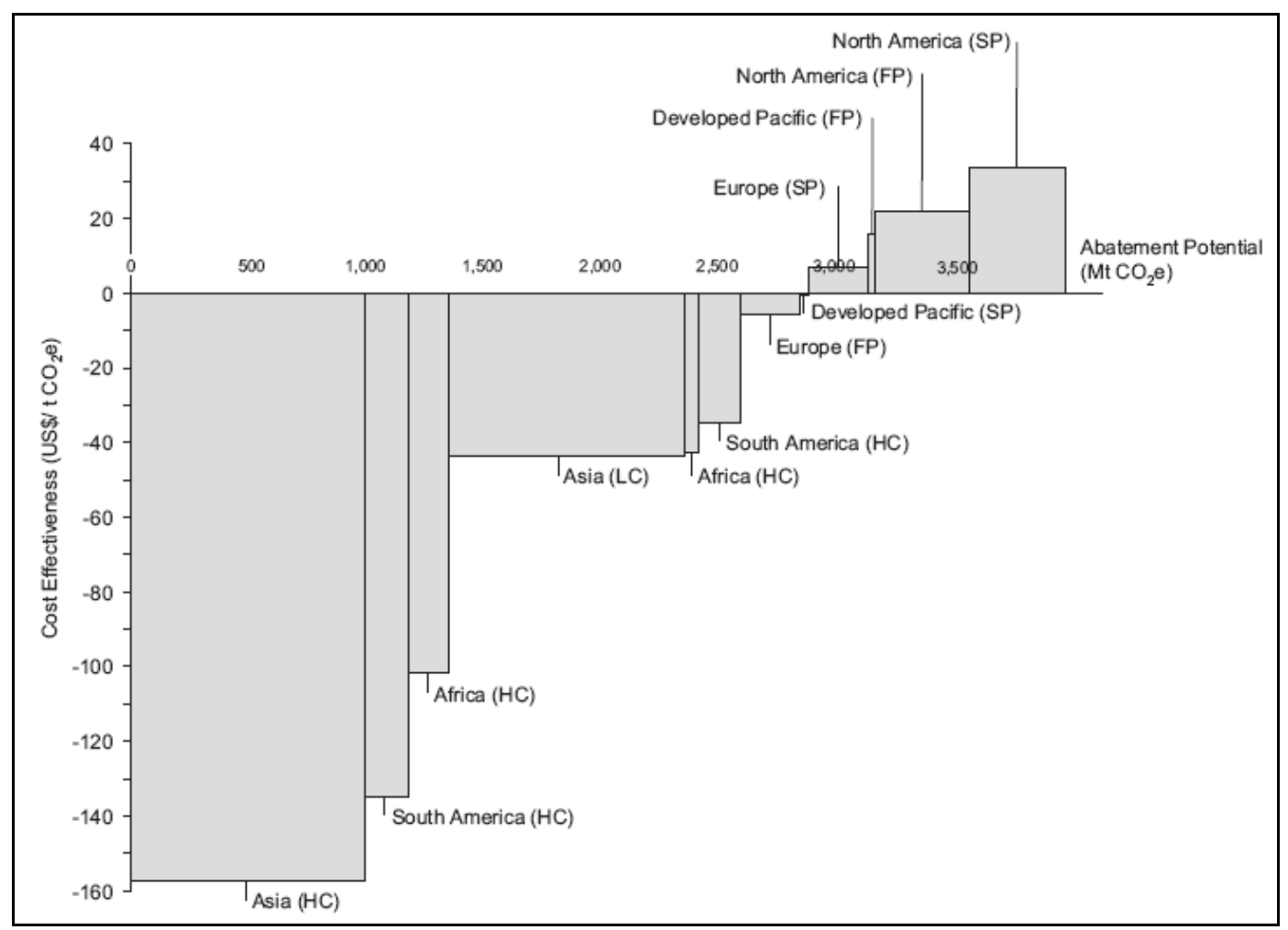

Figure 44: Marginal abatement cost curve of biochar projects in developed and developing regions for 2030. LC - low carbon price, HC - high carbon price, SP - slow pyrolysis, FP - fast pyrolysis (Pratt \& Moran, 2010, p. 6).

Calculations were made for a low and high carbon price scenario (US\$6 $\mathrm{t}^{-1} \mathrm{CO}_{2}$-e and US\$ $30 \mathrm{t}^{-1} \mathrm{CO}_{2}$-e). The MAC curves show the technology with the most cost-effective abatement potential on the far left. Negative cost-effective values indicate net savings from implementation of the technology. The breadth of each bar represents the quantity of

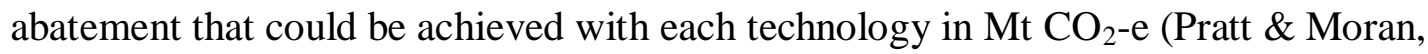
2010).

Figure 44 shows the abatement potential of biochar scenarios by region while Figure 45 locates these regional scenarios in a global MAC curve. This global MAC curve includes other mitigation technologies and strategies, such as Carbon Capture and Storage (CCS), biomass co-firing, wind power, agricultural land management techniques and lighting switch in residential buildings. Figure 45 enables a comparison of the regional biochar scenarios with other mitigation options. The chart also shows that the most expensive biochar projects (slow pyrolysis in North America) are still cost-competitive with CCS which is one of the most expensive abatement technologies considered. In terms of 
environmental effectiveness (i.e. abatement potential), however, CCS outperforms slow pyrolysis in North America.

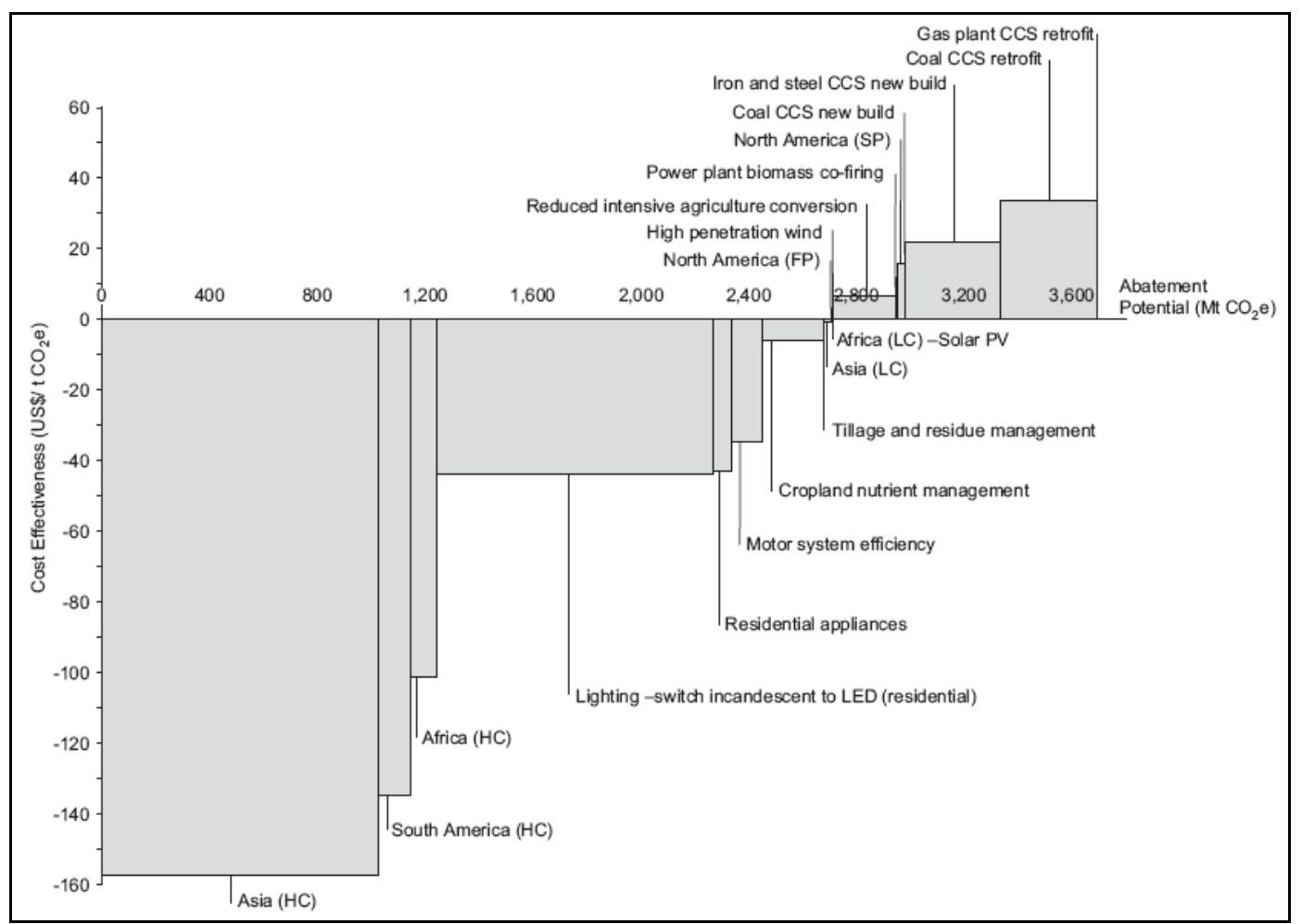

Figure 45: Marginal abatement cost curve of various abatement technologies and strategies for the world by 2030 (Pratt \& Moran, 2010, p. 7). Note: This chart includes abatement strategies and technologies so as to indicate the relative position of biochar projects in terms of abatement potential and cost-effectiveness along a global MAC curve.

In the developed world, cost effective scenarios are fast pyrolysis in Europe and slow pyrolysis in the developed Pacific (Figure 44). The largest mitigation potential for the developed world exists in North America. This is due to the quantities of agricultural residue being generated and the existing high investment in biomass technologies. However, this is also the least cost-effective scenario (Pratt \& Moran, 2010).

Biochar deployment in all developing regions is cost-effective under the assumptions made in this study. The largest abatement potential is located in Asia. Projects in Asia and Latin America would still be profitable even if excluded from carbon trading. The large abatement potential in the developed world results from implementing a large number of small-scale cheap projects. Although equipped with a more high-tech method and better 
infrastructure, projects in developed regions are less cost-effective than those in developing regions (Pratt \& Moran, 2010).

The analysis by Pratt and Moran used the criterion of cost-effectiveness only, but real-life decision-making needs to take into account a range of other criteria. The ethical and practical implications that such purely economic considerations may have for distributional justice and equity between the developed and developing world are in need of investigation and discussion, but are outside the scope of this thesis.

\subsubsection{Case Study}

Table 13 presents an economic analysis of slow pyrolysis optimised for biochar production with different feedstocks under various carbon valuation assumptions ${ }^{59}$. Biochar production from all feedstocks is uneconomic if no carbon value is assigned to the biochar. Yard waste, i.e. garden waste, is closest to the break-even point at about US\$2 per tonne of feedstock dry matter (DM). If the stable carbon in the biochar is assigned a carbon offset value, a net financial benefit is generated from all feedstocks in the high revenue scenario with yard waste showing the highest profit at about US\$44 $\mathrm{t}^{-1}$ DM. The low revenue scenario indicates again the highest profitability of yard waste while other feedstocks become increasingly marginal or uneconomic. All feedstocks are economically viable under a high revenue scenario if the entire life cycle emissions ${ }^{60}$ are accounted for. Again, yard waste remains the only profitable option under a low revenue scenario (Roberts, et al., 2010a, 2010b).

\footnotetext{
${ }^{59}$ The high and low revenue scenarios assume US\$80 and US\$20 per $\mathrm{t} \mathrm{CO}_{2}$-e. Late and early stover refer to the time of harvest which results in a different moisture contents (30\% for early stover and $15 \%$ for late stover on a wet basis) which in turn has repercussions on the pyrolysis process. Switchgrass scenarios A and B use two different underlying models. Both account for direct and indirect land-use change but vary in accounting methods for indirect land-use change resulting in net $\mathrm{GHG}$ emissions of $406.8 \mathrm{~kg} \mathrm{CO}_{2}-\mathrm{e} \mathrm{t}^{-1} \mathrm{DM}$ in scenario $\mathrm{A}$ and $886.0 \mathrm{~kg} \mathrm{CO}_{2}-\mathrm{e} \mathrm{t}^{-1} \mathrm{DM}$ in scenario B (Roberts, et al., 2010a).

${ }^{60}$ This includes the biochar-carbon and avoided emissions from fossil fuels, fertiliser and composting as well as avoided soil $\mathrm{N}_{2} \mathrm{O}$ emissions.
} 
Introd | Method | Biochar | Institutions | Theory | Analys\&Disc | Concl

Table 13: Net cost of biochar production under various feedstock and carbon valuation scenarios in US $\$ \mathrm{t}^{-1}$ feedstock dry matter (own table combining data from Tables S6 and S7 in Roberts, et al., 2010b, pp. S23-S24)

\begin{tabular}{|rccccc|}
\hline & Late stover & Early stover & Switchgrass A & Switchgrass B & Yard waste \\
\hline No C value & -34.35 & & -27.41 & -27.41 & -1.83 \\
\hline Value stable C in biochar only & & & & & \\
High revenue scenario & 12.77 & 16.77 & 16.77 & 43.91 \\
Low revenue scenario & -22.57 & 7.95 & 7.95 & 43.91 \\
\hline Value entire life cycle & & & & & \\
High revenue scenario & 35 & 11 & 11 & -26 & 69 \\
Low revenue scenario & -17 & -17 & -16 & -27 & 16 \\
\hline
\end{tabular}

A contribution analysis reveals that the superior economic performance of yard waste is mainly attributable to the tipping fees incurred upon landfilling. This highlights the revenue potential for waste streams that incur a tipping fee. Such wastes may differ in composition and may pose other challenges such as moisture content, for example in animal manures and sludge, that may make them uneconomic to process in a pyrolysis system. 


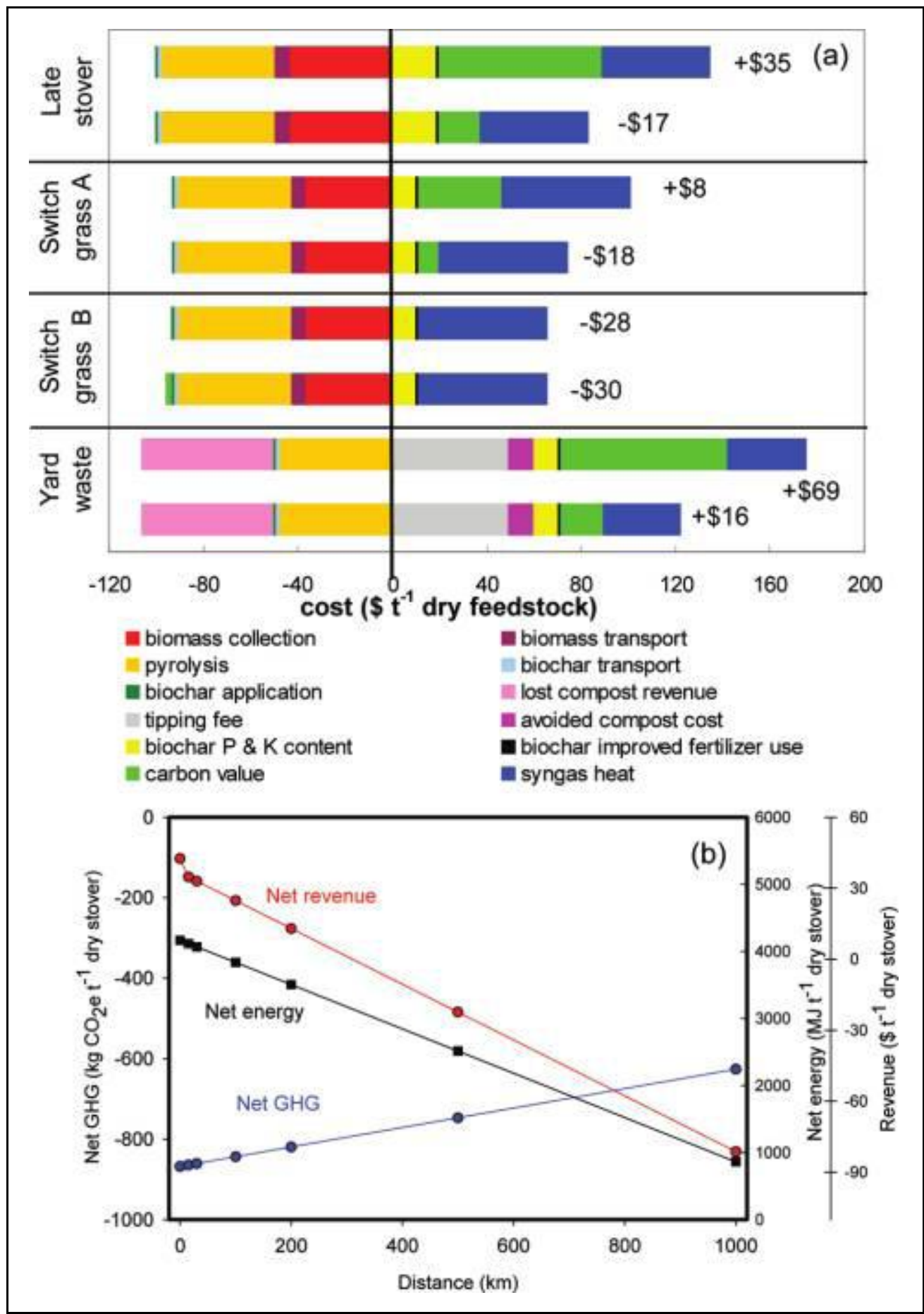

Figure 46: Contribution analysis for cost per tonne of dry feedstock (Roberts, et al., 2010a, p. 831)

(a) Top bars represent the high, and bottom bars the low, C price scenario for each feedstock with the net revenue (+) and cost (-) indicated adjacent to each bar.

(b) Effect of transportation distance on net GHG (blue circles), net energy (black squares) and net revenue (red circles) using the example of late stover feedstock under a high $\mathrm{C}$ price scenario (Roberts, et al., 2010a, p. 831).

As for the life cycle assessments in section 6.2.2 above, it is crucial to stress the highly case-specific nature of these results. A change of underlying assumptions and models will 
yield different outcomes. This analysis may, therefore, be seen as a general indication. Individual economic as well as environmental impact assessments are needed for each biochar deployment case so as to account for the specific context in which the project is implemented.

If economic viability of a pyrolysis project is heavily dependent on income from carbon offsets, it is prudent to first investigate biochar's potential as an offset. This means biochar quality standards, stability of biochar in soil, and methods for monitoring biochar utilisation and stability, must be established prior to its recognition in carbon crediting (Ogawa, et al., 2006).

\subsection{Potential Applications of Biochar in the NZ Context}

This section summarises potential applications of biochar in NZ as identified by research participants from across all stakeholder groups.

Interest in biochar from a public policy point of view arises from the strategic goal of enhancing performance of NZ's primary sector. Public sector interviewees explained NZ's publicly funded research efforts in biochar with the interest of exploring its potential to remedy some of the environmental and economic difficulties that the primary sector is struggling with. In agriculture, these include the high share of the sector in relation to NZ's total GHG emissions as well as more specifically water pollution from nitrate leaching due to fertiliser application and manure load on pastures. In forestry, large quantities of harvesting residues are generated which represent only a low-grade resource. Additionally, forestry products suffer from low prices on export markets. Participants reported depressed log prices as a major economic concern.

Interviewees pointed out that NZ will incur deforestation liabilities under the Kyoto Protocol, particularly post-2020 when large areas are due for harvesting. This is supported by the literature which indicates the Central North Island, Northland and the East Coast as the major harvesting areas over the next 10-20 years (Hall \& Gifford, 2007). In this context, biochar was identified by policy interviewees to be worth exploring in more 
depth as it may help to mitigate the GHG problem as well as providing a pathway for diversification of forestry products.

Public sector stakeholders also identified future utilisation options of bio-oil for NZ. While bio-oil cannot be readily used as a liquid transport fuel in motor vehicles, it may prove helpful in shipping as "a solution to NZ's bunker fuel problem" (policy interview participant). Additionally, interviewees identified the option of using bio-oil in the dairy industry where heating is required in milk powder production.

The stakeholder group of agriculturalists identified benefits from biochar land application in dry areas such as the east coasts of both the North and the South Island, particularly where this situation is compounded by overallocation of water (e.g. Canterbury). In adverse climate conditions, such as droughts, biochar was seen as a potential means to increase resilience and to give "longer shoulders" (agriculture interview participant) in dry months. In general, biochar was perceived as being a niche market or boutique solution but not a main stream tool. As a policy interviewee points out:
"There are some ideas which wouldn't be large areas but these are often expensive problems. So maybe there's a niche market for biochar rather than a general market." (Vera Power, Manager: Science, MfE)

Such expensive problems may include mining remediation or reduction of nitrogen leaching in sensitive catchment areas. The literature suggests that the latter application may provide a temporary solution only due to saturation of the biochar. Also, unclear desorption behaviour of biochar makes it difficult to predict the suitability for its longterm potential to remedy localised pollution (Haard, 2010; Krull, 2010).

Public sector stakeholders diagnosed bioremediation of heavy metals as a potential application of biochar. One suggestion was mitigation of elevated cadmium levels, resulting from phosphate application. An interview participant working in the public sector explains:

"It is quite possible that there are contaminated sites in NZ where an addition of biochar would reduce the bio-availability of chemicals or heavy metals. In other 
words, biochar could be used to prevent harm by avoiding chemicals or heavy metals ending up in the human food chain. Now, that is an entirely non-trivial matter because many NZ soils have elevated cadmium levels. The reason is that our soils are generally low-phosphate and therefore farmers add super phosphate to our soils to lift the phosphate levels and unfortunately a lot of the phosphate has quite high cadmium levels." (Peter Winsley, MED)

The potential benefits of both increased soil water holding capacity as well as pollution remediation arise from the sorption behaviour of biochar with its highly porous structure and large surface area. Biochar has been shown to be effective in adsorbing environmental pollutants, but biochar's desorption behaviour warrants further research. Interviewees from the stakeholder groups of academics emphasised that in dry conditions, biochar may potentially aggravate the situation if water is adsorbed but not desorbed and hence, unavailable to plants. Similarly, researchers pointed out that adsorption of hormones, heavy metals and other pollutants may be reversible, meaning that they become bio-available again.

Additional to environmental concerns and economic barriers, interviewees also pointed out that practicalities may pose barriers to large-scale utilisation of biochar as a soil amendment in $\mathrm{NZ}$ agriculture given that the dominant agricultural land use regime is pasture and not broadacre cropping, though maize crops are widespread in some areas. Participants imagined the actual land application of biochar being far more straightforward in broadacre cropping than under a pastoral regime where the soil is not regularly tilled or direct-drilled. Further, even if biochar could be applied in some cropping or pasture situations, different equipment would be needed, imposing additional costs. Denis Hocking from the NZ Farm Forestry Association pointed out that trying to incorporate biochar use into existing practices by simply mixing and spreading it with fertiliser may not work because grain sizes of biochar and fertiliser differ.

Despite such concerns, agriculturalists identified potential for use of biochar in high-value horticultural crops where profit margins allow for additional inputs. It was believed that in such circumstances, a net negative carbon balance of biochar, demonstrated in case-bycase assessments, could open up a new niche market for carbon-negative agricultural produce. Agriculturalists suggested that such a marketing strategy may enhance the 
environmentally friendly image of $\mathrm{NZ}$ agriculture. It may also enable the primary sector as a whole to demonstrate action to reduce the carbon footprint of NZ's primary sector. As with many other industries, NZ's organic sector produces for the export market. This implies that biochar needs to be formally recognised in the standards of those countries that NZ organic produce is exported to so as to ensure continued market access. The issue of consumer perception is also important, as David Wright from the Bio Dynamic Association points out:

“An important one is perception. It doesn't just matter that you're doing the right thing. You have to be seen to be doing the right thing and sometimes you can be seen to be doing the wrong thing. So what would the consumer perception of biochar be? Organic standards generally won't have anything that has a negative consumer perception if they can avoid it." (David Wright, Secretary, Bio Dynamic Farming and Gardening Association in New Zealand, Inc.)

To help enhance the sustainability of NZ agriculture, biochar would need to meet several conditions. Among others, these include that LCA show net GHG savings from biochar use compared to existing practices in $\mathrm{NZ}$ agriculture, harm to ecosystems can be excluded, biodiversity is not adversely impacted and water and fertiliser use efficiency will increase as a result of biochar soil application. If these and other beneficial impacts can be demonstrated, biochar may serve as a tool for enhancing the sustainability of NZ's agricultural sector. This in turn may serve to enhance the image of a sustainable, clean and green NZ agriculture and improve consumer perception. Organic agriculturalists contemplated that labelling organic products as 'carbon-negative' may have potential to boost demand. The importance of consumer perception, especially for NZ exports of primary produce, is also referred to by Vera Power from MfE when saying:

"There is also the issue in terms of international perception of NZ agriculture and sustainability, and obviously the fact that markets are very focused on how sustainably it is produced. For example, the UK and German markets very much focus on that. So potentially, even if there wasn't a role for biochar under the UNFCCC [i.e. international recognition as a carbon sink] there may be a role for it in terms of how sustainable NZ farms are." (Vera Power, Manager: Science, $M f E)$ 
Analysis of the stakeholder views elicited for this study suggests that the adoption of biochar by practitioners as well as acceptance by consumers are subject to the conditions that a net energy and GHG benefit is demonstrated over the entire life cycle and that the absence of short- and long-term environmental harm can be confidently asserted.

The need to actively search for environmental disbenefits of biochar to ensure the absence of harm is underlined by Charles Merfield who summarises:

"We need to find evidence of harm rather than assuming the lack of evidence is a proof for absence." (Charles Merfield, horticultural researcher and consultant)

Assuming that GHG benefit and absence of environmental harm have been demonstrated, barriers to biochar adoption may nonetheless exist. Profit margins may be insufficiently large to enable purchase and land application of biochar as suggested by farmer Max Purnell.

"I can't see the margin where biochar fits in. The profit margin in farming is so small that farmers could just not pay for the biochar. They are often highly indebted anyway and are struggling to cover their running costs." (Max Purnell, farmer trustee of AGMARDT)

The extent to which these economic constraints may differ between organic and conventional farms is excluded from the scope of this study and may be further explored in economic case studies on biochar feasibility.

If large-scale biochar use in NZ for carbon sequestration purposes is economically unfeasible and environmental externalities are uncertain, where else could carbon be sequestered in large quantities? ENGO stakeholders suggested improved management of native forests as an alternative that could achieve significant increase of carbon storage in NZ's terrestrial ecosystems. Kevin Hackwell from Forest and Bird remarks:

"Better that we stop grazing the hill country and let it regenerate. That's a much better sequestration process than say, 'oh we can keep the sheep and the cows on 
it, let's put biochar instead.' That would be a wrong answer ... Thinking it through in total: What is the biology, what is the system, what are we trying to achieve? What is the best outcome? Well, biochar in the hill country wouldn't be an outcome you want because that would just encourage further grazing of those soils. We'd be much better off saying 'let's get out of the hill country. Let's turn the hill country back into native vegetation.' ... I'm not saying no to biochar. I mean I'm sure it's got a lot of use even here in NZ. My question is about the extent, that's all." (Kevin Hackwell, Advocacy Manager, Royal Forest and Bird Protection Society of New Zealand Inc.)

Overall, NZ's terrestrial ecosystems have been found to be a net source rather than a sink of carbon (Tate, et al., 2000). Designing policy that aims to incentivise land-based carbon sequestration may wish to first identify NZ's terrestrial carbon pools and secondly to evaluate available options according to their potential for enhanced carbon uptake and storage.

As to carbon storage in terrestrial ecosystems, NZ's natural and planted forests are major terrestrial carbon sinks but the forested land area declined by two thirds over the past thousand years with an associated loss of about 3,500Mt vegetation carbon (Tate, et al., 1997). NZ plant biomass (above- and below-ground) is estimated to be 2,420 Mt C, including litter and humus. Significantly, “[m] ore than $80 \%$ of this carbon occurs in indigenous forested ecosystems on less than $26 \%$ of the land area, with only about $5 \%$ in planted forests" (Tate, et al., 1997, p. 315).

It has been estimated that $1.45 \mathrm{Mha}$ of pastoral land are marginal and would be suitable for afforestation and reforestation by indigenous shrubland or forest which could accumulate $2.9 \pm 0.5 \mathrm{Mt} \mathrm{C}$ per year (Trotter, et al., 2005). This equates to $10.63 \pm 1.83 \mathrm{Mt} \mathrm{CO}_{2}$-e per year, representing $14.2 \%$ of gross emissions or $21.9 \%$ of net emissions of NZ in 2008 (MfE, 2010b).

Comparing this with the NZ potential of carbon sequestration via biochar as estimated by Shrubsole (2009), it is calculated that domestically produced biochar could sequester 3.15-4.03 $\mathrm{Mt} \mathrm{CO}_{2}$-e, equating to 4.2-5.4\% of NZ's 2008 gross emissions and 6.5-8.3\% of net emissions. This is a third to a half of the carbon sequestration potential via 
afforestation and reforestation of marginal pasture land with native vegetation as estimated by Trotter and colleagues (2005). This suggests a higher carbon benefit from improved management of NZ's indigenous old-growth forests than from biochar deployment.

Several studies show contrasting results as to whether old-growth forests are in carbon equilibrium, i.e. their carbon accumulation equals respiration ${ }^{61}$ (Odum, 1969). Carey and colleagues (2001) compared net primary productivity (NPP) of natural coniferous oldgrowth forests in the Northern Rocky Mountains with models of NPP and found that the latter underestimated NPP by $50-100 \%$. This was due to the modelling assumption that productivity changes over time in complex, multi-aged, multi-species natural forests can be extrapolated from measurements of individual trees or even-aged stands. However, it has been shown that late succession and species diversity are significant drivers of the long-term carbon sequestration of old-growth forests (Carey, et al., 2001). Other studies support the finding that old-growth forests are a net sink of carbon (Luyssaert, et al., 2008; U, et al., 2004).

Additional to the above-ground carbon sequestration, below-ground processes significantly contribute to the carbon pool size of old-growth forests. Soil organic carbon (SOC) levels had previously been assumed to be in equilibrium in old-growth forests (Odum, 1969). A 24-year study found an increase of 1.4-2.35\% in SOC concentration in the top $20 \mathrm{~cm}$ soil layer with an average rate of $0.61 \mathrm{tC} \mathrm{ha}^{-1}$ year $^{-1}$ (Zhou, et al., 2006). In contrast, young forests, that are establishing after disturbances such as forest fires, harvest or insect infestation, are often a net source of carbon due to disturbance of soil and existing vegetation, leading to decomposition of coarse woody debris, litter and soil organic matter (Harmon, Ferrell, \& Franklin, 1990; Pregitzer \& Euskirchen, 2004). In NZ, soil carbon losses under pinus radiata are highest in year 1-10 and continue albeit at a lower rate until harvest at about year 26 (Scott, Tate, Ross, \& Parshotam, 2006; Tate, et al., 2004).

Old-growth forests in general and NZ's indigenous forests in particular are significant carbon sinks, and potential for additional sequestration is suggested. Native forests are out

${ }^{61}$ This assumption also underlies estimates of soil and forest carbon stocks in NZ's latest GHG Inventory. It is assumed that land reaches equilibrium after 28 years, corresponding to the average time after which plantation forests are harvested (MfE, 2010b). 
of balance due to introduced pests, mainly brushtail possums, wild pigs, goats and deer (Norton, 2009; Rogers, 1995b). Participants indicated that improved management of native forests and particularly pest control may help to rectify the imbalance. Kevin Hackwell from Forest and Bird illustrates this as follows.

"If NZ was going to invest significantly in trying to sequester carbon, which is what biochar is an argument for, if you look at the NZ context, we'd be much better off investing those sums of money and research into better ways of sequestering carbon in our indigenous vegetation. Particularly given that we had 150 years of introduced species and our native forests, which are the vast majority of our vegetative carbon, are not in balance because they have possums and goats and deer munching their way through them. If NZ wants to make a significant contribution to dealing with climate change by sequestering carbon, then the best way we could do it as a nation would actually be to invest in better management of our indigenous forests. Kill the pests basically. “ (Kevin Hackwell, Advocacy Manager, Royal Forest and Bird Protection Society of New Zealand Inc.)

Agricultural stakeholders frequently cited the need for policymakers to consider carbon sequestration options other than biochar. Participants emphasised the particular importance of soil carbon sequestration and of harnessing the beneficial effects of improved soil life and biological processes for the maintenance and enhancement of soil carbon levels. Many organic farmers expressed frustration about the fact that the current carbon accounting framework disregards soil carbon. Hence, it ignores the contribution to soil carbon sequestration that organic and biological farming practices are already making (Reganold, 1995; Reganold, Palmer, Lockhart, \& Macgregor, 1993). Participants felt that in terms of research funding, preference is given to potential future (bio)technological solutions rather than organic methods which are already available and have been shown to maintain or increase soil carbon levels. Seager Mason from BioGro summarises as follows:

"For us, what we would like to see is work done to measure the value that organic farms are producing already by sequestering carbon ... So that'll be the starting point. But yeah I think it would be good if part of the research effort was concerned with some direct measurements of to what extent organics are already 
a plus. And then to what extent the use of biochar could enhance or enter that. We just feel we are not recognised for something that clearly we are benefiting, to our knowledge we are benefiting, the carbon emission problem, but we are not recognised for it. It's a public good problem. And it is a common argument to organics that you have a small group of producers and a small group of consumers who are again producing a public good and the others are free-riding basically." (Seager Mason, Technical Manager, BioGro)

The need to search for carbon sequestration pathways other than biochar is also highlighted by David Wright from the Bio Dynamic Association who remarks:

"I think 'what else could you be doing?' is part of the equation." (David Wright, Secretary, Bio Dynamic Farming and Gardening Association in NZ, Inc.)

Various studies in the US, Australia, Europe, northern Africa and central Asia indicate increases in soil carbon in organic compared to conventional management (Johnson, et al., 2007). Overall, organic systems perform better that conventional agriculture in that soil organic carbon and nitrogen levels are higher, less fossil energy is being used and soil moisture retained (Pimentel, Hepperly, Hanson, Douds, \& Seidel, 2005).

In NZ, greater soil organic carbon content was found in biodynamic compared to conventional farming systems (Reganold, 1995; Reganold, et al., 1993). Overall, biological and physical parameters showed improved soil quality on biodynamic farms, and economic viability was comparable to that of conventional farms (Reganold, 1995; Reganold, et al., 1993).

In regard to biochar, stakeholders across all groups emphasised the importance of policy in determining the economic incentives framework as well as the conduct of fundamental research. Particularly increased publicly funded research on the matter was strongly supported by many stakeholders. While desirable, it is acknowledged that this is not extensive in NZ, where the science funding system is highly contestable, although public science agencies and public funding of university research is the norm. 
Policy directions and implementation on all levels of government directly and indirectly steer and shape NZ's path toward a low-carbon economy. But what are the key roles for government that public sector and other stakeholders identified specifically concerning biochar deployment? The following section aims to present suggestions on this matter by stakeholders and framing them in the light of theory.

\subsection{Role of Public Policy}

Public policy provides part of the socio-economic and institutional framework in which biochar deployment ultimately occurs. Legislation determines rules and responsibilities, allocates rights and obligations and thereby structures the socio-economic context. The roles of government in regard to biochar as identified by research participants are outlined in the following sections.

Interviewees working in the public sector identified the role of public policy in regard to biochar first and foremost as one of being an enabler rather than direct regulator. Facilitating collaboration in research on a national and international level as well as funding the public good of knowledge were cited by policy interviewees as the prioritised steps. Fundamental research regarding the performance of biochar under NZ conditions was identified as crucial for policy decision-making before any more far-reaching decisions are made. Rather than direct intervention, regulation or subsidisation, policy stakeholders saw the primary role of government as providing information that would enable the primary sector to make an informed decision about biochar adoption or rejection. In order to obtain the relevant information, some NZ research on biochar is publicly funded. Policy interviewees mentioned financial support in the form of grants for feasibility studies, scholarships (to steer research directions and build capability in soil science and related areas) as well as support for research coordination on a national and international level. Participants explained that part of the strategic approach is to fund continued capability built-up in the current absence of economic signals while hoping that private commercial interest might arise if research shows net benefits from biochar. 
A policy interview participant also identified a role for government in brokering arrangements between the supply and demand sides. That is, government could help to broker contracts for waste streams, thereby establishing a supply chain. Government may help to fund business case development. A hypothetical example mentioned by a public sector interviewee was the collaboration between biochar businesses and Central North Island iwi whose large forest estates may provide biochar feedstock.

A feed-in tariff for renewable energy from pyrolysis enjoyed little enthusiasm in policy circles as it essentially represents a subsidy, suspected to have other market-distorting effects. Despite such reservations, and provided that LCA of pyrolysis projects demonstrate an overall climate benefit, a feed-in tariff for renewable energy can provide an environmentally effective and economically efficient policy instrument to increase the uptake of the technology as described in Chapter Five.

The self-ascribed role of government as an enabler, an investor in the public good of knowledge and a broker between supply and demand appears to be in line with the interest of the primary sector. Both forestry and agriculture highlighted the need for further research, particularly in NZ soil and climate. Some agriculturalists expressed the wish to trial biochar on their land if it was available free. This suggests that enhanced collaboration between the primary sector and the research community may result in mutually satisfactory arrangements.

Public policy may wish to consider how to best enhance collaboration between the primary sector and the research community so as to enable trials under field conditions. Such arrangements may aim for longer-term collaboration, since research participants across all stakeholder groups identified the need for long-term field trials. Given that many domestic and overseas research projects have focused on small-scale laboratory experiments, trialling biochar under field conditions is expected to enhance understanding of environmental impacts. General best-practice standards must be adhered to so as to ensure the absence of contamination in the biochar and the minimisation if not elimination of other adverse environmental impacts, such as dust spreading during land application. 
Field trials may also increase practitioners' familiarity with biochar and provide the added benefit of an inclusive and participatory process. Increasing experience with the innovation biochar is likely to enhance its diffusion (Rogers, 1995a), provided an agronomic benefit is shown. The importance of inclusive, participatory processes involving a diverse range of stakeholders was also highlighted by Jim Jones from Massey University who said:

"One of the issues is stepping the technology into NZ. You can't just do a research project and say 'Ha, we have the answer! Here it is!' And you hand over a volume for the good of anyone who comes to the library. It's really a matter of finding partnerships to get the technology out there and tried and worked on and working on different systems" (Jim Jones, Professor of Biochar and Bioenergy Pyrolysis Engineering, NZ Biochar Research Centre, Massey University)

His comment also reflects the significance that diffusion research attaches to learning and communication. It also hints at the importance of adoption thresholds. That is, once a certain proportion of individuals has adopted an innovation, increasingly more individuals are willing to try the innovation and hence the rate of adoption increases (Valente, 1996). A further comment by Jim Jones may be seen in this context:

"It's a matter of stepping through a whole lot of different sectors to distribute the biochar technology. And once you've got that out there, wide enough and enough people are using it and are familiar with it, know what it is, some engineering firms making the units for people, then it can take off" (Jim Jones, Professor of Biochar and Bioenergy Pyrolysis Engineering, NZ Biochar Research Centre, Massey University.

When thinking about the spread of new agricultural technologies, Denis Hocking from the NZ Farm Forestry Association refers to direct drilling as an example when saying:

"Farmers do what their neighbours do. Farmers learn from farmers. Look at direct drilling, for example, that took maybe 20 years - as an off-the-cuff estimate - till it was adopted. Biochar would take at least 10 years from now." (Denis Hocking, NZ Farm Forestry Association) 
His comment also emphasises the importance of homophily. That is, one is more likely to adopt an innovation that has already been successfully adopted by a peer who is of similar socio-economic status, education, beliefs etc. (Rogers \& Shoemaker, 1971; Strang \& Macy, 2001). In the word of another research participant, this is expressed as follows:

"We need to get people comfortable with culture change. The farmers who are providing land for field trials should be 'normal' farmers and no greenies or hippies." (interview participant)

As established in Chapter Five, a high degree of homophily implies increased efficiency of communication. Ultimately, communication is what diffusion is all about, with the specific feature that the communication is concerned with a new idea (Rogers, 1995a). While the spread of information and learning are so essential for diffusion, agriculturalists expressed dissatisfaction about the extent of freely available and scientifically sound information on biochar. They deplored that information on biochar in the farmer's literature is "not investigative but just uncritical reporting of what they have heard" (agriculture interview participant). Additionally, agriculturalists identified high transaction costs as a barrier to obtaining scientific information via, for example, scholarly journals. Such transaction costs include time spent on researching and money spent on subscription fees for scholarly journals.

In sum, policy decision-making in regard to whether or not the innovation of biochar is to be diffused and encouraged in NZ will not be easy. NZ-specific research outcomes regarding environmental effectiveness and economic efficiency are still pending, public awareness is low and public acceptance highly diverse, even within the same stakeholder group. One interview participant expressed the situation for policy awaiting research outcomes prior to more far-reaching decision-making the following way:

"It is a matter of wait and see what we get." (policy interview participant)

The role of government in providing information and facilitating collaboration, instead of intervening and regulating directly is summed up by a policy interviewee who says: 
"What we can do is put the information out there for farmers to make a judgement." (policy interview participant)

Climate change is an urgent problem that demands broad-scale and immediate action. The difficulty for biochar deployment is the high variability of biochar performance, depending on factors such as feedstock, pyrolysis conditions, soil type and climate. For this reason, generalisability of research findings is very limited, suggesting that environmental impact assessments will need to be made on a case-by-case basis.

Other criteria to be taken into account when assessing the feasibility of biochar deployment are a country's reputation on an international level and compliance with international obligations. Vera Power from MfE expresses this the following way:

"NZ wants to be seen as a good global citizen by saying 'we want these technologies to be out there'. But the problem is that it's only effective if adoption occurs globally and then you've got all these issues that we have in general with international agreements [e.g. free-riding, hold-outs etc.]. From a policy perspective looking at how the rules are defined through the UNFCCC is very important. That enables us to consider these types of options. "(Vera Power, Manager: Science, MfE)

Concerning compliance with international obligations, as established in section 4.1.2 above, Article 3.4 of the Kyoto Protocol would theoretically enable biochar's inclusion as a means of carbon sequestration. At present, biochar is not formally recognised in any country's legislation as a way of meeting liabilities under the Kyoto Protocol.

While international policy experience with biochar is limited, NZ public policy may nonetheless wish to sound out the situation in the domestic context. By drawing on the stakeholder perspectives discussed in this chapter so far, the next chapter hopes to derive some suggestions for public policy in $\mathrm{NZ}$ and to indicate further research needs. 
Introd | Method | Biochar | Institutions | Theory | Analys\&Disc | Concl

\section{Conclusion}

This chapter derives policy suggestions based on the analysis and discussion of NZ stakeholder perspectives on biochar. It also suggests areas for further research and 'anchors' the conclusions by revisiting the aim and objectives of this study.

\subsection{Public Policy Suggestions}

This section aims to suggest approaches for public policy based on the empirical findings presented in this chapter.

From the stakeholder perspectives on biochar elicited in this study it appears that perceptions are dominated by the issue of scientific uncertainty. Immediate and long-term environmental impacts of biochar production and use, including anticipated and unanticipated side-effects and particularly negative externalities, are still subject to further research. Uncertainty arises from the high variability of biochar performance, determined by feedstock, manufacturing conditions, soil type and climate to name a few. This implies that environmental impacts will need to be assessed on a case-by-case basis. The same is true for economic issues. Not only quantity but also quality and competing uses of potential feedstock biomass are to be considered.

While scientific uncertainties remain, the policy principles of precaution and sustainability may provide guidance in decision-making. Ultimately, policy may wish to ensure prevention of harm to human and environmental health. For this reason it appears worthwhile to develop standards or include biochar production and use in existing standards and regulations, such as the National Environmental Standard for Assessing and Managing Contaminants in Soil that is being developed (MfE, 2010d).

To prevent perverse incentives for discharge of contaminated biochar (e.g. made from old tyres or sewage sludge) into the environment, it is also advisable to assess whether biochar would be subject to the Hazardous Substances and New Organisms Act or 
whether additional provisions would need to be included in the Act. Furthermore, the Resource Management Act (RMA) may serve to regulate pyrolysis plant development or spreading of biochar on land. Under the RMA as an effects-based piece of legislation, spreading of biochar could be restricted to certain areas or times of the year. This may help to minimise impacts on human and environmental health that could result from biochar losses due to wind and water erosion.

In addition to the abovementioned environmental standards and legislation that are not specific to a single substance, compiling sustainability criteria specific to biochar production and use may help to ensure responsible deployment. As minimum specifications these criteria should include acceptable and unacceptable land-use policies and a minimum threshold of carbon sequestration achieved by individual projects. Furthermore, industry standards could be developed that specify inputs and outputs, such as origin and quality of feedstocks, or minimum carbon content, as well as maximum contamination thresholds of the biochar product. Industry standards could also set benchmarks that require businesses to use the best available technology to minimise any adverse environmental impacts. Initiating such standards and regulations in the domestic context appears particularly important as international standards regarding the sustainability of biochar projects, quality controls of biochar and industry best practice codes are still absent.

In order to determine whether a precautionary approach should be taken toward biochar, the relative risks of climate change and biochar deployment may be considered as well as other available mitigation pathways and their associated risks and uncertainties.

Implementation of small-scale, locally confined biochar projects may be judicious rather than promoting nationwide adoption on a large-scale. This would allow for careful environmental impact assessment to ensure the prevention of harm. A project-based evaluation of risks and benefits may prove useful in these early stages of diffusion of the innovation of biochar.

The incentive structure will need to be carefully crafted so as to avoid perverse outcomes. Positive and negative externalities need to be anticipated and internalised where possible. 
The diffusion of an innovation is not only determined by scientific evidence about costs and benefits of the innovation but also by people's perception of it. Public acceptability will be low if it is made an exclusive and obscure process, open to input from the research and business communities only and highly inaccessible for practitioners (in a physical as well as intellectual sense). Assessing the costs and benefits of biochar deployment in NZ should include active involvement of the public. It should also make use of the experience by people working 'on the ground' such as agriculturalists, foresters and other groups who are potential stakeholders. A participatory process is recommended which establishes a continuous dialogue between the research, practitioners and policy communities.

Establishing and sustaining a continuous information flow between these groups may advance understanding of the physical impacts of biochar as well as affect perceptions. Extensive and intensive communication can be expected to build trust and familiarity, both of which are crucial for decision-making about adoption or rejection of an innovation. Transparency and full disclosure are pivotal. Information on what works and what does not work, and on which conditions biochar is found to enhance or diminish agronomic performance or overall energy and GHG balances, must be publicly available at no or little cost.

Participation and familiarity may further be enhanced by offering agriculturalists the option of trialling biochar on part of their land with the biochar provided free of charge. Funding for that may come from the Vote for Research, Science and Technology in the 2010 Budget where appropriations are made for both 'Engaging New Zealanders with Science and Technology' and 'Environmental Research' (Government of New Zealand, 2010).

Active involvement of stakeholders, seeking their opinion and input regarding various aspects may help to give biochar deployment in NZ a 'reality check' in terms of the practicalities of application (e.g. what equipment can best be used for spreading), pyrolysis design (e.g. mobile versus fixed plants) or operational health and safety and ease of use of pyrolysis equipment. 
A further option of increasing familiarity may be field days. These would ideally involve a mobile pyrolysis plant for live demonstration. The need for information involves the option for agriculturalists to get first-hand and literally hands-on experience with biochar.

Policies to increase the uptake of biochar systems might make use of financial incentives for the renewable energy that is generated during pyrolysis. This could stimulate investment in pyrolysis technology. Designed as a feed-in tariff, this may encourage small-scale installations that could feed energy back into the grid with the added benefits of increased community resilience and energy security. Further, provisions need to be made to facilitate the process for small generators to be connected to the grid.

Importantly, it is emphasised once more that the above suggestions concerning diffusion of the innovation biochar only apply if a net benefit of biochar deployment in NZ can be scientifically demonstrated. In regard to biochar as a climate change mitigation tool, scientific uncertainties remain about the exact quantification of the half-life of different biochars, the measurement of fixed and volatile carbon contents and the stabilisation mechanisms of biochar-carbon in soil. Biochar may fit into the climate change mitigation toolbox as one piece of a much larger puzzle. Exploration of a diverse range of abatement pathways is essential. Any overall climate benefit of biochar deployment in NZ is still subject to further research and will quantitatively not be enough to be a single solution. Efforts of better management of native vegetation, for example, offer environmental benefits additional to carbon sequestration, such as provision of wildlife habitat and biodiversity protection. At the same time, such public investments in enhancing carbon storage in native vegetation will have few risks.

In sum, further research is essential in regard to soil science, pyrolysis engineering and energy and GHG life cycle assessment on a case-by-case basis. While biochar may not have a large impact on carbon storage in NZ's terrestrial ecosystems, it may provide agronomic benefits. These are still to be scientifically demonstrated. For climate change mitigation purposes, reducing fossil fuel consumption and increasing energy efficiency are to be prioritised over any carbon offsetting activity via biochar. 
Introd | Method | Biochar | Institutions | Theory | Analys\&Disc | Concl

\subsection{Suggestions for Further Research}

This research has generated some insights into stakeholder perspectives and their implications for the diffusion of the innovation of biochar. It has also demonstrated the need for further research concerning various aspects of biochar. More robust data on the environmental impact of biochar under NZ conditions are needed to enable informed decision-making by policymakers as well as primary sector stakeholders. Further research on biochar performance in temperate climates, including long-term field trials is required to assess the usefulness or otherwise of biochar deployment in such regions.

Given that the dominant land-use regimes in NZ's primary sector are pasture and pine plantation forests, studies on biochar in forest soils and under pasture may provide valuable information. In particular, the effects of biochar on tree growth and native organic matter in NZ's high-carbon soils warrant further research. It needs to be determined whether biochar addition enhances mineralisation and decomposition of native organic matter and thus increases soil GHG emissions.

All these research needs identified above hint to the crux: we do not fully understand soil processes - irrespective of whether biochar has been added or not. Research needs include soil science at a fundamental level. Interactions between the mineral soil matrix and soil life as well as the relevance of various physical and chemical parameters for biophysical and biochemical soil processes await further clarification. Although of utmost importance to soil quality and hence agronomic value, soil life - bacteria, fungi and other microbes - is only poorly understood. Its diversity and the complexity of interactions pose ongoing research challenges.

Pyrolysis engineering also needs research, especially those related to the impact of various process parameters and feedstock characteristics on the quantity and quality of the pyrolysis products biochar, syngas and bio-oil.

All this information will help to assess the energy and GHG life cycle balance of biochar projects. These should be evaluated on a case-by case basis and for various scales in NZ, with underlying assumptions as close to realistic conditions as possible. This may help to reflect particular local conditions and the specific performance of biochar from different 
feedstocks and in different soils and climates. A full life cycle approach needs to be taken. Results of life cycle analyses will be highly sensitive to feedstock availability as well as to the economics of transport, distribution and the scale of pyrolysis equipment. Due to the high variability of biophysical as well as economic factors, a case-by-case assessment seems judicious. This would facilitate an assessment of all three dimensions of sustainability - environmental, social and economic - on a regional or local scale.

Comparative studies of biochar versus other agricultural GHG mitigation techniques are needed. Such studies may asses performance according to various criteria, e.g. environmental effectiveness, cost-efficiency, relative risks, reversibility, long-term consequences and ethical implications. More specifically, comparative analysis of biochar versus existing agricultural methods to enhance soil carbon sequestration, such as composting, green manuring, direct drilling or various grazing management regimes will provide valuable additions to the body of knowledge. This comparative analysis again, will need a holistic approach by having regard to the entire life cycle.

Valuable insights could be provided by studies conducted in close collaboration with practitioners. 'Real world issues' surrounding feedstock and/or biochar procurement as well as practicalities of application are often a neglected perspective, but are outside the scope of this study.

Investigation of stakeholder perspectives other than those identified for the purposes of this study will usefully complement this thesis. For example, within the stakeholder group of agriculturalists, this research focused on organic farmers. Not all participants were involved in formally organically certified agriculture, but they certainly showed a 'bias' in that they were environmentally inclined. Given the predominance of non-organic farming and its economic and political importance in NZ, it may be worthwhile to explore the perspectives of conventional farmers. 
Introd | Method | Biochar | Institutions | Theory | Analys\&Disc | Concl

\subsection{Closing the Loop in Seven Steps: Revisiting Aim and Objectives}

This section is intended to revisit the aim and objectives of this research presented in Chapter One. The aim of this study was to develop a picture of the current debate about biochar and to explore the implications for NZ public policy. The following subsections revisit and recapitulate the individual objectives and thus hope to demonstrate their accomplishment.

\subsubsection{Objective One, Chapter One}

Objective One was to briefly present the physical science base of climate change as a backdrop against which the concept of biochar as a mitigation tool is introduced. The guiding questions for Chapter One were:

- What are the wider environmental issues based on which biochar is introduced?

- What is biochar as a material?

Chapter One reviewed the scientific evidence for anthropogenic climate change. Significant emissions of GHG accrue from fossil fuel combustion and land-use change. The main GHG are $\mathrm{CO}_{2}, \mathrm{~N}_{2} \mathrm{O}$ and $\mathrm{CH}_{4}$. This study focused on $\mathrm{CO}_{2}$ due to both its abundance and longevity which make it the principal anthropogenic GHG that affects the Earth's radiative balance (IPCC, 2007b).

In striving to stabilise atmospheric $\mathrm{CO}_{2}$ levels, there is a quest for carbon sinks and reservoirs. One of the various climate change mitigation strategies and technologies that are proposed in the academic literature is biochar. Biochar soil application has been suggested to provide an effectively permanent carbon sink (Lehmann, 2007b; Lehmann, et al., 2006). Chapter One reviewed the literature on physical and chemical characterisation of biochar. The answer to what biochar actually is, based on a clear unambiguous scientific characterisation, has yet to be developed (Lehmann \& Joseph, 2009). As a minimal consensus, biochar is charcoal made for the specific purpose of 
Introd | Method | Biochar | Institutions | Theory | Analys\&Disc | Concl

application to agricultural land in order to sequester carbon and to enhance soil fertility (IBI, 2009b; Peacocke \& Joseph, 2009). It is "the stable carbon-rich product that results from heating biomass materials (such as municipal green waste, poultry litter, forestry and agricultural residues) in limited oxygen" (IBI, 2009a) at temperatures below $700^{\circ} \mathrm{C}$ (Lehmann \& Joseph, 2009).

\subsubsection{Objective Two, Chapter Two}

Objective Two was to establish the methodological framework for this study and present the specific methods employed in primary and secondary data collection and analysis. The guiding questions for Chapter Two were:

- What are the underlying paradigmatic assumptions of this study?

- Which specific methods are employed for primary and secondary data collection and analysis?

The paradigm adopted for the purpose of this study is environmental pragmatism. It emphasises the interconnectedness of humans and the environment and calls for an ethic of care with a long-term view (Parker, 1996; Rosenthal \& Buchholz, 1996). Pragmatic solutions to environmental problems may draw on various theoretical frameworks so as to achieve the best environmental outcome (Light, 1996) while maximising public participation in the policy formation process (Parker, 1996). Locating the research within this paradigm also means to caution against any claims to absoluteness and against generalising and extrapolating findings beyond the specific context studied.

Literature reviews of academic and policy publications were used for secondary data collection, and underpin various parts of this thesis. The multidisciplinary nature of the research required consultation of literature from sociology, psychology, economics and public policy as well as natural sciences.

In order to elicit the subjective perceptions of NZ stakeholders on biochar, a mixed methods approach was used for empirical data gathering and analysis. Semi-structured qualitative interviews were complemented by online surveys of the two largest 
stakeholder groups, forestry/wood processing and organic agriculture. Note that not all survey respondents and interview participants identified as strictly 'organic' in the sense of being formally certified, but they all certainly showed a 'bias' in that they were environmentally inclined. The surveys were not statistically representative but yielded a large amount of data for qualitative analysis. Thematic coding, as developed by Flick (2009), was employed to analyse the qualitative survey and interview data.

\subsubsection{Objective Three, Chapter Three}

Objective Three was to evaluate the evidence base for biochar in general and for NZ in particular. The guiding questions for Chapter Three were:

- What are the positives, negatives and unknowns about biochar in general and in the specific NZ context?

- Which potentially adverse side-effects may be anticipated?

Chapter Three reviewed the literature on biophysical and biochemical impacts of biochar in the environment as well as on aspects related to biochar production. The scholarly literature offers a differentiated picture of the environmental costs and benefits associated with biochar production and use as a soil amendment. Part of the academic literature suggests that biochar may have the potential to store carbon over geological time scales (Lehmann, 2007b; Lehmann, et al., 2006). Further GHG savings are suggested through renewable energy generation during biochar production as well as through agronomic benefits following biochar's incorporation into agricultural soil (Gaunt \& Lehmann, 2008; Joseph, et al., 2009; Steiner, et al., 2007).

On the other hand, research also suggests the loss of native soil organic carbon upon biochar addition to soil. This effect is attributed to stimulation of microbial growth and hence increased microbial respiration of native organic carbon and its release as $\mathrm{CO}_{2}$ (Wardle, et al., 2008a, 2008b; Pietikäinen, et al., 2000). It indicates that charcoal addition to high organic matter soils may result in increased rather than reduced soil GHG emissions. Given that NZ soils have a relatively high carbon content and that land use in 
Introd | Method | Biochar | Institutions | Theory | Analys\&Disc | Concl

the primary sector is predominantly pastoral agriculture and plantation forestry, limited benefit for NZ is suggested based on the review of scholarly literature.

Environmental impacts of biochar production and use may be detrimental or beneficial. A compounding problem is that the underlying mechanisms of many impacts are still unknown. The net GHG, energy and agronomic performance of biochar over its entire life cycle varies considerably, depending on a range of factors. These include feedstock, processing conditions, climate, soil type to which the biochar is applied and transport distances to name a few. For this reason, a blanket statement in support or dismissal of biochar is suggested to be impractical.

\subsubsection{Objective Four, Chapter Four}

Objective Four was to outline the institutional framework regarding (i) climate change policy and law (domestic and international as applicable) and (ii) the "biochar policy and research landscape' in NZ (domestic policy and public research institutions). The guiding questions for Chapter Four were:

- What is the existing framework in terms of legislation, policies and agencies into which biochar would need to be integrated?

- What repercussions and effects on climate change as well as other policy areas would a decision in favour of biochar entail?

Chapter Four surveyed the literature on the international and domestic institutional framework pertinent to climate change policy. Biochar could theoretically be acknowledged as a carbon reservoir under Article 3.4 of the Kyoto Protocol (UNFCCC, 1998), but no government is using this option (Gaunt \& Cowie, 2009). Such absence of recognition of biochar in international GHG accounting rules implies that even if biochar was included in the NZ Emissions Trading Scheme, biochar carbon offsets could not be sold on the international GHG market. In environmental terms there may still be a climate benefit from biochar as a carbon reservoir. The potential for long-term carbon storage 
Introd | Method | Biochar | Institutions | Theory | Analys\&Disc | Concl

through biochar in the NZ context will become clearer as domestic research efforts progress.

Under the Kyoto Protocol, NZ's responsibility target is to not let average total gross emissions per year over the period 2008-2012 exceed those of 1990 (UNFCCC, 1998). Such commitment notwithstanding, the country's gross emissions rose $22.8 \%$ from 19902008 (MfE, 2010b). Projections indicate that NZ will still fulfil its Kyoto obligation, but only by relying on carbon removals from land use, land-use change and forestry (LULUCF). These net removals more than compensate for the increase in GHG emissions since 1990. They are projected to even generate a net surplus of $11.4 \mathrm{Mt} \mathrm{CO}_{2}$-e for the 2008-2012 commitment period of the Kyoto Protocol (MfE, 2010c). LULUCF carbon removals vary with planting and harvesting rates each year and are difficult to predict with certainty. Especially considering that international accounting rules for a post-Kyoto period have yet to be specified, it is prudent to not rely too heavily on these offsets (The Treasury, 2009). NZ will incur deforestation liabilities under the Kyoto Protocol over the next 10-20 years because large areas in the Central North Island, Northland and the East Coast are due for harvesting (Hall \& Gifford, 2007).

Potential implications for and cross relations with existing laws and regulations need to be anticipated if policy was to decide on the diffusion or otherwise of biochar in NZ. Policy may wish to consider implications for the Climate Change Response Act, the Resource Management Act (RMA), various waste management laws and regulations, the Hazardous Substances and New Organisms (HSNO) Act, future biofuels policy and policies related to small-scale, distributed energy generation from renewable sources.

Domestic research on biochar is conducted by various universities and Crown Research Institutes throughout $\mathrm{NZ}$ and results will help to make an informed decision.

\subsubsection{Objective Five, Chapter Five}

Objective Five was to establish a theoretical framework based on theories as they apply to decision-making under risk and uncertainty, public policy, economics and innovations to 
Introd | Method | Biochar | Institutions | Theory | Analys\&Disc | Concl

frame the problem of biochar deployment in NZ. The guiding questions for Chapter Five were:

- What considerations for GHG policy design are suggested by theory and which policy criteria and principles can be applied when decisions have to be made in the face of risk and uncertainty?

- Which theoretical perspectives offer useful insights when biochar is framed as a new climate change mitigation tool?

From an economic perspective, GHG emissions are a negative externality. This study framed biochar as a potential means to help internalise this externality by drawing on neoclassical and ecological economic approaches and pollution control theory.

Using biochar as an 'internalisation tool' represents a new pathway among the existing array of climate change mitigation technologies. For this reason, biochar was also framed as an innovation. Chapter Five surveyed the literature on theories of innovation and their diffusion. It showed that additional to the factual knowledge about an innovation (such as that generated by the natural sciences and engineering science), subjective perceptions of an innovation are at least equally important in determining the adoption or rejection of an innovation. Beliefs and attitudes are shaped by the social context in which learning and communication between individuals occur (Rogers \& Shoemaker, 1971). Diffusion of Innovations Theory suggests that society and its various formal and informal institutions play a key role in shaping the diffusion pattern of an innovation (Rogers, 1995a). This is further explored in Chapter Six.

Decision-making on innovations means decision-making under conditions of risk and uncertainty due to the 'newness' of the innovation (Rogers, 1995a). As biochar is an innovation in the climate change mitigation toolbox, there is little guidance provided by overseas climate policy experience. In this context, policy may wish to invoke policy criteria and environmental policy principles to guide decision-making.

Biochar deployment in NZ may be evaluated using the sustainability principle and Precautionary Principle. This study suggests that use of these principles may facilitate a holistic assessment of the merits of diffusion of the innovation of biochar in NZ. The 
principles may offer a general approach and guidance in designing specific policies. This design process may be usefully complemented by specific policy criteria. These may be called on to assess the relative risks of biochar versus other mitigation techniques as well as versus inaction on climate change. Such policy criteria may include environmental effectiveness, static and dynamic efficiency, inter- and intragenerational equity (including between humans and the non-human world), reversibility and compliance with international obligations to reduce GHG emissions.

The context-specific nature and variability of the various environmental impacts of biochar production and soil application mean that the 'tool for internalisation' itself is associated with a raft of externalities. These complicate policy decision-making insofar as the very same environmental impact resulting from biochar production or soil application can be a positive or a negative externality. Impacts may depend on, for example, feedstock, production process, climate and soil type to which the biochar is applied. This necessitates a case-by-case assessment of net GHG and energy benefits as well as agronomic impacts over the life cycle of particular biochar projects.

Decision-making should be based on robust data and evidence of not only an immediate and long-term GHG benefit of biochar, but a holistic assessment of the consequences of biochar deployment. Negative and positive externalities need to be anticipated and accounted for as far as possible when determining the policy direction regarding adoption or rejection of biochar. The remaining challenge is that nature and extent of many externalities are still subject to further research and await clarification.

\subsubsection{Objectives Six and Seven, Chapter Six}

Objective Six was to establish a picture of stakeholder perceptions of biochar deployment in NZ. Objective Seven was to discuss the issues identified by stakeholders in light of the theoretical framework established in Chapter Five, and to flesh out implications of findings for $\mathrm{NZ}$ public policy as it concerns biochar deployment. The guiding questions for Chapter Six were: 
- What do stakeholders identify as positives, negatives and unknowns about biochar?

- What does the literature suggest in regard to the issues identified by stakeholders?

- What public policy approach can be suggested based on stakeholder concerns and the literature review? Should biochar deployment in NZ be encouraged or discouraged, and under what conditions?

Drawing on the methodological framework (Chapter Two), the natural sciences and engineering science background (Chapters One and Three) as well as the institutional context (Chapter Four) and the theoretical framework (Chapter Five), Chapter Six analysed and discussed stakeholder perspectives based on the empirical material gathered for this study.

As biochar is an innovation in the climate change mitigation toolbox, there is little guidance provided by overseas climate policy experience. Biochar is not recognised in any country's climate legislation as a means of carbon sequestration eligible to generate tradeable carbon offsets. Such non-recognition seems prudent in the absence of international standards for both quality of different biochars and monitoring of biochar carbon sequestration. Especially given the large variability of LCA even in small-scale, well-defined studies (Chiaramonti \& Recchia, 2010), it remains a challenging task to establish confidence in a truly carbon-negative life cycle of biochar projects.

The question for NZ policymakers is whether it is sensible and worthwhile to aim for a diffusion of the innovation of biochar in a domestic context. In addition to the aforementioned set of problems, this decision is made more difficult by scientific uncertainty. Some biophysical and biochemical environmental impacts of biochar, especially in the long term, warrant further research. These include half-life and carbon stabilisation mechanisms of biochar in soil. These aspects are essential information for policymakers when assessing the potential of biochar as a climate change mitigation tool.

This research confirmed the dependency of diffusion of an innovation on the social context. Opinions within and between stakeholder groups showed large variations. Agriculturalists' views ranged from perceiving it as an industrial, technological quick fix mainly aimed at serving corporate interests to a 'good old', sustainable pathway, used by 
pre-European Maori. ENGO members pointed out that the scale of carbon sequestration needed to make a beneficial climate impact may be more effectively and efficiently achieved by focusing efforts on NZ's existing carbon sink assets, namely native vegetation and soils.

In every stakeholder group sceptical as well as enthusiastic voices were present. Many participants showed a differentiated view. They also reflected on the context-specific potential advantages and disadvantages of biochar deployment and their nongeneralisability. Cautious attitudes toward large-scale biochar deployment in NZ were present in all stakeholder groups, although for different reasons. Participants from the forestry and wood processing industries emphasised the economic barriers of feedstock collection. Agriculturalists were mainly concerned about long-term impacts on soil biology. They also highlighted that existing organic and biological farming practices are proven methods for and already contribute to the public good of soil carbon sequestration.

A common theme across all stakeholder groups was that biochar's costs and benefits are a matter of 'wait and see', subject to NZ-specific research results. Stakeholder groups also shared the view that biochar in NZ may be a boutique solution for niche applications rather than a large-scale new market opportunity.

The range of perceptions and opinions shows that there is no easy answer and no onesize-fits-all approach for policy when deciding on whether or how biochar should be diffused in NZ. This research also showed that how an innovation is presented is at least as important as what objective factual information is communicated about the innovation. People's predisposition toward an innovation is at least in part determined by their own and their peers' experience with the innovation.

In this context, all stakeholders articulated a need for further information. Agriculturalists in particular indicated that first-hand experience would improve their ability to make an informed decision. These findings suggest that there may be a role for public policy in facilitating the establishment and maintenance of an information flow to practitioners. Results of NZ biochar research will need to be communicated as transparently as possible with full disclosure of biochar's agronomic and climate impacts, positive and negative. 
Particularly agricultural participants stated that knowing what works and what does not work would enable them to make an informed decision about biochar use on their land.

A participatory and transparent decision-making process, involving a diverse range of stakeholders, actively seeking their input and carefully weighing costs and benefits in the widest sense, is suggested. The imperative for such an approach is derived from the fact that biochar deployment touches on a wide range of issues and policy portfolios. Among these are climate change, biodiversity, energy, economics and research to name a few. Any decision for the diffusion of biochar in NZ must be preceded by careful crafting of policy instruments and incentive structures so as to avoid perverse incentives and adverse outcomes, for example, for biodiversity. An integrated policy approach needs to anticipate repercussions on existing legislation, if biochar is to be made part of the domestic mitigation portfolio. Ramifications with, for example, the RMA, the HSNO Act and the Waste Minimisation Act, may be worth exploring prior to any larger-scale uptake of biochar. Undesirable outcomes may result if such repercussions are not anticipated, and may include adverse impacts on biodiversity due to perverse incentives, the introduction of exotic and potentially genetically engineered species for dedicated feedstock production, confusion about resource consent for biochar soil application or pyrolysis plant construction, competition for waste streams as a resource (feedstock) or inadequate definition of wastes and permitted uses.

Policy may wish to introduce standards and regulations to ensure a sustainable deployment of biochar and the control of harm to human and environmental health. For this reason it appears worthwhile to develop standards, or to include biochar production and use in existing standards and regulations, such as the National Environmental Standard for Assessing and Managing Contaminants in Soil that is being developed (MfE, 2010d).

Compiling sustainability criteria specific to biochar production and use may help to ensure responsible deployment. As minimum specifications these criteria should include acceptable and unacceptable land-use policies and a minimum threshold of carbon sequestration achieved by individual projects (Heffernan, 2009). Industry standards could be developed that specify inputs and outputs, such as origin and quality of feedstocks or minimum carbon content as well as maximum contamination thresholds of the biochar 
product. Industry standards could also set benchmarks that require businesses to use the best available technology to minimise any adverse environmental impacts. Initiating such standards and regulations in the domestic context appears particularly important as international standards regarding the sustainability of biochar projects, quality controls of biochar and industry best practice codes are still absent. Such NZ standards may however face strong opposition from farmers or businesses.

To significantly advance carbon sequestration in NZ's terrestrial ecosystems, it is necessary to identify NZ's carbon pools and the various options to manage each. Comparing these options by using the abovementioned policy principles and criteria may help to determine where efforts are best targeted.

It has been estimated that $1.45 \mathrm{Mha}$ of $\mathrm{NZ}$ pastoral land are marginal and would be suitable for afforestation and reforestation by indigenous shrubland or forest which could

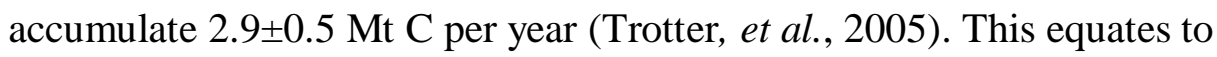
$10.63 \pm 1.83 \mathrm{Mt} \mathrm{CO}_{2}$-e per year, representing $14.2 \%$ of gross emissions or $21.9 \%$ of net emissions of NZ in 2008 (MfE, 2010b). Comparing this with the NZ potential of carbon sequestration via biochar as estimated by Shrubsole (2009), it is calculated that domestically produced biochar could sequester 3.15-4.03 $\mathrm{Mt} \mathrm{CO}_{2}$-e, equating to 4.2-5.4\% of NZ's 2008 gross emissions and $6.5-8.3 \%$ of net emissions. This is a third to a half of the carbon sequestration potential via afforestation and reforestation of marginal pasture land with native vegetation as estimated by Trotter and colleagues (2005). This suggests a higher carbon sequestration benefit from improved management of NZ's indigenous oldgrowth forests than from biochar deployment.

The uniqueness of NZ's biological systems suggests limited transferability of overseas research findings as regards the mitigation potential of biochar. Public policy may thus consider continued capability building in research to advance a holistic understanding of biochar's impacts in the NZ context. This may usefully be complemented by comparative studies that investigate the merits of biochar versus those of other agricultural mitigation techniques, including existing practices in organic farming and the fostering of sinks in native vegetative ecosystems. 


\section{Appendices}

\section{Appendix 1: Interview Themes}

\section{Organic Agriculturalists}

1. Have you heard of biochar? How have you heard of it?

2. Is the concept of biochar interesting to you? Why? Why not?

3. Does the biochar concept fit with your understanding of sustainability or, more specifically, with your approach towards environmental sustainability?

4. Do your friends/workmates know about biochar?

5. What do they think about it?

6. Do you agree or disagree with them?

7. Are neighbouring agriculturalists using biochar? Did you talk with them about their experiences with it?

8. Please rate your knowledge of biochar on a scale from 1-5 with 1 being very little and 5 being very much.

9. Do you consider the scientific basis of biochar research as 'robust'?

10. Would it make any difference to you if biochar were acknowledged domestically and/or in an international agreement as a means to offset carbon?

11. Do you think the additional greenhouse gas savings from application of biochar to land should be accounted for in carbon offset generation?

12. If so, how could that be done?

13. Would the potential additional income stream from carbon credits provide an incentive for you to start using biochar if you haven't done so already?

14. What do you think about the concept of 'carbon-negative food'? Do you think there will be a market for it?

15. What would be your main motivation if you did adopt biochar?

16. Do you take any measures to increase soil carbon storage?

17. Would the option of making your own biochar from your own green waste be more attractive (as opposed to purchasing biochar)? If so, would you purchase a mobile pyrolysis unit or do you favour a DIY solution, e.g. using an old steel drum as a kiln?

18. Could you imagine selling your biochar or would you use it on-site?

19. What would your ideal biochar scenario look like?

20. Overall, do you consider biochar deployment useful for climate change mitigation in NZ? 


\section{Forest Growers and Wood Processors}

1. Have you heard of biochar? How have you heard of it?

2. How are forestry residues currently being processed? Are they collected anyway? If so, for what purpose? Or are residues left on site to compost or rot?

3. Is there demand from other industries for forestry residues? (e.g. biofuels)

4. Have you been approached by a company to supply wood waste as biochar feedstock?

5. Could biochar feedstock supply be a new stream of income for you or would you give it away for free to get it out of the way?

6. Could you imagine using biochar in your forests to improve productivity? If so, how would you apply it?

7. Would a mobile pyrolysis unit be of interest to you to draw down forest management costs for thinning or to provide on-site treatment of infested wood (saving the shipping costs to a centralised plant)?

8. Are there any issues with overload of fuel loads in the form of dead wood or slash in your forests?

9. Are there any issues with infestation of trees by, for example, by pine beetle?

10. Would it make any difference to you if biochar were acknowledged as a means to offset carbon?

11. What would your ideal biochar scenario look like?

12. Overall, do you consider biochar deployment useful for climate change mitigation in NZ?

\section{Companies}

1. Have you heard of biochar? How have you heard of it?

2. Which kind of feedstock are you currently using?

3. From where is it sourced?

4. Could you imagine working together with forestry or wood processing businesses to provide treatment for infested wood or wood waste from forest thinning or other such?

5. Could you use different kinds of biomass or is the technology you use specifically designed for a particular feedstock?

6. Would you like to see government intervention to increase demand for biochar? If so, which kind of policy instruments do you consider suitable?

7. Would you experiment with and build your own pyrolysis units or would you look to find one on the market?

8. Where do you see the bigger problems looming: in the sourcing of (sustainable) feedstock, in the efficient production process itself or in the sale of the final product or in 
some other area, e.g. government policy? Please rank your answers with 1 being the biggest problem.

9. Does it make sense to offer biochar in different forms: briquettes, pellets, bulk/powdergrind for agricultural applications?

10. In what way is the decision to produce a higher proportion of biochar rather than bio-oil a strategic choice and on what aspects does it depend?

11. Do you perceive a lack of standards and coherent classification of biochar products?

12. Do you perceive an overregulation that stifles the emerging biochar industry?

13. Would regulation such as manufacturing standards, categorisation and classification of biochar make biochar production more favourable?

14. Do you consider selling the biochar in bulk or would you like to provide it as an 'ingredient' in other products, for example including it in a potting mix?

15. A biochar company in the US has partnered with a project management company for order fulfilment and shipping logistics. Customers can now order biochar online at this internet retail distributor. Would that kind of outsourcing of distribution be profitable for you?

16. How would recognition of biochar in NZ's ETS change the economics for your business at a price of $\mathrm{NZ} \$ 10, \mathrm{NZ} \$ 25, \mathrm{NZ} \$ 50, \mathrm{NZ} \$ 75$ and $\mathrm{NZ} \$ 100$ per tonne carbon dioxide respectively?

17. Imagine a scenario where biochar is included in emissions trading, globally as well as domestically. How would you change your production decisions?

18. Are syngas and bio-oil captured and used in the pyrolysis process or do they provide energy for other processes within your company? Is the excess energy transmitted/supplied to an industrial consumer?

19. How would a feed-in tariff for supplying excess energy from pyrolysis to the grid affect your production decisions?

20. How important is the concept of being 'carbon-negative' to you?

21. Have you made an assessment of whether your production process as a whole is carbonnegative?

22. What effects might an oil price of US\$50, US\$75 and US\$100 per barrel respectively have on your business/sale of your products?

23. What effects might mandatory standards for a certain percentage of renewable energy have on your business/sale of your products?

24. Do you see a market for your product in NZ? What is the range of profiles of your customers?

25. What would your ideal biochar scenario look like?

26. Overall, do you consider biochar deployment useful for climate change mitigation in NZ?

27. Do you see any problems? 


\section{ENGO}

1. Have you heard of biochar? How have you heard of it?

2. Do you know anyone who uses it?

3. Do you think biochar deployment does or could fit with sustainability in general and environmental sustainability in particular?

4. Which issues do you think might arise in the context of biodiversity in NZ?

5. How could it be ensured that feedstocks are sustainable?

6. Would on-site treatment of forestry residues or horticultural and cropping waste be a sustainable pathway in your opinion?

7. Do you see similarities with other concepts/technologies? (e.g. bad track record of biofuels)

8. What do you think about the concept of 'carbon-negative' products? Do you think there will be a market for it?

9. What is/are the role(s) of your organisation in the debate: What stance, which influence, which core competencies?

10. Where and how would you like to see your organisation making a significant contribution to shaping public policy that affects biochar deployment in NZ?

11. What information is still lacking in order to make an informed decision about your organisation's positioning? (scientific (un)certainty?) Where in the political debate do you position your organisation or where would you like to see your organisation making a contribution?

12. What would your ideal biochar scenario look like? (e.g. feedstock sourcing, application method etc. or no biochar at all)

13. From your perspective, could biochar make a positive or negative contribution to climate change mitigation (based on which assumptions)?

14. From your perspective, could biochar make a positive or negative contribution to sustainability in general (based on which assumptions)?

15. How do you think would biochar deployment affect the balance between emissions offsetting and emissions reductions, if at all?

16. Are you concerned about potential future funding sources for biochar research? (e.g. indirect funding from oil or mining companies)

17. Do you consider a feed-in tariff suitable to foster renewable energy generation from pyrolysis?

18. Overall, do you consider biochar deployment useful for climate change mitigation in NZ? 


\section{Academics}

1. Have you heard of biochar? How have you heard of it?

2. What sparked your interest in biochar?

3. Do you do any research on biochar, and if so, what are the areas that you research? Does your research bear on biochar directly or indirectly or both?

4. Which key research needs in regard to the different science and non-science aspects of biochar deployment in NZ do you identify?

5. What are in your opinion the major uncertainties that demand further research?

6. Should a precautionary approach mean that biochar is not deployed at all or at least with a considerable delay?

7. Would you recommend the use of or at least further exploration of biochar as a climate change mitigation tool?

8. Which conditions would need to be met in order to make biochar a feasible option?

9. Do you have any suggestions how public policy could go about dealing with these issues and uncertainties?

10. How can policymakers take the uncertainties into account without compromising further diffusion of biochar technology?

11. Do you consider a feed-in tariff suitable to foster renewable energy generation from pyrolysis?

12. What do you think about on-site treatment of biomass? Is that a sustainable option in your view?

13. Is research in NZ already at the stage where you could make any recommendations in regard to biochar utilisation?

14. Is it possible to deploy biochar in NZ now? Would you like to see deployment of this technology becoming effective in the short, medium or in the long term?

15. What would your ideal biochar scenario look like?

16. Overall, do you consider biochar deployment useful for climate change mitigation in NZ?

\section{Government}

1. Have you heard of biochar? How have you heard of it?

2. What are your criteria regarding a 'biochar policy', i.e. what conditions would need to be met as a prerequisite to include biochar in the 'climate change mitigation toolbox'?

3. Are there policy considerations or criteria for ranking and prioritising different climate change mitigation tools in NZ's climate policy approach? If so, what are these considerations or criteria? 
4. Which if any public agencies would have which responsibilities regarding the practicalities of biochar deployment in NZ?

5. Could a change in existing regulation alter the conditions for making biochar production and use profitable (e.g. change in EU waste disposal legislation enabled profitable production for an Italian company)

6. Do you support the inclusion (and retention) of biochar in the draft negotiating text (labelled as paragraph 134) for the UNFCCC in December 2009 in Copenhagen?

7. Is biochar deployment for carbon offset generation consistent with NZ's international obligations under the UNFCCC framework and particularly the Kyoto Protocol?

8. Which practicalities do you see unresolved? (e.g. difficulties in monitoring carbon loss over time, differentiating greenhouse gas reductions due to biochar application from greenhouse gas reductions due to other practices such as no-till agriculture)

9. Would the regulation in the form of manufacturing standards along with a categorisation and classification system of different kinds of biochar create useful leverage for public policy to shape the market context (influence supply and demand)? (i.e. a 'designer biochar' that yields predictable and uniform results for a given crop (in a given soil and climate)

10. Is there a public health risk of particulate matter from wind-blown biochar?

11. Is there a public health risk from smoke when people make their own biochar, i.e. when smoke and gas are not captured as is the case with a commercial pyrolysis unit?

12. Would biochar application require a resource consent when a farmer or other land user intends to apply biochar? Should the application method be specified to land users to minimise dispersal of biochar particulate matter or other effects? What effects might such requirements have?

13. Once biochar is in the soil it is infeasible to take it out again. How significant do you consider the issue of irreversibility? Would that be too high a risk?

14. How soon if at all should we try to use biochar as a climate change mitigation option?

15. How safe is safe enough? Is there any quantitative-numeric threshold when you would consider the issues around biochar to be 'sufficiently proven' in a scientific way? Is there a sufficient level of reduction in uncertainty? (precautionary principle vs. demand for rapid action regarding the urgency of the climate problem)

16. Does biochar count as a renewable fuel? (This would favour its combustion rather than soil application.)

17. Do you consider a feed-in tariff suitable to foster renewable energy generation from pyrolysis?

18. How was the decision made to conduct $R \& D$ about biochar in the first place? (research at the newly established New Zealand Biochar Research Centre at Massey University)

19. How is the policy of climate change mitigation via biochar related to other policies (within the climate change portfolio as well as other portfolios)?

20. Are there any plans to acknowledge biochar carbon sequestration in emissions trading? 
21. Are there any plans yet as to which policy instruments might be used to discourage or incentivise (depending on the policy goal) biochar feedstock sourcing, manufacture and soil application?

22. What do you think about on-site treatment of biomass? Is that a sustainable option in your view?

23. What do you think about research funding from non-government sources? Could they potentially conflict with your overall goal of research funding? (e.g. funding from oil companies)

24. Is it possible to deploy biochar in NZ now? Would you like to see deployment of this technology becoming effective in the short, medium or in the long term?

25. What would your ideal biochar scenario look like?

26. Overall, do you consider biochar deployment useful for climate change mitigation in NZ? 


\section{Appendix 2: Survey Questionnaires}

\section{Organic Agriculturalists}

1. Which kind of food production are you involved in? (please tick all that apply)

other horticulture

$\square$ orchards

$\square$ grapes

maize

cereal crops

other, please specify:

2. Which local government district(s) is your agricultural land in?

3. Prior to this questionnaire, have you heard of biochar?

$\square$ yes

$\square$ no (please go to question 9)

4. How have you heard of it? (please tick all that apply)

$\square$ print magazine / newspaper / newsletter for agriculturalists

$\square$ general print magazine / newspaper / newsletter not specifically targeted at agriculturalists

$\square$ online magazine/newspaper/newsletter for agriculturalists

$\square$ other websites not specifically targeted at agriculturalists

$\square$ friends / family

$\square$ fellow members of the agricultural organisation of which I am a member

$\square$ public seminar, talk or conference

$\square$ seminar or talk arranged by an agriculture or horticulture organisation of which you are a member

$\square$ other (please specify):

5. What interests you about biochar? 
6. Does the biochar concept fit with your understanding of sustainability or, more specifically, with your approach towards environmental sustainability?

$\square$ yes, because

no, because

7. Have you talked with others about biochar?

$\square$ yes, with (please underline all applicable): family members, friends, workmates, other agriculturalists or horticulturalists, fellow members of the agricultural organisation of which you are a member

$\square$ no (please go to question 9)

a) If you answered yes: I talk with others about biochar:

$\square$ not at all $\square$ just once $\quad \square$ rarely $\quad \square$ regularly $\quad \square$ very frequently

b) When you talked about it, the main issues raised were 
8. When considering using biochar on my land, the opinion of a) family members is of:

$\square$ utmost $\square$ high $\quad \square$ moderate $\quad \square$ limited $\square$ zero importance to me.

b) friends is of:

$\square$ utmost $\square$ high $\square$ moderate $\square$ limited $\square$ zero importance to me.

c) workmates or other agriculturalists is of:

$\square$ utmost $\square$ high $\square$ moderate $\quad \square$ limited $\quad \square$ zero importance to me.

d) fellow members of the agricultural organisation of which I am a member is of:

$\square$ utmost $\square$ high $\square$ moderate $\square$ limited $\square$ zero importance to me.

9. What are the most important sources of information regarding agricultural practices for you? (please rank them with 1 being the most important):

$\square$ print magazine/newspaper/newsletter for agriculturalists

$\square$ general print magazine/newspaper/newsletter not specifically targeted at agriculturalists

$\square$ online magazine/newspaper/newsletter for agriculturalists

$\square$ other websites not specifically targeted at agriculturalists

$\square$ friends / family

$\square$ fellow members of the agricultural organisation of which I am a member

$\square$ public seminar, talk or conference

$\square$ seminar, talk or conference arranged by the agricultural organisation of which I am a member (if applicable)

$\square$ other (please specify):

10. In order to make an informed decision about biochar application to my land, I would require more information on:

11. Please rate your overall knowledge of biochar on a scale from 1 to 5 with 1 being very little and 5 being very much. Please circle:

1 very little

2 limited

3 moderate

4 somewhat

5 very much 
12. Please tick the statement that describes your current situation:

$\square$ I already use biochar.

$\square$ I consider using it.

$\square$ I do not intend to use it.

13. What would be your three main motivations if you did adopt biochar? (please rank them by listing the most important motivation first)

1)

2)

3)

14. What would be your three main motivations if you did NOT adopt biochar? (please rank them by listing the most important motivation first)

1)

2)

3)

15. Would the option of making your own biochar be more attractive (as opposed to purchasing biochar)?

$\square$ yes $\quad \square$ no $\quad \square$ yes, but I don't know how to do it

a) If 'yes' or 'yes, but I don't know how to do it': Would you

$\square$ purchase a pyrolysis unit

$\square$ favour a do-it-yourself solution, e.g. using an old steel drum as a kiln?

$\square$ decision depends on the price of the biochar

$\square$ decision depends on the relative prices of the available pyrolysis unit on the market and the materials needed to built my own.

b) If yes, which kind of biomass would you use as a feedstock? (please tick all that apply)
$\square$ wood waste
$\square$ horticultural prunings
$\square$ manure
$\square$ maize; e.g. corn stover
$\square$ crop waste
$\square$ other, please specify: 
c) Could you imagine selling your biochar or would you use it on-site? (please tick all that apply)
$\square$ sale
$\square$ on-site utilisation $\square$ both $\square$ depends on the price for which I can sell it

16. If you purchase your biochar, where do you buy it from?

a NZ company; name of company:

$\square$ an overseas company; name of company:

$\square$ other source, please specify:

17. What would your ideal biochar scenario look like?

18. Overall, I consider biochar deployment useful for climate change mitigation in NZ?

$\square$ strongly agree $\square$ agree $\square$ neutral $\square$ disagree $\square$ strongly disagree

19. Do you see any risks?

20. Do you have any additional comments? 
Appendices

\section{Thank you very much for your participation!}

Please return this questionnaire in the stamped addressed envelope that is enclosed.

I may follow up this survey with an interview. Please give your contact details below if you are happy to be contacted for that purpose. As stated in the attached Information Sheet, data security will be guaranteed. The information you provide in this questionnaire as well as in a follow-up interview will not allow for your identification if you do not give your explicit written consent.

$\rightarrow$ Please see the following page for providing your contact details. 
Please fill in your contact details here:

Last name:

First name:

Street address:

City:

Postcode:

Phone:

Mobile phone:

Email: 


\section{Forest Growers and Wood Processors}

1. Are you:

2. Which local government region(s) is / are your forest / wood processing facility in?

3. Prior to this questionnaire, have you heard of biochar?

yes

$\square$ no (please go to question 6)

4. How have you heard of it? (please tick all that apply)

$\square$ print magazine/newspaper / newsletter for forestry / wood processing

$\square$ general print magazine / newspaper / newsletter not specifically targeted at forestry and wood processing

$\square$ online magazine / newspaper / newsletter for forestry / wood processing

$\square$ other websites not specifically targeted at forestry / wood processing

$\square$ friends / family

$\square$ fellow members of the forestry / wood processing organisation of which I am a member

$\square$ public seminar, talk or conference

$\square$ seminar, talk or conference arranged by the forestry / wood processing organisation of which I am a member

other (please specify):

5. Why, if at all, is the concept of biochar interesting to you?

\section{How are forestry residues currently being processed?}

$\square$ They are collected anyway. If so, for what purpose?

$\square$ They are left on site to compost or rot.

7. Is there demand for forestry residues or wood processing waste from other industries?

$\square$ yes, please specify (e.g. for biofuels, composting):

no

8. Have you been approached by a company to supply forestry or wood processing waste as biochar feedstock?

yes

no 
9. Could biochar feedstock supply

$\square$ be a new stream of income for you or

$\square$ would you give it away for free to get it out of the way?

other, please specify:

10. Could you imagine using biochar in your forests to improve productivity?

$\square$ yes $\square$ no

11. Are there any issues with overload of fuel loads in the form of dead wood or slash in your forests?

$\square$ yes $\square$ no

12. Are there any issues with infestation of trees by, for example, by pine beetle in your forests?
yes
no

13. Would a mobile pyrolysis unit be of interest to you to draw down forest management costs for thinning or to provide on-site treatment of infested wood (saving the shipping costs to a centralised plant)?

yes, because

no, because

14. Imagine that biochar is acknowledged as a means to offset greenhouse gas emissions in a domestic and / or global emissions trading system. Would the potential additional income stream from carbon credits provide an incentive for you to get involved in the biochar industry if you are not already?

yes, because

no, because 
15. What would your ideal biochar scenario look like?

16. Overall, I consider biochar deployment useful for climate change mitigation in NZ?

$\square$ strongly agree $\quad \square$ agree $\quad \square$ neutral $\quad \square$ disagree $\quad \square$ strongly disagree

17. Do you see any risks?

18. Do you have any additional comments?

\section{Thank you very much for your participation!}

Please return this questionnaire in the stamped addressed envelope that is enclosed.

I may follow up this survey with an interview. Please give your contact details below if you are happy to be contacted for that purpose. As stated in the attached Information Sheet, data security will be guaranteed. The information you provide in this questionnaire as well as in a follow-up interview will not allow for your identification if you do not give your explicit written consent.

$\rightarrow$ Please see the following page for providing your contact details. 
Please fill in your contact details here:

Last name:

First name:

Street address:

City:

Postcode:

Phone:

Mobile phone:

Email: 


\section{Appendix 3: VUW Human Ethics Committee Approval}

\section{MEMORANDUM}

\begin{tabular}{l|l}
\hline TO & Dorothee Quade \\
\hline COPY TO & Catherine Wallace \\
\hline FROM & Dr Allison Kirkman, Convener, Human Ethics Committee \\
\hline
\end{tabular}

\begin{tabular}{l|l}
\hline DATE & November 202009 \\
\hline PAGES & 1 \\
\hline
\end{tabular}

SUBJECT $\quad$ Ethics Approval: No 17036 - What are the Implications for Public Policy in New Zealand Regarding Biochar as a climate Change Mitigation Tool?

Thank you for your application for ethical approval, which has now been considered by the Standing Committee of the Human Ethics Committee.

Your application has been approved from the above date and this approval continues until 02 March 2010. If your data collection is not completed by this date you should apply to the Human Ethics Committee for an extension to this approval.

Best wishes with the research.

Allison Kirkman

Convener 


\section{Appendix 4: International Agreements pertinent to Climate Change}

\section{United Nations Framework Convention on Climate Change 1992}

Adopted in 1992 and entered into force in 1994, the United Nations Framework Convention on Climate Change (UNFCCC) provides the major footing for global climate change policy, with 194 parties to date (as of 09/06/2010) (United Nations Framework Convention on Climate Change (UNFCCC), 2010b). The Convention sets out the goal of keeping GHG emissions at or below those of 1990. Article 2 states ultimate objective as the "stabilization of greenhouse gas concentrations in the atmosphere at a level that would prevent dangerous anthropogenic interference with the climate system" (United Nations (UN), 1992, p. 4).

The Convention provides for co-operation of governments on gathering and sharing of GHG emissions data, domestic policies and best practices. Signatories committed to domestic strategies for mitigation and adaptation while also providing technology transfer and financial support for developing countries (UN, 1992).

The Convention states an overall intent, but does not specify prescriptive rules on how to achieve the objective. Further, the phrase "dangerous anthropogenic interference" escapes a unanimously agreed definition and is subject to much scientific and probably even more political debate.

Annex I of the Convention lists parties that committed to undertake and report climate change mitigation measures and to issue GHG inventories that calculate emissions and removals (Article 12). Annex I includes 41 developed country parties, 14 of which undergoing transition to a market economy at that time. Annex I parties represent $63.7 \%$ of global GHG emissions (UNFCCC, 2009b).

The declared leadership role of Annex I parties in regard to GHG mitigation contrasts with the absence of quantified commitments. The Convention only states a general "aim of returning individually or jointly to their 1990 levels these anthropogenic emissions of 
carbon dioxide and other greenhouse gases not controlled by the Montreal Protocol" (UN, 1992, p. 7). Quantified and legally binding responsibility targets have been established in the Kyoto Protocol attached to the Convention which is the focus of the following section.

\section{Kyoto Protocol 1997}

Under the UNFCCC, the Kyoto Protocol (KP) is attached as a legally binding agreement. It has been ratified by 191 parties (as of 09/06/2010). The US is the only major developed country that has not ratified the Protocol to date (UNFCCC, 2010c). Parties are required to prepare annual national GHG inventories (Article 7) that calculate anthropogenic GHG emissions by sources and removals by sinks for the six gases regulated under the KP: carbon dioxide $\left(\mathrm{CO}_{2}\right)$, methane $\left(\mathrm{CH}_{4}\right)$, nitrous oxide $\left(\mathrm{N}_{2} \mathrm{O}\right)$, hydrofluorocarbons (HFCs), perfluorocarbons (PFCs) and sulphur hexafluoride $\left(\mathrm{SF}_{6}\right)$ (UNFCCC, 1998). Collectively, parties listed in Annex B of the KP agreed to a 5\% overall reduction of GHG emissions in the 2008-2012 first commitment period compared to 1990 levels (UNFCCC, 1998). Annex B parties are largely identical with Annex I parties under the UNFCCC.

The KP provides three flexibility mechanisms for countries to fulfil their responsibility targets: emissions trading (ET), joint implementation (JI) and clean development mechanism (CDM) (UNFCCC, 1998).

Article 17 enables countries listed in Annex B of the Protocol to trade emission allowances (UNFCCC, 1998). This cap-and-trade system for the group of Annex B countries derives from the least cost theorem. In capitalising on the differences in marginal abatement cost of polluters, emissions reductions occur where they are cheapest. Enabling trade of emission units between polluters then leads to the establishment of a market price for the unit at a level that is equal to the marginal abatement cost of all firms in the emissions trading market (Common \& Stagl, 2005; Jacoby \& Ellerman, 2004).

Article 6 of the Kyoto Protocol establishes a project-based approach, called joint implementation (JI). It allows an UNFCCC Annex I party to invest in an emissions reduction or sink enhancement project in another Annex I country and the following transfer of the resulting emission reduction units (ERU) to the investing party (UNFCCC, 
1998). Subject to the project being additional, supplementary to domestic reduction actions, verifiable and reportable, $\mathrm{JI}$ is also aimed at reducing compliance costs.

The CDM as outlined in Article 12 of the Kyoto Protocol allows for Annex I countries (also called developed countries) to undertake projects that lead to emissions reductions from the business-as-usual path in non-Annex I countries (also called developing countries). Such projects can include emission reductions or sink enhancements and generate units of emission permits called Certified Emission Reductions (CER) ${ }^{62}$ (UNFCCC, 1998).

\section{Copenhagen Accord 2009}

The $15^{\text {th }}$ Conference of the Parties to the Kyoto Protocol (COP 15) took place in December 2009 in the Danish capital and is also called the Copenhagen Climate Conference. It was hoped that the meeting would result in a strong and legally binding post-Kyoto agreement. Neither has been achieved in the official outcome that is known as the Copenhagen Accord. This document was hammered out by only five major countries: the US, China, India, Brazil and South Africa (Tollefson, 2009). The US has not been able to provide leadership and come forward with a strong commitment, partly due to still pending domestic climate change legislation. While the US climate bill (official title H.R. 2454 American Clean Energy and Security Act of 2009) has passed the House, a vote in the Senate is still outstanding (as at 18/05/2010) (GovTrack, 2010).

The Copenhagen Accord merely "recognize[s]" (UNFCCC, 2009a, p. 1) the scientific imperative for limiting global warming to $2^{\circ} \mathrm{C}$ above pre-industrial levels (Articles 1 and 2) but does not specify a pathway toward that target. A lot of time went into agreeing on the $2^{\circ} \mathrm{C}$ target which seems very hard if not impossible to achieve unless significant GHG sinks are found. Scientists are by now discussing adaptation to a temperature increase of $4^{\circ} \mathrm{C}$ and more, for example, at the International Climate Conference in Oxford 2009,

\footnotetext{
${ }^{62}$ The climate and human development benefits of the CDM are however contested. Global GHG emission reductions are not achieved as emission savings in developing countries merely enable higher emissions in developing countries. High transaction costs for proof of additionality of the GHG reduction and their independent verification in a project-based approach discriminate against least developed countries. Only the more developed non-Annex I parties with have the technological, financial and human capital at their disposal to satisfy the CDM standards are able to participate (Environmental Defense Fund, 2007a).
} 
titled "4 degrees and beyond" (Alcamo, 2009; Malhi, 2009; Schellnhuber, 2009; Thornton, 2009; Vellinga, 2009). Climate and ecosystem changes beyond $2^{\circ} \mathrm{C}$ of warming may lead to a "terra quasi-incognita" (Schellnhuber, 2009, p. 1). Significant environmental and societal disruptions are likely due to ecosystem degradation and loss of ecosystem services. Impacts include biodiversity loss, changes in the nitrogen, carbon and phosphorus cycles, ocean acidification and reduced freshwater availability (IPCC, 2007b; Schellnhuber, 2009).

The Accord did not quantify national responsibility targets, but Annex I parties of the UNFCCC were required to submit their 2020 targets by January 31, 2010 (Article 4), but even this was made non-mandatory. In contrast to the Kyoto Protocol, individual countries are free to choose the base year against which emission reductions are measured. Hence, major weaknesses of the Accord are that no caps on emissions have been specified and that even the Accord itself does not have diplomatic consensus and is not legally binding.

The biggest achievement, if any, in the Copenhagen Accord is marked by the first-ever commitment by developing countries, i.e. non-Annex I countries, to undertake nationally appropriate mitigation actions. These actions will be subject to "international consultations and analysis under clearly defined guidelines that will ensure that national sovereignty is respected" (Article 5) (UNFCCC, 2009a, p. 2). Nationally appropriate mitigation actions are also to be submitted by January 31, 2010 (Article 5) and will be recorded in Appendix II to the Copenhagen Accord.

Notwithstanding several years of controversial debate (Blom, Sunderland, \& Murdiyarso, 2010; Börner, et al., 2010; Phelps, Guerrero, Dalabajan, Young, \& Webb, 2010), Article 6 mobilises substantial payments to developing countries via the REDD-plus mechanism (Reduced Emissions from Deforestation and forest Degradation ${ }^{63}$ ).

\footnotetext{
${ }^{63}$ The 'plus' in REDD-plus indicates that beyond deforestation and forest degradation other pathways of avoiding emissions are included. These comprise rewarding of enhanced carbon sinks through forest restoration, rehabilitation and afforestation/reforestation. Further, the focus of debate about payments for avoided or reduced emissions moves from forests to entire landscapes (including agriculture) and from carbon only to other GHG, mainly methane and nitrous oxide (Campbell, 2009).
} 
For adaptation purposes, the Accord aims for financial flows of US\$10 billion per year over three years starting in 2010 and US\$100 billion per year beginning in 2020 in adaptation aid for developing countries that are hardest hit by climate change and least able to afford adaptive measures (Article 8). To this end, Article 10 establishes the Copenhagen Green Climate Fund to administer and operationalise the financing mechanisms under the UNFCCC. To further enhance development and transfer of technologies relevant to mitigation and adaptation, Article 11 establishes a Technology Mechanism. There is no outline of which countries are to contribute which share of the US\$100bn and who is going to pay for it (e.g. taxpayers, private sources). For example, the US has announced that about $30 \%$ of its share will come from private sources but there is no outline yet as to how this will be accomplished.

Finally, Article 12 allows for a tightening of the target from $2{ }^{\circ} \mathrm{C}$ to $1.5^{\circ} \mathrm{C}$ and for a review of the Accord to be completed by 2015 should overall commitments be found to put the $2^{\circ} \mathrm{C}$ target at risk (UNFCCC, 2009a).

Similar to the 1992 UNFCCC, the Copenhagen Accord is intent-based but not prescriptive in nature. Article 2 specifies the outcome of holding "the increase in global temperature below 2 degrees Celsius" (UNFCCC, 2009a, p. 2) but no precise rules on how to achieve it. To compound problems, it is not legally binding. Substantive action is adjourned if not indefinitely to at least until late 2010 when the next Conference of the Parties as COP 16 is scheduled to take place in Cancún, Mexico, from November $29-$ December 10, 2010. Every day of delay in taking action means costs are being shifted into the future with much more ambitious reductions needed in order to achieve a similar outcome to early action scenarios (German Advisory Council on Global Change, 2009; Schellnhuber, 2009). It is hoped that the following meeting in Bonn, Germany, in May/June 2010 will help to shape a strong, truly international and legally binding agreement on climate action which can be finalised in Cancún in late 2010.

An analysis of eleven policy strategies found that a failure to negotiate a post-Kyoto agreement was the most inefficient of all strategies considered (Bosetti \& Buchner, 2009). Further, a scenario outlined by the German Advisory Council on Global Change found that even a seemingly positive outcome of COP 15, may put the world on a path towards 
$3^{\circ} \mathrm{C}$ of warming ${ }^{64}$ (German Advisory Council on Global Change, 2009), mainly due to retention of offsetting practices in the new climate deal. Acknowledging carbon sinks from land use, land-use change and forestry (LULUCF), avoided emissions from REDD, reductions from $\mathrm{CDM}$ projects and unused allowances from the first Kyoto commitment period may well lead to rising emissions in real terms and at best slow down their increase. All of these mean real cuts in emissions are further pushed into the future (German Advisory Council on Global Change, 2009). This suggests that the acknowledgement of biochar as an offset may actually do more harm than good in the long term as far as overall emissions are concerned. The reason is that the direct and indirect GHG savings associated with biochar use may further support current practices rather than breaking the lock-in and stimulating major shifts in current practices leading to real emission reductions rather than just offsets.

On the other hand, the urgency of the climate crisis with indication that tipping points are already being reached (Shakhova, et al., 2010), demands immediate action. Additionally, the stability of some potential tipping elements of the climate system has been overestimated in current climate models (Hofmann \& Rahmstorf, 2009). Expert judgement on probabilities of tipping points is imprecise in the sense that large uncertainties exist, but consistent in that major changes in the climate system are being assigned high probabilities (Kriegler, Hall, Held, Dawson, \& Schellnhuber, 2009).

\footnotetext{
${ }^{64}$ This positive scenario assumes: majority of industrialised countries reduce emissions by $30 \%$ by 2020 compared to 1990 levels; US reduces emissions to 1990 levels by 2020; China increases energy efficiency by $5 \%$ per year; emerging economies (including China) commit to voluntary mitigation measures and pledge to reduce emissions (as opposed to continue on a business-as-usual path) with financial and technology transfers from developed countries (German Advisory Council on Global Change, 2009).
} 


\section{Appendix 5: New Zealand's 2020 Target}

On 10 August 2009 the National Government announced a target of 10-20\% emissions reductions by 2020 compared to 1990 levels (Smith \& Groser, 2009). This means that NZ's offered unconditional emission cut is $10 \%$, with higher net reductions being subject to other countries' co-operation and matching by putting forward commensurable targets. NZ's target is further qualified by several conditions as outlined in the submission to the UNFCCC: achieving a global agreement that limits atmospheric GHG concentrations to $450 \mathrm{ppm} \mathrm{CO}_{2}$-e and a global average surface temperature increase of $2^{\circ} \mathrm{C}$, effective rules on forestry, and ensuring NZ's access to global carbon markets (UNFCCC, 2010a).

The statement of Climate Change Minister Nick Smith of striving to be a fast follower "doing our fair share" (Smith \& Groser, 2009, 10 August) rather than a leader on an international level left little room for excitement in NZ's environmental circles. The hope that NZ would live up to its clean, green image was frustrated by the announcement of a $10-20 \%$ target range by 2020 which seems to inadequately position the country in international climate negotiations. 
Appendices

Table 14 lists the quantified economy-wide emissions targets for 2020 as submitted to the UNFCCC. The range of emissions reduction targets given for individual parties represents the unilateral and multilateral commitments. While the table does not include the various conditions to which the individual targets are tied, it becomes apparent that unilateral commitments of the EU, Liechtenstein, Iceland, Norway and Japan seem far more ambitious than NZ's target, especially given that all chose 1990 as the base year against which reductions are to be measured. 
Table 14: Quantified economy-wide emissions targets for 2020 (UNFCCC, 2010a:

http://unfccc.int/home/items/5264.php). Note that this is the same as Table 5 in Chapter Four. It is repeated here for convenience.

\begin{tabular}{|c|c|c|}
\hline Annex I Parties & Emissions reduction in 2020 & Base year \\
\hline Australia & $5 \%$, up to $15-25 \%$ & 2000 \\
\hline Belarus & $5-10 \%$ & 1990 \\
\hline Canada & $17 \%$ & 2005 \\
\hline Croatia & $5 \%$ & 1990 \\
\hline $\begin{array}{l}\text { EU1 and its Member States (Belgium, } \\
\text { Bulgaria, Czech Republic, Denmark, } \\
\text { Germany, Estonia, Ireland, Greece, } \\
\text { Spain, France, Italy, Cyprus, Latvia, } \\
\text { Lithuania, Luxembourg, Hungary, } \\
\text { Malta, Netherlands, Austria, Poland, } \\
\text { Portugal, Romania, Slovenia, } \\
\text { Slovakia, Finland, Sweden, United } \\
\text { Kingdom) acting in common }\end{array}$ & $20-30 \%$ & 1990 \\
\hline Iceland & $30 \%$ & 1990 \\
\hline Japan & $25 \%$ & 1990 \\
\hline Kazakhstan² & $15 \%$ & 1992 \\
\hline Liechtenstein & $20-30 \%$ & 1990 \\
\hline Monaco & $30 \%$ & 1990 \\
\hline New Zealand & $10-20 \%$ & 1990 \\
\hline Norway & $30-40 \%$ & 1990 \\
\hline Russian Federation & $15-25 \%$ & 1990 \\
\hline Switzerland & $20-30 \%$ & 1990 \\
\hline Ukraine & $20 \%$ & 1990 \\
\hline United States of America & $17 \%^{3}$ & 2005 \\
\hline \multicolumn{3}{|c|}{$\begin{array}{l}1 \text { Currently, not all EU Member States are Annex I Parties. } \\
2 \text { Kazakhstan is a Party included in Annex I for the purposes of the Kyoto Protocol in } \\
\text { accordance with Article 1, paragraph 7, of the Protocol, but Kazakhstan is not a Party } \\
\text { included in Annex I for the purposes of the Convention. }\end{array}$} \\
\hline \multicolumn{3}{|c|}{$\begin{array}{l}3 \text { Pending legislation would entail a } 30 \% \text { reduction in } 2025 \text { and a } 42 \% \text { reduction in } \\
2030 .\end{array}$} \\
\hline
\end{tabular}

While NZ's 2020 target does not suggest leadership in the international arena it actually seems 'ambitious' given that the Treasury's recommendation, calculated through an equal-cost approach, was an emissions increase of 15\% above 1990 levels (The Treasury, 2009). 
The Treasury's modelling outcomes presented in Table 15 suggest that NZ has relatively high emissions reductions costs compared to other developed countries. For example, the EU's target of $-20 \%$ incurs direct costs of $0.11 \%$ of 2020 GDP while for NZ a target of $+15 \%$ above 1990 would incur the same percentage of 2020 GDP according to Treasury modelling (The Treasury, 2009). This may be partly due to NZ's delayed action which implies that costs are incurred later but are also higher than if early action would have been taken. In contrast, the EU has been re-gearing the economy at earlier stages and now faces lower costs for meeting a higher reduction target.

Table 15: The direct costs of different 2020 targets (using $\$ \mathbf{1 0 0 / t o n n e ) ~ ( T h e ~ T r e a s u r y , ~ 2 0 0 9 , ~ p . ~ 6 ) ~}$

\begin{tabular}{|l|l|c|}
\hline \multicolumn{1}{|c|}{ Country } & \multicolumn{1}{|c|}{ Target } & $\begin{array}{c}\text { Direct cost } \\
\text { (\% of 2020 GDP) }\end{array}$ \\
\hline Annex I in aggregate & $15 \%$ below 1990 (current pledges*) & 0.11 \\
& $25 \%$ below 1990 & 0.31 \\
& $40 \%$ below 1990 & 0.68 \\
\hline Australia & $5 \%$ below 2000 (unconditional) & 0.35 \\
& $15 \%$ below 2000 & 0.68 \\
& $25 \%$ below 2000 & 1.02 \\
\hline European Union & $20 \%$ below 1990 (unconditional) & 0.11 \\
& $30 \%$ below 1990 & 0.28 \\
\hline United States & $14 \%$ below 2005 & 0.11 \\
\hline New Zealand & $15 \%$ above 1990 (Treasury) & 0.11 \\
& $12 \%$ below 1990 (Minister's) & 0.81 \\
& $20 \%$ below 1990 (Minister's) & 1.03 \\
* uses the unconditional targets proposed by the EC and Australia \\
\hline
\end{tabular}

The Treasury's equal cost argument only takes into account the economic dimension of sustainability and ignores social and most importantly environmental aspects. The scientific imperative for much bigger and sooner emission cuts by all developing countries if global temperature increase is to be capped at $2^{\circ} \mathrm{C}$ is compelling (IPCC, 2007b). Given the large-scale environmental consequences of unabated climate change, even costs of $1.03 \%$ of NZ's 2020 GDP for a $20 \%$ emission reduction seem trifling (see Table 15). 
A report by NZIER and Infometrics, commissioned by the National Government, estimated the costs of $-15 \%$ by 2020 to be $\mathrm{NZ} \$ 1,400$ per person per year (Stroombergen, et al., 2009). Most critically, under all target scenarios analysed (up to -40\%), NZ's GDP showed continued growth (Stroombergen, et al., 2009). This demonstrates climate action would result in a very slight delay in GDP growth (compared to inaction) rather than in a decline in welfare. Furthermore, NZ's clean, green image - so important for tourism and export market access - may be put at risk if no action is taken.

Buying additional Assigned Amount Units overseas (to make up NZ's shortfall) will reduce household consumption and hence welfare (Stroombergen, et al., 2009). This assertion only holds true as long as it follows the narrow understanding of welfare as being equated with consumption or utility as in neoclassical economics, i.e. where marginal private benefit is equal to marginal private costs. Welfare, benefit or happiness for that matter, depends not only on increased consumption of material goods but also on health, education, social relationships, employment, an intact environment and other variables (Duncan, 2005; Inglehart \& Klingemann, 2000). Moreover, the damage to GDP in the future from accelerated climate change is most likely to be significantly higher than any 'loss' in welfare now (Stern, 2007). 


\section{References}

\section{A}

Abdullah, H., Mediaswanti, K. A., \& Wu, H. (2010). Biochar as a Fuel: 2. Significant differences in fuel quality and ash properties of biochars from various biomass components of Mallee trees. Energy \& Fuels, 24(3), 1972-1979.

Abrahamson, E. (1991). Managerial Fads and Fashions: The Diffusion and Rejection of Innovations. The Academy of Management Review, 16(3), 586-612.

Abrahamson, E., \& Rosenkopf, L. (1993). Institutional and Competitive Bandwagons: Using Mathematical Modeling as a Tool to Explore Innovation Diffusion. The Academy of Management Review, 18(3), 487-517.

Ackerman, F., Stanton, E. A., Hope, C., \& Alberth, S. (2008). Did the Stern Review underestimate U.S. and global climate damages? Somerville, MA: SEI (Stockholm Environment Institute).

Ackerman, F., Stanton, E. A., DeCanio, S. J., Goodstein, E., Howarth, R. B., Norgaard, R. B., et al. (2009). The Economics of 350: The Benefits and Costs of Climate Stabilization. Draft. Portland, OR: Economics for Equity and Environment Network.

Adams, M. D. (2002). The precautionary principle and the rhetoric behind it. Journal of Risk Research, 5(4), 301 - 316.

Agency for Toxic Substances and Disease Registry (ATSDR) (1995). Toxicological profile for polycyclic aromatic hydrocarbons. Atlanta, GA: U.S. Department of Health and Human Services, Public Health Service.

Alaya, M. N., Girgis, B. S., \& Mourad, W. E. (2000). Activated Carbon from Some Agricultural Wastes Under Action of One-Step Steam Pyrolysis. Journal of Porous Materials, 7, 509-517.

Alcamo, J. (2009, 28-30 September). Water availability in a $4+{ }^{\circ} \mathrm{C}$ world. Paper presented at the International Climate Conference: 4 degrees and beyond, Oxford, UK.

Alchian, A. A., \& Demsetz, H. (1973). The Property Right Paradigm. The Journal of Economic History, 33(1), 16-27.

Allen-King, R. M., Grathwohl, P., \& Ball, W. P. (2002). New modeling paradigms for the sorption of hydrophobic organic chemicals to heterogeneous carbonaceous matter in soils, sediments, and rocks. Advances in Water Resources, 25(8-12), 985-1016.

Allen, D. E., Mendham, D. S., Singh, B., Cowie, A., Wang, W., Dalal, R. C., et al. (2009). Nitrous oxide and methane emissions from soil are reduced following afforestation of pasture lands in three contrasting climatic zones. Australian Journal of Soil Research, 47(5), 443-458.

Altheide, D. L., \& Johnson, J. M. (1998). Criteria for assessing interpretive validity in qualitative research. In N. K. Denzin \& Y. S. Lincoln (Eds.), Collecting and interpreting qualitative materials (pp. 283-312). Thousand Oaks, CA: Sage Publications. 
Anderson, C., \& Condron, L. (2010, 11-12 February). Influence of biochar amendments on rhizosphere processes. Paper presented at the Biochar Workshop: Opportunities for New Zealand Stakeholders, Palmerston North.

Andreae, M. O., \& Gelencsér, A. (2006). Black carbon or brown carbon? The nature of light-absorbing carbonaceous aerosols. Atmospheric Chemistry and Physics, 6(10), 3131-3148.

Antal, M. J., \& Gronli, M. (2003). The Art, Science, and Technology of Charcoal Production. Ind. Eng. Chem. Res., 42(8), 1619-1640.

Arrow, K. (1994). The production and distribution of knowledge. In G. Silverberg \& L. Soete (Eds.), The economics of growth and technical change: technologies, nations, agents. Aldershot, Hants, England: Edward Elgar.

Atkins, M. J. (1984). Practitioner as researcher: some techniques for analysing semistructured data in small-scale research. British Journal of Educational Studies, 32(3), 251-261.

Attewell, P. (1992). Technology Diffusion and Organizational Learning: The Case of Business Computing. Organization Science, 3(1), 1-19.

Atul-Nayyar, A., Hamel, C., Hanson, K., \& Germida, J. (2009). The arbuscular mycorrhizal symbiosis links N mineralization to plant demand. Mycorrhiza, 19(4), 239-246.

Australia and New Zealand Biochar Researchers Network (ANZBRN) (2008, 28/01/2010). Projects: BEST Energies - Pyrolysis Demonstration Facility. Retrieved 6 April, 2010, from http://www.anzbiochar.org/projects.html\#five

Australian Government. (2007, 16/11/2007). Australian Agriculture Assessment 2001. Australian Natural Resources Atlas. Retrieved 25 February, 2010, from http://www.anra.gov.au/topics/agriculture/pubs/national/agriculture_kandosols.ht $\mathrm{ml}$

Australian Government. (2008). Australia's Low Pollution Future: The Economics of Climate Change Mitigation. Report. Canberra: Australian Government, The Treasury.

Azargohar, R., \& Dalai, A. K. (2006). Biochar as a precursor of activated carbon. Applied Biochemistry and Biotechnology, 131(1-3), 762-773.

\section{B}

Baldock, J. A., \& Skjemstad, J. O. (1999). Soil organic carbon/soil organic matter. In K. I. Peverill, L. A. Sparrow \& D. J. Reuter (Eds.), Soil Analysis: an Interpretation Manual (pp. 159-170 ). Collingwood, VIC, Australia: CSIRO Publishing.

Baldock, J. A., \& Smernik, R. J. (2002). Chemical composition and bioavailability of thermally altered Pinus resinosa (Red pine) wood. Organic Geochemistry, 33, 1093-1109.

Barry, M., \& Chapman, R. (2009). Distributed small-scale wind in New Zealand: Advantages, barriers and policy support instruments. Energy Policy, In Press, Corrected Proof. 
Bass, F. M. (1969). A new product growth model for consumer durables. Management Science, 15(5), 215-227.

Batjes, N. H. (1996). Total carbon and nitrogen in the soils of the world. European Journal of Soil Science, 47(2), 151-163.

Beck, U. (1988). Gegengifte: die organisierte Unverantwortlichkeit. Frankfurt am Main: Suhrkamp.

Beck, U. (1992a). From Industrial Society to the Risk Society: Questions of Survival, Social Structure and Ecological Enlightenment. Theory Culture Society, 9(1), 97123.

Beck, U. (1992b). Risk society: towards a new modernity. London: Sage Publications.

Beck, U. (1995). Ecological politics in an age of risk (A. Weisz, Trans.). Cambridge: Polity Press.

Beck, U. (1996). World Risk Society as Cosmopolitan Society?: Ecological Questions in a Framework of Manufactured Uncertainties. Theory Culture Society, 13(4), 1-32.

Beck, U., Giddens, A., \& Lash, S. (1994). Reflexive modernization: politics, tradition and aesthetics in the modern social order. Cambridge, UK: Polity.

Beddoe, R., Costanza, R., Farley, J., Garza, E., Kent, J., Kubiszewski, I., et al. (2009). Overcoming systemic roadblocks to sustainability: The evolutionary redesign of worldviews, institutions, and technologies. PNAS, 106(8), 2483-2489.

Beesley, L., Moreno-Jiménez, E., \& Gomez-Eyles, J. L. (2010). Effects of biochar and greenwaste compost amendments on mobility, bioavailability and toxicity of inorganic and organic contaminants in a multi-element polluted soil.

Environmental Pollution, In Press, Corrected Proof.

Beets, P. N., Oliver, G. R., \& Clinton, P. W. (2002). Soil carbon protection in podocarp/hardwood forest, and effects of conversion to pasture and exotic pine forest. Environmental Pollution, 116(Supplement 1), S63-S73.

Bernal, J. D. (1924). The Structure of Graphite. Proceedings of the Royal Society of London. Series A, Containing Papers of a Mathematical and Physical Character, 106(740), 749-773.

Bertram, G. (2000). Greenhouse Emissions Policy Timing: A Review of Reports by NZIER and the Centre for International Economics. Wellington: Victoria University \& Simon Terry Associates Ltd.

Bertram, G. (2001). Climate Change Policy and Forestry: Review of an NZIER report entitled: Effects of New Zealand's Climate Change Policies on the Forestry Sector - Stage I: Preliminary Assessment. Wellington: Simon Terry Associates Ltd.

Bertram, G., Barrett, P., Boston, J., Chapman, R., Lawrence, J., Manning, M., et al. (2009). Submission on the Climate Change Response (Moderated Emissions Trading) Amendment Bill: A submission to the Parliamentary Select Committee on the Climate Change Response (Moderated Emissions Trading) Amendment Bill. Wellington: The Institute of Policy Studies \& The New Zealand Climate Change Research Institute, Victoria University of Wellington.

BEST Energies Australia (2008). BEST Pyrolysis - Renewable Energy and Agrichar, Garnaut Climate Change Review Submission, Land use - Agriculture and Forestry. Somersby, NSW: BEST Energies Australia, Pty Ltd. 
Bever, J. D., Schultz, P. A., Pringle, A., \& Morton, J. B. (2001). Arbuscular Mycorrhizal Fungi: More Diverse than Meets the Eye, and the Ecological Tale of Why. Bioscience, 51(11), 923-931.

Blaikie, P. M. (1996). Post-modernism and global environmental change. Global Environmental Change, 6(2), 81-85.

Blom, B., Sunderland, T., \& Murdiyarso, D. (2010). Getting REDD to work locally: lessons learned from integrated conservation and development projects. Environmental Science \& Policy, 13(2), 164-172.

Boateng, A. A. (2007). Characterization and Thermal Conversion of Charcoal Derived from Fluidized-Bed Fast Pyrolysis Oil Production of Switchgrass. Ind. Eng. Chem. Res., 46(26), 8857-8862.

Bolinger, M. (2001). Community wind power ownership schemes in Europe and their relevance to the United States. Berkeley, CA: Ernest Orlando Lawrence Berkeley National Laboratory.

Bond, G. R. (2002). The role of activated charcoal and gastric emptying in gastrointestinal decontamination: A state-of-the-art review. Annals of Emergency Medicine, 39(3), 273-286.

Börner, J., Wunder, S., Wertz-Kanounnikoff, S., Tito, M. R., Pereira, L., \& Nascimento, N. (2010). Direct conservation payments in the Brazilian Amazon: Scope and equity implications. Ecological Economics, 69(6), 1272-1282.

Borner, S., Bodmer, F., \& Kobler, M. (2004). Institutional efficiency and its determinants: The role of political factors in economic growth. Paris: Organisation for Economic Co-operation and Development, Development Centre.

Bosetti, V., \& Buchner, B. (2009). Data Envelopment Analysis of different climate policy scenarios. Ecological Economics, 68(5), 1340-1354.

Boston, J. (2007). Stern Lessons on Climate Change: Stabilisation Targets and Emission Reductions. Policy Quarterly, 3(1), 11-19.

Bourke, J., Manley-Harris, M., \& Antal, M. J. (2010, 11-12 February). MALDI-TOF spectrometry of biocarbons. Paper presented at the Biochar Workshop:

Opportunities for New Zealand Stakeholders, NZBRC, Massey University, Palmerston North.

Bourke, J., Manley-Harris, M., Fushimi, C., Dowaki, K., Nunoura, T., \& Antal, M. J. (2007). Do All Carbonized Charcoals Have the Same Chemical Structure? 2. A Model of the Chemical Structure of Carbonized Charcoal. Ind. Eng. Chem. Res., 46(18), 5954-5967.

Boyatzis, R. E. (1998). Transforming qualitative information: thematic analysis and code development. Thousand Oaks, CA: Sage Publications.

Boyd, P. W. (2008). Ranking geo-engineering schemes. Nature Geoscience, 1(11), 722724.

Boyer, R. (1990). The regulation school: a critical introduction. New York: Columbia University Press.

Brady, N. C., \& Weil, R. R. (2002). The nature and properties of soils (13 ed.). Upper Saddle River, New Jersey: Prentice Hall. 
Braida, W. J., Pignatello, J. J., Lu, Y., Ravikovich, P. I., Neimark, A. V., \& Xing, B. (2003). Sorption hysteresis of benzene in charcoal particles. Environmental Science and Technology, 37(2), 409-417.

Brandão, M., Milà i Canals, L., \& Clift, R. (2010). Soil organic carbon changes in the cultivation of energy crops: Implications for GHG balances and soil quality for use in LCA. Biomass and Bioenergy, In Press, Corrected Proof.

Brennan, T. J. (1995). Discounting the future: economics and ethics. Resources, 120(Summer 1995), 3-6.

Bridgwater, A. V. (2003). Renewable fuels and chemicals by thermal processing of biomass. Chemical Engineering Journal, 91(2-3), 87-102.

Bridgwater, A. V. (2007). Biomass pyrolysis. Paris: IEA Bioenergy.

Bronson, D., Mooney, P., \& Wetter, K. J. (2009). Retooling the planet: climate chaos in the geoengineering age. Stockholm: ETC Group \& Swedish Society for Nature Conservation.

Brouwer, C., Goffeau, A., \& Heibloem, M. (1985). Irrigation Water Management: Training Manual No. 1 - Introduction to Irrigation. Rome, Italy: Food and Agriculture Organization of the United Nations (FAO).

Brown Weiss, E. (1989). The Theory of Intergenerational Equity In Fairness to Future Generations: International Law, Common Patrimony and Intergenerational Equity (pp. 17-47). Japan: The United Nations University Japan \& Transnational Publishers Inc.

Brownlee, G. (2009). Unlocking New Zealand's Energy and Resources Potential (Speech). Wellington: New Zealand Government.

Brownsort, P. A. (2009). Biomass pyrolysis processes: performance parameters and their influence on biochar system benefits. University of Edinburgh, Edinburgh.

Bruun, S., El-Zahery, T., \& Jensen, L. (2009). Carbon sequestration with biochar: stability and effect on decomposition of soil organic matter. IOP Conference Series: Earth and Environmental Science, 6(24).

Bryman, A. (2004). Social research methods (2 ed.). Oxford: Oxford University Press.

Burgess, A. (2002). A precautionary tale: the British response to cell phone EMF. Technology and Society Magazine, IEEE, 21(4), 14-18.

Burrage, L. J. (1933). Studies on Adsorption. The Relation of Water Held by Charcoal at Zero Pressure to the Ash Content. J. Phys. Chem., 37(9), 1095-1101.

Callan, S., \& Thomas, J. M. (2007). Environmental economics \& management: theory, policy, and applications (4 ed.). Mason, $\mathrm{OH}$ : Thomson/South-Western.

Campbell, B. M. (2009). Beyond Copenhagen: REDD+, agriculture, adaptation strategies and poverty. Global Environmental Change, 19(4), 397-399. 
Camps-Arbestain, M., Bishop, P., Wisnubroto, E. I., Hina, K., Aitkenhead, W., Calvelo - Pereira, R., et al. (2010, 11-12 February). Biochar research at the NZBRC: the soil science stream Paper presented at the Biochar Workshop: Opportunities for New Zealand Stakeholders, Palmerston North.

Canadell, J. G., Quéré, C. L., Raupach, M. R., Field, C. B., Buitenhuis, E. T., Ciais, P., et al. (2007). Contributions to accelerating atmospheric $\mathrm{CO}_{2}$ growth from economic activity, carbon intensity, and efficiency of natural sinks. Proceedings of the National Academy of Sciences of the United States of America, 104(47), 1886618870.

Cao, X., Ma, L., Gao, B., \& Harris, W. (2009). Dairy-manure derived biochar effectively sorbs lead and atrazine. Environmental Science and Technology, 43(9), 32853291.

Carbon Gold Ltd (2009a). The Carbon Gold team. Retrieved 2 August, 2009, from http://www.carbon-gold.com/the_carbon_gold_team.html

Carbon Gold Ltd (2009b). General Methodology for Quantifying the Greenhouse Gas Emission Reductions from the Production and Incorporation of Soil of Biochar in Agricultural and Forest Management Systems. London: Carbon Gold Ltd.

Carey, E. V., Sala, A., Keane, R., \& Callaway, R. M. (2001). Are old forests underestimated as global carbon sinks? Global Change Biology, 7(4), 339-344.

Carran, R. A., Theobald, P. W., \& Evans, J. P. (1995). Emission of nitrous-oxide from some grazed pasture soils in New Zealand. Australian Journal of Soil Research, 33(2), 341-352.

Carraro, C. (1999). Environmental conflict, bargaining and cooperation. In J. C. J. M. van den Bergh (Ed.), Handbook of environmental and resource economics (pp. 461). Cheltenham, UK: Edward Elgar.

Cavalieri, J., Hepworth, G., Fitzpatrick, L. A., Shephard, R. W., \& Macmillan, K. L. (2006). Manipulation and control of the estrous cycle in pasture-based dairy cows. Theriogenology, 65(1), 45-64.

Cetin, E., Moghtaderi, B., Gupta, R., \& Wall, T. F. (2004). Influence of pyrolysis conditions on the structure and gasification reactivity of biomass chars. Fuel 83(16), 2139-2150.

Chan, K. Y., Van Zwieten, L., Meszaros, I., Downie, A., \& Joseph, S. (2007). Agronomic values of greenwaste biochar as a soil amendment. Australian Journal of Soil Research, 45, 629-634.

Chan, K. Y., \& Xu, Z. H. (2009). Biochar: nutrient properties and their enhancement. In J. Lehmann \& S. Joseph (Eds.), Biochar for Environmental Management: Science and Technology (pp. 67-84). London: Earthscan.

Chari, V. V., \& Jones, L. E. (2000). A Reconsideration of the Problem of Social Cost: Free Riders and Monopolists. Economic Theory, 16(1), 1-22.

Charmaz, K. (2003). Grounded theory: objectivist and constructivist methods. In N. K. Denzin \& Y. S. Lincoln (Eds.), Strategies of qualitative inquiry (2 ed., pp. 249291). Thousand Oaks, CA: Sage Publications.

Charmaz, K. (2005). Grounded theory in the 21st century: applications for advancing social justice studies. In N. K. Denzin \& Y. S. Lincoln (Eds.), The SAGE 
handbook of qualitative research (pp. 507-536). Thousand Oaks, CA: Sage Publications.

Chen, B., Zhou, D., \& Zhu, L. (2008). Transitional Adsorption and Partition of Nonpolar and Polar Aromatic Contaminants by Biochars of Pine Needles with Different Pyrolytic Temperatures. Environmental Science and Technology, 42(14), 51375143.

Cheng, C.-H., \& Lehmann, J. (2009). Ageing of black carbon along a temperature gradient. Chemosphere, 75(8), 1021-1027.

Cheng, C.-H., Lehmann, J., Thies, J. E., \& Burton, S. D. (2008). Stability of black carbon in soils across a climatic gradient. J. Geophys. Res., 113.

Cheng, C.-H., Lehmann, J., Thies, J. E., Burton, S. D., \& Engelhard, M. H. (2006). Oxidation of black carbon by biotic and abiotic processes. Organic Geochemistry, 37(11), 1477-1488.

Chiaramonti, D., \& Recchia, L. (2010). Is life cycle assessment (LCA) a suitable method for quantitative $\mathrm{CO}_{2}$ saving estimations? The impact of field input on the LCA results for a pure vegetable oil chain. Biomass and Bioenergy, In Press, Corrected Proof.

Clark, C. W. (1999). Renewable resources: fisheries. In J. C. J. M. van den Bergh (Ed.), Handbook of environmental and resource economics (pp. 109-121). Cheltenham, UK: Edward Elgar.

Clough, P., \& Nutbrown, C. (2002). A student's guide to methodology: justifying enquiry. Thousand Oaks, CA: Sage Publications.

Clough, T. J., Bertram, J. E., Ray, J. L., Condron, L. M., O'Callaghan, M., Sherlock, R. R., et al. (2010). Unweathered Wood Biochar Impact on Nitrous Oxide Emissions from a Bovine-Urine-Amended Pasture Soil. Soil Science Society of America Journal, 74(3), 852-860.

Coase, R. H. (1960). The Problem of Social Cost. Journal of Law and Economics, 3, 144.

Cohen, M. A. (1999). Monitoring and enforcement of environmental policy. In H. Folmer \& T. Tietenberg (Eds.), The International Yearbook of Environmental and Resource Economics 1999/2000 - A Survey of Current Issues (pp. 44-106). Cheltenham, UK: Edward Elgar.

Common, M., \& Stagl, S. (2005). Ecological Economics: An Introduction. Cambrige: Cambridge University Press.

Commonwealth Scientific and Industrial Research Organisation (CSIRO) (2009). An analysis of greenhouse gas mitigation and carbon biosequestration opportunities from rural land use. St. Lucia, QLD, Australia: Commonwealth Scientific and Industrial Research Organisation (CSIRO).

Communities for Climate Protection - New Zealand (CCP-NZ) (2008). About CCP-NZ. Retrieved 18 March, 2010, from http://www.iclei.org/index.php?id=3922

Coombs, R., Saviotti, P., \& Walsh, V. (1987). Economics and technological change. Basingstoke: Macmillan Education. 
Cornelissen, G., \& Gustafsson, O. (2004). Sorption of Phenanthrene to Environmental Black Carbon in Sediment with and without Organic Matter and Native Sorbates. Environ. Sci. Technol., 38(1), 148-155.

Cornelissen, G., Haftka, J., Parsons, J., \& Gustafsson, O. (2005). Sorption to Black Carbon of Organic Compounds with Varying Polarity and Planarity. Environ. Sci. Technol., 39(10), 3688-3694.

Cory, K., Couture, T., \& Kreycik, C. (2009). Feed-in Tariff Policy: Design, Implementation, and RPS Policy Interactions. Golden, CO, USA: National Renewable Energy Laboratory, US Department of Energy.

Costanza, R., Hart, M., Posner, S., \& Talberth, J. (2009). Misuse of the GDP and the Need for New Measures of Progress. The Pardee Papers(4), January 2009.

Cowie, A. (2009). Biochar: understanding the potential and challenges. Armidale, NSW, Australia: University of New England, National Centre for Rural Greenhouse Gas Research.

Cowie, A., \& Singh, B. (2008, September 8-10, 2008). Decomposition rate of biochar in soil: an important factor affecting the greenhouse gas balance. Paper presented at the Second Conference of the International Biochar Initiative: Biochar, Sustainability and Security in a Changing Climate, Newcastle, UK.

Crabbé, A., \& Leroy, P. (2008). Policy evaluation and environmental policy. In A. Crabbé \& P. Leroy (Eds.), The handbook of environmental policy evaluation. London: Earthscan.

Creswell, J. W. (1994). Research design: qualitative \& quantitative approaches. Thousand Oaks, CA: Sage Publications.

Creswell, J. W. (2003). Research design: qualitative, quantitative and mixed methods approaches ( 2 ed.). Thousand Oaks, CA: Sage Publications.

Czernik, S., \& Bridgwater, A. V. (2004). Overview of Applications of Biomass Fast Pyrolysis Oil. Energy \& Fuels, 18(2), 590-598.

D

Daey Ouwens, C., den Uil, H., \& Boerrigter, H. (2001). Tri-generation from biomass and residues: options for the co-production of Fischer-Tropsch liquids, electricity and heat. In A. V. Bridgwater (Ed.), (Vol. 1, pp. 488-498). Oxford: Blackwell Science.

Daly, H. E., \& Farley, J. (2004). Ecological economics principles and applications. Washington: Island Press.

Damsgaard, J., \& Lyytinen, K. (1997). Hong Kong's EDI bandwagon: derailed or on the right track? In T. McMaster, E. Mumford, E. B. Swanson, B. Warboys \& D. Wastell (Eds.), Proceedings of the IFIP TC8 WG8.6 international working conference on diffusion, adoption and implementation of information technology in Ambleside, Cumbria, UK (pp. 39-63). London: Chapman \& Hall.

Day, D., Evans, R. J., Lee, J. W., \& Reicosky, D. (2004). The utilization of CO2 for the creation of a valuable and stable carbon co-product from fossil fuel exhaust scrubbing. 11. 
Decker, W. A., \& Corby, D. G. (1970). Activated charcoal as a gastrointestinal decontaminant: Experiences with experimental animals and human subjects. Clinical Toxicology, 3(1), 1-4.

de Jager, D., \& Rathmann, M. (2008). Policy instrument design to reduce financing costs in renewable energy technology projects. Utrecht, The Netherlands: ECOFYS, International Energy Agency.

de Vos, R., Fortuin, S., Heubeck, S., \& Hall, P. (2009). EnergyScape ${ }^{T M}$ Basis Review: Section 3: Bioenergy resources. Auckland: NIWA, SCION.

Demirbas, A. (2008a). Biofuels sources, biofuel policy, biofuel economy and global biofuel projections. Energy Conversion and Management, 49(8), 2106-2116.

Demirbas, A. (2008b). Bio-fuels from agricutural residues. Energy Sources, Part A: Recovery, Utilization and Environmental Effects, 30(2), 101-109.

Denmead, O. T. (2008). Approaches to measuring fluxes of methane and nitrous oxide between landscapes and the atmosphere. Plant and Soil, 309(1-2), 5-24.

Denne, T., Irvine, R., Atreya, N., \& Robinson, M. (2007). Recycling: cost benefit analysis. Prepared for Ministry for the Environment. Auckland: Covec Ltd., MfE.

Di Marian, F., \& Fantozzi, F. (2004). Life cycle assessment of waste to energy micropyrolysis system: Case study for an Italian town. International Journal of Energy Research, 28, 449-461.

DiCicco-Bloom, B., \& Crabtree, B. F. (2006). The qualitative research interview. Medical Education, 40(4), 314-321.

Dickinson, D. N., Kim, J. P., Hayman, A. R., \& Dickinson, W. W. (2010, 11-12

February). Char production by hydrothermal carbonization. Paper presented at the Biochar Workshop: Opportunities for New Zealand Stakeholders, Palmerston North.

Dinica, V. (2010). Wind Technology: A Framework for the Evaluation of Innovations' Impacts on the Diffusion Potential. Sustainability, 2(3), 757-782.

Dodgson, M., \& Bessant, J. (1996). Effective innovation policy: a new approach. New York: International Thompson Business Press.

Dovers, S. R., \& Handmer, J. W. (1992). Uncertainty, sustainability and change. Global Environmental Change, 2(4), 262-276.

Downie, A., Crosky, A., \& Munroe, P. (2009). Physical properties of biochar. In J. Lehmann \& S. Joseph (Eds.), Biochar for Environmental Management: Science and Technology (pp. 13-34). London: Earthscan.

Downie, A., \& Lau, D. (2010, 11-12 February). Pacific Pyrolysis: greenhouse gas life cycle analysis. Paper presented at the Biochar Workshop: Opportunities for New Zealand Stakeholders, Palmerston North.

Downie, A., \& Pepper, C. (2010, 11-12 February). Palmerston North City Council Biochar Project. Paper presented at the Biochar Workshop: Opportunities for New Zealand Stakeholders, Palmerston North.

Downie, A., Van Zwieten, L., Chan, K. Y., Crosky, A., \& Munroe, P. (2008). Biochar Feedstock Choice: An economic/agronomic balance. Paper presented at the Second Conference of the International Biochar Initiative: Biochar, Sustainability 
and Security in a Changing Climate. from http://www.biocharinternational.org/sites/default/files/Adriana Downie IBI 2008 poster.pdf

Downie, A., Van Zwieten, L., Chan, K. Y., Dougherty, W., \& Joseph, S. (2007, April 30 May 2, 2007). Nutrient Retention Characteristics of Agrichar and the Agronomic Implications. Paper presented at the International Agrichar Initiative Conference 2007, Terrigal, NSW, Australia.

Downie, C. (2007). Carbon offsets: saviour or cop-out? Manuka, ACT, Australia: The Australia Institute.

Duncan, G. (2005). What Do We Mean By "Happiness"? The Relevance of Subjective Wellbeing to Social Policy. Social Policy Journal of New Zealand(25), 16-31.

Dutschke, M. (2002). Fractions of permanence: squaring the cycle of sink carbon accounting. Mitigation and Adaptation Strategies for Global Change, 7(4), 381402.

\section{$\mathbf{E}$}

Eckersley, R. (2005). Ecocentrism explained and defended. In J. S. Dryzek \& D. Schlosberg (Eds.), Debating the Earth: the environmental politics reader (pp. 364-381). Oxford: Oxford University Press.

Eckmeier, E., Gerlach, R., Skjemstad, J. O., Ehrmann, O., \& Schmidt, M. W. I. (2007). Minor changes in soil organic carbon and charcoal concentrations detected in a temperate deciduous forest a year after an experimental slash-and-burn. Biogeosciences, 4, 377-383.

Ehrenfeld, D. (2005). Sustainability: Living with the Imperfections. Conservation Biology, 19(1), 33-35.

Ekins, P., Simon, S., Deutsch, L., Folke, C., \& De Groot, R. (2003). A framework for the practical application of the concepts of critical natural capital and strong sustainability. Ecological Economics, 44(2-3), 165-185.

Elmquist, M., Cornelissen, G., Kukulska, Z., \& Gustafsson, Ö. (2006). Distinct oxidative stabilities of char versus soot black carbon: Implications for quantification and environmental recalcitrance. Global Biogechemical Cycles, 20(GB2009), doi:10.1029/2005GB002629.

Emissions Trading Scheme Review Committee (2009). Review of the Emissions Trading Scheme and related matters: Report of the Emissions Trading Scheme Review Committee. Wellington: Emissions Trading Scheme Review Committee.

Energy Efficiency and Conservation Authority (EECA) (2006). Renewable energy assessment: Marlborough District. Wellington: EECA.

Energy Efficiency and Conservation Authority (EECA) (2010). What we do. Retrieved 18 March, 2010, from http://www.eeca.govt.nz/about-eeca/what-we-do

Engel, S., Pagiola, S., \& Wunder, S. (2008). Designing payments for environmental services in theory and practice: An overview of the issues. Ecological Economics, 65(4), 663-674. 
Enkvist, P.-A., Nauclér, T., \& Rosander, J. (2007). A cost curve for greenhouse gas reduction. McKinsey Quarterly, February 2007(1), 34-45.

Environmental Defense Fund (2007a). CDM and the Post-2012 Framework: Discussion Paper. New York: Environmental Defense Fund.

Environmental Defense Fund (2007b, 12/02/2007). Why Safety Valves Are Very

Dangerous. Retrieved 21 March, 2010, from

http://www.edf.org/page.cfm?tagID $=1087$

Environmental Protection Authority (EPA) (2009, 01/10/2009). Environmental Protection Authority launched. Retrieved 20 March, 2010, from http://www.epa.govt.nz/news-and-notices/2009-10-01.html

Ernsting, A., Anderson, T., \& Maina, A. (2009). Biochar land grabbing: the impacts on Africa: The African Biodiversity Network, Biofuelwatch and the Gaia Foundation.

Ernsting, A., \& Rughani, D. (2008). Climate Geo-engineering with 'Carbon Negative' Bioenergy: Climate saviour or climate endgame? : Biofuelwatch UK.

Ernsting, A., \& Smolker, R. (2009). Biochar for Climate Change Mitigation: Fact or Fiction? : Biofuel Watch UK.

European Energy Exchange (EEX) (2009, 07/01/2010). EU Emission Allowances: Preise und Handelsvolumen 07.01.2010 - European Energy Exchange: Chart. Retrieved 8 January, 2010, from http://www.eex.com/de/Marktdaten/Handelsdaten/Emissionsrechte/EU\%20Emissi on\%20Allowances\%20\%7C\%20Spotmarkt/EU\%20Emission\%20Allowances\%20 Chart\%20\%7C\%20Spotmarkt/spot-eua-chart/2010-01-07/1/1/a

European Union (EU) (2009). Directive 2009/28/EC of the European Parliament and of the Council of 23 April 2009 on the promotion of the use of energy from renewable sources and amending and subsequently repealing Directives 2001/77/EC and 2003/30/EC. Official Journal of the European Union, L 140(05/06/2009), 16-62.

Eyre, N. (1997). External costs : What do they mean for energy policy? Energy Policy, 25(1), 85-95.

\section{$\mathbf{F}$}

Fagerberg, J. (2003). Schumpeter and the revival of evolutionary economics: an appraisal of the literature. Journal of Evolutionary Economics, 13(2), 125-159.

Fagerberg, J., \& Verspagen, B. (2009). Innovation studies: the emerging structure of a new scientific field. Research Policy, 38(2), 218-233.

Fargione, J., Hill, J., Tilman, D., Polasky, S., \& Hawthorne, P. (2008). Land Clearing and the Biofuel Carbon Debt. Science, 319(5867), 1235-1238.

Feng, H., Rubin, O. D., \& Babcock, B. A. (2010). Greenhouse gas impacts of ethanol from Iowa corn: Life cycle assessment versus system wide approach. Biomass and Bioenergy, In Press, Corrected Proof. 
Flick, U. (2009). An introduction to qualitative research (4 ed.). London: Sage Publications.

Forbes, M. S., Raison, R. J., \& Skjemstad, J. O. (2006). Formation, transformation and transport of black carbon (charcoal) in terrestrial and aquatic ecosystems. Science of The Total Environment, 370(1), 190-206.

Foundation for Research, Science and Technology (FRST), (2010). Portfolio Overview: Understanding and Adapting to Global Process and Change (GLO). Retrieved 22 May, 2010, from http://www.frst.govt.nz/investframe/areas/research/GLO

Frances, J. (2004). Institutions, Firms and Economic Growth. New Zealand Treasury Working Paper 04/19. Wellington: The Treasury.

Freeman, C., \& Perez, C. (1988). Structural crisis of adjustment: business cycles and investment behaviour. In G. Dosi, C. Freeman, R. Nelson, G. Silverberg \& L. Soete (Eds.), Technical change and economic theory (pp. 38-66). London: Pinter Publishers.

Furey, L. (2006). Maori Gardening: An Archaeological Perspective. Wellington: Department of Conservation (DOC).

Fynn, A. J., Alvarez, P., Brown, J. R., George, M. R., Kustin, C., Laca, E. A., et al. (2009). Soil Carbon Sequestration in U.S. Rangelands: Issues Paper for Protocol Development. Sacramento, CA: Environmental Defense Fund.

\section{G}

Gadd, J. B., Tremblay, L. A., \& Northcott, G. L. (2010). Steroid estrogens, conjugated estrogens and estrogenic activity in farm dairy shed effluents. Environmental Pollution, 158(3), 730-736.

Garnaut, R. (2008). The Garnaut Climate Change Review: Final Report. Cambridge: Cambridge University Press.

Gaskin, J. W., Speir, A., Morris, L. M., Ogden, L., Harris, K., Lee, D., et al. (2007, March 27-29). Potential for pyrolysis char to affect soil moisture and nutrient status of a loamy sand soil. Paper presented at the Georgia Water Resources Conference, University of Georgia, Athens, GA.

Gaskin, J. W., Steiner, C., Harris, K., Das, K. C., \& Bibens, B. (2008). Effect of lowtemperature pyrolysis conditions on biochar for agricultural use. Transactions of the ASABE, 51(6), 2061-2069.

Gaunt, J., \& Cowie, A. (2009). Biochar, greenhouse gas accounting and emissions trading. In J. Lehmann \& S. Joseph (Eds.), Biochar for Environmental Management: Science and Technology (pp. 317-340). London: Earthscan.

Gaunt, J., \& Lehmann, J. (2008). Energy Balance and Emissions Associated with Biochar Sequestration and Pyrolysis Bioenergy Production. Environmental Science and Technology, 42(11), 4152-4158.

German Advisory Council on Global Change (2009). Solving the climate dilemma: The budget approach. Special Report. Berlin: German Advisory Council on Global 
Change (Wissenschaftlicher Beirat der Bundesregierung Globale Umweltveränderungen, WBGU).

Ghani, A., Mackay, A., Clothier, B., Curtin, D., \& Sparling, G. (2009). A literature review of soil carbon under pasture, horticulture and arable land uses: Report prepared for AGMARDT. Hamilton: AgResearch Ltd.

Giddens, A. (1990). The consequences of modernity. Stanford, CA: Stanford University Press.

Giddens, A. (1999). Risk and Responsibility. The Modern Law Review, 62(1), 1-10.

Giddens, A. (2009). The politics of climate change. Cambridge, UK: Polity Press.

Giltrap, D., Saggar, S., Li, C., \& Wilde, H. (2008). Using the NZ-DNDC model to estimate agricultural $\mathrm{N} 2 \mathrm{O}$ emissions in the Manawatu-Wanganui region. Plant and Soil, 309(1-2), 191-209.

Girgis, B. S., Yunis, S. S., \& Soliman, A. M. (2002). Characteristics of activated carbon from peanut hulls in relation to conditions of preparation. Materials Letters, 57, 164-172.

Glaser, B., Balashov, E., Haumaier, L., Guggenberger, G., \& Zech, W. (2000). Black carbon in density fractions of anthropogenic soils of the Brazilian Amazon region. Org. Geochem., 31, 669-678.

Glaser, B., Haumaier, L., Guggenberger, G., \& Zech, W. (2001). The 'Terra Preta' phenomenon: a model for sustainable agriculture in the humid tropics. Naturwissenschaften, 88(1), 37-41.

Glaser, B., Lehmann, J., \& Zech, W. (2002). Ameliorating physical and chemical properties of highly weathered soils in the tropics with charcoal - a review. Biology of Fertile Soils, 35, 219-230.

Glaser, B. G., \& Strauss, A. L. (1967). The discovery of grounded theory: strategies for qualitative research. Chicago: Aldine Pub. Co.

Global Forest Coalition (2010). Wood-based bioenergy: the green lie. The impact of wood-based bio-energy on forests and forest dependent people. Amsterdam, The Netherlands: Global Forest Coalition.

Goldberg, E. D. (1985). Black Carbon in the Environment. New York: John Wiley.

Gomulka, S. (1990). The theory of technological change and economic growth. London: Routledge.

Gonçalves da Silva, C. (2010). Renewable energies: Choosing the best options. Energy, In Press, Corrected Proof(doi: 10.1016/j.energy.2010.03.061).

Government of New Zealand (2010). The Estimates of Appropriations for the Government of New Zealand for the Year Ending 30 June 2011. Wellington: The Treasury.

Govindasamy, B., Caldeira, K., \& Duffy, P. B. (2003). Geoengineering Earth's radiation balance to mitigate climate change from a quadrupling of $\mathrm{CO}_{2}$. Global and Planetary Change, 37(1-2), 157-168.

GovTrack (2010, 18 May 2010). H.R. 2454: American Clean Energy and Security Act of 2009. Retrieved 13 June, 2010, from http://www.govtrack.us/congress/bill.xpd?bill=h111-2454 
Grace, J., Kruijt, B., Freibauer, A., Benndorf, R., Carr, R., Dutschke, M., et al. (2003). Scientific and Technical Issues in the Clean Development Mechanism. Wageningen, The Netherlands: CarboEurope Cluster.

Graf, H. (2006). Networks in the innovation process: local and regional interactions. Cheltenham, UK: Edward Elgar.

Graham, J. D. (2001). Decision-analytic refinements of the precautionary principle. Journal of Risk Research, 4(2), 127 - 141.

Granovetter, M. (1973). The Strength of Weak Ties. The American Journal of Sociology, 78(6), 1360-1380.

Granovetter, M. (1978). Threshold Models of Collective Behavior. The American Journal of Sociology, 83(6), 1420-1443.

Granovetter, M. (1985). Economic Action and Social Structure: The Problem of Embeddedness. The American Journal of Sociology, 91(3), 481-510.

Graves, D. (2010, 11-12 February). Biochar as a carrier medium to introduce fresh mycorrhizal inocula into plant root zones Paper presented at the Biochar Workshop: Opportunities for New Zealand Stakeholders, NZBRC, Massey University, Palmerston North.

Gregory, A. S., Watts, C. W., Griffiths, B. S., Hallett, P. D., Kuan, H. L., \& Whitmore, A. P. (2009). The effect of long-term soil management on the physical and biological resilience of a range of arable and grassland soils in England. Geoderma, 153(12), 172-185.

Griliches, Z. (1957). Hybrid Corn: An Exploration in the Economics of Technological Change. Econometrica, 25(4), 501-522.

Grinlinton, D. (1996). Property Rights and the Environment. Australian Property Law Journal, 4(41).

Grinlinton, D. P. (2002). Contemporary Environmental Law in New Zealand. In K. Bosselmann \& D. P. Grinlinton (Eds.), Environmental Law for a Sustainable Society (Vol. 1 of New Zealand Centre for Environmental Law Monograph Series, pp. 19 - 46). Auckland: New Zealand Centre for Environmental Law, Monograph 1 .

Grossman, S. J., \& Hart, O. D. (1980). Takeover Bids, The Free-Rider Problem, and the Theory of the Corporation. The Bell Journal of Economics, 11(1), 42-64.

Groves, T., \& Ledyard, J. (1977). Optimal Allocation of Public Goods: A Solution to the "Free Rider" Problem. Econometrica, 45(4), 783-809.

Guerin, K. (2003). Property rights and environmental policy: a New Zealand perspective. New Zealand Treasury Working Paper 03/02. Wellington: New Zealand Treasury.

Guerrero, M., Ruiz, M. P., Millera, A., Alzueta, M., \& Bilbao, R. (2008). Characterization of Biomass Chars Formed under Different Devolatilization Conditions: Differences between Rice Husk and Eucalyptus. Energy Fuels, 22(2), 1275-1284.

Gupta, S., Tirpak, D. A., Burger, N., Gupta, J., Höhne, N., Boncheva, A. I., et al. (2007). Policies, Instruments and Co-operative Arrangements. In B. Metz, O. R. Davidson, P. R. Bosch, R. Dave \& L. A. Meyer (Eds.), Climate Change 2007: Mitigation. Contribution of Working Group III to the Fourth Assessment Report of 
the Intergovernmental Panel on Climate Change (pp. 745-807). Cambridge, UK and New York, USA: Cambridge University Press.

\section{H}

Haard, R. (2010, 05/01/2010). A simple test for functional biochar Retrieved 17 May, 2010, from http://terrapreta.bioenergylists.org/content/simple-test-functionalbiochar

Hägerstrand, T. (1966). Aspects of the spatial structure of social communication and the diffusion of information. Papers in Regional Science, 16(1), 27-42.

Hägerstrand, T. (1967). Innovation diffusion as a spatial process (A. Pred, Trans.). Chicago: Chicago University Press.

Hall, P., \& Gifford, J. (2007). Bioenergy Options for New Zealand: Situation Analysis. Rotorua: Scion, Energy Group.

Hall, P., \& Jack, M. (2008). Bioenergy Options for New Zealand: Pathway Analysis. Rotorua: Scion, Energy Group.

Hammes, K., Smernik, R. J., Skjemstad, J. O., Herzog, A., Vogt, U. F., \& Schmidt, M. W. I. (2006). Synthesis and characterisation of laboratory-charred grass straw (Oryza sativa) and chestnut wood (Castanea sativa) as reference materials for black carbon quantification. Organic Geochemistry, 37(11), 1629-1633.

Hanks, R. J., Holmes, W. E., \& Tanner, C. B. (1954). Field Capacity Approximation Based on the Moisture-Transmitting Properties of the Soil. Soil Sci Soc Am J, 18(3), 252-254.

Hanlon, D. W., Williamson, N. B., Wichtel, J. J., Steffert, I. J., Craigie, A. L., \& Pfeiffer, D. U. (1997). Ovulatory responses and plasma luteinizing hormone concentrations in dairy heifers after treatment with exogenous progesterone and estradiol benzoate. Theriogenology, 47(5), 963-975.

Hansen, J., Sato, M., Kharecha, P., Beerling, D., Berner, R., Masson-Delmotte, V., et al. (2008). Target Atmospheric $\mathrm{CO}_{2}$ : Where Should Humanity Aim? The Open Atmospheric Science Journal, 2(2008), 217-231.

Hansen, J., Sato, M., Ruedy, R., Nazarenko, L., Lacis, A., Schmidt, G. A., et al. (2005). Efficacy of climate forcings. J. Geophys. Res., 110, D18104.

Hansson, S. O. (2010). Risk: objective or subjective, facts or values. Journal of Risk Research, 13(2), 231 - 238.

Hardin, G. (1968). The tragedy of the commons. Science, 162(3859), 1243-1248.

Harmon, M. E., Ferrell, W. K., \& Franklin, J. F. (1990). Effects on carbon storage of conversion of old-growth forests to young forests. Science, 247, 699-702.

Harris, A., \& Hill, R. (2007). Carbon-negative primary production: role of biocarbon and challenges for organics in Aotearoa/New Zealand. Journal of Organic Systems, 2(2), 2-13.

Harris, J. M. (2006). Environmental and natural resource economics: a contemporary approach. Boston: Houghton Mifflin. 
Hedley, M. (2010, 21/01/2010). SFF Project Summary: New Zealand Biochar Network. Grant No.: LC08/044. Sustainable Farming Fund (SFF): Projects. Retrieved 9 June, 2010, from http://www.maf.govt.nz/sff/about-projects/search/LC08044/index.htm

Heffernan, O. (2009). Best practice for biochar. [Editorial]. Nature Reports Climate Change, 3.

Heitzmann, M. (2007, 30-31 May). Beyond the Resource Management Act: Lessons from the Past and Advice for the Future. Paper presented at the Beyond the Resource Management Act Conference, Environmental Defence Society, Auckland.

Henning, K.-D., \& Schäfer, S. (1993). Impregnated activated carbon for environmental protection. Gas Separation \& Purification, 7(4).

Hewitt, A. (2009, 01/03/2009). Soils - The most extensive soils. Te Ara - the Encyclopedia of New Zealand Retrieved 25 February, 2010, from http://www.teara.govt.nz/en/soils/4

Hirschman, E. C. (1980). Innovativeness, Novelty Seeking, and Consumer Creativity. The Journal of Consumer Research, 7(3), 283-295.

Ho, M.-W. (2009). Black carbon warms the planet second only to $\mathrm{CO}_{2}$. London: Institute of Science in Society (ISIS).

Hockaday, W. C., Grannas, A. M., Kim, S., \& Hatcher, P. G. (2006). Direct molecular evidence for the degradation and mobility of black carbon in soils from ultrahighresolution mass spectral analysis of dissolved organic matter from a fire-impacted forest soil. Organic Geochemistry, 37, 501-510.

Hockaday, W. C., Grannas, A. M., Kim, S., \& Hatcher, P. G. (2007). The transformation and mobility of charcoal in a fire-impacted watershed. Geochimica et Cosmochimica Acta, 71(14), 3432-3445.

Hofmann, M., \& Rahmstorf, S. (2009). On the stability of the Atlantic meridional overturning circulation. Proceedings of the National Academy of Sciences, 106(49), 20584-20589.

Holmes, A., Rahman, M. H., Saunders, S. J., \& Mowat, A. (2010, 11-12 February). Biochar generated from Kiwifruit vine prunings: scope and characterization. Paper presented at the Biochar Workshop: Opportunities for New Zealand Stakeholders, NZBRC, Massey University, Palmerston North.

Hom, A. G., Plaza, R. M., Feijóo, S. F., \& Palmén, R. (2009). From precautionary inadequacy to participatory risk management. Futures, 41(5), 260-268.

Horgan, G. (2008). The opportunities for biochar in New Zealand. Rotorua: Ministry of Agriculture and Forestry.

Houghton, R. A. (1999). The annual net flux of carbon to the atmosphere from changes in land use 1850 to 1990. Tellus B, 51(2), 298-313.

Houghton, R. A., Hackler, J. L., \& Lawrence, K. T. (1999). The US carbon budget: contributions from land-use change. Science, 285(5427), 574-578.

Huberman, A. M., \& Miles, M. B. (1998). Data management and analysis methods. In N. K. Denzin \& Y. S. Lincoln (Eds.), Collecting and interpreting qualitative materials (pp. 179-210). Thousand Oaks, CA: Sage Publications. 
Husk, B., \& Major, J. (2010). Commercial scale agricultural biochar field trial in Québec, Canada over two years: effects of biochar on soil fertility, biology and crop productivity and quality. Québec: BlueLeaf Inc.

Huwig, A., Freimund, S., Käppeli, O., \& Dutler, H. (2001). Mycotoxin detoxication of animal feed by different adsorbents. Toxicology Letters, 122(2), 179-188.

Ibarrola, R. (2009). Pyrolysis for waste management: a life cycle assessment of biodegradable waste, bioenergy generation and biochar production in Glasgow and the Clyde Valley. University of Edinburgh, Edinburgh.

ICF International (2008). Final Report: Voluntary Carbon Market Opportunities - Soil Carbon Management in New Zealand. Wellington: Ministry of Agriculture and Forestry (MAF).

Inglehart, R., \& Klingemann, H.-D. (2000). Genes, culture, democracy, and happiness. In E. Diener \& E. M. Suh (Eds.), Culture and Subjective Well-being. Cambridge, MA: MIT Press.

Intergovernmental Panel on Climate Change (IPCC) (1996). Revised 1996 IPCC Guidelines for National Greenhouse Gas Inventories: The Reference Manual. Bracknell: UK Meteorological Office.

Intergovernmental Panel on Climate Change (IPCC) (2000a). Good Practice Guidance and Uncertainty Management in National Greenhouse Gas Inventories. Hayama, Kanagawa, Japan: Institute for Global Environmental Strategies (IGES) for the IPCC.

Intergovernmental Panel on Climate Change (IPCC) (2000b). Land Use, Land-Use Change and Forestry. Cambridge, UK: Cambridge University Press.

Intergovernmental Panel on Climate Change (IPCC) (2007a). Climate Change 2007: Mitigation. Contribution of Working Group III to the Fourth Assessment Report of the Intergovernmental Panel on Climate Change. Cambridge, UK and New York, USA: Cambridge University Press.

Intergovernmental Panel on Climate Change (IPCC) (2007b). Climate Change 2007: Synthesis Report. Contribution of Working Groups I, II and III to the Fourth Assessment Report of the Intergovernmental Panel on Climate Change. Geneva: IPCC.

Intergovernmental Panel on Climate Change (IPCC) (2007c). Climate Change 2007: The Physical Science Basis. Contribution of Working Group I to the Fourth Assessment Report of the Intergovernmental Panel on Climate Change. Cambridge, UK and New York, USA: Cambridge University Press.

International Biochar Initiative (IBI) (2009a). About Biochar. Retrieved 16 June, 2009, from http://www.biocharinternational.org/upcomingibiconferences/2009asiapacificregion.html 
International Biochar Initiative (IBI) (2009b). Biochar: A Soil Amendment that Combats Global Warming and Improves Agricultural Sustainability and Environmental Impacts. Philadelphia, PA: International Biochar Initiative (IBI).

International Biochar Initiative (IBI) (2009c, 09/2009). International Policy: Biochar Climate Scorecard. Retrieved 25 October, 2009, from http://www.biocharinternational.org/policy/international

International Union for Conservation of Nature (IUCN), United Nations Environment Programme (UNEP), \& World Wide Fund for Nature (WWF) (1991). Caring for the Earth: a strategy for sustainable living. Gland, Switzerland: International Union for Conservation of Nature (IUCN), United Nations Environment Programme (UNEP), World Wide Fund for Nature (WWF).

Ioannidou, O., \& Zabaniotou, A. (2007). Agricultural residues as precursors for activated carbon production: a review. Renewable and Sustainable Energy Reviews, 11, 1966-2005.

Ishii, T., \& Kadoya, K. (1994). Effect of Charcoal as a soil conditioner on citrus growth and vesicular-arbuscular mycorrhizal development. Journal of the Japanese Society for Horticultural Science, 63(3), 529-535.

$\mathbf{J}$

Jacoby, H. D., \& Ellerman, A. D. (2004). The safety valve and climate policy. Energy Policy, 32(4), 481-491.

Jaffe, A. B., Newell, R. G., \& Stavins, R. N. (2005). A tale of two market failures: Technology and environmental policy. Ecological Economics, 54(2-3), 164-174.

James, W. (1898). Philosophical conceptions and practical results. University Chronicle, l(1), 287-310.

James, W. (1907). Pragmatism: A new name for some old ways of thinking: Popular lectures on philosophy. New York: Longmans, Green.

James, W. (1909). The meaning of truth: A sequel to 'pragmatism'. New York: Longmans, Green.

Johnson, J. M.-F., Franzluebbers, A. J., Lachnicht Weyers, S., \& Reicosky, D. C. (2007). Agricultural opportunities to mitigate greenhouse gas emissions. Environmental Pollution, 150, 107-124.

Johnson, R. B., \& Onwuegbuzie, A. J. (2004). Mixed Methods Research: A Research Paradigm Whose Time Has Come. Educational Researcher, 33(7), 14-26.

Jones, C., Lowe, J., Liddicoat, S., \& Betts, R. (2009). Committed terrestrial ecosystem changes due to climate change. Nature Geoscience, 2(7), 484-487.

Jones, S. K., Rees, R. M., Skiba, U. M., \& Ball, B. C. (2007). Influence of organic and mineral N fertiliser on N2O fluxes from a temperate grassland. Agriculture, Ecosystems and Environment, 121, 74-83. 
Jones, J. (2010, 11-12 February). Biochar research at the NZBRC: pyrolysis stream. Paper presented at the Biochar Workshop: Opportunities for New Zealand Stakeholders, Palmerston North.

Joseph, S., Munroe, P., van Zwieten, L., Cowie, A., Krull, E., Singh, B., et al. (2009). Biochar for soil fertility and carbon sequestration: a review of current understanding. A presentation of the ANZBRN to the Australian Department of Climate Change. Canberra: Australia New Zealand Biochar Researchers Network (ANZBRN).

\section{K}

Kahneman, D. (2003). Maps of Bounded Rationality: Psychology for Behavioral Economics. The American Economic Review, 93(5), 1449-1475.

Kanase-Patil, A. B., Saini, R. P., \& Sharma, M. P. (2010). Integrated renewable energy systems for off grid rural electrification of remote area. Renewable Energy, 35(6), 1342-1349.

Katz, E., \& Lazarsfeld, P. (1955). Personal influence: the part played by people in the flow of mass communications. New York: Free Press.

Keeney, R. L., \& Von Winterfeldt, D. (2001). Appraising the precautionary principle: a decision analysis perspective. Journal of Risk Research, 4(2), 191 - 202.

Kelliher, F. M., \& de Klein, C. A. M. (2006). Review of New Zealand's fertiliser nitrous oxide emission factor (EF1) data. A Report for the Ministry for the Environment. Wellington: Ministry for the Environment.

Kheifets, L. I., Hester, G. L., \& Banerjee, G. L. (2001). The precautionary principle and EMF: implementation and evaluation. Journal of Risk Research, 4(2), 113 - 125.

Kim, O., \& Walker, M. (1984). The Free Rider Problem: Experimental Evidence. Public Choice, 43(1), 3-24.

Kimetu, J. M., Lehmann, J., Ngoze, S. O., Mugendi, D. N., Kinyangi, J. M., Riha, S., et al. (2008). Reversibility of soil productivity decline with organic matter of differing quality along a degradation gradient. Ecosystems, 11(5), 726-739.

Kishimoto, S., \& Sugiura, G. (1985). Charcoal as soil conditioner. International Achievements for the Future, 5, 12-23.

Klein, A., Pfluger, B., Held, A., Ragwitz, M., Resch, G., \& Faber, T. (2008). Evaluation of different feed-in tariff design options: best practice paper for the International Feed-In Cooperation. Berlin: Fraunhofer Institute Systems and Innovation Research, Energy Economics Group.

Kollmuss, A., Lazarus, M., Lee, C., \& Polycarp, C. (2008a). A review of offset programs: trading systems, funds, protocols, standards and retailers. Stockholm: Stockholm Environment Institute.

Kollmuss, A., Zink, H., \& Polycarp, C. (2008b). Making Sense of the Voluntary Carbon Market: A Comparison of Carbon Offset Standards. Stockholm: Stockholm Environment Institute and Tricorona. 
Kottek, M., Grieser, J., Beck, C., Rudolf, B., \& Rubel, F. (2006). World Map of the Köppen-Geiger climate classification updated. Meteorologische Zeitschrift, 15(3), 259-263.

Kriegler, E., Hall, J. W., Held, H., Dawson, R., \& Schellnhuber, H. J. (2009). Imprecise probability assessment of tipping points in the climate system. Proceedings of the National Academy of Sciences, 106(13), 5041-5046.

Krull, E. (2010, 11-12 February). Biochar research in Australia: an update on the DAFF and GRDC projects. Paper presented at the Biochar Workshop: Opportunities for New Zealand Stakeholders, Palmerston North.

Krull, E. S., Skjemstad, J. O., \& Baldock, J. A. (2004). Functions of Soil Organic Matter and the Effect on Soil Properties. Glen Osmond: CSIRO Land \& Water.

Kuhlbusch, T. A. J. (1995). Method for Determining Black Carbon in Residues of Vegetation Fires. Evironmental Science and Technology, 29, 2695-2702.

Kuhlbusch, T. A. J. (1998). Black carbon and the carbon cycle. [Research Commentaries]. Science, 280(5371), 1903-1904.

Kuhlbusch, T. A. J., \& Crutzen, P. J. (1996). Black carbon, the global carbon cycle, and atmospheric carbon dioxide. In J. S. Levine (Ed.), Biomass Burning and Global Change (pp. 160-169). Cambridge, Massachusetts: MIT Press.

Kuhn, T. S. (1962). The structure of scientific revolutions. Chicago: University of Chicago Press.

Kuzyakov, Y., Subbotina, I., Chen, H., Bogomolova, I., \& Xu, X. (2009). Black carbon decomposition and incorporation into soil microbial biomass estimated by ${ }^{14} \mathrm{C}$ labeling. Soil Biology and Biochemistry, 41(2), 210-219.

Laird, D. A. (2008). The Charcoal Vision: A Win-Win-Win Scenario for Simultaneously Producing Bioenergy, Permanently Sequestering Carbon, while Improving Soil and Water Quality. Agronomy Journal, 100(1), 178-181.

Laird, F. N. (1993). Participatory Analysis, Democracy, and Technological Decision Making. Science, Technology, \& Human Values, 18(3), 341-361.

Lal, R. (1999). Soil management and restoration for C sequestration to mitigate the accelerated greenhouse effect. Progress in Environmental Science, 1, 307-326.

Landcare Research Manaaki Whenua (2010). Geospatial Data Integration Portal: Soil, geology and geophysics: NZFSL - Total Carbon (New Zealand Fundamental Soil Layer - Topsoil Carbon). Retrieved 24 February, 2010, from http://gisportal.landcareresearch.co.nz/WebForms/map.aspx

Lather, P. (1986). Research as praxis. Harvard Educational Review, 56(3), 257-277.

Lazarsfeld, P. F., \& Merton, R. K. (1954). Friendship as social process: a substantative and methodological analysis. In M. Berger, T. Abel \& C. H. Page (Eds.), Freedom and control in modern society (pp. 18-66). New York: Van Nostrand. 
Lehmann, J. (2007a). Bio-energy in the black. Frontiers in Ecology and the Environment, $5(7), 381-387$.

Lehmann, J. (2007b). Biochar for mitigating climate change: carbon sequestration in the black. Forum Geooekologie 18 (2), 2007, 18(2), 15-17.

Lehmann, J. (2007c). A handful of carbon. [commentary]. Nature, 447(7141), 143-144.

Lehmann, J. (2009). Biochar: Science and Policy. Paper presented at the 1st Asia Pacific Biochar Conference. Retrieved 15 June, 2009, from http://www.anzbiochar.org/2009presentations.html

Lehmann, J., Czimczik, C., Laird, D., \& Sohi, S. (2009). Stability of biochar in the soil. In J. Lehmann \& S. Joseph (Eds.), Biochar for Environmental Management: Science and Technology (pp. 183-205). London: Earthscan.

Lehmann, J., da Silva Jr., J. P., Steiner, C., Nehls, T., Zech, W., \& Glaser, B. (2003a). Nutrient availability and leaching in an archaeological Anthrosol and a Ferralsol of the Central Amazon basin: fertilizer, manure and charcoal amendments. Plant and Soil, 249, 343-357.

Lehmann, J., Gaunt, J. L., \& Rondon, M. (2006). Bio-char sequestration in terrestrial ecosystems: a review. Mitigation and Adaptation Strategies for Global Change, $11(2), 403-427$.

Lehmann, J., \& Joseph, S. (2009). Biochar for Environmental Management: An Introduction. In J. Lehmann \& S. Joseph (Eds.), Biochar for Environmental Management: Science and Technology (pp. 1-12). London: Earthscan.

Lehmann, J., Kern, D. C., German, L. A., McCann, J., C., M. G., \& Moreira, A. (2003b). Soil fertility and production potential. In J. Lehmann, D. C. Kern, B. Glaser \& W. I. Woods (Eds.), Amazonian Dark Earths: Origin, Properties, Management (pp. 105-124). Dordrecht: Kluwer.

Lenton, T. M., \& Vaughan, N. E. (2009). The radiative forcing potential of different climate geoengineering options. Atmos. Chem. Phys. Discuss., 9(1), 2559-2608.

Leopold, A. (1949). A sand county almanac, and sketches here and there. New York: Oxford University Press.

Lewens, T. (2010). The risks of progress: precaution and the case of human enhancement. Journal of Risk Research, 13(2), 207 - 216.

Li, X., Hagaman, E., Tsouris, C., \& Lee, J. W. (2003). Removal of carbon dioxide from flue gas by ammonia carbonation in the gas phase. Energy \& Fuels, 17(1), 69-74.

Liang, B., Lehmann, J., Solomon, D., Kinyangi, J., Grossman, J., O’Neill, B., et al. (2006). Black Carbon Increases Cation Exchange Capacity in Soils. Soil Science Society of America Journal, 70, 1719-1730.

Light, A. (1996). Compatibilism in political ecology. In A. Light \& E. Katz (Eds.), Environmental pragmatism (pp. 161-186). London: Routledge.

Lind, R. C. (1995). Intergenerational equity, discounting, and the role of cost-benefit analysis in evaluating global climate policy. Energy Policy, 23(4-5), 379-389.

Liou, H. M. (2010). Policies and legislation driving Taiwan's development of renewable energy. Renewable and Sustainable Energy Reviews, In Press, Corrected Proof(doi: 10.1016/j.rser.2010.02.013). 
Lipietz, A. (1995). Enclosing the Global Commons: Global Environmental Negotiations in a North-South conflictual Approach. In V. Bhaskar \& A. Glyn (Eds.), The North, the South and the Environment (pp. 118-145). New York: St. Martin's Press.

Lovelock, J. (2008). A geophysiologist's thoughts on geoengineering. Philosophical Transactions of the Royal Society A: Mathematical, Physical and Engineering Sciences, 366(1882), 3883-3890.

Lua, A. C., Yang, T., \& Guo, J. (2004). Effects of pyrolysis conditions on the properties of activated carbons prepared from pistachio-nut shells. Journal of Analytical and Applied Pyrolysis, 72, 279-287.

Lucy, M. C., McDougall, S., \& Nation, D. P. (2004). The use of hormonal treatments to improve the reproductive performance of lactating dairy cows in feedlot or pasture-based management systems. Animal Reproduction Science, 82-83, 495512.

Lundvall, B.-A. (1992). National systems of innovation: towards a theory of innovation and interactive learning. London: Pinter Publishers.

Lundvall, B.-A. (1996). The social dimension of the learning economy. DRUID Working Paper No. 96-1. Copenhagen, Aalborg (Denmark): Danish Research Unit for Industrial Dynamics (DRUID).

Lundvall, B.-Å., Johnson, B., Andersen, E. S., \& Dalum, B. (2002). National systems of production, innovation and competence building. Research Policy, 31(2), 213231.

Luo, J., Saggar, S., Bhandral, R., Bolan, N., Ledgard, S., Lindsey, S., et al. (2008). Effects of irrigating dairy-grazed grassland with farm dairy effluent on nitrous oxide emissions. Plant and Soil, 309(1-2), 119-130.

Luyssaert, S., Schulze, E.-D., Börner, A., Knohl, A., Hessenmöller, D., Law, B. E., et al. (2008). Old-growth forests as global carbon sinks. Nature, 455(7210), 213-215.

Lyytinen, K., \& Damsgaard, J. (2001). What's wrong with the Diffusion of Innovation Theory? The case of a complex and networked technology. In M. A. Ardis \& B. L. Marcolin (Eds.), Diffusing Software Product and Process Innovations (pp. 120). Boston: Kluwer Academic Press.

\section{M}

Macías, F., \& Camps-Arbestain, M. (2010). Soil carbon sequestration in a changing global environment. Mitigation and Adaptation Strategies for Global Change, Online First(doi: 10.1007/s11027-010-9231-4).

Mackintosh, L., \& NIWA (2001). Overview of New Zealand Climate. Auckland: NIWA.

MacNab, J. W. (1969). Sweet potatoes and Maori terraces in the Wellington area. The Journal of the Polynesian Society(78), 83-111.

Mahajan, V., Muller, E., \& Bass, F. M. (1990). New Product Diffusion Models in Marketing: A Review and Directions for Research. The Journal of Marketing, 54(1), 1-26. 
Mahajan, V., Muller, E., \& Srivastava, R. K. (1990). Determination of Adopter Categories by Using Innovation Diffusion Models. Journal of Marketing Research, 27(1), 37-50.

Major, J., Di Tommaso, A., Lehmann, J., \& Falcão, N. P. S. (2005). Weed dynamics on Amazonian Dark Earth and adjacent soils of Brazil. Agriculture, Ecosystems and Environment, 111, 1-12.

Major, J., Rondon, M., \& Lehmann, J. (2007). Field maize yield and yield determining factors for four years following biochar application on a Colombian savanna Oxisol. Paper presented at the International Agrichar Initiative.

Major, J., Rondon, M., Molina, D., Riha, S., \& Lehmann, J. (2010). Maize yield and nutrition during 4 years after biochar application to a Colombian savanna oxisol. Plant and Soil, Online First, 1-12.

Major, J., Steiner, C., Downie, A., \& Lehmann, J. (2009). Biochar Effects on Nutrient Leaching. In J. Lehmann \& S. Joseph (Eds.), Biochar for Environmental Management: Science and Technology (pp. 271-287). London: Earthscan.

Malhi, Y. (2009, 28-30 September). Tropical forests in a $4+{ }^{\circ} \mathrm{C}$ World. Paper presented at the International Climate Conference: 4 degrees and beyond, Oxford, UK.

Marris, E. (2006). Black is the new green. Nature, 442(7103), 624-626.

Marschner, B., Brodowski, S., Dreves, A., Gleixner, G., Gude, A., Grootes, P. M., et al. (2008). How relevant is recalcitrance for the stabilization of organic matter in soils? Journal of Plant Nutrition and Soil Science, 171(1), 91-110.

Marsh, H. (1987). Adsorption methods to study microporosity in coals and carbons - a critique. Carbon, 25(1), 49-58.

Martinez-Alier, J. (1998). From Political Economy to Political Ecology. In R. Guha \& J. Martinez-Alier (Eds.), Varieties of Environmentalism: Essays North and South (pp. 22-45). Delhi: Oxford University Press.

Masiello, C. A. (2004). New directions in black carbon organic geochemistry. Marine Chemistry, 92, 201-213.

Masiello, C. A., \& Druffel, E. R. M. (1998). Black Carbon in Deep-Sea Sediments. Science, 280, 1911-1913.

Maslow, A. H. (1943). A theory of human motivation. Psychological Review, 50(4), 370396.

Mason, I. G., Page, S. C., \& Williamson, A. G. (2010). A 100\% renewable electricity generation system for New Zealand utilising hydro, wind, geothermal and biomass resources. Energy Policy, 38(8), 3973-3984.

Massey University (2007). Massey University Biochar Initiative: Proposal from Massey University to the Ministry of Agriculture and Forestry to Establish Two Professorships in Biochar Research. Palmerston North: Massey University.

Mathews, J. A. (2008). Carbon-negative biofuels. Energy Policy, 36(3), 940-945.

Matthews, H. D., \& Caldeira, K. (2008). Stabilizing climate requires near-zero emissions. Geophysical Research Letters, 35(L04705), 1-5.

Maxcy, S. J. (2003). Pragmatic threads in mixed methods research in the social sciences: The search for multiple modes of inquiry and the end of the philosophy of 
formalism. In A. Tashakkori \& C. Teddlie (Eds.), Handbook of mixed methods in social \& behavioral research (pp. 51-90). Thousand Oaks, CA: Sage Publications.

Mayer, S., \& Stirling, A. (2002). Finding a precautionary approach to technological developments: lessons for the evaluation of GM crops. Journal of Agricultural and Environmental Ethics 15(1), 57-71.

McCarl, B. A., Peacocke, C., Chrisman, R., Kung, C.-C., \& Sands, R. D. (2009). Economics of Biochar Production, Utilization and Greenhouse Gas Offsets. In J. Lehmann \& S. Joseph (Eds.), Biochar for Environmental Management: Science and Technology (pp. 341-358). London: Earthscan.

Meinshausen, M. (2006). What does a $2^{\circ} \mathrm{C}$ target mean for greenhouse gas concentrations? A brief analysis based on multi-gas emission pathways and several climate sensitivity uncertainty estimates. In H. J. Schellnhuber, W. Cramer, N. Nakicenovic, T. Wigley \& G. Yohe (Eds.), Avoiding dangerous climate change (pp. 265-279). Cambridge: Cambridge University Press.

Meinshausen, M. (2008). How to jointly avoid dangerous climate change? Principles, models and options for burden sharing. Paper presented at the Post-2012 Burden Sharing Symposium, Wellington.

Meinshausen, M., Meinshausen, N., Hare, W., Raper, S. C. B., Frieler, K., Knutti, R., et al. (2009). Greenhouse-gas emission targets for limiting global warming to $2^{\circ} \mathrm{C}$. Nature, 458, 1158-1163.

Melillo, J. M., Reilly, J. M., Kicklighter, D. W., Gurgel, A. C., Cronin, T. W., Paltsev, S., et al. (2009). Indirect emissions from biofuels: how important? Science, 326(5958), 1397-1399.

Mendonça, M. (2007). Feed-in tariffs: accelerating the deployment of renewable energy. London: Earthscan.

Mendonça, M. (2009). Managing Biosolids. Wellington: CitiOperations.

Merfield, C. (2008). Soil husbandry and tillage. The big debate (part 1). Organic NZ, 67(3), 30-33.

Merton, R. K., Fiske, M., \& Kendall, P. L. (1956). The focused interview: a manual of problems and procedures. Glencoe, Illinois: Free Press.

Merton, R. K., \& Kendall, P. L. (1946). The Focused Interview. The American Journal of Sociology, 51(6), 541-557.

Metcalfe, J. S. (1981). Impulse and diffusion in the study of technical change. Futures, 13(5), 347-359.

Metcalfe, J. S. (1988). The diffusion of innovation: an interpretative survey. In G. Dosi, C. Freeman, R. Nelson, G. Silverberg \& L. Soete (Eds.), Technical change and economic theory (pp. 560-589). London: Pinter Publishers.

Middleton, A. (2007). Potatoes and muskets: Maori gardening at Kerikeri. In J. Binney (Ed.), Te Kerikeri 1770-1850: the meeting pool (pp. 33-39). Wellington: Bridget Williams Books.

Midgley, D. F., \& Dowling, G. R. (1978). Innovativeness: The Concept and Its Measurement. The Journal of Consumer Research, 4(4), 229-242. 
Mikan, C. J., \& Abrams, M. D. (1995). Altered forest composition and soil properties of historic charcoal hearths in southeastern Pennsylvania. Canadian Journal of Forest Research, 25(5), 687-696.

Ministry for the Environment (MfE) (2002). The New Zealand Waste Strategy. Wellington: Ministry for the Environment (MfE).

Ministry for the Environment (MfE) (2007). New Zealand's climate change solutions: An overview. Wellington: Ministry for the Environment.

Ministry for the Environment (MfE) (2008, 25/11/2008). National environmental standards for air quality. Retrieved 21 March, 2010, from http://www.mfe.govt.nz/laws/standards/air-quality-standards.html

Ministry for the Environment (MfE) (2009a, 02/07/2009). Climate change information New Zealand: our responsibility. Retrieved 18 March, 2010, from http://www.climatechange.govt.nz/reducing-our-emissions/our-responsibility.html

Ministry for the Environment (MfE) (2009b, May 2009). Greenhouse gas emissions and removals. Retrieved 8 January, 2010, from http://www.mfe.govt.nz/environmental-reporting/atmosphere/greenhousegases/emissions.html

Ministry for the Environment (MfE) (2009c, 11/12/2009). Questions and answers about amendments to the New Zealand Emissions Trading Scheme (ETS) Retrieved 30 December, 2009, from http://www.climatechange.govt.nz/emissions-tradingscheme/questions-and-answers-amendment-act.html\#whatchanges

Ministry for the Environment (MfE) (2010a, 06/04/2010). Climate change information New Zealand: Government - who does what? Retrieved 22 May, 2010, from http://www.climatechange.govt.nz/reducing-our-emissions/who-does-what.html

Ministry for the Environment (MfE) (2010b). New Zealand's Greenhouse Gas Inventory 1990-2008. Wellington: Ministry for the Environment (MfE).

Ministry for the Environment (MfE) (2010c, 15/04/2010). New Zealand's net position under the Kyoto Protocol. Retrieved 21 May, 2010, from http://www.mfe.govt.nz/issues/climate/greenhouse-gas-emissions/netposition/index.html\#latest

Ministry for the Environment (MfE) (2010d, 05/03/2010). Proposed National Environmental Standard for Assessing and Managing Contaminants in Soil. Retrieved 21 March, 2010, from http://www.mfe.govt.nz/laws/standards/contaminants-in-soil/index.html

Ministry for the Environment (MfE) (2010e). Waste Minimisation in New Zealand: A Discussion Document from the Ministry for the Environment. Retrieved 22 May, 2010, from http://www.mfe.govt.nz/publications/waste/waste-minimisationdiscussion-document/index.html

Ministry of Agriculture and Forestry (MAF) (2007a). Government Investment Initiatives under the Plan of Action: Climate Change Mitigation: Biochar. Wellington: Ministry of Agriculture and Forestry.

Ministry of Agriculture and Forestry (MAF) (2007b). New Zealand's climate change solutions: Sustainable land management and climate change: Plan of action: A partnership approach. Wellington: Ministry of Agriculture and Forestry. 
Ministry of Economic Development (MED) (2009). New Zealand Energy Data File 2009. Wellington: MED.

Ministry of Research, Science and Technology (MoRST), (2008, 14/05/2008). How funding is organised. Retrieved 22 May, 2010, from http://www.morst.govt.nz/funding/how/

Ministry of Research, Science and Technology (MoRST), (2010, 11/05/2010). What we do. Retrieved 22 May, 2010, from http://www.morst.govt.nz/about/what-we-do/

Ministry of Transport (MoT) (2008). New Zealand Transport Strategy. Wellington: Ministry of Transport (MoT).

Ministry of Transport (MoT) (2009). Government Policy Statement on Land Transport Funding 2009/10 - 2018/19. Wellington: New Zealand Government, Ministry of Transport.

Minteer, B. A., \& Manning, R. E. (2003). Pragmatism in environmental ethics: Democracy, pluralism, and the management of nature. In A. Light \& H. Rolston (Eds.), Environmental ethics: An anthology (pp. 319-330). Malden, MA: Blackwell Publishers.

Mintz, J. A. (2004). Some thoughts on the merits of pragmatism as a guide to environmental protection. Boston College Environmental Affairs Law Review, 31(1), 1-26.

Molina, M., Zaelke, D., Sarma, K. M., Andersen, S. O., Ramanathan, V., \& Kaniaru, D. (2009). Reducing abrupt climate change risk using the Montreal Protocol and other regulatory actions to complement cuts in $\mathrm{CO}_{2}$ emissions. Proceedings of the National Academy of Sciences of the United States of America, 106(49; Special Feature: Tipping elements in Earth systems), 20616 - 20621.

Monbiot, G. (2009, 24/03/2009). Woodchips with everything. It's the Atkins plan of the low-carbon world. The Guardian, from http://www.guardian.co.uk/environment/2009/mar/24/george-monbiot-climatechange-biochar

Monti, A., Fazio, S., \& Venturi, G. (2009). Cradle-to-farm gate life cycle assessment in perennial energy crops. European Journal of Agronomy, 31(2), 77-84.

Mullen, C. A., Boateng, A. A., Hicks, K. B., Goldberg, N. M., \& Moreau, R. A. (2010). Analysis and Comparison of Bio-Oil Produced by Fast Pyrolysis from Three Barley Biomass/Byproduct Streams. Energy \& Fuels, 24(1), 699-706.

Musgrave, R. A. (1959). The theory of public finance: a study in public economy. New York: McGraw-Hill.

Mytelka, L. K., \& Smith, K. (2001). Innovation theory and innovation policy: bridging the gap. Paper presented at the DRUID Conference. Retrieved 9 March, 2009, from http://www.druid.dk/uploads/tx_picturedb/ds2001-278.pdf 
National Institute of Water and Atmospheric Research (NIWA) (2003, 2008). Climate mapping. Retrieved 23 January, 2010, from http://www.niwa.co.nz/ourscience/climate/our-services/mapping

National Institute of Water and Atmospheric Research (NIWA) (2008). Projected annual mean precipitation change between 1980-1999 and 2030-2049. Auckland: NIWA. Retrieved 25 January, 2010, from http://www.niwa.co.nz/_data/assets/image/0007/71971/prann2040_hs2_450.jpg

National Institute of Water and Atmospheric Research (NIWA) (2010). Current Climate January 2010. New Zealand Climate Update, 128(February 2010). Retrieved 23 March, 2010, from http://www.niwa.co.nz/ourscience/climate/publications/all/cu/new-zealand-climate-update-128-a-february2010/current-climate---january-2010

Newcombe, G., Drikas, M., \& Hayes, R. (1997). Influence of characterised natural organic material on activated carbon adsorption: II. Effect on pore volume distribution and adsorption of 2-methylisoborneol. Water Research, 31(5), 10651073.

Newell, R. G., \& Pizer, W. A. (2004). Uncertain discount rates in climate policy analysis. Energy Policy, 32(4), 519-529.

New Zealand Institute of Economic Research (NZIER) (2001a). Effects of New Zealand's climate change policies on the forestry sector. Stage I: preliminary assessment. Report to Wood Processing Strategy Climate Change Group. Wellington: NZIER.

New Zealand Institute of Economic Research (NZIER) (2001b). Effects of New Zealand's climate change policies on the forestry sector. Stage II: initial quantification. Report to Wood Processing Strategy Climate Change Group. Wellington: NZIER.

New Zealand Parliament (2004). Resource Management (Energy and Climate Change) Amendment Act 2004. Wellington: New Zealand Parliament.

New Zealand Parliament (2008a). Electricity Governance (Connection of Distributed Generation) Regulations 2007: Reprint as at 28 May 2008. Wellington: New Zealand Parliament.

New Zealand Parliament (2008b). Environment Act 1986: Reprint as at 1 August 2008. Wellington: New Zealand Parliament.

New Zealand Parliament (2008c). Hazardous Substances and New Organisms Act 1996: Reprint as at 1 August 2008. Wellington: New Zealand Parliament.

New Zealand Parliament (2008d). Waste Minimisation Act 2008. Wellington: New Zealand Parliament.

New Zealand Parliament (2009a). Climate Change Response Act 2002: Reprint as at 8 December 2009. Wellington: New Zealand Parliament.

New Zealand Parliament (2009b). Resource Management Act 1991: Reprint as at 8 December 2009. Wellington: New Zealand Parliament.

New Zealand Parliament (2009c). Waste Minimisation (Calculation and Payment of Waste Disposal Levy) Regulations 2009. Wellington: New Zealand Parliament.

New Zealand Parliament (2010a). Electricity Act 1992: Reprint as at 1 April 2010. Wellington: New Zealand Parliament. 
New Zealand Parliament (2010b). Energy (Fuels, Levies, and References) Act 1989: Reprint as at 1 January 2010. Wellington: New Zealand Parliament.

New Zealand Parliament (2010c). Land Transport Management Act 2003: Reprint as at 1 January 2010. Wellington: New Zealand Parliament.

New Zealand Parliament (2010d). Legislation: Bills: Sustainable Biofuel Bill. Retrieved 22 May, 2010, from http://www.parliament.nz/enNZ/PB/Legislation/Bills/d/e/e/00DBHOH_BILL9256_1-Sustainable-BiofuelBill.htm

New Zealand Parliament (2010e). Sustainable Biofuel Bill 49-1 (2009), Members Bill. Wellington: New Zealand Parliament.

Newell, R. G., \& Pizer, W. A. (2004). Uncertain discount rates in climate policy analysis. Energy Policy, 32(4), 519-529.

Newton, J. L., \& Freyfogle, E. T. (2005a). All About Nature. Conservation Biology, 19(1), 42-44.

Newton, J. L., \& Freyfogle, E. T. (2005b). Sustainability: a Dissent. Conservation Biology, 19(1), 23-32.

Nguyen, B. T., Lehmann, J., Kinyangi, J., Smernik, R., Riha, S. J., \& Engelhard, M. H. (2008). Long-term black carbon dynamics in cultivated soil. Biogeochemistry, 89, 295-308.

Nishio, M. (1996). Microbial fertilizers in Japan. Taipei, Taiwan: Food and Fertilizer Technology Center for the Asian and Pacific Region.

North, D. C. (1991). Institutions. The Journal of Economic Perspectives, 5(1), 97-112.

North, D. C. (1994). Economic Performance Through Time. The American Economic Review, 84(3), 359-368.

Norton, B. G. (1996). Integration or reduction: Two approaches to environmental values. In A. Light \& E. Katz (Eds.), Environmental pragmatism (pp. 105-138). London: Routledge.

Norton, D. A. (2009). Species Invasions and the Limits to Restoration: Learning from the New Zealand Experience. Science, 325(5940), 569 - 571.

\section{0}

O'Riordan, T., \& Rayner, S. (1991). Risk management for global environmental change. Global Environmental Change, 1(2), 91-108.

Odum, E. P. (1969). The strategy of ecosystem development. Science, 164, 262-270.

Office of the Parliamentary Commissioner for the Environment. (1998). Towards sustainable development, the role of the Resource Management Act 1991, PCE environmental management review No. 1. Wellington: PCE.

Office of the Parliamentary Commissioner for the Environment (2010). Functions and powers. Retrieved 20 March, 2010, from http://www.pce.parliament.nz/about_us/functions_and_powers 
Ogawa, M., Okimori, Y., \& Takahashi, F. (2006). Carbon sequestration by carbonization of biomass and forestation: three case studies. Mitigation and adaptation strategies for global change, 11(2), 429-444.

Ogawa, M., Yambe, Y., \& Sugiura, G. (1983). Effect of charcoal on the root nodule and VA mycorrhizal formation of soybean. Paper presented at the Third International Mycology Congress, Tokyo, Japan.

Oliver, G. R., Beets, P. N., Garrett, L. G., Pearce, S. H., Kimberly, M. O., FordRobertson, J. B., et al. (2004). Variation in soil carbon in pine plantations and implications for monitoring soil carbon stocks in relation to land-use change and forest site management in New Zealand. Forest Ecology and Management, 203(13), 283-295.

Olsson, B. A., Bengtsson, J., \& Lundkvist, H. (1996). Effects of different forest harvest intensities on the pools of exchangeable cations in coniferous forest soils. Forest Ecology and Management, 84(1-3), 135-147.

Onwuegbuzie, A. J., Johnson, R. B., \& Collins, K. M. T. (2010). A call for mixed analysis among stress and coping researchers: Deconstructing separatist qualitative and quantitative analysis in mixed research. In K. M. T. Collins, A. J. Onwuegbuzie \& Q. G. Jiao (Eds.), Toward a broader understanding of stress and coping: Mixed methods approaches (pp. 105-143): Information Age Publishing.

Onwuegbuzie, A. J., \& Teddlie, C. (2003). A framework for analyzing data in mixed methods research. In A. Tashakkori \& C. Teddlie (Eds.), Handbook of mixed methods in social \& behavioral research (pp. 351-384). Thousand Oaks, CA: Sage Publications.

Ostrom, E. (2003). How types of goods and property rights jointly affect collective action. Journal of Theoretical Politics, 15(3), 239-270.

\section{$\mathbf{P}$}

Pacala, S., \& Socolow, R. (2004). Stabilization Wedges: Solving the Climate Problem for the Next 50 Years with Current Technologies. Science, 305(5686), 968-972.

Page, T. (1978). A generic view of toxic chemicals and similar risks. Ecology Law Quarterly, 7(2), 207-244.

Page, T. (1997). On the Problem of Achieving Efficiency and Equity, Intergenerationally. Land Economics, 73(4), 580-596.

Pang, S., Li, J., \& Shaw, K. (2010, 11-12 February). Biomass pyrolysis for biomass densification. Paper presented at the Biochar Workshop: Opportunities for New Zealand Stakeholders, Palmerston North.

Parfitt, R. L., Percival, H. J., Dahlgren, R. A., \& Hill, L. F. (1997). Soil and solution chemistry under pasture and radiata pine in New Zealand. Plant and Soil, 191(2), 279-290.

Parfitt, R. L., Schipper, L. A., Baisden, W. T., \& Elliott, A. H. (2006). Nitrogen inputs and outputs for New Zealand in 2001 at national and regional scales. Biogeochemistry, 80(1), 71-88. 
Parker, K. A. (1996). Pragmatism and environmental thought. In A. Light \& E. Katz (Eds.), Environmental pragmatism (pp. 21-37). London: Routledge.

Paul, E. A. (2007). Soil microbiology, ecology, and biochemistry (3 ed.). Amsterdam: Academic Press.

Paul, H., Semino, S., Lorch, A., Andersen, B. H., Gura, S., \& Ernsting, A. (2009). Agriculture and climate change: Real problems, false solutions. Preliminary report by Grupo de Reflexion Rural, Biofuelwatch, EcoNexus and NOAH Friends of the Earth Denmark. Prepared for the Bonn Climate Change Talks, June 2009. Bonn, GER: Grupo de Reflexion Rural, Biofuelwatch, EcoNexus, NOAH - Friends of the Earth Denmark.

Pawson, R. (1996). Theorizing the interview. The British Journal of Sociology, 47(2), 295-314.

Peacocke, C., \& Joseph, S. (2009). Notes on Terminology and Technology in Thermal Conversion: International Biochar Initiative (IBI).

Pearson, P. N., \& Palmer, M. R. (2000). Atmospheric carbon dioxide concentrations over the past 60 million years. Nature, 406(6797), 695-699.

Peel, M. C., Finlayson, B. L., \& McMahon, T. A. (2007). Updated world map of the Köppen-Geiger climate classification. Hydrology and Earth System Sciences, 11(5), 1633-1644.

Peirce, C. S. (1877). Illustrations of the logic of science: The fixation of belief. [comprising six papers]. Popular Science Monthly, 12(November), 1-15.

Pemberton, H. E. (1936). The Curve of Culture Diffusion Rate. American Sociological Review, 1(4), 547-556.

Perez, C. (1983). Structural change and assimilation of new technologies in the economic and social systems. Futures, 15(5), 357-375.

Perrow, C. (1984). Normal acidents: living with high-risk technologies. New York: Basic Books.

Pessenda, L. C. R., Gouveia, S. E. M., \& Aravena, R. (2001). Radiocarbon dating of total soil organic matter and humin fraction and its comparison with ${ }^{14} \mathrm{C}$ ages of fossil charcoal. Radiocarbon, 43, 595-601.

Petit, J. R., Jouzel, J., Raynaud, D., Barkov, N. I., Barnola, J.-M., Basile, I., et al. (1999). Climate and atmospheric history of the past 420,000 years from the Vostok ice core, Antarctica. Nature, 399(6735), 393-501.

Phelps, J., Guerrero, M. C., Dalabajan, D. A., Young, B., \& Webb, E. L. (2010). What makes a 'REDD' country? Global Environmental Change, 20(2), 322-332.

Pietikäinen, J., Kiikkilä, O., \& Fritze, H. (2000). Charcoal as a habitat for microbes and its effect on the microbial community of the underlying humus. Oikos, 89, 231242.

Pigneri, A. (2010, 11-12 February). Biochar systems analysis: Central North Island case study. Paper presented at the Biochar Workshop: Opportunities for New Zealand Stakeholders, Palmerston North.

Pigneri, A., \& Hedley, M. (2008, 14-15 April). Massey University Biochar Initiative. Paper presented at the Conference CARBON - Global Cycle to Regional Budget, National Library, Wellington. 
Pigou, A. C. (1912). Wealth and Welfare. New York: Macmillan Company.

Pimentel, D., Hepperly, P., Hanson, J., Douds, D., \& Seidel, R. (2005). Environmental, Energetic, and Economic Comparisons of Organic and Conventional Farming Systems. Bioscience, 55(7), 573-582.

Plattner, G.-K. (2009). Terrestrial ecosystem inertia. Nature Geoscience, 2(7), 467-468.

Polanyi, M. (1958). Personal knowledge: towards a post-critical philosophy. London: Routledge \& Kegan Paul.

Polanyi, M. (1966). The tacit dimension. London: Routledge \& Kegan Paul.

Pratt, K., \& Moran, D. (2010). Evaluating the cost-effectiveness of global biochar mitigation potential. Biomass and Bioenergy, In Press, Corrected Proof.

Pregitzer, K. S., \& Euskirchen, E. S. (2004). Carbon cycling and storage in world forests: biome patterns related to forest age. Global Change Biology, 10(12), 2052-2077.

Preston, C. M., \& Schmidt, M. W. I. (2006). Black (pyrogenic) carbon: a synthesis of current knowledge and uncertainties with special consideration of boreal regions. Biogeosciences, 3(1), 397-420.

\section{$\mathbf{R}$}

Rainforest Rescue (2009, 26/03/2009). Declaration: 'Biochar', a new big threat to people, land, and ecosystems. Retrieved 6 May, 2010, from http://www.regenwald.org/international/englisch/news.php?id=1226

Read, P. (2009, 27/03/2009). This gift of nature is the best way to save us from climate catastrophe. The Guardian. Retrieved 16 June, 2009, from http://www.guardian.co.uk/commentisfree/2009/mar/27/biochar

Reganold, J. P. (1995). Soil quality and profitability of biodynamic and conventional farming systems: a review. Organic Farming \& Biodynamic Agriculture Training resource book, 10(1), 64-75.

Reganold, J. P., Palmer, A. S., Lockhart, J. C., \& Macgregor, A. N. (1993). Soil Quality and Financial Performance of Biodynamic and Conventional Farms in New Zealand. Science, 260(5106), 344-349.

Reijnders, L. (2008). Ethanol production from crop residues and soil organic carbon. Resources, Conservation and Recycling, 52(4), 653-658.

Reijnders, L. (2009). Are forestation, bio-char and landfilled biomass adequate offsets for the climate effects of burning fossil fuels? Energy Policy, 37, 2839-2841.

Reisinger, A. (2009). Closing windows and opening flood gates: recent climate change science and implications for climate policy. Policy Quarterly, 5(2), 45-51.

Roberts, K. G., Gloy, B. A., Joseph, S., Scott, N. R., \& Lehmann, J. (2010a). Life Cycle Assessment of Biochar Systems: Estimating the Energetic, Economic, and Climate Change Potential. Environmental Science \& Technology, 44(2), 827-833.

Roberts, K. G., Gloy, B. A., Joseph, S., Scott, N. R., \& Lehmann, J. (2010b). Supporting Information for: Life Cycle Assessment of Biochar Systems: Estimating the 
Energetic, Economic, and Climate Change Potential. Environmental Science \& Technology, 44(2), S1-S32.

Rogers, E. M. (1995a). Diffusion of innovations (4 ed.). New York: Free Press.

Rogers, E. M., \& Shoemaker, F. (1971). Communication of innovations: a cross-cultural approach. New York: Free Press.

Rogers, G. (1995b). World of wounds. In I. Close (Ed.), Forest \& Bird (pp. 23-30). Wellington: Royal Forest and Bird Protection Society of New Zealand.

Rogosic, J., Pfister, J. A., Provenza, F. D., \& Grbesa, D. (2006). The effect of activated charcoal and number of species offered on intake of Mediterranean shrubs by sheep and goats. Applied Animal Behaviour Science, 101(3-4), 305-317.

Rohling, E. J., Grant, K., Bolshaw, M., Roberts, A. P., Siddall, M., Hemleben, C., et al. (2009). Antarctic temperature and global sea level closely coupled over the past five glacial cycles. Nature Geoscience, 2(7), 500-504.

Rondon, M. A., Lehmann, J., Ramirez, J., \& Hurtado, M. (2007). Biological nitrogen fixation by common beans (Phaseolus vulgaris L.) increases with bio-char additions. Biology and Fertility of Soils, 43(6), 699-708.

Rondon, M. A., Molina, D., Hurtado, M., Ramirez, J., Lehmann, J., Major, J., et al. (2006, 9-15/07/2006). Enhancing the Productivity of Crops and Grasses while Reducing Greenhouse Gas Emissions through Bio-Char Amendments to Unfertile Tropical Soils. Paper presented at the 18th World Congress of Soil Science, Philadelphia, PA.

Rondon, M. A., Ramirez, J. A., \& Lehmann, J. (2005). Greenhouse Gas Emissions Decrease with Charcoal Additions to Tropical Soils. Paper presented at the Third USDA Symposium on Greenhouse Gases and Carbon Sequestration in Agriculture and Forestry, March 21-24, 2005, Baltimore, Maryland.

Rorty, R. (1979). Philosophy and the mirror of nature. Princeton: Princeton University Press.

Rosenthal, S. B., \& Buchholz, R. A. (1996). How pramatism in an environmental ethic. In A. Light \& E. Katz (Eds.), Environmental pragmatism (pp. 38-49). London: Routledge.

Ryan, B., \& Gross, N. C. (1943). The diffusion of hybrid seed corn in two Iowa communities. Rural Sociology, 8(1), 15-24.

S

Sadhukhan, A. K., Gupta, P., \& Saha, R. K. (2008). Modelling and experimental studies on pyrolysis of biomass particles. Journal of Analytical and Applied Pyrolysis, 81(2), 183-192.

Saggar, S., Tate, K. R., Giltrap, D. L., \& Singh, J. (2008). Soil-atmosphere exchange of nitrous oxide and methane in New Zealand terrestrial ecosystems and their mitigation options: a review. Plant and Soil, 309(1-2), 25-42. 
Saidur, R., Islam, M. R., Rahim, N. A., \& Solangi, K. H. (2010). A review on global wind energy policy. Renewable and Sustainable Energy Reviews, In Press, Corrected Proof. doi:10.1016/j.rser.2010.03.007

Saito, M., \& Marumoto, T. (2002). Inoculation with arbuscular mycorrhizal fungi: the status quo in Japan and the future prospects. Plant and Soil, 244, 273-279.

Sale, J. E. M., Lohfeld, L. H., \& Brazil, K. (2002). Revisiting the Quantitative-Qualitative Debate: Implications for Mixed-Methods Research. Quality and Quantity, 36(1), 43-53.

Samuelson, P. A. (1954). The Pure Theory of Public Expenditure. The Review of Economics and Statistics, 36(4), 387-389.

Sander, M., \& Pignatello, J. J. (2005). Characterization of Charcoal Adsorption Sites for Aromatic Compounds: Insights Drawn from Single-Solute and Bi-Solute Competitive Experiments. Environ. Sci. Technol., 39(6), 1606-1615.

Sander, M., \& Pignatello, J. J. (2007). On the Reversibility of Sorption to Black Carbon: Distinguishing True Hysteresis from Artificial Hysteresis Caused by Dilution of a Competing Adsorbate. Environ. Sci. Technol., 41(3), 843-849.

Sarkar, B., Chakrabarti, P. P., Vijaykumar, A., \& Kale, V. (2006). Wastewater treatment in dairy industries - possibility of reuse. Desalination, 195, 141-152.

Sarmah, A. K., Northcott, G. L., \& Scherr, F. F. (2008). Retention of estrogenic steroid hormones by selected New Zealand soils. Environment International, 34(6), 749755.

Sawin, J. L. (2004). National Policy Instruments: Policy Lessons for the Advancement \& Diffusion of Renewable Energy Technologies Around the World. Bonn, Germany: Worldwatch Institute.

Schellnhuber, H.-J. (2009). Terra quasi-incognita: beyond the $2^{\circ} \mathrm{C}$ line. Paper presented at the International Climate Conference 28-30 September 2009, Oxford, UK.

Retrieved 2 November, 2009, from http://www.eci.ox.ac.uk/4degrees/programme.php

Schenkel, Y. (2001). Influence of temperature, residence time and heating rate on pyrolytic carbon deposition in beech wood chars. In A. V. Bridgwater (Ed.), (Vol. 2, pp. 1633-1641). Oxford: Blackwell Science.

Scherr, S. J., \& Sthapit, S. (2009). Mitigating Climate Change Through Food and Land Use. Washington, D.C.: Worldwatch Institute.

Schimel, D. S. (1995). Terrestrial ecosystems and the carbon-cycle. Global Change Biology, 1(1), 77-91.

Schipper, L. A., Baisden, W. T., Parfitt, R. L., Ross, C., Claydon, J. J., \& Arnold, G. (2007). Large losses of soil $\mathrm{C}$ and $\mathrm{N}$ from soil profiles under pasture in New Zealand during the past 20 years. Global Change Biology, 13(6), 1138-1144.

Schlamadinger, B., Spitzer, J., Kohlmaier, G. H., \& Lüdeke, M. (1995). Carbon balance of bioenergy from logging residues. Biomass and Bioenergy, 8(4), 221-234.

Schmidt, M. W. I., Masiello, C. A., \& Skjemstad, J. O. (2003). Final Recommendations for Reference Materials in Black Carbon Analysis. Eos, 84(52), 582-583. 
Schmidt, M. W. I., \& Noack, A. G. (2000). Black Carbon in soils and sediments: Analysis, distribution, implications, and current challenges. Global Biogeochemical Cycles, 14(3), 777-793.

Schulze, E.-D., Wirth, C., \& Heimann, M. (2000). Managing forests after Kyoto. [Climate Change: Perspectives]. Science, 289(5487), 2058 - 2059.

Schumpeter, J. A. (1934). The theory of economic development: an inquiry into profits, capital, credit, interest and the business cycle. Cambrigde, MA: Harvard University Press.

Scott, N. A., Tate, K. R., Ford-Robertson, J., Giltrap, D. J., \& Smith, C. T. (1999). Soil carbon storage in plantation forests and pastures: land-use change implications. Tellus B, 51(2), 326-335.

Scott, N. A., Tate, K. R., Ross, D. J., \& Parshotam, A. (2006). Processes influencing soil carbon storage following afforestation of pasture with Pinus radiata at different stocking densities in New Zealand. Australian Journal of Soil Research, 44(2), 85-96.

Searchinger, T., Heimlich, R., Houghton, R. A., Dong, F., Elobeid, A., Fabiosa, J., et al. (2008). Use of U.S. Croplands for Biofuels Increases Greenhouse Gases Through Emissions from Land-Use Change. Science, 319(5867), 1238-1240.

Searchinger, T. D., Hamburg, S. P., Melillo, J., Chameides, W., Havlik, P., Kammen, D. M., et al. (2009). Fixing a critical climate accounting error. Science, 326(5952), 527-528.

Searcy, E., \& Flynn, P. C. (2010). A criterion for selecting renewable energy processes. Biomass and Bioenergy, In Press, Corrected Proof(doi: 10.1016/j.biombioe.2010.01.023).

Seiler, W., \& Crutzen, P. J. (1980). Estimates of gross and net fluxes of carbon between the biosphere and the atmosphere from biomass burning. Climatic Change, 2(3), 207-247.

Seymour, G., \& Tecle, A. (2004). Impact of Slash Pile Size and Burning on Ponderosa Pine Forest Soil Physical Characteristics. Journal of the Arizona-Nevada Academy of Science, 37(2), 74-82.

Shakhova, N., Semiletov, I., Salyuk, A., Yusupov, V., Kosmach, D., \& Gustafsson, Ö. (2010). Extensive Methane Venting to the Atmosphere from Sediments of the East Siberian Arctic Shelf. Science, 327(5970), 1246-1250.

Sharma, R. K., Wooten, J. B., Baliga, V. L., Lin, X., Geoffrey Chan, W., \& Hajaligol, M. R. (2004). Characterization of chars from pyrolysis of lignin. Fuel, 83(11-12), 1469-1482.

Sherlock, R. R., Jewell, P., \& Clough, T. (2009). Review of New Zealand Specific

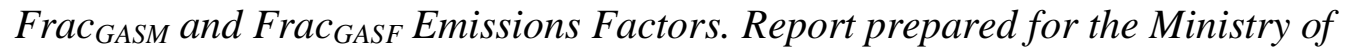
Agriculture and Forestry. Wellington: Ministry of Agriculture and Forestry.

Shrubsole, G. (2009). Biochar: research, commercialisation and economics. Wellington: Ministry of Agriculture and Forestry.

Siddiqui, A. S., Marnay, C., Firestone, R. M., \& Zhou, N. (2006). Distributed Generation with Heat Recovery and Storage. Berkeley, CA: Ernest Orlando Lawrence Berkeley National Laboratory. 
Sigenthaler, U., Monnin, E., Kawamura, K., Spahni, R., Schwander, J., Stauffer, B., et al. (2005). Supporting evidence from the EPICA Dronning Maud Land ice core for atmospheric $\mathrm{CO}_{2}$ changes during the past millennium. Tellus $B, 57 B(1), 51-57$.

Simon, H. A. (1956). Rational choice and the structure of the environment. Psychological Review, 63(2), 129-138.

Simpson, R., Vogeler, I., \& Deurer, M. (2010, 11-12 February). The effect of biochar on methane-metabolising soil microbes. Paper presented at the Biochar Workshop: Opportunities for New Zealand Stakeholders, NZBRC, Massey University, Palmerston North.

Sivakumaran, S., Dunlop, S., Deurer, M., Simpson, R., McIvor, I., Jeyakumar, P., et al. (2010, 11-12 February). The impact of charcoal on biophysical soil functions in an apple orchard in Hawke's Bay. Paper presented at the Biochar Workshop: Opportunities for New Zealand Stakeholders, NZBRC, Massey University, Palmerston North.

Smith, N., \& Groser, T. (2009, 10/08/2009). 2020 target balances economy \& environment. Releases. Retrieved 13 October, 2009, from http://www.beehive.govt.nz/release/2020+target+balances+economy+amp+enviro nment

Smith, N. J. H. (1980). Anthrosols and human carrying capacity in Amazonia. Annals of the Association of American Geographers, 70(4), 553-566.

Smith, P. (2004). Soils as carbon sinks: the global context. Soil Use and Management, 20(2), 212-218.

Smith, P., Martino, D., Cai, Z., Gwary, D., Janzen, H., Kumar, P., et al. (2007). Agriculture. In B. Metz, O. R. Davidson, P. R. Bosch, R. Dave \& L. A. Meyer (Eds.), Climate Change 2007: Mitigation. Contribution of Working Group III to the Fourth Assessment Report of the Intergovernmental Panel on Climate Change (pp. 497-540). Cambridge, UK and New York, USA: Cambridge University Press.

Smolander, A., Levula, T., \& Kitunen, V. (2008). Response of litter decomposition and soil $\mathrm{C}$ and $\mathrm{N}$ transformations in a Norway spruce thinning stand to removal of logging residue. Forest Ecology and Management, 256(5), 1080-1086.

Smolker, R., Tokar, B., Petermann, A., \& Hernandez, E. (2009). Devastated lands, displaced peoples: agrofuel costs in Indonesia, Malaysia, Papua New Guinea. Pacific Ecologist(17, Summer 2009), 36-39.

Sohi, S., Lopez-Capel, E., Krull, E., \& Bol, R. (2009). Biochar, climate change and soil: A review to guide future research: CSIRO.

Solomon, D., Lehmann, J., Thies, J., Schäfer, T., Liang, B., Kinyangi, J., et al. (2007). Molecular signature and sources of biochemical recalcitrance of organic $\mathrm{C}$ in Amazonian Dark Earths. Geochimica et Cosmochimica Acta, 71, 2285-2298.

Solomon, S., Plattner, G.-K., Knutti, R., \& Friedlingstein, P. (2009). Irreversible climate change due to carbon dioxide emissions. Proceedings of the National Academy of Sciences of the United States of America (PNAS), 106(6), 1704-1709.

Sombroek, W. G. (1966). Amazon soils: a reconnaissance of the soils of the Brazilian Amazon region. Wageningen: Centre for Agricultural Publications and Documentations. 
Spokas, K. A., Koskinen, W. C., Baker, J. M., \& Reicosky, D. C. (2009). Impacts of woodchip biochar additions on greenhouse gas production and sorption/degradation of two herbicides in a Minnesota soil. Chemosphere, 77(4), 574-581.

Srinivasan, P., Sarmah, A. K., Manley-Harris, M., Smernik, R. J., Downie, A., \& van Zwieten, L. (2010, 11-12 February). Effect of pyrolysis temperature on the retention capacity of green waste biochar to sorb hormones and veterinary antibiotics. Paper presented at the Biochar Workshop: Opportunities for New Zealand Stakeholders, NZBRC, Massey University, Palmerston North.

Steiner, C., Teixeira, W. G., Lehmann, J., Nehls, T., Vasconcelos de Macêdo, J. L., Blum, W. E. H., et al. (2007). Long term effects of manure, charcoal and mineral fertilization on crop production and fertility on a highly weathered Central Amazonian upland soil. Plant Soil, 291, 275-290.

Stern, N. (2007). The Economics of Climate Change: The Stern Review. Cambridge:

Cambridge University Press, Cabinet Office - HM Treasury.

Strang, D., \& Macy, M. W. (2001). In Search of Excellence: Fads, Success Stories, and Adaptive Emulation. The American Journal of Sociology, 107(1), 147-182.

Strauss, A. L. (1987). Qualitative analysis for social scientists. Cambridge, UK: Cambridge University Press.

Stroombergen, A., Schilling, C., \& Ballingall, J. (2009). Macroeconomic impacts of climate change policy: final report to the Ministry for the Environment. Wellington: NZIER \& Infometrics.

\section{$\mathbf{T}$}

Tans, P. (2010a, 2/2010). Trends in atmospheric carbon dioxide: globally averaged marine surface monthly mean data. Retrieved 05 May, 2010, from ftp://ftp.cmdl.noaa.gov/ccg/co2/trends/co2_mm_gl.txt

Tans, P. (2010b, 3/2010). Trends in atmospheric carbon dioxide: Mauna $\mathrm{Loa} \mathrm{CO}_{2}$ monthly mean data. Retrieved 05 May, 2010, from ftp://ftp.cmdl.noaa.gov/ccg/co2/trends/co2_mm_mlo.txt

Tarde, G. (1890). Les lois de l'imitation. Paris: Félix Alcan.

Tate, K. R., Giltrap, D. J., Claydon, J. J., Newsome, P. F., Atkinson, A. E., Taylor, M. D., et al. (1997). Organic Carbon Stocks in New Zealand's Terrestrial Ecosystems. Journal of the Royal Society of New Zealand, 27(3), 315-335.

Tate, K. R., Scott, N. A., Parshotam, A., Brown, L., Wilde, R. H., Giltrap, D. J., et al. (2000). A multi-scale analysis of a terrestrial carbon budget: Is New Zealand a source or sink of carbon? Agriculture, Ecosystems \& Environment, 82(1-3), 229246.

Tate, K. R., Wilde, R. H., Giltrap, D. J., Baisden, W. T., Saggar, S., Trustrum, N. A., et al. (2004, 5-9 December). Soil carbon changes and uncertainties with New Zealand land-use change. Paper presented at the SuperSoil 2004: 3rd Australian New Zealand Soils Conference, University of Sydney, Australia. 
The Royal Society (2009). Geoengineering the climate: science, governance and uncertainty. London: The Royal Society.

The Treasury (2009). Treasury Report T2009/1811: 2020 Emissions Reduction Target: Further Analysis. Wellington: The Treasury.

Thomas, S. M., Beare, M. H., Francis, G. S., Barlow, H. E., \& Hedderley, D. I. (2008). Effects of tillage, simulated cattle grazing and soil moisture on $\mathrm{N} 2 \mathrm{O}$ emissions from a winter forage crop. Plant and Soil, 309(1-2), 131-145.

Thorlby, T. (2009). The sugar cane Holocaust: the ethanol academic road-show is in town. Pacific Ecologist(17, Summer 2009), 28-31.

Thornton, P. (2009, 28-30 September). $4+{ }^{\circ} \mathrm{C}$ : what might this mean for agriculture in sub-Saharan Africa? Paper presented at the International Climate Conference: 4 degrees and beyond, Oxford, UK.

Tietenberg, T. H. (2006). Environmental and natural resource economics (7 ed.). Boston: Addison Wesley.

Tilman, D., Hill, J., \& Lehman, C. (2006). Carbon-Negative Biofuels from Low-Input High-Diversity Grassland Biomass. Science, 314(5805), 1598-1600.

Tollefson, J. (2009). World looks ahead post-Copenhagen. Nature, 462(7276), 966-967.

Topoliantz, S., \& Ponge, J.-F. (2003). Burrowing activity of the geophagous earthworm Pontoscolex corethrurus (Oligochaeta: Glossoscolecidae) in the presence of charcoal. Applied Soil Ecology, 23, 267-271.

Topoliantz, S., Ponge, J.-F., \& Ballof, S. (2005). Manioc peel and charcoal: a potential organic amendment for sustainable soil fertility in the tropics. Biology and Fertility of Soils, 41(1), 15-21.

Troeh, F. R., \& Thompson, L. M. (2005). Soils and Soil Fertility (6th ed.). Ames, Iowa, USA: Blackwell Publishing.

Trotter, C., Tate, K., Scott, N., Townsend, J., Wilde, H., Lambie, S., et al. (2005).

Afforestation/reforestation of New Zealand marginal pasture lands by indigenous shrublands: the potential for Kyoto forest sinks. Annals of Forest Science, 62(8), 865-871. 
U, K. T. P., Falk, M., Suchanek, T. H., Ustin, S. L., Chen, J., Park, Y.-S., et al. (2004). Carbon Dioxide Exchange between an Old-Growth Forest and the Atmosphere. Ecosystems, 7(5), 513-524.

United Nations (1992). United Nations Framework Convention on Climate Change. New York: United Nations.

United Nations (UN) (1992). United Nations Framework Convention on Climate Change. New York: United Nations.

United Nations (UN) (2001). Stockholm Convention on Persistent Organic Pollutants. Stockholm: United Nations.

United Nations Convention to Combat Desertification (UNCCD) (2008). Submission containing ideas and proposals on Paragraph 1 of the Bali Action Plan: Use of biochar (charcoal) to replenish soil carbon pools, restore soil fertility and sequester $\mathrm{CO}_{2}$. Poznan: UNCCD. Retrieved 5 June, 2008, from http://www.unccd.int/publicinfo/poznanclimatetalks/docs/Submission_by_UNCC D_to_AWG-LCA_on_Biochar.pdf

United Nations Convention to Combat Desertification (UNCCD) (2009). Submission by the United Nations Convention to Combat Desertification, 5th Session of the Ad Hoc Working Group on Long-term Cooperative Action under the Convention (AWG-LCA 5), Bonn, Germany, 29 March-8 April 2009, Submission containing ideas and proposals on Paragraph 1 of the Bali Action Plan: Required policy actions to include carbon contained in soils including the use of biochar (charcoal) to replenish soil carbon pools, and restore soil fertility and sequester $\mathrm{CO}_{2}$. Poznan, Poland: UNCCD. Retrieved 18 February, 2009, from http://www.unced.int/publicinfo/AWGLCA5/UNCCD_2nd_submission_land_soil s_and_UNFCCC_process_05Feb.pdf

United Nations Economic and Social Commission for Asia and the Pacific (UNESCAP) (2007). Access to basic services for the poor: the importance of good governance. Bangkok, Thailand: United Nations Economic and Social Commission for Asia and the Pacific (ESCAP), United Nations Development Programme (UNDP), Asian Development Bank (ADB). Retrieved 24 March, 2010, from http://www.unescap.org/pdd/publications/MDG-access2basic-service/MDGaccess-to-basic-services.pdf

United Nations Environment Programme (UNEP) (1992). Rio Declaration on Environment and Development. Rio de Janeiro: UNEP. Retrieved 13 May, 2010, from

http://www.unep.org/Documents.Multilingual/Default.asp?documentid=78\&articl eid $=1163$

United Nations Framework Convention on Climate Change (UNFCCC) (1998). Kyoto Protocol to the United Nations Framework Convention on Climate Change. Kyoto: UNFCCC.

United Nations Framework Convention on Climate Change (UNFCCC) (2009a). Decision -/CP.15: Copenhagen Accord. Copenhagen: United Nations (UN). Retrieved 15 March, 2010, from http://unfccc.int/resource/docs/2009/cop15/eng/107.pdf 
United Nations Framework Convention on Climate Change (UNFCCC) (2009b). Kyoto Protocol: status of ratification. New York: UNFCCC.

United Nations Framework Convention on Climate Change (UNFCCC) (2010a, 02/02/2010). Appendix I - Quantified economy-wide emissions targets for 2020. Retrieved 22 May, 2010, from http://unfccc.int/home/items/5264.php

United Nations Framework Convention on Climate Change (UNFCCC) (2010b). Status of Ratification of the Convention. Retrieved 9 June, 2010, from http://unfccc.int/essential_background/convention/status_of_ratification/items/263 1.php

United Nations Framework Convention on Climate Change (UNFCCC) (2010c). Status of Ratification of the Kyoto Protocol. Retrieved 9 June, 2010, from http://unfccc.int/kyoto_protocol/status_of_ratification/items/2613.php

Unruh, G. C., \& Carrillo-Hermosilla, J. (2006). Globalizing carbon lock-in. Energy Policy, 34(10), 1185-1197.

\section{V}

Valente, T. W. (1996). Social network thresholds in the diffusion of innovations. Social Networks, 18(1), 69-89.

Valente, T. W., \& Davis, R. L. (1999). Accelerating the Diffusion of Innovations Using Opinion Leaders. Annals of the American Academy of Political and Social Science, 566, 55-67.

van der Linden, P., \& Mitchell, J. F. B. (2009). Climate Change and its Impacts: Summary of research and results from the ENSEMBLES project. Exeter, UK: ENSEMBLES: Met Office Hadley Centre.

Van, D. T. T., Mui, N. T., \& Ledin, I. (2006). Effect of method of processing foliage of Acacia mangium and inclusion of bamboo charcoal in the diet on performance of growing goats. Animal Feed Science and Technology, 130(3-4), 242-256.

van Kooten, G. C. (2009). Biological carbon sequestration and carbon trading re-visited. Climatic Change.

van Noort, P. C. M., Jonker, M. T. O., \& Koelmans, A. A. (2004). Modeling Maximum Adsorption Capacities of Soot and Soot-like Materials for PAHs and PCBs. Environmental Science and Technology, 38(12), 3305-3309.

Van Zwieten, L., Kimber, S., Morris, S., Chan, K. Y., Downie, A., Rust, J., et al. (2009a). Effects of biochar from slow pyrolysis of papermill waste on agronomic performance and soil fertility. Plant and Soil(Online First).

Van Zwieten, L., Singh, B., Cowie, A., Joseph, S., Rust, J., \& Kimber, S. (2008, September 8-10, 2008). Biochar has potential to reduce greenhouse gas emissions. Paper presented at the Second Conference of the International Biochar Initiative: Biochar, Sustainability and Security in a Changing Climate, Newcastle, UK.

Van Zwieten, L., Singh, B., Joseph, S., Kimber, S., Cowie, A., \& Chan, K. Y. (2009b). Biochar and Emissions of Non- $\mathrm{CO}_{2}$ Greenhouse Gases from Soil. In J. Lehmann 
\& S. Joseph (Eds.), Biochar for Environmental Management: Science and Technology (pp. 227-250). London: Earthscan.

Vatn, A. (2005). Institutions and the environment. Cheltenham, UK: Elgar.

Vellinga, P. (2009, 28-30 September). Sea level rise and impacts in a $4+{ }^{\circ}$ world. Paper presented at the International Climate Conference: 4 degrees and beyond, Oxford, UK.

Verheijen, F. G. A., Jeffery, S., Bastos, A. C., Velde, M. v. d., \& Diafas, I. (2009).

Biochar application to soils: a critical scientific review of effects on soil properties, processes and functions. EUR 24099 EN. Luxembourg: Office for Official Publications of the European Communities.

Victoria University of Wellington (VUW), Research Policy Group, (2007). Human Ethics Policy. Wellington: Victoria University of Wellington.

Voluntary Carbon Standard Association (VCSA) (2009, 30/07/2009). General Methodology for Quantifying the Greenhouse Gas Emission Reductions from the Production and Incorporation of Soil of Biochar in Agricultural and Forest Management Systems. Methodology Element Information. Retrieved 2 August, 2009, from http://www.v-c-s.org/methodology_gmfqtgger.html

\section{W}

Wallack, J., \& Ramanathan, V. (2009). The Other Climate Changers: Why Black Carbon and Ozone Also Matter. Foreign Affairs, 88(5), 105-113.

Wang, H. (2010, 11-12 February). Additional carbon sequestration in forest plantations through application of biochar to soils: a challenging opportunity. Paper presented at the Biochar Workshop: Opportunities for New Zealand Stakeholders, NZBRC, Massey University, Palmerston North.

Wardle, D. A., Nilsson, M.-C., \& Zackrisson, O. (2008a). Fire-Derived Charcoal Causes Loss of Forest Humus. Science, 320(5876), 629.

Wardle, D. A., Nilsson, M.-C., \& Zackrisson, O. (2008b). Response to Comment on "Fire-Derived Charcoal Causes Loss of Forest Humus". Science, 321, 1295d.

Warnock, D. D., Lehmann, J., Kuyper, T. W., \& Rillig, M. C. (2007). Mycorrhizal responses to biochar in soil - concepts and mechanisms. Plant and Soil, 300(1-2), 9-20.

Wejnert, B. (2002). Integrating Models of Diffusion of Innovations: A Conceptual Framework. Annual Review of Sociology, 28, 297-326.

Wen, B., Li, R.-j., Zhang, S., Shan, X.-q., Fang, J., Xiao, K., et al. (2009). Immobilization of pentachlorophenol in soil using carbonaceous material amendments. Environmental Pollution, 157(3), 968-974.

Weston, A. (2003). Beyond intrinsic value: Pragmatism in environmental ethics. In A. Light \& H. Rolston (Eds.), Environmental ethics: An anthology (pp. 307-318). Malden, MA: Blackwell Publishers. 
Weyers, S. L., Liesch, A. M., Gaskin, J. W., \& Das, K. C. (2009, Nov. 1-5, 2009). Earthworms contribute to increased turnover in biochar amended soils. Paper presented at the ASA-CSSA-SSSA Annual Meeting, Nov. 1-5, 2009, Pittsburgh, PA.

Wilkinson, S. (1998). Focus groups in feminist research: power, interaction, and the coconstruction of meaning. Women's Studies International Forum, 21(1), 111-125.

Winsley, P. (2007a). Biochar and bioenergy production for climate change mitigation. New Zealand Science Review, 64(1), 5-10.

Winsley, P. (2007b). Biochar Project Plan. Wellington: Ministry of Agriculture and Forestry (MAF).

Wise, M., Calvin, K., Thomson, A., Clarke, L., Bond-Lamberty, B., Sands, R., et al. (2009). Implications of Limiting $\mathrm{CO}_{2}$ Concentrations for Land Use and Energy. Science, 324, 1183-1186.

Wood, S. L., \& Swait, J. (2002). Psychological Indicators of Innovation Adoption: CrossClassification Based on Need for Cognition and Need for Change. Journal of Consumer Psychology, 12(1), 1-13.

World Commission on Environment and Development (WCED) (1987). Report of the World Commission on Environment and Development: Our Common Future. Oxford: Oxford University Press.

World Resources Institute (2009). Climate Analysis Indicators Tool (CAIT): Navigating the Numbers. Retrieved 6 August, 2009, from http://cait.wri.org/figures.php?page=ntn/

Worldwatch Institute (2010). State of the World 2010: Transforming Cultures: From Consumerism to Sustainability. Washington, DC: Worldwatch Institute.

Wynne, B. (1992). Uncertainty and environmental learning: Reconceiving science and policy in the preventive paradigm. Global Environmental Change, 2(2), 111-127.

$\mathbf{Y}$

Yanai, Y., Toyota, K., \& Okazaki, M. (2007). Effects of charcoal addition on $\mathrm{N}_{2} \mathrm{O}$ emissions from soil resulting from rewetting air-dried soil in short-term laboratory experiments. Soil Science and Plant Nutrition, 53, 181-188.

Yang, X.-B., Ying, G.-G., Peng, P.-A., Wang, L., Zhao, J.-L., Zhang, L.-J., et al. (2010). Influence of Biochars on Plant Uptake and Dissipation of Two Pesticides in an Agricultural Soil. Journal of Agricultural and Food Chemistry, In Press(doi: 10.1021/jf1011352).

Yeardley, R. B., Lazorchak, J. M., \& Gast, L. C. (1996). The potential of an earthworm avoidance test for evaluation of hazardous waste sites. Environmental Toxicology and Chemistry, 15(9), 1532-1537.

Young, D. (2007). Keeper of the long view: sustainability and the PCE. Wellington: Parliamentary Commissioner for the Environment. 
Young, M. D., Gunningham, N., Elix, J., Lambert, J., Howard, B., Grabosky, P., et al. (1996). Reimbursing the future: an evaluation of motivational, voluntary, pricebased, property-right, and regulatory incentives for the conservation of biodiversity: CSIRO Division of Wildlife and Ecology, the Australian Centre for Environmental Law, and Community Solutions Biodiversity Unit, Department of the Environment, Sport and Territories.

Young, M. D., \& McColl, J. C. (2002). Robust Separation: A search for a generic framework to simplify registration and trading of interests in natural resources. Canberra: CSIRO Land and Water, Policy and Economic Research Unit.

Yu, X. Y., Ying, G. G., \& Kookana, R. S. (2006). Sorption and desorption behaviors of diuron in soils amended with charcoal. Journal of Agricultural and Food Chemistry, 54(22), 8545-8550.

\section{Z}

Zahran, H. H. (1999). Rhizobium-legume symbiosis and nitrogen fixation under severe conditions and in an arid climate. Microbiology and Molecular Biology Reviews, 63(4), 968-989.

Zaltman, G., Duncan, R., \& Holbek, J. (1973). Innovations and organizations. New York: Wiley.

Zhang, T., Walawender, W. P., Fan, L. T., Fan, M., Daugaard, D., \& Brown, R. C. (2004). Preparation of activated carbon from forest and agricultural residues through $\mathrm{CO}_{2}$ activation. Chemical Engineering Journal 105, 53-59.

Zhang, Z., \& Baranzini, A. (2004). What do we know about carbon taxes? An inquiry into their impacts on competitiveness and distribution of income. Energy Policy, 32(4), 507-518.

Zheng, W., Guo, M., Chow, T., Bennett, D. N., \& Rajagopalan, N. (2010). Sorption Properties of Greenwaste Biochar for Two Triazine Pesticides. Journal of Hazardous Materials, In Press, Accepted Manuscript(doi: 10.1016/j.jhazmat.2010.04.103).

Zhou, G., Liu, S., Li, Z., Zhang, D., Tang, X., Zhou, C., et al. (2006). Old-Growth Forests Can Accumulate Carbon in Soils. Science, 314(5804), 1417.

Zhu, D., Kwon, S., \& Pignatello, J. J. (2005). Adsorption of Single-Ring Organic Compounds to Wood Charcoals Prepared under Different Thermochemical Conditions. Environ. Sci. Technol., 39(11), 3990-3998.

Zinn, J. O., \& Taylor-Gooby, P. (2006). Risk as an interdisciplinary research area. In P. Taylor-Gooby \& J. O. Zinn (Eds.), Risk in social science (pp. 20-53). Oxford: Oxford University Press. 